\title{
01
}

IntechOpen

\section{Diesel and Gasoline Engines}

Edited by Richard Viskup
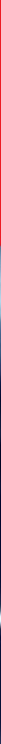



\title{
Diesel and Gasoline Engines
}

\author{
Edited by Richard Viskup
}



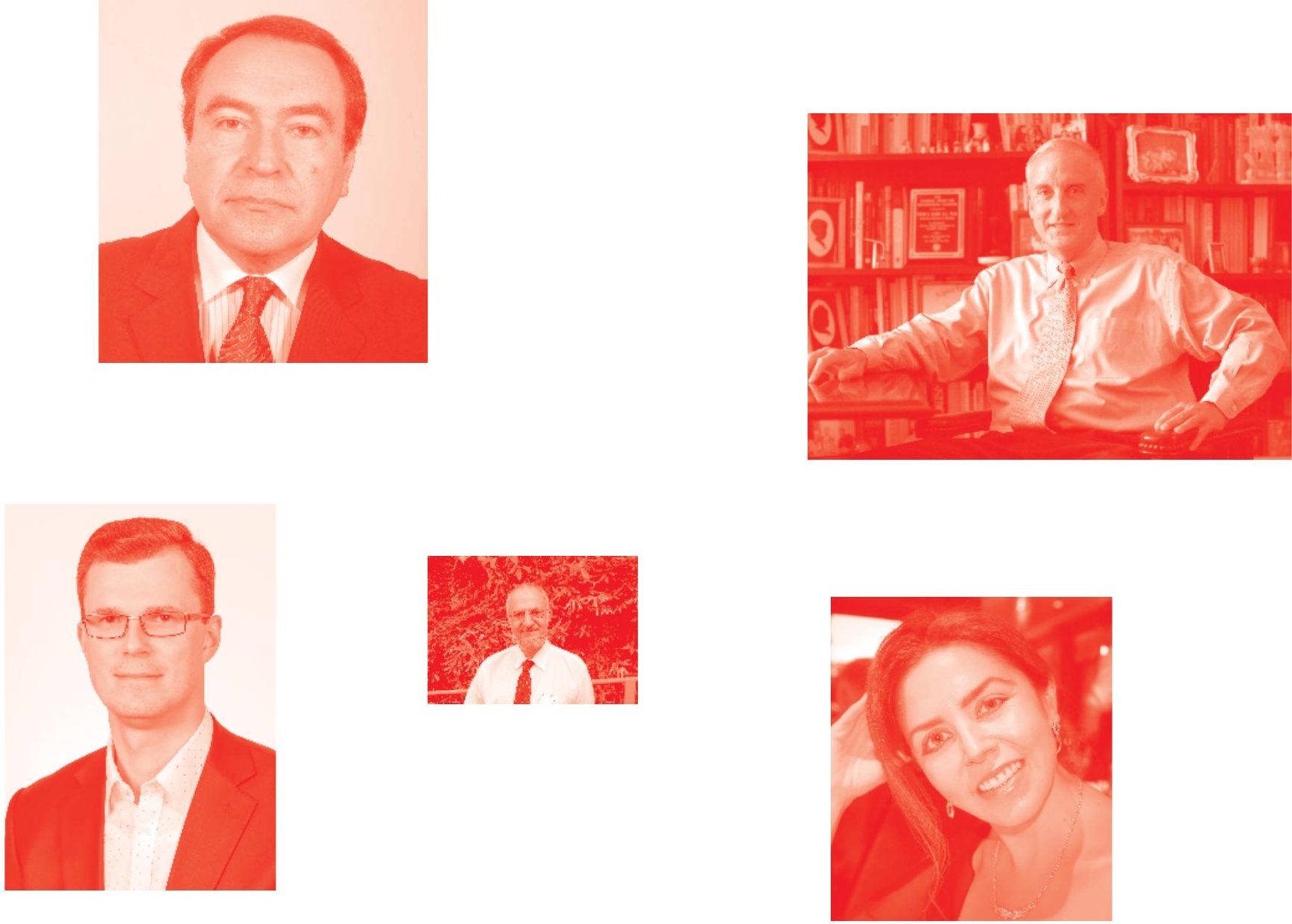

Supporting open minds since 2005
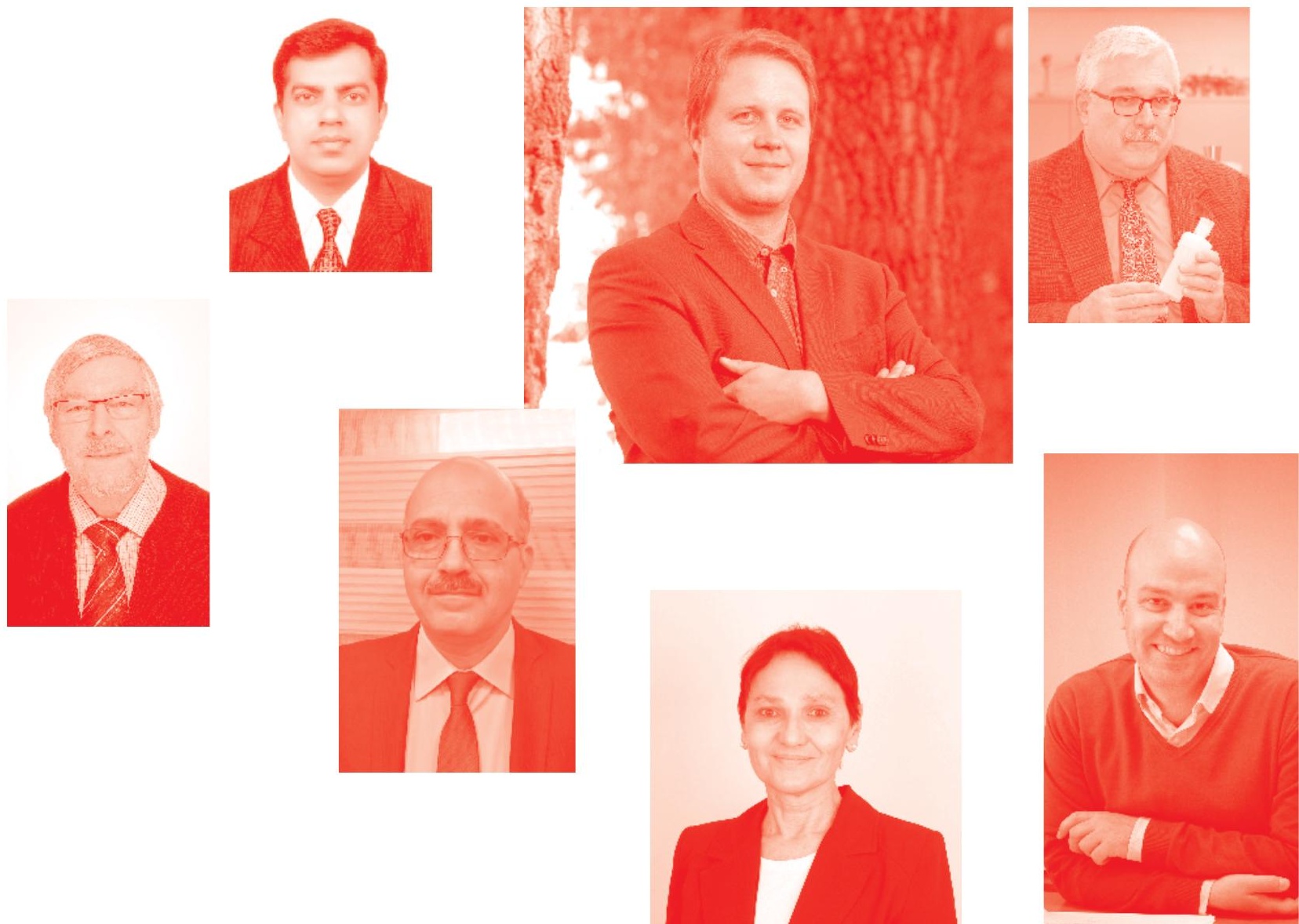
Diesel and Gasoline Engines

http: //dx. doi.org/10.5772/intechopen. 75259

Edited by Richard Viskup

\section{Contributors}

İbrahim Aslan Reşitoğlu, António Simões, Hasan Koten, Naveen Kumar, Harveer Singh Pali, Ankit Sonthalia, Sidharth Bansal, Tien Anh Tran, Richard Viskup, Christoph Wolf, Werner Baumgartner, Emad Monemian, Alasdair Cairns, Selçuk Sarıkoç, Aniket Kulkarni, Devendra Deshmukh

$\odot$ The Editor(s) and the Author(s) 2020

The rights of the editor(s) and the author(s) have been asserted in accordance with the Copyright, Designs and Patents Act 1988. All rights to the book as a whole are reserved by INTECHOPEN LIMITED . The book as a whole (compilation) cannot be reproduced, distributed or used for commercial or non-commercial purposes without INTECHOPEN LIMITED's written permission. Enquiries concerning the use of the book should be directed to INTECHOPEN LIMITED rights and permissions department (permissions@intechopen.com).

Violations are liable to prosecution under the governing Copyright Law .

\section{(c)) BY-NC}

Individual chapters of this publication are distributed under the terms of the Creative Commons Attribution - NonCommercial 4.0 International which permits use, distribution and reproduction of the individual chapters for non-commercial purposes, provided the original author(s) and source publication are appropriately acknowledged. More details and guidelines concerning content reuse and adaptation can be found at http : //www . intechopen . com/copyright-policy . html .

\section{Notice}

Statements and opinions expressed in the chapters are these of the individual contributors and not necessarily those of the editors or publisher. No responsibility is accepted for the accuracy of information contained in the published chapters. The publisher assumes no responsibility for any damage or injury to persons or property arising out of the use of any materials, instructions, methods or ideas contained in the book.

First published in London, United Kingdom, 2020 by IntechOpen

IntechOpen is the global imprint of INTECHOPEN LIMITED, registered in England and Wales, registration number: 11086078 , 7th floor, 10 Lower Thames Street, London,

EC3R 6AF, United Kingdom

Printed in Croatia

British Library Cataloguing-in-Publication Data

A catalogue record for this book is available from the British Library

Additional hard and PDF copies can be obtained from orders@intechopen.com

Diesel and Gasoline Engines

Edited by Richard Viskup

p. $\mathrm{cm}$.

Print ISBN 978-1-78985-248-6

Online ISBN 978-1-78985-447-3

eBook (PDF) ISBN 978-1-78985-448-0

An electronic version of this book is freely available, thanks to the support of libraries working with Knowledge Unlatched. KU is a collaborative initiative designed to make high quality books Open Access for the public good. More information about the initiative and links to the Open Access version can be found at www. knowledgeunlatched. org 


\section{We are IntechOpen, \\ the world's leading publisher of Open Access books}

\section{Built by scientists, for scientists}

\section{$4,600+$}

Open access books available

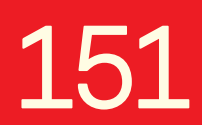

Countries delivered to

\section{$120,000+$}

International authors and editors

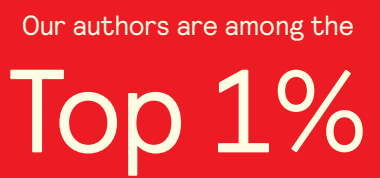

most cited scientists

Contributors from top 500 universities
$135 \mathrm{M}+$

Downloads
1200

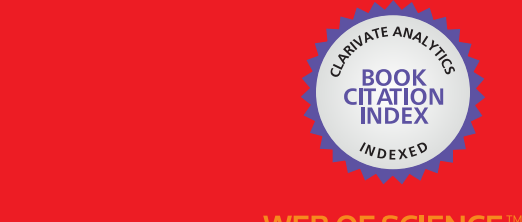

Selection of our books indexed in the Book Citation Index in Web of Science ${ }^{\mathrm{TM}}$ Core Collection (BKCI)

\section{Interested in publishing with us? \\ Contact book.department@intechopen.com}





\section{Contents}

Preface $\quad$ XI

Section 1

Alternative Fuels of Diesel and Gasoline Engines

Chapter 1

Alternative Fuels for Diesel Engines: New Frontiers

by Naveen Kumar, Ankit Sonthalia, Harveer S. Pali and Sidharth

Chapter 2

Fuels of the Diesel-Gasoline Engines and Their Properties

by Selçuk Sarıkoç

Chapter 3

Compressed Bio Gas (CBG) in Diesel Engine

by Hasan Köten

Section 2

Fuel and Combustion

Chapter 4

Hydrogen Fumigation on HD Diesel Engine: An Experimental and Numerical Study

by Emad Monemian and Alasdair Cairns

Chapter 5

Planar Drop-Sizing in Dense Fuel Sprays Using Advanced Laser

Diagnostic Techniques

by Aniket P. Kulkarni and D. Deshmukh

Chapter 6

Some Methods to Prevent the Wear of Piston-Cylinder When Using

Low Sulphur Fuel Oil (LSFO) for All Ships Sailing on Emission Control

Areas (ECAs)

by Tien Anh Tran

\section{Section 3}

Diesel Engine and Pollutants 
Chapter 8

$\mathrm{NO}_{\mathrm{x}}$ Pollutants from Diesel Vehicles and Trends in the Control

Technologies

by İbrahim Aslan Reşitoğlu

Chapter 9

177

Identification of the Minor Chemical Elements in the Particulate Matter

Exhaust Emissions From In-Use Diesel Engine Passenger Vehicles

by Richard Viskup, Christoph Wolf and Werner Baumgartner 


\section{Preface}

The internal combustion engine was invented around 1790 by various scientists and engineers worldwide. Since then the engines have gone through many modifications and improvements. Today, different applications of engines form a significant technological importance in our everyday lives, leading to the evolution of our modern civilization. The invention of diesel and gasoline engines has definitely changed our lifestyles as well as shaped our priorities. The current engines serve innumerable applications in various types of transportation, in harsh environments, in construction, in diverse industries, and also as back-up power supply systems for hospitals, security departments, and other institutions.

However, heavy duty or light duty engines have certain major disadvantages, which are well known to everyone. With the increasing usage of diesel and gasoline engines, and the constantly rising number of vehicles worldwide, the main concern nowadays is engine exhaust emissions.

Is it coincidence that this groundbreaking invention meant for all has such serious consequences on our environment and civilization? Or is it just the next step in human evolution, technology, and knowledge? What will come next?

The main concern of this book is to expand readers' knowledge and bring together new, up-to-date research findings related to diesel and gasoline engines. The idea is to connect scientists and engineers within different fields of engine and emission mitigation: mechanical engineers, engine scientists, mechatronics developers, researchers, related scientists, environmental specialists, medical and biomedical researchers, and other experts. We should all be active as one team, not as competitors, changing the future for our children and preserving the environment for a new upcoming generation of people.

Diesel and Gasoline Engines is divided into three main sections: Alternative Fuels of Diesel and Gasoline Engines, Fuel and Combustion, and Diesel Engine and Pollutants.

Here, readers can find topics dealing with combustion engine-related phenomena, as well as references or internet links that can help to further develop this interesting research into a new era.

In conclusion, I would like to thank all of the authors for their rigorous preparation of the individual book chapters, and I wish all readers an enjoyable time learning about this important subject. 

Section 1

Alternative Fuels of Diesel and Gasoline Engines 



\title{
Alternative Fuels for Diesel Engines: New Frontiers
}

\author{
Naveen Kumar, Ankit Sonthalia, Harveer S. Pali and Sidharth
}

\begin{abstract}
The world at present is mainly dependent upon petroleum-derived fuels for meeting its energy requirement. However, perturbation in crude prices, which concerns about long-term availability of these fuels coupled with environmental degradation due to their combustion, has put renewable alternative fuels on the forefront of policy maker's agenda. The diesel engines are considered workhorse in the global economy due to better thermal efficiency, ruggedness, and load carrying capacity. They, however, are also the main contributor to air pollution as they emit more oxides of nitrogen, suspended particulate matter as compared to gasoline engines. The most potential fuel either to supplement or to substitute diesel is biodiesel, butanol, producer gas, dimethyl ether, hydrogen, and so on. This chapter presents the developments about the use of alternative fuels in diesel engines. The exhaustive literature has evolved the main trends in the development of alternative fuels around the world. The chapter also describes the research directions on production and use of alternative fuels in off-road and transport vehicles powered by diesel engines.
\end{abstract}

Keywords: alternative fuels, biodiesel, Butanol, producer gas, hydrogen, dimethyl ether

\section{Introduction}

World's $80 \%$ population resides in the developing countries, but these consume only $40 \%$ of the total energy consumption. Per capita energy consumption gauges the prosperity and economic growth of any country. The significant energy demand of the world is fulfilled by the petroleum sources. The fuel consumption region wise is shown in Figure 1 for the year 2017-2018. It is seen that Asia is the leading consumer of coal, oil, hydroelectricity, and renewable power. North America leads in consuming natural gas and nuclear energy. Asia's consumption of coal is nearly $74.5 \%$ of the world coal consumption [1]. The fast depletion of petroleum resources is a major concern for the economic development of many countries. Therefore, the energy crisis is debated on all forums, and evolution from conventional to sustainable energy sources has become very relevant to maintain the momentum of economic growth. Renewable sources of energy can provide the energy sustainably and without harming the environment. Figure 2 shows the broad classification of renewable energy sources.

Biofuels are the most effective and efficient form of renewable energy. They can be easily extracted from the biomass, and they are biodegradable and are environment-friendly [3]. Their combustion is almost similar to fossil fuels [4], and 


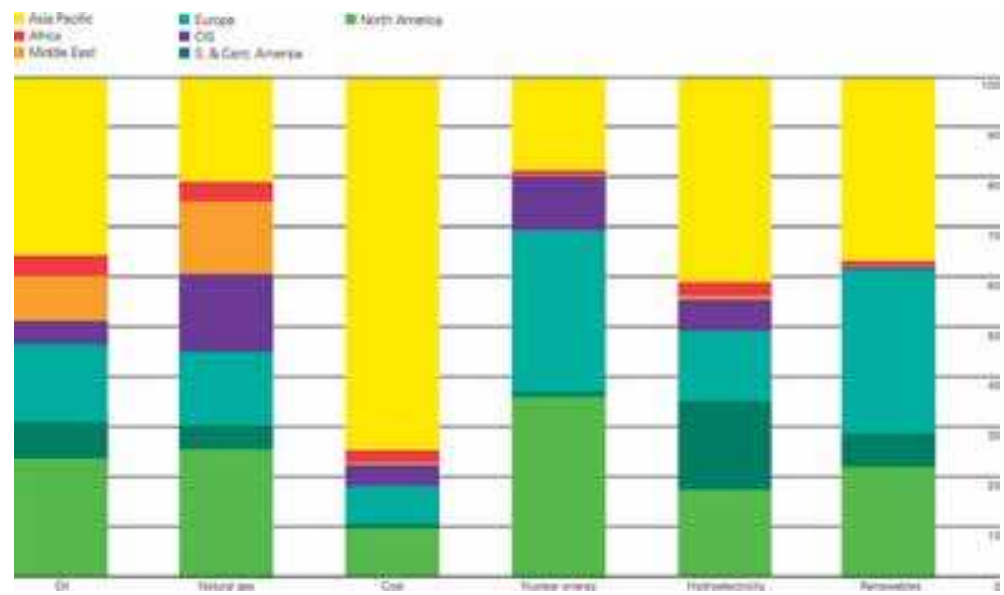

Figure 1.

Fuel consumption (in percentage) region wise for the year 2017 [1].

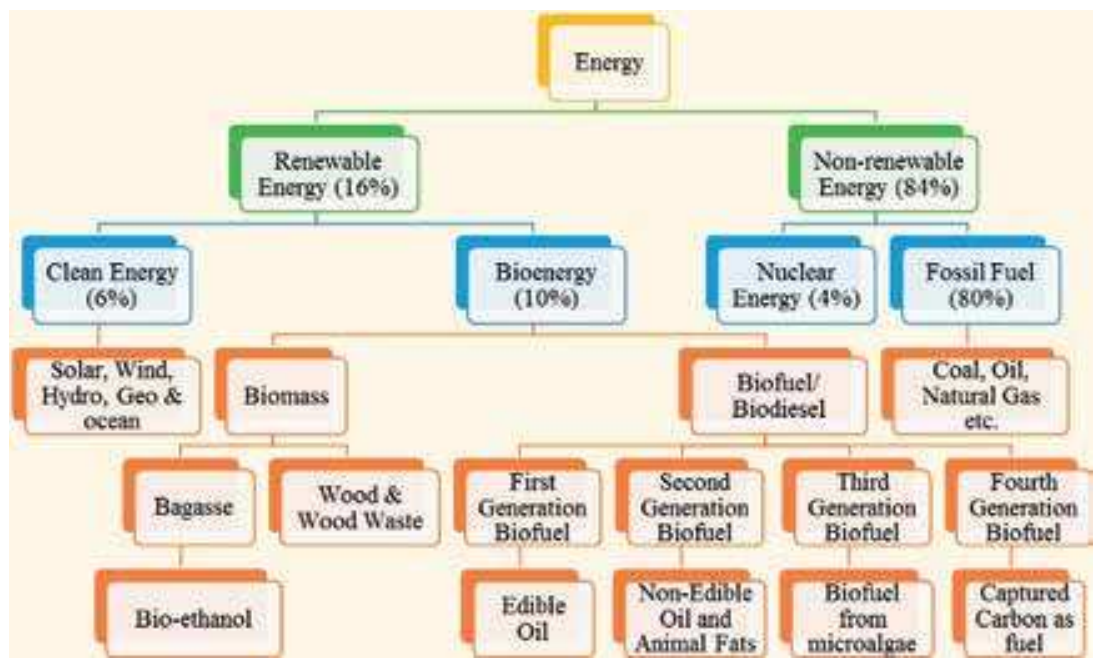

Figure 2.

Classification of energy by source type [2].

they produce less toxic compounds $[5,6]$. The biomass absorbs carbon dioxide from the atmosphere, and when they are used as energy source, they release the carbon dioxide back into the atmosphere. However, the amount of carbon dioxide released into the atmosphere is less than that absorbed by the biomass [7]. The biofuels' production of the world increased by 3.5\% in 2017, shown in Figure 3. The United States alone provided the largest increment of 950 ktoe. Ethanol production grew at the rate of $3.3 \%$ and contributed over $60 \%$ of the total biofuels' growth. Biodiesel production also rose by $4 \%$ on the account of growth in Argentina, Brazil, and Spain [1]. Several alternatives in diesel engines are available and can be used with minor or no modification. The advantages of these fuels include lower emissions, and since most of them are derived from renewable biomass sources, it will decrease the dependency on nonrenewable petroleum. The most potential fuel either to supplement or to substitute diesel is biodiesel, butanol, producer gas, dimethyl ether, hydrogen, and so on. 


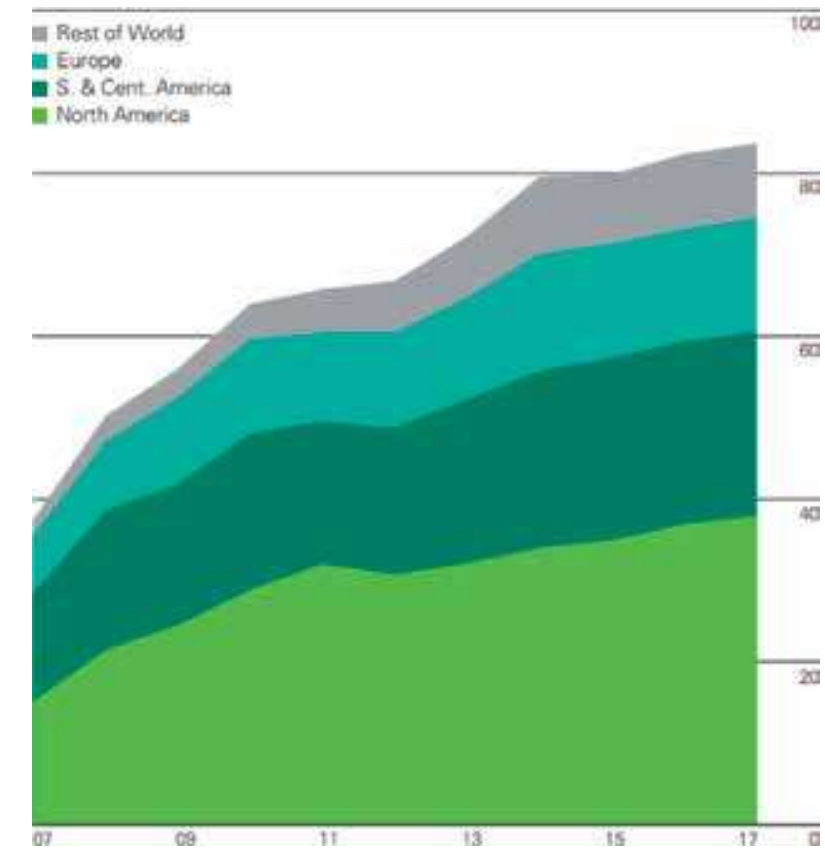

Figure 3.

World biofuels' production (million tons of oil equivalent).

\section{Biodiesel}

Biodiesel appears more attractive for many factors because it is nontoxic and biodegradable. It is the substitution of petroleum diesel for either power generation or motive power without major modification. Furthermore, it releases significantly low aromatic compounds, sulfates, and chemical matters that pollute the atmosphere. Emissions of carbon dioxide are relatively low when the life cycle analysis is considered. Presently, biodiesel has been utilized throughout the world such as the United States, Brazil, Germany, Indonesia, Italy, France, Malaysia, and European countries. Consequently, there is a great prospect for its production and utilization. As of now, annual biodiesel production in the world is around 28 billion liters [1].

Over 350 oil-bearing crops were identified worldwide, which are appropriate for the production of biodiesel. Biodiesel feedstocks are regionally diversified [8]. It mainly depends on the soil conditions, climate, methods of cultivation and harvesting, and geographical locations of the country $[9,10]$. The availability of potential feedstock plays a major role, which contributes to nearly $75 \%$ of the total cost of biodiesel $[11,12]$. Therefore, it is very important to select an economical feedstock for improving the economics of biodiesel production.

Apart from that, the percentage of oil in the feedstock and the yield per hectare are also significant factors. Several edible oil resources namely sunflower, rice bran, palm oil, rapeseed, soybean, peanut, and coconut are considered the firstgeneration feedstock of biodiesel. However, food versus fuel is a major concern for the researchers. Also, it is felt that plantation of feedstocks for biodiesel may require deforestation, reduction in available cultivatable land, and damage to soil resources. Moreover, the raw vegetable oil cost has seen a steep rise in the last decade that has changed the cost-effectiveness of biodiesel production $[13,14]$. Furthermore, a 
number of countries are unable to cope with the growing gap between their demand and supply, which has created a challenge for them to produce cost-effective biodiesel from edible oil resources.

Several nonedible oils, waste oils, greases, and animal fats are considered as the second-generation biodiesel feedstocks [15]. Despite a large list of feedstocks of the second generation, it was believed that these might not be sufficient to fulfill the energy requirements. Moreover, animal fats and saturated fats have under-performed in low-temperature regions [16]. Collection mechanism of waste cooking oil [17] is tough because of its scattered sources, and there is always a problem of contamination with foreign particles $[11,16]$.

Numerous new researches are carried out nowadays to highlight the limitations of edible oils and the advantages of nonedible oils as a biodiesel feedstock. Nonedible oils for producing biodiesel can help in providing the key to tackle the problems of harmful emissions, cost-effectiveness, and the never-ending debate of food versus fuel [18]. Moreover, the plants used to produce seeds for nonedible oils can be cultivated on marginal lands, which can be degraded forests, arid lands, vacant lands, along highways, railways, and irrigation waterways and poverty-stricken areas. Various rural and low-income communities can take advantage of adopting the methods of production of biodiesel from nonedible sources to empower them. They also help in providing energy security and self-reliance. Nonedible feedstocks of biodiesel being sustainable shall be very advantageous as a substitute for diesel $[11,19]$.

Biodiesel or similar fuels can be produced by various methods such as pyrolysis, blending with other fuels, forming microemulsions and transesterification. These methods are briefly discussed later.

Pyrolysis is carried out at high temperatures in the presence of catalyst and the absence of oxygen for decomposing the organic matters. The materials that are normally used for pyrolysis are oils derived from seeds, methyl esters of fatty acids, and animal fats. Several investigations were carried out in the past to obtain a diesel substitute by pyrolysis. Aromatics, alkanes, carboxylic acids, alkenes, alkadienes, and small quantities of gaseous products are produced by pyrolysis [20]. When compared to diesel, the fats and oils that have been pyrolyzed have a lower pour point, flash point, viscosity, and comparable calorific values. Other benefits of pyrolyzed vegetable oils include acceptable levels of copper corrosion values, sulfur, and water content. However, lower cetane number, ash, and carbon residual make their usage in diesel engine challenging [21]. It is worthwhile to mention that the pyrolysis process is a good alternative to diesel because of its simplicity, effectiveness, and pollution-free nature [15, 22].

To make vegetable oil suitable for usage in a diesel engine, they are normally blended or simply diluted with diesel. The main benefit of blending is a reduction in viscosity of the blend and also improves the overall performance of the engine [23]. Hundred percent vegetable oil can be used in a diesel engine, but it gives rise to certain new challenges, which question its practical use on a long run $[14,24,25]$. Therefore, vegetable oil/diesel blends up to $25 \%$ shall be one of the choices for diesel engine $[14,24,25]$. However, the usage of vegetable oil and diesel blends in engines also brings some unwanted problems that need to be addressed thoroughly.

Dimensions of a colloidal dispersion of optically isotropic fluid fall in the range of 1-150 $\mathrm{nm}$ that forms a microemulsion. It consists of one and more ionic amphiphiles and two immiscible liquids. Microemulsion of vegetable oils can be formed with alcohols, surfactant, cetane improver, or with an ester and dispersant (cosolvent) [22]. Microemulsion is beneficial due to their viscosity being similar to diesel. It has been observed that for both microemulsions (ionic and nonionic), the short-term performances are nearly equal to diesel [14, 24-26]. 
Transesterification also known as alcoholysis is one of the most popular, cost-effective, and simple chemical processes of conversion of high viscosity vegetable oils to a very low viscosity substance known as biodiesel. In transesterification process, 1 mole of vegetable oil and 3 moles of alcohol are allowed to react in the presence of a catalyst to produce 3 moles of alkyl ester and 1 mole of glycerine [27]. The triglycerides are first converted into diglycerides, which are further converted to monoglyceride and finally to glycerol. The products thus formed can be separated into two layers on its own by gravity. Biodiesel floats in the upper region, and glycerol settles at the bottom. In the cosmetic industry, glycerol is used extensively. Methanol and ethanol being economical are used commonly in the transesterification process. However, various higher chain alcohols namely propanol, butanol, and octanol could also be used for the production of biodiesel.

Transesterification process can be carried out by catalytic and noncatalytic methods. In the catalytic method, the catalyst is added to alcohols to increase its solubility, which enhances the reaction rate. Catalytic transesterification can be processed by an alkaline or an acid catalyst. Use of an alkaline catalyst is preferred because of its fast reaction, high yield, and economical nature. It is commonly seen that alkaline catalyst gives 4000 times faster reactions than acid catalyst $[28,29]$. Alkaline catalyst namely sodium hydroxide, potassium hydroxide, potassium methoxide, and sodium methoxide are extensively used. Despite the higher cost of potassium and sodium hydroxide, they are most preferred due to their higher yields.

Alkaline catalysts are normally employed when the free fatty acid (FFA) level of the oil or fat is lower than $3 \%$. Beyond this limit, the reaction proceeds with difficulty and challenges such as soap formation and reduced ester yields [30]. Some other limitations of the alkaline catalytic process include higher energy for production of biodiesel, difficulty in removal of unused catalyst from the final product, difficulty in glycerol recovery, and wastage of water during washing $[10,31]$.

Hydrochloric acid, phosphoric acid, sulfuric acid, ferric sulfate acid, para toluene sulfonic acid (PTSA), and Lewis acid $\left(\mathrm{AlCl}_{3}\right.$ or $\left.\mathrm{ZnCl}_{2}\right)$ are normally used as an acid catalyst. The acid catalyst is preferable over alkaline catalysts for their better results with high FFA oil and the presence of water. However, the time taken for the reaction is much more $(3-48 \mathrm{~h}$ ). It is observed that wet washing of the oil uses a large quantity of water for the removal of unreacted acid or base catalyst and the leftover salt of the neutralization process [32].

Transesterification process has relatively high conversion efficiency, small energy usage, and lower cost of catalyst and reactants $[10,31]$. The transesterification process has certain challenges including long reaction time, poor catalyst solubility, and poor separation of the products. Besides this, the wastewater produced during the process can cause environmental issues. To overcome these challenges, other faster methods such as supercritical fluid methods have been developed, which complete in a very short time (2-4 min).

Furthermore, the absence of catalyst helps in easy recovery of glycerol and purification of biodiesel, which makes the process environment-friendly [10, 25, 33]. However, the method is having a limitation of the higher cost of equipment and working at high temperature and pressures. Methanol requirement is also higher (methanol to oil molar ratio-40:1) [34, 35]. Transesterification reaction is dependent upon several factors. For better yield, reaction time, temperature, agitation speed, molar ratio, and catalyst concentration need to be set in the right manner $[14,31]$. 


\subsection{Biodiesel as a fuel in diesel engines}

As described in the previous section, biodiesel is a preferable choice as an alternative to diesel. Jatropha biodiesel has received a great attention due to high conversion and its relatively competitive cost. Several exhaust and performance characteristics were evaluated by Chauhan et al. [36] on blends of diesel and biodiesel derived from oil of Jatropha in an unmodified diesel engine. The authors reported that for the test blends, performance and emission parameters were better, with some higher $\mathrm{NO}_{\mathrm{x}}$ emissions and BSFC than that of diesel. Similar studies were conducted by Nalgundwar et al. [37], and Huang et al. [38], which showed the same characteristics of Jatropha biodiesel. According to Bari et al. [39], combustion characteristics of 20\% Jatropha biodiesel (B20) blend and D100 were comparable. Due to heavier particles and low volatility of biodiesel, B20 takes more combustion time than D100. The authors concluded that in a conventional diesel engine, B20 (a blend of diesel and Jatropha biodiesel) can be used without any modification. Similarly, Ganapathy et al. [40] conducted experiments on a full-factorial design using diesel and Jatropha biodiesel with 27 runs for each fuel. Some increase in BTE was observed with an advancement in injection timing. This has also caused a reduction in HC, CO, smoke emissions, and BSFC. For Jatropha biodiesel, small increments are observed for $\mathrm{HRR}_{\max }, \mathrm{P}_{\max }$, and $\mathrm{NO}$ emission. Injection timing of 340 crank angle degree (CAD) increased $\mathrm{HRR}_{\max }, \mathrm{P}_{\max }$, and BTE. Mofijur et al. [41] evaluated the feasibility of biodiesel derived from Jatropha oil in Malaysia. Interestingly, only 10 and $20 \%$ of biodiesel was blended with diesel to consider engine performance and emission as compared to $100 \%$ diesel. There is $4.67 \%$ reduction in brake power (BP) for $\mathrm{B} 10$ and $8.86 \%$ for $\mathrm{B} 20$. It was seen that there is some increase in BSFC with the increase in the amount of biodiesel in the blends. In comparison to D100, 16 and $25 \%$ reduction in $\mathrm{CO}$ emission, 3.8 and $10.2 \%$ reduction in $\mathrm{HC}$ emission and 3 and $6 \%$ increase in $\mathrm{NO}_{\mathrm{x}}$ emission using B10 and B20 blends were observed. The authors concluded that up to $20 \%$ biodiesel can be a potential substitute to diesel, which can be used without alteration in the diesel engine.

Karanja biodiesel is another substitute in which researcher showed more interest. Dhar and Agarwal [42] investigated several characteristics of blends of diesel and Karanja biodiesel on the engine. The engine is set to run at variable loads and speed. The authors observed that 10 and 20\% Karanja biodiesel blends exhibited higher values of maximum torque than diesel. However, for higher biodiesel concentrations in the blends, maximum torque attained was slightly lower. It is also observed that the BSFC of biodiesel blends increases with a percentage increase of biodiesel in the blends, while, for lower concentrations, it is very close to diesel. From emission results, it is seen that $\mathrm{HC}, \mathrm{CO}$, and smoke emissions were lower for the blends than diesel with slightly higher $\mathrm{NO}_{\mathrm{x}}$ emissions. The authors concluded that up to $20 \%$ blends of Karanja biodiesel and petroleum diesel are well suited for an unmodified diesel engine. Similar outcomes were found by Raheman and Phadatare [43] and Nabi et al. [44]. The engine emissions including CO and smoke reduced with some reduction in engine noise, but $\mathrm{NO}_{\mathrm{x}}$ emissions increased in small quantities. Hundred percent $\mathrm{KME}$ reduced $\mathrm{CO}$ emissions from the diesel engine by $50 \%$ and smoke emissions by $43 \%$, while $\mathrm{NO}_{\mathrm{x}}$ emission increased by $15 \%$. Chauhan et al. [45] conducted transesterification of Karanja oil and observed that all the properties were within the standard limits. The engine trials confirmed that BTE for Karanja biodiesel blended with diesel in a ratio of 5, 10, 20, 30, and 100\% was about $3-5 \%$ lower with respect to neat diesel. It was also revealed by the engine trials that $\mathrm{CO}, \mathrm{CO}_{2}$, UBHC, and smoke emissions were lowered by the use of biodiesel derived from Karanja oil. However, Karanja biodiesel and its blends as compared to diesel produced a little higher quantities of $\mathrm{NO}_{\mathrm{x}}$ emissions with lower values of $\mathrm{HRR}$ and 
peak cylinder pressure. The results suggested that Karanja biodiesel and its blends will be a viable alternative to diesel, and they shall also be beneficial for small- and medium-energy production.

Sahoo et al. [46] explored Polanga (Calophyllum inophyllum) biodiesel and its blends (0-100\%) as a substitute in a single-cylinder diesel engine at varying loads. It was found that the Polanga methyl ester fueled engine has better brake-specific energy consumption (BSEC), BTE, lower smoke emissions, and lower value of all other emissions including $\mathrm{NO}_{\mathrm{x}}$. Moreover, $100 \%$ biodiesel has $0.1 \%$ superior BTE than other fuels. BSEC also followed the similar trend with lower values of exhaust emissions. For B60, a 35\% reduction in smoke was observed in comparison to baseline diesel. Owing to the reduction in exhaust gas temperature, $\mathrm{NO}_{\mathrm{x}}$ emissions decreased by nearly 4\% for B100 at full load. In another study, Sahoo et al. [47] tested various neat and blended biodiesels in a single-cylinder diesel engine at different loads. Various engine combustion analyses were carried out on biodiesel obtained from Jatropha, Karanja, and Polanga and their blends, which revealed that for Jatropha biodiesel, ignition delay was shorter by $4.9-5.2^{\circ} \mathrm{CA}$. Similar trends were observed with the ignition delay of other biodiesels in comparison to neat diesel. Moreover, B20 Polanga biodiesel has shown the maximum peak cylinder pressure.

Raheman and Ghadge [48] used biodiesel derived from Mahua (Madhuca indica) in different proportions with diesel. The authors determined different properties of the test fuels and found them similar to diesel. Engine performance (BSFC, BTE, and exhaust gas temperature) was reduced. However, BSFC increased with an increase in brake power. Emissions ( $\mathrm{CO}$, smoke density, and $\mathrm{NO}_{\mathrm{x}}$ ) were also reduced. In another study, Godiganur et al. [49] assessed the performance of mahua methyl ester and its blends (0,20, 40,60, and 100) with diesel under varying loads and constant speeds. Exhaust emissions namely $\mathrm{HC}$ and $\mathrm{CO}$ reduced considerably by increasing the percentage of biodiesel in the blends with some penalty on fuel consumption and $\mathrm{NO}_{\mathrm{x}}$ emission as compared to diesel. Moreover, the performance parameters, that is, BTE improved, whereas BSEC reduced slightly for $20 \%$ biodiesel blends. Puhan et al. [50] performed an analysis of methyl ester of Mahua oil in a diesel engine. It was reported by the authors that BTE of the fuel sample decreased by $13 \%$. Puhan et al. [51] in a different study evaluated ethyl ester of Mahua oil as diesel fuel and found comparable thermal efficiency. In another study by Puhan et al. [52], Mahua oil ethyl ester revealed significantly lower $\mathrm{HC}, \mathrm{CO}, \mathrm{NO}_{\mathrm{x}}$, and smoke emissions than diesel in a single-cylinder diesel engine. Similarly, its performance tests revealed power loss with biodiesel. A $20 \%$ lower HC and $26 \%$ lower CO emissions were observed with biodiesel compared to petroleum diesel, whereas $\mathrm{NO}_{\mathrm{x}}$ emission was reduced by $4 \%$ for Mahua biodiesel compared to diesel.

Hajra et al. [53] produced biodiesel from Sal oil (Shorea robusta) using the transesterification. $\mathrm{NO}_{\mathrm{x}}, \mathrm{HC}$, and $\mathrm{CO}$ emissions were reduced by 12,25 , and $45 \%$, respectively, with a marginal difference in BTE. Based on this study, it is concluded that the Sal methyl ester can be a possible substitute to diesel, which can be employed without modifications in the engine. Sharma and Singh [54] produced biodiesel using Kusum oil (Schleichera triguga) and found that various physical and chemical parameters of Kusum biodiesel are very well suited to diesel engine operation. In another study, Silitonga et al. [55] found that Schleichera oleosa possesses the desired benefits for biodiesel production.

Some researcher showed their interest in waste cooking oil biodiesel. In this sequence, Muralidharan et al. [56] tested biodiesel blends (20, 40, 60, and 80\%) in a single-cylinder VCR engine at $21 \mathrm{CR}$ and a constant speed of $1500 \mathrm{rpm}$. The performance parameters included brake power, specific fuel consumption, brake thermal efficiency, exhaust gas temperature, mechanical efficiency, and indicated 
mean effective pressure. The exhaust gas emission was found to contain nitrogen oxides, hydrocarbon, carbon monoxide, and carbon dioxide. The results confirmed substantial improvement in the performance parameters and exhaust emissions as compared to diesel. The blends helped in reduction of hydrocarbon, carbon monoxide, and carbon dioxide with slightly higher nitrogen oxide emissions. It has been deduced that waste cooking oil biodiesel and diesel blend combustion characteristics are very close to diesel.

\section{Butanol}

Butanol in the last decade has emerged as a promising biofuel for its application in the diesel engines. Like ethanol, butanol is a biomass-based renewable fuel that may be produced by fermentation [55-58]. It is a next-generation greener fuel and also known as 1-butanol, n-butanol, or butyl alcohol. Efforts are made by the research community to explore efficient methods for obtaining this alcohol in bio-refineries, wherein higher alcohols are produced from shorter alcohols $[59,60]$. Butanol is linear four carbon aliphatic alcohol having a molecular weight of $74.12 \mathrm{~g} /$ mol. It has a distinct aroma with a strong alcoholic odor. It is low hydrophobic colorless and flammable liquid.

Ethanol has received more attention the world over. However, butanol is a better option with high energy content and better physicochemical properties. Butanol was discovered in 1852 by Wirtz, and in 1862, Pasteur concluded that butyl alcohol was a direct product of anaerobic conversion [57].

Butanol having excellent fuel qualities is very suitable as a diesel engine fuel. Butanol being renewable is not only sustainable but also possesses higher cetane number and heating value than ethanol. It has a higher flash point making it safer, and it has a lower vapor pressure. Butanol is hydrophilic in nature and easy miscible with diesel. This eliminates the problems, which are experienced with lower alcohols such as nonmiscibility [58]. The important properties of n-butanol, ethanol, and diesel are shown in Table 1.

\subsection{Production of butanol}

Production of butanol is carried through the chemical process, that is, fermentation by bacteria. Clostridium acetobutylicum is the most popular species of bacteria used for fermentation. The process is abbreviated as ABE because of the end products - acetone, butanol, and ethanol are obtained from it. Butanol production is carried out by molasses (consists of fermentable sugars- $55 \mathrm{wt} . \%$ and nonfermentable solids-30 wt.\%), water, and nutrients in the reactor. Nutrients and diluted molasses are allowed to combine in the tank. Sterilization of the mixture is continuously carried out. The broth containing ethanol, acetone, and butanol is removed from the reactor. It also contains small quantities of butyric acids, acetic acids, proteins, cells, and molasses (in the form of nonfermentable solids), which are then separated in distillation columns to give the final products [60].

\section{2 $\mathrm{n}$-Butanol as a fuel in diesel engine}

Some experimental studies have highlighted the favorable effects of $\mathrm{n}$-butanol/diesel fuel blend in diesel engine [61]. Work of different researchers is highlighted later. 


\begin{tabular}{|c|c|c|c|}
\hline Properties & Diesel fuel & n-Butanol & Ethanol \\
\hline Chemical formula & $\mathrm{C}_{14.09} \mathrm{H}_{24.78}$ & $\mathrm{C}_{4} \mathrm{H}_{9} \mathrm{OH}$ & $\mathrm{C}_{2} \mathrm{H}_{5} \mathrm{OH}$ \\
\hline Specific gravity & 0.85 & 0.81 & 0.79 \\
\hline Boiling point & $190-280$ & 108.1 & 78.3 \\
\hline Net heating value $(\mathrm{MJ} / \mathrm{kg})$ & 42.6 & 33 & 27 \\
\hline Heat of vaporization $(\mathrm{KJ} / \mathrm{kg})$ & 600 & 578.4 & 900 \\
\hline Octane number & NA & 94 & 92 \\
\hline Cetane number & 45 & 17 & 8 \\
\hline Flash point $\left({ }^{\circ} \mathrm{C}\right)$ & $65-88$ & 35 & 13 \\
\hline Viscosity $\left(\mathrm{mm}^{2} / \mathrm{s}\right)$ at $40^{\circ} \mathrm{C}$ & $1.9-3.2$ & 2.63 & 1.2 \\
\hline Auto-ignition temperature $\left({ }^{\circ} \mathrm{C}\right)$ & 210 & 385 & 434 \\
\hline Stoichiometric air/fuel ratio & 14.6 & 11 & 9 \\
\hline Molecular weight & 193.9 & 74 & 46 \\
\hline Latent heat of evaporation $(\mathrm{kJ} / \mathrm{kg})$ & 265 & 585 & 900 \\
\hline Bulk modulus (bar) & 16,000 & 15,000 & 13,200 \\
\hline Lubricity $(\mu \mathrm{m})$ & 310 & 590 & 950 \\
\hline$\%$ of carbon (wt.) & 86.7 & 64.9 & 52.1 \\
\hline$\%$ of hydrogen (wt.) & 12.7 & 13.5 & 13.1 \\
\hline$\%$ of oxygen (wt.) & 0 & 21.5 & 34.7 \\
\hline $\mathrm{C} / \mathrm{H}$ ratio & 6.8 & 4.8 & 4 \\
\hline
\end{tabular}

Table 1.

Properties of diesel, n-butanol, and ethanol [57-59].

Atmanli et al. performed an engine trial on wide operating conditions at varying blend of diesel fuel, cotton oil, and n-butanol using RSM. Homogeneity was observed along with no phase separation. BMEP, brake power, and thermal efficiency of the blend were reduced; however, BSFC has increased marginally. Emissions namely $\mathrm{HC}, \mathrm{NO}_{\mathrm{x}}$, and $\mathrm{CO}$ of the blends have reduced [62]. Yilmaz et al. studied the emissions and performance characteristic of butanol/biodiesel blends in a multi-cylinder, indirect injection diesel engine. Butanol blended with biodiesel was compared with standard diesel (D100) and neat biodiesel (B100) at four engine loads. Lower exhaust gas temperatures and nitrogen oxide $\left(\mathrm{NO}_{\mathrm{x}}\right)$ emissions with higher $\mathrm{CO}$ and $\mathrm{HC}$ emissions were found [63]. Zhu et al. [64] carried experiments on n-butanol blends, EGR rate, and injection timing on a modified diesel engine. The results suggested that with increased EGR rate, $\mathrm{NO}_{\mathrm{x}}$ emissions reduce, but smoke emissions increase. With the increase of n-butanol fraction, smoke emissions were found to decrease with a small increase in $\mathrm{NO}_{\mathrm{x}}$.

Dogan conducted some studies on a diesel engine at four different loads. No phase separation was observed in $20 \%$ butanol/diesel blend. The performance was slightly improved in comparison to diesel. Gaseous emissions, for example, $\mathrm{NO}_{\mathrm{x}}, \mathrm{CO}$, smoke content, and exhaust gas temperature reduced with the blends [65]. Butanol/diesel blends (8, 16, and 24\%) were prepared by Rakopoulos et al., and it was found during the trial that the smoke opacity, $\mathrm{NO}_{\mathrm{x}}$, and $\mathrm{CO}$ emissions were significantly reduced. However, the $\mathrm{HC}$ emissions were higher. Greater SFC and BTE and slightly lesser exhaust gas temperatures were noted in comparison to petroleum diesel [66]. In a similar study, Karabektas et al. evaluated the suitability 
of butanol-diesel blends in a diesel engine. Four blends were prepared consisting of $5,10,15$, and $20 \%$ butanol by volume. Brake power was lower, whereas BSFC rose with the addition of butanol. $\mathrm{CO}$ and $\mathrm{NO}_{\mathrm{x}}$ levels were lower for blends; however, there was a considerable increase in HC emissions [67]. In another study, Lebedevas et al. conducted investigations on a multi-cylinder diesel engine.

Two types of test fuels were prepared. The first is comprised of diesel, rapeseed methyl ester (RME), and butanol, and the second consisted of diesel, rapeseed oil butyl esters (RBE), and butanol. Almost the same efficiency was observed, and there was a significant reduction in $\mathrm{CO}$ and $\mathrm{HC}$ emissions. $\mathrm{NO}_{\mathrm{x}}$ emissions remained almost the same; however, there was a reduction in smoke emissions for all butanolbased fuels as compared to petroleum diesel [68]. The above studies suggest that butanol-diesel blends are potential alternative fuel in a diesel engine.

\section{Producer gas}

Biomass-based producer gas is a viable alternative to conventional fuels, where there is a large availability of the biomass as a primary source. Biomass feasible for producer gas is dry materials such as wood, charcoal, rice husks, and coconut shell. Producer gas is produced by gasifying these dry carbonaceous organic materials. In the gasification process, the solid biomass is broken down by the use of heat. The gasification system consists of a reactor or container into which the biomass is fed along with a gasification agent such as air, oxygen, and steam. According to the supply, producer gas with different calorific values is produced. When air is used, the gas with 4-6 MJ/Nm ${ }^{3}$ calorific value is produced, and the gas can be used for direct combustion or as an internal combustion engine fuel. With oxygen, the gas produced has $10-15 \mathrm{MJ} / \mathrm{Nm}^{3}$ calorific value. The producer gas with $13-20 \mathrm{MJ} / \mathrm{Nm}^{3}$ calorific value is produced with steam as a gasifying agent, and the gas can be subsequently used as a feedstock for methane and methanol production $[69,70]$.

Producer gas was produced from sugarcane bagasse and carpentry waste by Singh and Mohapatra [71]. The authors mixed the raw materials thoroughly in the ratio 1:1, and the major steps followed for gasification are mentioned here. (1) In the first step, the mixed raw material is fed from the top into a downdraft gasifier, and air enters over air inlets through which firing also takes place using a diesel torch. After operation of the gasifier for 15-20 min, the gas constantly comes out of the gasifier at a temperature of nearly $450^{\circ} \mathrm{C}$. (2) In the second step, the gas is cooled and cleaned in the scrubber. As the gas is passed through a jet of cold water, the particulates, dust, and gases such as $\mathrm{HCl}, \mathrm{H}_{2} \mathrm{~S}, \mathrm{SO}_{2}$, and $\mathrm{NH}_{3}$ are removed as they are water soluble. All the tar present in the gas is also washed in the scrubber. (3) In the third step, the gas is passed through a drum-shaped secondary filter containing a mixture of wood chips and powder. As the gas passes through the filter, the particulate matter is absorbed along with the excessive moisture present. Gas with high purity and temperature of nearly $50^{\circ} \mathrm{C}$ comes out of the filter. (4) In the final step, the gas is passed through a safety filter, which contains a paper filter. The minute soot particles are absorbed by the filter and gas with higher purity, and $35^{\circ} \mathrm{C}$ temperature is obtained.

In spark ignition engines, the use of producer gas is already established. However, its use in a dual fuel CI engine as an inducted fuel is still a topic of research [72]. In dual fuel engines, the producer gas is inducted along with the air into the cylinder, and it is ignited by injecting a small quantity of diesel or other similar fuel such as biodiesel. Some of the research on producer gas being used as a dual fuel compression ignition engine fuel is discussed here. Ramadhas et al. [73] used producer gas produced from coir pith and wood for fueling a dual fuel engine with diesel as the direct injected fuel. The authors observed a reduction in brake thermal efficiency 
with dual fuel operation as compared to neat diesel operation. The energy consumption of dual fuel operation was also higher. At part-load conditions, carbon monoxide and carbon dioxide emissions were higher with dual fuel operations. The smoke density was similar for all the tested fuels. The authors found that producer gas (made from wood chips) fueled dual fuel operation performed well than coir pith engine operation. Also, the engine could be run only to $50-60 \%$ of the maximum load. In another study by Ramadhas et al. [74], coir pith was used to produce producer gas, and rubber seed oil was used as the direct injected fuel. The authors observed that with diesel and rubber seed oil, the engine performance reduced in dual fuel mode. The fuel consumption with rubber seed oil as direct injected fuel is more than diesel as a pilot fuel. At all loads, the carbon monoxide and carbon dioxide emissions are higher with rubber seed oil-fueled dual fuel operation on account of higher fuel consumption due to lower calorific value of fuel. The other exhaust emissions are almost the same. Similar study was conducted by Singh and Mohapatra [71], who directly injected diesel and inducted producer gas in the air produced from sugarcane bagasse and carpentry waste mixed equally during gasification. The authors observed a maximum reduction of $45.7 \%$ in consumption of diesel and $69.5 \%$ reduction in $\mathrm{NO}_{\mathrm{x}}$ emissions along with a slight increase in engine noise.

Singh et al. [75] blended refined rice bran oil (75\% v/v) with diesel and used producer gas produced from wood in a three-cylinder diesel engine. It was observed that at $84 \%$ of the maximum engine load with a compression ratio of $18.4: 1$, the pollutant concentration reduced by $48.28,61.06$, and $80.49 \%$ for $\mathrm{HC}, \mathrm{NO}$, and $\mathrm{NO}_{2}$, respectively; however, in comparison to diesel, CO emission increased by $16.31 \%$. The authors also observed an increase in noise levels with producer gas induction at all the loads. Honge oil and Honge oil methyl ester were used as a pilot fuel with producer gas as the injected fuel with and without carburetor by Banapurmath and Tiwari [76]. The authors found that producer gas and honge oil engine operation resulted in higher emission levels and low thermal efficiency due to lower heat content and high viscosity of honge oil along with the low burning speed of producer gas. With methyl ester of honge oil and producer gas in dual-fuel engine operation, brake thermal efficiency improves on account of higher calorific value and low viscosity. Overall, with dual fuel operation, smoke and $\mathrm{NO}_{\mathrm{x}}$ emissions reduce, whereas $\mathrm{HC}$ and $\mathrm{CO}$ emissions increase considerably.

Carlucci et al. [77] used biodiesel and a synthetic producer gas for a dual fuel engine operation. The authors initially varied the injection pressure, injection timing of biodiesel with a single-pilot injection, and also varied the producer gas flow rate. The results revealed that the combustion is affected by both injection timing and pressure. The thermal efficiency was higher with slightly advanced injection timing along with low injection pressure. Lowering of unburned hydrocarbons and carbon monoxide emissions was observed, whereas an increase in $\mathrm{NO}_{\mathrm{x}}$ emission occurs. In the second phase, the splitting of the pilot fuel injection was carried out, which leads to improved fuel efficiency and reduced pollutants compared to singlepilot fuel injection at low loads. The authors also concluded that injection pressure plays a vital role in reducing gaseous emissions.

\section{Hydrogen}

Hydrogen is a colorless, odorless gas, which produces heat and water when combusted with oxygen at high pressure and temperature. Hydrogen has high energy content as compared to other fuels. However, its density is low, that is, the storage space required for a vehicle to run on hydrogen for the same distance is more than gasoline [78]. Table 2 compares the properties of hydrogen with diesel and gasoline. 


\begin{tabular}{lccc}
\hline Property & Gasoline & Diesel & Hydrogen \\
\hline Density at $1 \mathrm{~atm}$. and $15^{\circ} \mathrm{C}\left(\mathrm{kg} / \mathrm{m}^{3}\right)$ & $721-785$ & $833-881$ & 0.0898 \\
\hline Stoichiometric A/F & 14.8 & 14.5 & 34.3 \\
\hline Flammability limits $($ Vol.\% in air) & $1.4-7.6$ & $0.6-7.5$ & $4-75$ \\
\hline Auto-ignition temperature $\left({ }^{\circ} \mathrm{C}\right)$ & $246-280$ & 210 & 585 \\
\hline Lower calorific value at $1 \mathrm{~atm}$. and $15^{\circ} \mathrm{C}(\mathrm{kJ} / \mathrm{kg})$ & 44,500 & 42,500 & 120,000 \\
\hline
\end{tabular}

Table 2.

Properties of gasoline, diesel, and hydrogen.

The flammability limits of hydrogen are wide, which make its use suitable for a wide range of air-fuel mixture. The engine can be operated at lean mixtures, which considerably improves the fuel economy as complete combustion takes place with few residues. Hydrogen has high diffusivity and flame speed because of which faster combustion takes place at near constant volume. However, due to its high autoignition temperature, it is suitable for a spark ignition engine, whereas for its use in a diesel engine, a low auto-ignition temperature fuel is required to initiate combustion. Also, the engine may knock or detonate due to its low ignition energy requirement.

Hydrogen in gaseous state is not available on Earth due to its low density as it is pushed out from the gravitational pull of the Earth. However, it exists in the combined form in natural resources such as coal, natural gas, fossil fuels, and water. Presently, small amount of hydrogen is produced using renewable sources such as wind, solar, geothermal energy, and biomass, and nearly $95 \%$ of hydrogen is produced from fossil fuels. Therefore, the hydrogen production is costly, and a large amount of emissions are produced. For a true hydrogen economy to exist, the hydrogen needs to be produced abundantly and economically from renewable sources. Hydrogen can be produced by natural gas reforming, gasification of biomass, and electrolysis of water.

Methane reforming is the most common method of hydrogen production in the United States. In this method, methane and steam are reformed at 3-25 bar pressure and $700-1000^{\circ} \mathrm{C}$ temperature in the presence of a catalyst. The by-products of the reaction are carbon monoxide and carbon dioxide. Heat is required for the process as it is endothermic. The carbon monoxide subsequently is reacted with steam in the presence of a catalyst, resulting in the formation of carbon dioxide and hydrogen. This reaction is called water gas shift reaction. Lastly, using the pressureswing adsorption process, the gas is freed of all the carbon dioxide and other impurities, which leaves only pure hydrogen [79]. The steam reforming can also be carried out on other fuels such as ethanol, propane, and even gasoline. This process can become truly renewable if hydrogen is produced from renewable sources.

Hydrogen can be produced by gasification of biomass and coal. Biomass is a renewable source, which includes crop residue, forest residue, algae, crops grown specifically for energy use (switchgrass), municipal wastes, and animal waste. Since carbon dioxide is captured from the atmosphere by biomass itself, the net carbon emissions of the process are low. In gasification process, the carbon-rich material at a temperature greater than $700^{\circ} \mathrm{C}$ is converted to hydrogen, carbon monoxide, and carbon dioxide in the presence of oxygen and/or steam. Water is then reacted with carbon monoxide to form carbon dioxide and more amount of hydrogen via the water-gas shift mechanism. Gasification process can also be carried out using solar energy [80].

Hydrogen and oxygen can form by passing an electric current through water. The process is called electrolysis, and this process consumes the highest energy for production of hydrogen [81]. However, the process is clean and free of emission if the energy source used for electricity production is renewable. 
Hydrogen can also be produced from other sources such as reforming of renewable liquid, splitting of water using solar, high-temperature thermochemical water splitting, and microbes [82, 83].

\subsection{Use of hydrogen in compression ignition (CI) engines}

Hydrogen is a carbon-free substance; therefore, no greenhouse gas emissions take place from its combustion in an IC engine. Hydrogen has good heat transfer characteristics, which increases the combustion temperature resulting in improved engine efficiency even at lean mixture operation [84]. This section describes the methods and the compression ignition engine performance characteristics when operated in dual fuel mode with hydrogen.

Back in 1978, Homan et al. [85] used hydrogen to operate a diesel engine. The authors realized that the engine has limited operation range because of its high auto-ignition temperature, which could not be resolved by even increasing the compression ratio up to 29 . They later investigated the use of glow plugs and a multiple strike spark plug. The results showed that both the methods resulted in providing reliable ignition and smooth engine operation. The authors also observed reduction in ignition delay; however, the indicated mean effective pressure was higher than diesel-fueled engine operation. Moreover, the cyclic variations in ignition delay were significant along with the formation of high amplitude waves in the combustion chamber [86].

An indirect injection single-cylinder diesel engine was operated with hydrogen only by Ikegami et al. $[87,88]$. The authors found that the engine had limited operation range with hydrogen. The authors were able to extend the operating limit and attain smoother combustion by injecting small amounts of pilot fuel in the swirl chamber as the pilot fuel became the source of ignition for the hydrogen. However, excessive pilot fuel presence resulted in its auto-ignition resulting in rough engine operation.

Direct use of hydrogen as CI engine fuel is possible within a limited operating range due to its high auto-ignition temperature. To increase the engine's operation range, hydrogen needs to be supplemented by a low auto-ignition temperature fuel such as diesel, vegetable oils, and biodiesel. Such an engine is called dual fuel engine, wherein hydrogen is either inducted in a carburetor or injected in the intake manifold or the intake port. The low auto-ignition fuel, called pilot fuel, is injected directly into the combustion chamber when the piston is approaching top dead center and the fuel ignites the hydrogen-air mixture. It has been observed that port injection of hydrogen shows better engine performance and reduction of emissions in comparison to manifold injection or use of a carburetor [89-91].

Varde and Frame [92] aspirated small amounts of hydrogen in the intake of a single-cylinder diesel engine for investigating the possibility of smoke reduction. They observed that the smoke levels reduced at part- and full-load conditions. The optimum hydrogen energy share for smoke reduction lies between 10 and 15\%. At optimum energy share, the smoke reduced by nearly 50 and $17 \%$ at part- and fullload conditions, respectively. Unburned hydrocarbon emission was not affected by hydrogen injection; however, $\mathrm{NO}_{\mathrm{x}}$ emission increased with an increase in hydrogen addition especially at loads above $50 \%$ of full load. The $\mathrm{NO}_{\mathrm{x}}$ emission increase is due to the increase in the combustion temperature, which increases with an increase in hydrogen addition as well as load. Lilik et al. [93] also observed an increase in $\mathrm{NO}_{\mathrm{x}}$ emission for a hydrogen dual fuel engine with diesel as a pilot fuel. The authors injected hydrogen in the intake air up to $15 \%$ of the energy share. The authors also observed a shift in the ratio of nitrogen oxide to nitrogen dioxide, wherein the nitrogen oxide decreased and nitrogen dioxide increased. 
Exhaust gas recirculation (EGR) has been proved to be the best method for $\mathrm{NO}_{\mathrm{x}}$ reduction and for suppressing knocking in a hydrogen dual fuel engine [94-96]. In EGR, the exhaust gas is reintroduced in the cylinder. As it has high-specific heat, it absorbs the combustion heat and reduces the cylinder temperature leading to reduction in $\mathrm{NO}_{\mathrm{x}}$ formation. However, introducing the exhaust gas also reduces the amount of oxygen available resulting in increase in smoke, $\mathrm{CO}$, and $\mathrm{HC}$ emission. Although these emissions may increase, they will be still lower than diesel operation [97].

Bose and Maji [95] compared the performance and emission characteristics with and without EGR of a neat diesel engine and a hydrogen diesel dual-fuel engine. The brake thermal efficiency without EGR for hydrogen fueled engine was higher than neat diesel operation. Higher flow rates of hydrogen deteriorated the engine efficiency. The engine efficiency was adversely affected by EGR. The smoke emissions reduced with hydrogen induction; however, with EGR, the smoke levels increased, but they were still lower than neat diesel operation. The authors observed that in order to reduce $\mathrm{NO}_{\mathrm{x}}$ emissions by $40 \%, 20 \%$ EGR is necessary.

Saravanan and Nagarajan [98] injected hydrogen in a dual-fuel diesel engine using a carburetor, injector placed in the port (TPI) and injector placed in the manifold (TMI). The port injector and manifold injector were located 5 and $100 \mathrm{~mm}$ from the intake valve seat, respectively. The injection timing used for diesel was $23^{\circ}$ BTDC. The optimized injection timing for hydrogen port injection was $5^{\circ}$ before gas exchange top dead center (BGTDC) with $30^{\circ} \mathrm{CA}$ injection duration. The observations made during running of the engine at different operating conditions were as follows: (a) engine operation was unstable during the late injection ( $30^{\circ}$ AGTDC) especially at higher loads and with the injection duration of $90^{\circ} \mathrm{CA}$, (b) knocking of the engine at flow rates greater than $25 \mathrm{lpm}$, and (c) with port and manifold injection of hydrogen greater than $20 \mathrm{lpm}$ flow rate, smoke emissions increased rapidly. The brake thermal efficiency and peak heat release rate were high for both port and manifold injections. The engine efficiency with carburetion was lower than neat diesel operation. $\mathrm{NO}_{\mathrm{x}}$ was higher for both TPI and TMI modes. $\mathrm{HC}, \mathrm{CO}, \mathrm{CO}_{2}$, and smoke emissions reduced with all the three modes. It was concluded that using $\mathrm{H}_{2}$ as a fuel and adopting TPI gave better efficiency and emission reduction than all the other modes.

The challenge with hydrogen induction is that at high loads, the engine performance is limited due to knocking. EGR is one of the ways to extend the knock limit of the engine, but as discussed earlier, it tends to increase the harmful emissions. Another way of reducing the knock at higher loads is injection of water as it can control the combustion phase. Chintala and Subramanian [99] inducted water at various specific water consumption (SWC) in a hydrogen-fueled dual fuel engine. The authors found that the optimum SWC of $200 \mathrm{~h} / \mathrm{kWh}$ lead to a knock-free operation up to $20 \%$ hydrogen energy share resulting in $24 \% \mathrm{NO}_{\mathrm{x}}$ emission reduction and $5.7 \%$ reduction in efficiency. The carbon monoxide emission increased from $0 \mathrm{~g} / \mathrm{kWh}$ without water injection to $1.2 \mathrm{~g} / \mathrm{kWh}$ with water injection. The authors conducted another study [100], wherein they were able to increase the hydrogen energy share without knocking of the engine from 18 to 24 and 36\% by retarding the injection timing and injecting water, respectively.

Natural gas can also be used as an injected fuel in a dual fuel engine. However, the engine efficiency is low followed by high emissions due to slow rate of burning of natural gas. Hydrogen can be used to supplement natural gas such that the engine's performance can improve and the emissions can reduce. One such study was conducted by McTaggart-Cowan et al. [101], wherein the authors used a singlecylinder engine fueled with natural gas blended with 10 and $23 \%$ hydrogen (by volume). In this study, the mixture of hydrogen and methane was injected directly into the cylinder, and diesel was used as a pilot fuel. Diesel was injected approximately $1 \mathrm{~ms}$ prior to the natural gas to initiate the combustion process. 
The dual fuel injector used concentric needles. The results show that with $10 \%$ $\mathrm{H}_{2}, \mathrm{NO}_{\mathrm{x}}$, and $\mathrm{PM}$ emissions remained almost the same though $\mathrm{CO}$ and THC were slightly reduced. With $23 \% \mathrm{H}_{2}, \mathrm{NO}_{\mathrm{x}}$ increased slightly, while $\mathrm{CO}, \mathrm{THC}$, and $\mathrm{CO}_{2}$ were reduced. Also, the peak heat release rate was $20 \%$ higher than natural gas. With PM, significant influence was seen at latest injection timings ( $15^{\circ}$ ATDC), where it was found to decrease. At such timings, the burn duration for $23 \% \mathrm{H}_{2}$ was also substantially reduced. The combustion variability (COVGIMEP) for $10 \% \mathrm{H}_{2} /$ methane fuel reduced only at late timings, while with $23 \% \mathrm{H}_{2}$, it reduced for all injection timings. The combustion stability was found to improve, and the effect of hydrogen addition was observed to be consistent with variations in injection timings and pressure.

Biodiesel and its blends with diesel have also been used by many researchers as a pilot fuel in a hydrogen-fueled dual fuel engine. Geo et al. [102] used rubber seed oil and rubber seed oil methyl ester as the direct injected fuel and hydrogen as the injected fuel in the intake port in a dual fuel engine to reduce smoke and increase the engine's thermal efficiency. The brake thermal efficiency of the engine increased by nearly $1.5 \%$, whereas the smoke emission reduced by more than $30 \%$ with hydrogen induction. The maximum hydrogen energy share at full load that the engine can tolerate was $12.69 \%$ with diesel, $11.2 \%$ with rubber seed oil methyl ester, and $10.76 \%$ with rubber seed oil. The $\mathrm{HC}$ and $\mathrm{CO}$ emissions reduced at all loads with hydrogen induction for all the fuels. However, the $\mathrm{NO}_{\mathrm{x}}$ emissions increased for all the fuels with an increase in hydrogen induction. The authors attributed the increase to high combustion temperature because of high premixed combustion. The authors also observed higher emission values and lower efficiency with rubber seed oil due to poor mixture formation because of high viscosity of the fuel.

Palm oil methyl ester was blended with diesel in various proportion, and the blends were used as a pilot fuel in a single-cylinder dual fuel engine along with hydrogen as the injected fuel [103]. The performance and emission characteristics of the engine were recorded at $50 \%$ load and full load. The authors observed that at $25 \%$ blend of palm oil methyl ester in a liter of diesel, the engine gave the best efficiency at $5 \mathrm{lpm}$ flow rate of hydrogen. Hydrogen induction resulted in drastic reduction in carbon monoxide emissions. However, unburnt hydrocarbon emissions increased at $5 \mathrm{lpm}$ flow rate, but with increase in flow rate to $10 \mathrm{lpm}$, some reduction in emission level was observed.

Biodiesel produced from waste cooking oil can also be used as a pilot fuel in a hydrogen dual fuel engine. Kumar and Jaikumar [104] used waste cooking oil (WCO) and emulsion of waste cooking as direct injected fuel and hydrogen as manifold injected fuel in a dual fuel engine. Dual fuel operation reduced CO, HC, and smoke emissions with waste cooking oil as a pilot fuel at all loads; however, thermal efficiency reduced at $40 \%$ load. The ignition delay with WCO emulsion is higher than neat WCO, which further increases with hydrogen induction. The authors observed improvement in engine performance with hydrogen induction at high loads and fall in performance at low loads with WCO emulsion as a pilot fuel.

\section{Dimethyl ether}

Dimethyl ether (DME) is the simplest ether with chemical formula of $\mathrm{CH}_{3} \mathrm{OCH}_{3}$. DME in gaseous state is colorless, nontoxic, and highly flammable with a slight narcotic effect. By slightly pressurizing the gas, it can also be handled as a liquid fuel. $\mathrm{DME}$ and liquefied petroleum gas have similar properties. Moreover, the cetane number of DME is greater than 55. A blue flame is visible while burning DME, and it has wide flammability limits [105-108]. Table 3 shows the physicochemical properties of DME and diesel. 


\begin{tabular}{lcc}
\hline Property & DME & Diesel \\
\hline Vapor pressure at $20^{\circ} \mathrm{C}(\mathrm{bar})$ & 5.1 & $<0.01$ \\
\hline Boiling temperature $\left({ }^{\circ} \mathrm{C}\right)$ & -25 & $\sim 150-380$ \\
\hline Liquid density at $20^{\circ} \mathrm{C}\left(\mathrm{kg} / \mathrm{m}^{3}\right)$ & 660 & $800-840$ \\
\hline Liquid viscosity at $25^{\circ} \mathrm{C}(\mathrm{kg} / \mathrm{ms})$ & $0.12-0.15$ & $2-4$ \\
\hline Gas specific gravity $(\mathrm{vs} \mathrm{air})$ & 1.59 & - \\
\hline Lower heating value $(\mathrm{MJ} / \mathrm{kg})$ & 28.43 & 42.5 \\
\hline Cetane number & $55-60$ & $40-55$ \\
\hline Stoichiometric A/F ratio $(\mathrm{kg} / \mathrm{kg})$ & 9.0 & 14.6 \\
\hline $\begin{array}{l}\text { Enthalpy of vaporization at normal temperature and } \\
\text { pressure }(\mathrm{kJ} / \mathrm{kg})\end{array}$ & $460\left(-20^{\circ} \mathrm{C}\right)$ & 250 \\
\hline
\end{tabular}

Table 3.

Properties of DME and diesel [109].

Advantages of dimethyl ether are as follows: (a) high content of oxygen and the absence of any bond between carbon atoms result in low smoke formation, (b) low boiling point results in quick evaporation of fuel spray, and (c) auto-ignition temperature of DME is low, and its cetane number is high, which reduces the physical ignition delay [110]. The disadvantages of DME are as follows: (a) the calorific value is less due to the presence of oxygen molecules, hence the fuel required to produce the same power is more; (b) it has viscosity lower than diesel, which causes leakage in the fuel system, and due to its low lubricity, the fuel injection system surface wear may be high; and (c) its bulk modulus of elasticity is low, it can be compressed nearly four to six times that of diesel, and more work has to be put in the fuel pump to compress the fuel to the same level of diesel [111].

DME is usually used as a spray-can propellant and in cosmetics. Both fossil fuels and renewable energy sources can be used to produce DME. Dehydrogenation of methanol and direct conversion of syngas [112] are the two processes used for DME production. The two methods are essentially similar.

In the direct conversion method, syngas can be used to simultaneously produce DME and methanol using suitable catalysts. The first step of the direct conversion process is the conversion to syngas by either reforming natural gas using steam or partial oxidation of coal and biomass by using pure oxygen. In the second step, a copper-based catalyst is used to synthesize methanol from syngas. In the third step, alumina or zeolite-based catalyst is used to dehydrogenate methanol to form DME. Lastly, the raw product is purified as it may contain some amount of methanol and water. Bio-DME can be produced using renewable sources; however, the production route is costly relative to diesel [110].

\subsection{Use of dimethyl ether as a CI engine fuel}

DME can be used in an engine as a neat fuel or by blending it with diesel, biodiesel, or LPG. This section briefly describes the effect of DME on a diesel engine in terms of its efficiency, combustion, and the exhaust emissions.

A direct injection single-cylinder diesel engine was used by Sato et al. [113] for operating with DME. The engine was supercharged with a multiple hole injector. The authors observed that heat release and combustion pressure with DME-fueled engine are higher than diesel. Also, the engine had lower ignition delay and higher indicated mean effective pressure with DME engine operation than diesel engine 
operation. The authors found $\mathrm{NO}_{\mathrm{x}}$ emission reduction by one-third with $\mathrm{DME}$ with an increase in the exhaust gas recirculation rate. Carbon dioxide emission was lower than diesel. In middle- and low-load conditions, the energy consumption was higher than diesel.

The fuel injection system of a diesel engine needs to be redesigned for operating with DME due to its low lubricity, viscosity, lower heating value, and elasticity. Lubricity can be improved by adding additives; however, for other issues, new materials need to be developed. DME is soluble in hydrocarbons, which make it a lucrative proposition, such as propane blending improves the calorific value of the blend or biodiesel blending improves the lubricity and viscosity of the blend.

Ying et al. [114] blended DME with diesel in various proportions and found decrease in lower heating value, kinematic viscosity, and aromatic fraction of the blends. Cetane number, carbon to hydrogen ratio, and oxygen content of the blends increased. The authors found low fuel consumption for the blends at high engine speed than diesel operation. At high engine speeds, the velocity of the plunger is high in the fuel pump, which makes the pressure in the plunger lower than DME vapor pressure, hence vaporizing the DME in the plunger, thereby reducing the effective stroke of the plunger and fuel delivered per stroke. However, at lower speed, the vaporizing rate is not much, hence more quantity of blended fuel is delivered due to high delivery pressure and the fuel consumption is higher. The impact on emissions due to blends varies with varying load conditions. At high loads, the effect of blends on smoke is significant, whereas at low loads, the smoke emission is slightly affected. $\mathrm{NO}_{\mathrm{x}}$ emission decreases a little, whereas $\mathrm{HC}$ and $\mathrm{CO}$ emissions increase at all operating conditions. The decrease in $\mathrm{NO}_{\mathrm{x}}$ emission is due to lower combustion temperature caused by shorter ignition delay and less amount of fuel prepared for premixed combustion caused by high cetane number and lower auto-ignition temperature $[113,115]$. Also, the blend injection timing is delayed due to low elasticity [116] than diesel, which further reduces the $\mathrm{NO}_{\mathrm{x}}$ emission.

Rapeseed oil was blended with DME at 2, 4, 6, and 10\% volume by volume ratio by Wang and Zhou [117]. The results show that engine performance is good with different blends in all operating conditions. With the increase in rapeseed oil percentage in the blend, the power and torque output of the engine increase as well as the $\mathrm{NO}_{\mathrm{x}}$ emission increases. Smoke emissions were insignificant up to $6 \%$ of rapeseed oil in the blend; however, with further increase in rapeseed percentage, the emission level increased drastically. The authors also observed increase in the heat release rate and the fraction of the fuel burned in premixed combustion phase with an increase in rapeseed oil mass fraction.

In another study, Hou et al. [118] used blends of used cooking oil and DME in a turbocharged compression ignition engine. The authors also observed that increase of DME proportion in the blends reduced the peak in-cylinder temperature, pressure, ignition delay, and peak heat release rate. The authors varied the nozzle hole diameter $(0.35$ and $0.4 \mathrm{~mm})$ and found that peak cylinder pressure and heat release are higher for $0.35 \mathrm{~mm}$ nozzle, and the combustion phase is also advanced. $\mathrm{NO}_{\mathrm{x}}$ emissions with $0.4 \mathrm{~mm}$ diameter are lower than $0.35 \mathrm{~mm}$ diameter at $100 \% \mathrm{DME}$, whereas at $50 \%$ blend of $\mathrm{DME}, \mathrm{NO}_{\mathrm{x}}$ emission is higher with $0.4 \mathrm{~mm}$ diameter than $0.35 \mathrm{~mm}$ diameter. $\mathrm{HC}$ and $\mathrm{CO}$ emissions are lower with $0.4 \mathrm{~mm}$ diameter at $50 \%$ blend of DME, and the emissions increased when $100 \%$ DME is used with $0.4 \mathrm{~mm}$ diameter nozzle.

Since DME and LPG have similar physicochemical properties, DME can be handled and stored in a similar manner. Also, the infrastructure used to supply LPG 
can be used for DME supply for DME-fueled vehicles [119, 120]. DME and LPG can be easily blended, and they compensate for each other's disadvantage namely LPG's low cetane number and DME's low calorific value.

Lee et al. [121] used a single-cylinder diesel engine for operating with blends of $n$-butane and DME. The n-butane was varied from 0 to $40 \%$ by mass in the blend. The n-butane content above $30 \%$ resulted in poor self-ignition and unstable combustion, especially at low loads. The increase in n-butane content led to late start of combustion due to ignition delay caused by reduced cetane number. High $\mathrm{HC}$ and $\mathrm{CO}$ emissions were observed with higher $\mathrm{n}$-butane content due to partial burning of the charge caused by over mixing of the unburnt charge and the burnt charge. $\mathrm{NO}_{\mathrm{x}}$ emissions were higher at low loads and low $\mathrm{n}$-butane content, which are mainly due to early start of combustion giving more time for $\mathrm{NO}_{\mathrm{x}}$ formation. Whereas, at high load and high n-butane content, the $\mathrm{NO}_{\mathrm{x}}$ emission is higher. Also, the $\mathrm{NO}_{\mathrm{x}}$ emissions are lower with blended fuels than diesel engine operation. Less smoke emissions were detected for medium and low loads.

\section{Conclusions}

As already highlighted, depleting petroleum reserves and climate change is mandating the use of alternative fuel to give a new life to millions of off- and on-road engines. The benefits of alternative fuels are enormous for developing countries such as energy security, social empowerment, employment generation, and substantial savings of foreign exchange. The fossil fuels are neither sustainable nor inexhaustible, and alternatives must be explored to address different issues with the use of petroleum-derived fuels.

There are greater challenges with the use of alternative fuels due to their adaptability with the vital parts of engines, cost, availability of feedstocks, and so on. Also, knowledge of important chemical, physical, thermodynamic, and logistics features of the alternative fuel are very much required for large-scale adaptation. Moreover, production of alternative fuels is a complex process, and keeping track of constantly upgrading technology shall be very helpful to drastically reduce the cost and production time.

It is not possible for a single-alternative fuel to completely replace the diesel, and various options have both positive and negative attributes. The alternative fuels reduce the risk to health as they are clean burning. The engine performance is quite similar, and well-to-wheel analysis is required for estimating the operating cost. Since various disciplines are linked with production and adaptation of alternative fuels, synergy is necessary among research fraternity to understand the efficacy of different options. Some of the fuels are very promising, but further research is required to prove their potential. It is envisaged that with the enforcement of more stringent norms, the alternative fuels would become more attractive either as a drop in fuels or blend. It can be concluded that diesel engines can be fueled in an efficient and sustainable way with various options of alternative fuels with some trade-off on price and performance; however, they are capable of bringing a new era of green environment. 


\section{Author details}

Naveen Kumar' ${ }^{1 *}$ Ankit Sonthalia ${ }^{2,3}$, Harveer S. Pali ${ }^{2,4}$ and Sidharth ${ }^{2,5}$

1 Department of Mechanical Engineering, Delhi Technological University, Delhi, India

2 Centre for Advanced Studies and Research in Automotive Engineering, Delhi Technological University, Delhi, India

3 Department of Automobile Engineering, SRM IST, Ghaziabad, Uttar Pradesh, India

4 Department of Mechanical Engineering, JSS Academy of Technical Education, Noida, Uttar Pradesh, India

5 Department of Mechanical Engineering, MAIT, Delhi, India

*Address all correspondence to: naveenkumardce@gmail.com

IntechOpen

(C) 2018 The Author(s). Licensee IntechOpen. Distributed under the terms of the Creative Commons Attribution - NonCommercial 4.0 License (https://creativecommons.org/ licenses/by-nc/4.0/), which permits use, distribution and reproduction for non-commercial purposes, provided the original is properly cited. (cc) BY-NC 


\section{References}

[1] British Petroleum. BP statistical review of world energy 2018. British Petroleum. 2018;66:1-52

[2] Azad AK, Rasul MG, Khan MMK, Sharma SC, Hazrat MA. Prospect of biofuels as an alternative transport fuel in Australia. Renewable and Sustainable Energy Reviews. 2015;43:331-351

[3] Gaurav N, Sivasankari S, Kiran GS, Ninawe A, Selvin J. Utilization of bioresources for sustainable biofuels: A review. Renewable and Sustainable Energy Reviews. 2017;73(November 2016):205-214

[4] Oumer AN, Hasan MM, Baheta AT, Mamat R, Abdullah AA. Bio-based liquid fuels as a source of renewable energy: A review. Renewable and Sustainable Energy Reviews. 2018;88(October 2017):82-98

[5] Surriya O, Saleem SS, Waqar K, Kazi AG, Öztürk M. Biofuels: A blessing in disguise. In: Phytoremediation for Green Energy. Dordrecht: Springer; 2015. pp. 11-54

[6] Nigam PS, Singh A. Production of liquid biofuels from renewable resources. Progress in Energy and Combustion Science. 2011;37:52-68

[7] Thiyagarajan S, Edwin Geo V, Martin LJ, Nagalingam B. Carbon dioxide $\left(\mathrm{CO}_{2}\right)$ capture and sequestration using biofuels and an exhaust catalytic carbon capture system in a singlecylinder CI engine: An experimental study. Biofuels. 2017:1-10. https://doi. org/10.1080/17597269.2017.1292019

[8] Milazzo MF, Spina F, Vinci A, Espro C, Bart BJ. Brassica biodiesels: Past, present and future. Renewable and Sustainable Energy Reviews. 2013;18:350-389

[9] Atadashi IM, Aroua MK, Aziz AA. High quality biodiesel and its diesel engine application: A review. Renewable and Sustainable Energy Reviews. 2010;14(7):1999-2008

[10] Shahid EM, Jamal Y. Production of biodiesel: A technical review. Renewable and Sustainable Energy Reviews.

2011;15(9):4732-4745

[11] Ahmad AL, Yasin NHM, Derek CJC, Lim JK. Microalgae as a sustainable energy source for biodiesel production: A review. Renewable and Sustainable Energy Reviews. 2011;15(1):584-593

[12] Takase M, Zhao T, Zhang M, Chen Y, Liu H, Yang L, et al. An expatiate review of neem, jatropha, rubber and karanja as multipurpose non-edible biodiesel resources and comparison of their fuel, engine and emission properties. Renewable and Sustainable Energy Reviews. 2015;43:495-520

[13] Balat M. Potential alternatives to edible oils for biodiesel production-A review of current work. Energy Conversion and Management. 2011;52(2):1479-1492

[14] Balat M, Balat H. Progress in biodiesel processing. Applied Energy. 2010;87(6):1815-1835

[15] Singh P, Singh A. Production of liquid biofuels from renewable resources. Progress in Energy and Combustion Science. 2010;37(1):52-68

[16] Kafuku G, Mbarawa M. Alkaline catalyzed biodiesel production from Moringa oleifera oil with optimized production parameters. Applied Energy. 2010;87:2561-2565

[17] Li J, Li L, Tong J, Wang Y, Chen S. Research development on lipasecatalyzed biodiesel. Energy Procedia. 2011;16(Part B):1014-1021

[18] Gui MM, Lee KT, Bhatia S.

Feasibility of edible oil vs. 
non-edible oil vs. waste edible oil as biodiesel feedstock. Energy. 2008;33(11):1646-1653

[19] Kumar N, Sharma PB. Jatropha curcus-A sustainable source for production of biodiesel. Journal of Scientific and Industrial Research (India). 2005;64(11):883-889

[20] Lam SS, Liew RK, Jusoh A, Chong CT, Ani FN, Chase HA. Progress in waste oil to sustainable energy, with emphasis on pyrolysis techniques. Renewable and Sustainable Energy Reviews. 2016;53:741-753

[21] Qu W, Zhou Q, Wang YZ, Zhang J, Lan WW, Wu YH, et al. Pyrolysis of waste tire on ZSM-5 zeolite with enhanced catalytic activities. Polymer Degradation and Stability. 2006;91(10):2389-2395

[22] Agarwal AK. Biofuels (alcohols and biodiesel) applications as fuels for internal combustion engines. Progress in Energy and Combustion Science. 2007;33:233-271

[23] Koh MY, Mohd GTI. A review of biodiesel production from Jatropha curcas L. oil. Renewable and Sustainable Energy Reviews. 2011;15(5):2240-2251

[24] Chauhan BS, Kumar N, Cho HM. Performance and emission studies on an agriculture engine on neat Jatropha oil. Journal of Mechanical Science and Technology. 2010;24(2):529-535

[25] Demirbas A. Progress and recent trends in biodiesel fuels. Energy Conversion and Management. 2009;50(1):14-34

[26] Jain S, Sharma MP. Stability of biodiesel and its blends: A review. Renewable and Sustainable Energy Reviews. 2010;14(2):667-678

[27] Gerpen JV. Biodiesel processing and production. Fuel Processing Technology. 2005;86(10):1097-1107
[28] Silitonga AS, Atabani AE, Mahlia TMI, Masjuki HH, Badruddin IA, Mekhilef S. A review on prospect of Jatropha curcas for biodiesel in Indonesia. Renewable and Sustainable Energy Reviews. 2011;15(8):3733-3756

[29] Atabani AE, Silitonga AS, Ong HC, Mahlia TMI, Masjuki HH, Badruddin IA, et al. Non-edible vegetable oils: A critical evaluation of oil extraction, fatty acid compositions, biodiesel production, characteristics, engine performance and emissions production. Renewable and Sustainable Energy Reviews. 2013;18:211-245

[30] Lin CY, Fan CL. Fuel properties of biodiesel produced from Camellia oleifera Abel oil through supercriticalmethanol transesterification. Fuel. 2011;90(6):2240-2244

[31] Sharma YC, Singh B, Upadhyay SN. Advancements in development and characterization of biodiesel: A review. Fuel. 2008;87(12):2355-2373

[32] Teo CL, Jamaluddin H, Zain NAM, Idris A. Biodiesel production via lipase catalysed transesterification of microalgae lipids from Tetraselmis sp. Renewable Energy. 2014;68:1-5

[33] Manuale DL, Mazzieri VM, Torres G, Vera CR, Yori JC. Noncatalytic biodiesel process with adsorption-based refining. Fuel. 2011;90(3):1188-1196

[34] Gupta DK, Sharma A, Pathak V, Kumar N. Synthesis of linseed oil biodiesel using a non-catalytic supercritical transesterification process. SAE International Journal of Fuels and Lubricants. 2014;7(1):317-322

[35] Deshpande A, Anitescu G, Rice PA, Tavlarides LL. Supercritical biodiesel production and power cogeneration: Technical and economic feasibilities. Bioresource Technology. 2010;101(6):1834-1843 
[36] Chauhan BS, Kumar N, Cho HM. A study on the performance and emission of a diesel engine fueled with Jatropha biodiesel oil and its blends. Energy. 2012;37(1):616-622

[37] Nalgundwar A, Paul B, Sharma SK. Comparison of performance and emissions characteristics of DI CI engine fueled with dual biodiesel blends of palm and jatropha. Fuel. 2016;173:172-179

[38] Huang J, Wang Y, Qin J, Roskilly AP. Comparative study of performance and emissions of a diesel engine using Chinese pistache and jatropha biodiesel. Fuel Processing Technology. 2010;91(11):1761-1767

[39] Bari S. Performance, combustion and emission tests of a metrobus running on biodiesel-ULSD blended (B20) fuel. Applied Energy. 2014;124:35-43

[40] Ganapathy T, Gakkhar RP, Murugesan K. Influence of injection timing on performance, combustion and emission characteristics of Jatropha biodiesel engine. Applied Energy. 2011;88(12):4376-4386

[41] Mofijur M, Masjuki HH, Kalam MA, Atabani AE. Evaluation of biodiesel blending, engine performance and emissions characteristics of Jatropha curcas methyl ester: Malaysian perspective. Energy. 2013;55:879-887

[42] Dhar A, Agarwal AK. Performance, emissions and combustion characteristics of Karanja biodiesel in a transportation engine. Fuel. 2014;119:70-80

[43] Raheman H, Phadatare AG. Diesel engine emissions and performance from blends of karanja methyl ester and diesel. Biomass and Bioenergy. 2004;27(4):393-397

[44] Nabi MN, Hoque SMN, Akhter MS. Karanja (Pongamia pinnata) biodiesel production in Bangladesh, characterization of karanja biodiesel and its effect on diesel emissions. Fuel Processing Technology. 2009;90(9):1080-1086

[45] Chauhan BS, Kumar N, Cho HM, Lim HC. A study on the performance and emission of a diesel engine fueled with Karanja biodiesel and its blends. Energy. 2013;56:1-7

[46] Sahoo PK, Das LM, Babu MKG, Naik SN. Biodiesel development from high acid value polanga seed oil and performance evaluation in a CI engine. Fuel. 2007;86(3):448-454

[47] Sahoo PK, Das LM. Combustion analysis of Jatropha, Karanja and Polanga based biodiesel as fuel in a diesel engine. Fuel. 2009;88(6):994-999

[48] Raheman H, Ghadge SV.

Performance of compression ignition engine with mahua (Madhuca indica) biodiesel. Fuel. 2007;86(16):2568-2573

[49] Godiganur S, Suryanarayana Murthy CH, Reddy RP. 6BTA 5.9 G2-1 cummins engine performance and emission tests using methyl ester mahua (Madhuca indica) oil/ diesel blends. Renewable Energy. 2009;34(10):2172-2177

[50] Puhan S, Vedaraman N, Ram BVB, Sankarnarayanan G, Jeychandran K. Mahua oil (Madhuca indica seed oil) methyl ester as biodiesel-preparation and emission characterstics. Biomass and Bioenergy. 2005;28(1):87-93

[51] Puhan S, Vedaraman N, Sankaranarayanan G, Ram BVB. Performance and emission study of Mahua oil (Madhuca indica oil) ethyl ester in a 4-stroke natural aspirated direct injection diesel engine. Renewable Energy. 2005;30(8):1269-1278 
[52] Puhan S, Saravanan N, Nagarajan G, Vedaraman N. Effect of biodiesel unsaturated fatty acid on combustion characteristics of a DI compression ignition engine. Biomass and Bioenergy. 2010;34(8):1079-1088

[53] Hajra B, Kumar M, Pathak AK, Guria C. Surface tension and rheological behavior of Sal oil methyl ester biodiesel and its blend with petrodiesel fuel. Fuel. 2016;166:130-142

[54] Sharma YC, Singh B. An ideal feedstock, kusum (Schleichera triguga) for preparation of biodiesel: Optimization of parameters. Fuel. 2010;89(7):1470-1474

[55] Silitonga AS, Masjuki HH, Mahlia TMI, Ong HC, Kusumo F, Aditiya HB, et al. Schleichera oleosa L. oil as feedstock for biodiesel production. Fuel. 2015;156:63-70

[56] Muralidharan K, Vasudevan D, Sheeba KN. Performance, emission and combustion characteristics of biodiesel fuelled variable compression ratio engine. Energy. 2011;36(8):5385-5393

[57] Jin C, Yao M, Liu H, Lee CF, Ji J. Progress in the production and application of n-butanol as a biofuel. Renewable and Sustainable Energy Reviews. 2011;15(8):4080-4106

[58] Sidharth, Singh Y, Kumar P, Pali HS, Kumar N. Butanol as a CI engine fuel: A review. In: 5th International Symposium on Fusion of Science \& Technology, Delhi. 2016

[59] Giakoumis EG, Rakopoulos CD, Dimaratos AM, Rakopoulos DC. Exhaust emissions with ethanol or n-butanol diesel fuel blends during transient operation: A review. Renewable and Sustainable Energy Reviews. 2013;17:170-190

[60] Gajendra Babu MK, Subramanian KA. Alternative Transportation Fuels, Utilisation in
Combustion Engines. Boca Raton: CRC Press Taylor \& Francis Group; 2013

[61] Kumar N, Bansal S, Vibhanshu V, Singh A. Utilization of blends of Jatropha oil \& n-butanol in a naturally aspirated compression ignition engine. SAE Technical Paper Series. 2013;2013-01-2684

[62] Atmanlı A, Yüksel B, İleri E, Deniz Karaoglan A. Response surface methodology based optimization of diesel-n-butanol-cotton oil ternary blend ratios to improve engine performance and exhaust emission characteristics. Energy Conversion and Management. 2015;90:383-394

[63] Yilmaz N, Vigil FM, Benalil K, Davis SM, Calva A. Effect of biodieselbutanol fuel blends on emissions and performance characteristics of a diesel engine. Fuel. 2014;135:46-50

[64] Zhu Y, Chen Z, Liu J. Emission, efficiency, and influence in a diesel n-butanol dual-injection engine. Energy Conversion and Management. 2014;87:385-391

[65] Doğan O. The influence of n-butanol/diesel fuel blends utilization on a small diesel engine performance and emissions. Fuel. 2011;90(7):2467-2472

[66] Rakopoulos DC, Rakopoulos CD, Giakoumis EG, Dimaratos AM, Kyritsis DC. Effects of butanol-diesel fuel blends on the performance and emissions of a high-speed DI diesel engine. Energy Conversion and Management. 2010;51(10):1989-1997

[67] Karabektas M, Hosoz M.

Performance and emission characteristics of a diesel engine using isobutanol-diesel fuel blends. Renewable Energy. 2009;34(6):1554-1559

[68] Lebedevas S, Lebedeva G, Sendzikiene E, Makareviciene V. 
Investigation of the performance and emission characteristics of biodiesel fuel containing butanol under the conditions of diesel engine operation. Energy \& Fuels. 2010;24(8):4503-4509

[69] Gil J, Corella J, Aznar MP, Caballero MA. Biomass gasification in atmospheric and bubbling fluidized bed: Effect of the type of gasifying agent on the product distribution. Biomass and Bioenergy. 1999;17(5):389-403

[70] McKendry P. Energy production from biomass (part 3): Gasification technologies. Bioresource Technology. 2002;83(1):55-63

[71] Singh H, Mohapatra SK. Production of producer gas from sugarcane bagasse and carpentry waste and its sustainable use in a dual fuel CI engine: A performance, emission, and noise investigation. Journal of the Energy Institute. 2018;91(1):43-54

[72] Pradhan A, Baredar P, Kumar A. Syngas as an alternative fuel used in internal combustion engines: A review. Journal of Pure and Applied Sciences and Technology. 2015;5(2):51-66

[73] Ramadhas AS, Jayaraj S, Muraleedharan C. Power generation using coir-pith and wood derived producer gas in diesel engines. Fuel Processing Technology. 2006;87(10):849-853

[74] Ramadhas AS, Jayaraj S, Muraleedharan C. Dual fuel mode operation in diesel engines using renewable fuels: Rubber seed oil and coir-pith producer gas. Renewable Energy. 2008;33(9):2077-2083

[75] Singh RN, Singh SP, Pathak BS. Investigations on operation of $\mathrm{CI}$ engine using producer gas and rice bran oil in mixed fuel mode. Renewable Energy. 2007;32(9):1565-1580

[76] Banapurmath NR, Tewari PG. Comparative performance studies of a 4-stroke CI engine operated on dual fuel mode with producer gas and Honge oil and its methyl ester (HOME) with and without carburetor. Renewable Energy. 2009;34(4):1009-1015

[77] Carlucci AP, Ficarella A, Laforgia D, Strafella L. Improvement of dualfuel biodiesel-producer gas engine performance acting on biodiesel injection parameters and strategy. Fuel. 2017;209(June):754-768

[78] Dimitriou P, Tsujimura T. A review of hydrogen as a compression ignition engine fuel. International Journal of Hydrogen Energy. 2017;42(38):24470-24486

[79] U.S. Department of Energy. Fuel Cell Technologies Program. 2010

[80] Arribas L, Arconada N, GonzálezFernández C, Löhrl C, González-Aguilar J, Kaltschmitt M, et al. Solar-driven pyrolysis and gasification of low-grade carbonaceous materials. International Journal of Hydrogen Energy. 2017;42(19):13598-13606

[81] Kato T. Present status of hydrogen production by electrolysis. Journal of the Japan Institute of Energy. 2009;88:371-377

[82] Dincer I, Acar C. Review and evaluation of hydrogen production methods for better sustainability. International Journal of Hydrogen Energy. 2015;40(34):11094-11111

[83] Kothari R, Buddhi D, Sawhney RL. Comparison of environmental and economic aspects of various hydrogen production methods. Renewable and Sustainable Energy Reviews. 2008;12(2):553-563

[84] Karim GA. Hydrogen as a spark ignition engine fuel. International Journal of Hydrogen Energy. 2003;28(5):569-577

[85] Homan HS, Reynolds RK, De Boer PCT, McLean WJ. Hydrogen-fueled 
diesel engine without timed ignition. International Journal of Hydrogen Energy. 1979;4(4):315-325

[86] Homan HS. An Experimental Study of Reciprocating Internal Combustion Engines Operated on Hydrogen.

Cornell: Cornell University; 1989

[87] Ikegami M, Miwa K, Shioji M, Esaki M. A study on hydrogen fuelled diesel combustion. Bulletin of JSME. 1980;23(181):1187-1193

[88] Ikegami M, Miwa K, Shioji M. A study of hydrogen fuelled compression ignition engines. International Journal of Hydrogen Energy. 1982;7(4):341-353

[89] Saravanan N, Nagarajan G. Performance and emission studies on port injection of hydrogen with varied flow rates with diesel as an ignition source. Applied Energy. 2010;87(7):2218-2229

[90] Saravanan N, Nagarajan G. Experimental investigation in optimizing the hydrogen fuel on a hydrogen diesel dual-fuel engine. Energy \& Fuels. 2009;23(5):2646-2657

[91] Saravanan N, Nagarajan G. An experimental investigation on manifoldinjected hydrogen as a dual fuel for diesel engine system with different injection duration. International Journal of Energy Research. 2009;33(15):1352-1366

[92] Varde KS, Frame GA. Hydrogen aspiration in a direct injection type diesel engine-its effects on smoke and other engine performance parameters. International Journal of Hydrogen Energy. 1983;8(7):549-555

[93] Lilik GK, Zhang H, Herreros JM, Haworth DC, Boehman AL. Hydrogen assisted diesel combustion. International Journal of Hydrogen Energy. 2010;35(9):4382-4398
[94] Roy MM, Tomita E, Kawahara N, Harada Y, Sakane A. An experimental investigation on engine performance and emissions of a supercharged $\mathrm{H}_{2-}$ diesel dual-fuel engine. International Journal of Hydrogen Energy. 2010;35(2):844-853

[95] Bose PK, Maji D. An experimental investigation on engine performance and emissions of a single cylinder diesel engine using hydrogen as inducted fuel and diesel as injected fuel with exhaust gas recirculation. International Journal of Hydrogen Energy. 2009;34(11):4847-4854

[96] Shin B, Cho Y, Han D, Song S, Chun KM. Hydrogen effects on $\mathrm{NO}_{\mathrm{x}}$ emissions and brake thermal efficiency in a diesel engine under low-temperature and heavy-EGR conditions. International Journal of Hydrogen Energy. 2011;36(10):6281-6291

[97] SinghYadav V, Soni SL, Sharma D. Performance and emission studies of direct injection C.I. engine in duel fuel mode (hydrogen-diesel) with EGR. International Journal of Hydrogen Energy. 2012;37(4):3807-3817

[98] Saravanan N, Nagarajan G. Experimental investigation on performance and emission characteristics of dual fuel DI diesel engine with hydrogen fuel. SAE Technical Paper Series. 2009;2009-26-0032

[99] Chintala V, Subramanian KA. Hydrogen energy share improvement along with $\mathrm{NO}_{\mathrm{x}}$ (oxides of nitrogen) emission reduction in a hydrogen dualfuel compression ignition engine using water injection. Energy Conversion and Management. 2014;83:249-259

[100] Chintala V, Subramanian KA. An effort to enhance hydrogen energy share in a compression ignition engine under dual-fuel mode using low temperature combustion strategies. Applied Energy. 2015;146:174-183 
[101] McTaggart-Cowan GP, Jones HL, Rogak SN, Bushe WK, Hill PG, Munshi SR. Direct-injected hydrogenmethane mixtures in a heavy-duty compression ignition engine. SAE Technical Paper. 2006;2006-01-0653

[102] Edwin Geo V, Nagarajan G, Nagalingam B. Studies on dual fuel operation of rubber seed oil and its biodiesel with hydrogen as the inducted fuel. International Journal of Hydrogen Energy. 2008;33(21):6357-6367

[103] Boopathi D, Sonthalia A, Devanand S. Experimental investigations on the effect of hydrogen induction on performance and emission behaviour of a single cylinder diesel engine fuelled with palm oil methyl ester and its blend with diesel. Journal of Engineering Science and Technology. 2017;12(7):1972-1984

[104] Senthil Kumar M, Jaikumar M. Studies on the effect of hydrogen induction on performance, emission and combustion behaviour of a WCO emulsion based dual fuel engine. International Journal of Hydrogen Energy. 2014;39(32):18440-18450

[105] Youn IM, Park SH, Roh HG, Lee CS. Investigation on the fuel spray and emission reduction characteristics for dimethyl ether (DME) fueled multicylinder diesel engine with commonrail injection system. Fuel Processing Technology. 2011;92(7):1280-1287

[106] Park SH, Lee CS. Combustion performance and emission reduction characteristics of automotive DME engine system. Progress in Energy and Combustion Science. 2013;39(1):147-168

[107] Crookes RJ, Bob-Manuel KDH. RME or DME: A preferred alternative fuel option for future diesel engine operation. Energy Conversion and Management. 2007;48(11):2971-2977
[108] Zhang J, Qiao X, Wang Z, Guan B, Huang Z. Experimental investigation of low temperature combustion (LTC) in an engine fueled with dimethyl ether (DME). Energy \& Fuels. 2009;23(1):170-174

[109] Park SH, Lee CS. Applicability of dimethyl ether (DME) in a compression ignition engine as an alternative fuel. Energy Conversion and Management. 2014;86:848-863

[110] Arcoumanis C, Bae C, Crookes R, Kinoshita E. The potential of di-methyl ether (DME) as an alternative fuel for compression-ignition engines: A review. Fuel. 2008;87(7):1014-1030

[111] Sorenson SC, Glensvig M, Abata DL. Dimethyl ether in diesel fuel injection systems. SAE Technical Paper. 1998;981159

[112] Verbeek, RP, Van Doom, A, van Walwijk M. Global Assessment of di-Methyl Ether as an Automotive Fuel. TNO Road-Vehicles Research Institute. 1996.

[113] Sato Y, Noda A, Sakamoto T, Goto Y. Performance and emission characteristics of a DI diesel engine operated on dimethyl ether applying EGR with supercharging. SAE Technical Paper. 2000;2000-01-1809

[114] Ying W, Longbao Z, Hewu W. Diesel emission improvements by the use of oxygenated DME/diesel blend fuels. Atmospheric Environment. 2006;40(13):2313-2320

[115] Ying W, Longbao Z, Zhongji Y, Hongyi D. Study on combustion and emission characteristics of a vehicle engine fuelled with dimethyl ether. Proceedings of the Institution of Mechanical Engineers Part D Journal of Automobile Engineering. 2005;219(2):263-269

[116] Christensen R, Sorenson SC, Jensen MG, Hansen KF. Engine operation on 
dimethyl ether in a naturally aspirated, DI diesel engine. SAE Technical Paper. 1997;971665

[117] Wang Y, Zhou L. Performance and emissions of a compression-ignition engine fueled with dimethyl ether and rapeseed oil blends. Energy \& Fuels. 2007;21(3):1454-1458

[118] Hou J, Wen Z, Jiang Z, Qiao X.

Study on combustion and emissions of a turbocharged compression ignition engine fueled with dimethyl ether and biodiesel blends. Journal of the Energy Institute. 2014;87(2):102-113

[119] Lee MC, Bin SS, Chung JH, Joo YJ, Ahn DH. Industrial gas turbine combustion performance test of DME to use as an alternative fuel for power generation. Fuel. 2009;88(4):657-662

[120] Marchionna M, Patrini R, Sanfilippo D, Migliavacca

G. Fundamental investigations on di-methyl ether (DME) as LPG substitute or make-up for domestic uses. Fuel Processing Technology. 2008;89(12):1255-1261

[121] Lee S, Oh S, Choi Y, Kang K. Performance and emission characteristics of a CI engine operated with n-butane blended DME fuel. Applied Thermal Engineering. 2011;31(11-12):1929-1935 



\title{
Fuels of the Diesel-Gasoline Engines and Their Properties
}

\author{
Selçuk Sarıkoç
}

\begin{abstract}
Hydrocarbon-based fuels which are gasoline, diesel, natural gas, and liquefied petroleum gas (LPG) have been generally used in the diesel and gasoline engines as a fuel. In this study, hydrocarbon-based fuels such as alkanes (paraffins), naphthenes (cycloparaffins), alkenes (olefins), alkynes (acetylenes), and aromatics (benzene derivatives) have been classified. Their molecular structure and properties have been comprehensively explained. In addition to this, some of the important fuel properties of the commonly used fossil-based fuels such as gasoline and diesel in the internal combustion engine have been evaluated. Thus, hydrocarbon derivative fuels which are diesel, gasoline, natural gas, and liquefied petroleum gas (LPG) have been investigated as an internal combustion engine fuel. Their physical and chemical properties were explained and compared to each other. Octane number and cetane number substantially affect the fuel ignition delay period and selfignition temperature properties. Therefore, the gasoline and diesel engine running is dominantly affected by the octane and cetane numbers, respectively. As a result, fossil-based fuel's physical and chemical properties, advantages, and disadvantages have been comprehensively explained and compared to each other. The fuels, which are commonly used in the diesel and gasoline engine, have been investigated, and their important properties have been revealed.
\end{abstract}

Keywords: fuels, hydrocarbons, diesel fuel, gasoline fuel, diesel and gasoline engine

\section{Introduction}

Fuels can be classified into three groups as solid, liquid, and gas. Although liquid hydrocarbons are generally used in internal combustion engines, in urban transportation where air pollution is a problem, biofuels such as alcohols and biodiesel or gaseous fuels, which are liquefied petroleum gas (LPG) or natural gas, have been rarely used as a fuel. The importance of using alternative fuels in internal combustion engines emerges because of limited oil resources and decreasing reserves, increasing oil prices, and increasing environmental problems. In order to reduce dependence on oil, alternative engine fuels such as vegetable oils, biofuels (alcohols, biodiesel, biogas), and liquefied hydrogen gas have been of particular interest to researchers $[1,2]$. 


\section{Hydrocarbon-based fuels}

Fuel compounds containing carbon and hydrogen atoms in their basic molecular structure are called hydrocarbon-based fuels. Hydrocarbons can be divided into two main groups, aliphatic and aromatic. Aliphatic hydrocarbons are divided into two subclasses as saturated and unsaturated hydrocarbons. The carbon atom in hydrocarbon is called saturated if it has bonded with four hydrogen atoms and unsaturated if the carbon atoms have made double or triple carbon-carbon bonds.

Saturated hydrocarbons are classified as alkanes; unsaturated hydrocarbons are classified as alkenes or alkynes [3, 4]. Hydrocarbons can be in the solid, liquid, and gas phases according to the number of carbons in the chemical structure. Generally, hydrocarbons with carbon atoms 1-4 are in gas, 5-19 are liquid, and molecules with 20 and more carbon atoms are in the solid phase [5]. $\mathrm{C}_{\mathrm{n}} \mathrm{H}_{\mathrm{m}}$ is the general closed chemical formula of liquid hydrocarbons used as a fuel in the internal combustion engines. However, hydrocarbons consist of hydrogen and carbon and also small amounts of $\mathrm{O}_{2}, \mathrm{H}_{2}, \mathrm{~S}, \mathrm{H}_{2} \mathrm{O}$, and some metals containing crude oil derivatives [2]. Figure 1 gives the classification of the compounds of hydrocarbons.

\subsection{Alkanes (paraffins)}

Alkanes are saturated hydrocarbons with the general closed formula $\mathrm{C}_{n} \mathrm{H}_{2 n+2}$, also known in the literature as paraffins, which add the suffix "-an" at the end of the Latin carbon numbers. Alkanes contain more hydrogen in their chemical structure compared to other hydrocarbons, this high number of hydrogen atoms lead to be higher thermal values and lower density than other hydrocarbons $\left(620-770 \mathrm{~kg} / \mathrm{m}^{3}\right)$. As the number of carbon atoms in the hydrocarbon chain increases, the properties of the alkanes such as autoignition tendencies, molecular weights, and melting and boiling points increase. Each increase in carbon number in the hydrocarbon chain causes the boiling point to rise by about $20-30^{\circ} \mathrm{C}$. Alkanes are insoluble in water because they are apolar. Among the apolar molecules such as hydrocarbons and inert gases are Van der Waals forces, in other words, London dispersion forces. Dispersion force is as a weak intermolecular force between all molecules by means of temporary dipoles induced in the atoms or molecules. The dispersion forces are commonly expressed as London forces. Electron numbers and surface area of the molecules are the most important affecting factors of the magnitude of dispersion forces. These tensile forces directly affect the boiling point of these materials. The alkanes may exist in a straight chain, branched chain, and cyclic form depending on

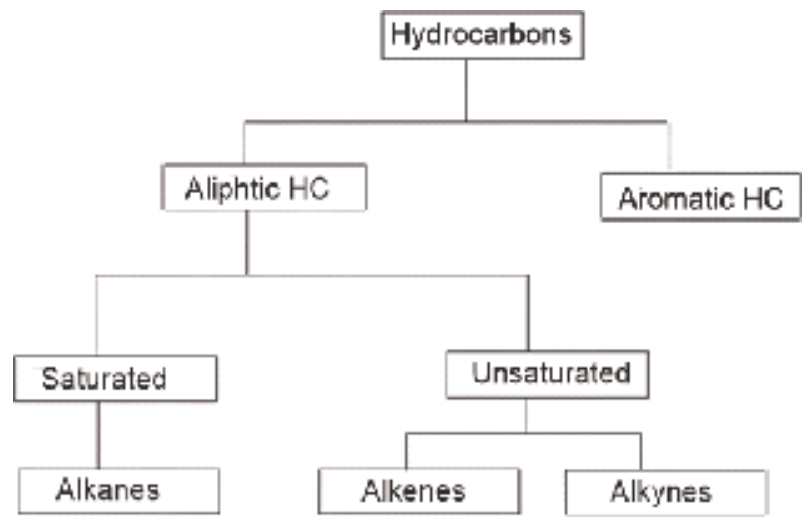

Figure 1.

Classification of hydrocarbons [3]. 
the arrangement of the carbon atoms. Van der Waals forces are more effective than branched ones because the molecular surfaces of the straight-chain alkanes are more in contact with each other. Thus, the boiling point of the straight-chain alkanes having the same molecular weight is higher than the branched ones. In other words, as the branching increases, the boiling point decreases, because the branched structure makes the molecule tighter. However, the increasing of branching has led to the surface area of the molecule to become narrow, and the boiling point decreases with the reduction of Van der Waals forces between itself and neighboring molecules. The ignition tendencies of straight-chain alkanes are generally higher than the branched chain ones due to it being more easily broken down. Unlike straight-chain molecule structures, branched chain and ring structures have higher ignition resistance. Therefore, straight-chain alkanes are more suitable for use as diesel fuel rather than as gasoline fuel. However, alkane isomers which are of the same closed formula but with different branched chains and rings are more suitable for use as a gasoline engine fuel since they have higher engine knocking resistance. The property that defines whether the fuel ignites spontaneously is called the octane number. In other words, it is defined as ignition resistance. Straight long chain fuels generally have a lower octane number, whereas branched structures have a higher octane number. To summarize this briefly, the octane number is usually inversely proportional to the chain length of the molecules of the fuels. The shorter the chain structure of the fuel molecules, the higher the octane number. The octane number is directly proportional to the branched side chain components. Besides, having a ring molecular structure of fuels leads to high octane numbers. Alkanes are present in solid, liquid, and gaseous form according to their carbon number. The carbon number 1-4 is present in gas, 5-25 in liquid form, and more than 25 in solid form. Alkanes contain less than 4 carbon atoms in their natural gas and petroleum gases, 5-12 atoms in gasoline, 12-20 atoms in diesel fuels, and 20-38 atoms in lubricating oils [1-8]. Figure 2 shows the molecular structure of the first four alkanes.<smiles>C</smiles>

Methane<smiles>CC</smiles>

Ethane<smiles>CC</smiles>

Propane<smiles>CCC</smiles>

Butane

Figure 2.

The molecular structure of the first four alkanes [8].

\subsection{Naphthenes (cycloparaffins)}

Another type of alkanes is cyclic structures which demonstrate as the general formula $\mathrm{C}_{\mathrm{n}} \mathrm{H}_{2 \mathrm{n}}$. Two hydrogen atoms are missing from normal alkanes because their structures are cyclic-shaped and in closed form. As the number of hydrogen atoms is low compared to normal alkanes, they have lower thermal values but higher densities $\left(740-790 \mathrm{~kg} / \mathrm{m}^{3}\right)$. Cycloalkanes are difficult to break up because of their closed cycle structure and have higher ignition resistance than straight-chain alkanes. However, they are also suitable for use as both petrol and diesel fuel due to that they have lower ignition resistance than branched ones. Thermal values of naphthenes are lower than alkanes and higher than aromatics [2]. Figure 3 shows the cyclic molecular structure of cyclohexane. 


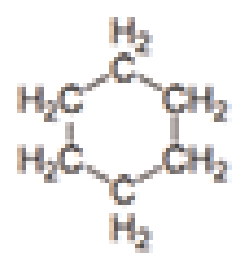

Figure 3 .

The cyclic molecular structure of cyclohexane [5].

\subsection{Alkenes (olefins)}

Alkenes are unsaturated hydrocarbons that have double bond between carbon atoms shown as the general formula $\mathrm{C}_{n} \mathrm{H}_{2 n}$. The olefins with one double bond in the molecular structure are called monoolefins $\left(\mathrm{C}_{n} \mathrm{H}_{2 n}\right)$, and those with two double bonds are called die-olefins $\left(\mathrm{C}_{n} \mathrm{H}_{2 n-2}\right)$. Monoolefins are entitled after the "en" or "ilen" suffix at the end of the carbon number, while die-olefins are entitled by attaching the "dien" suffix to the roots showing the carbon number. Many isomers are formed by displacement of the double bonds of alkenes. Alkenes' thermal values are lower than alkanes, and their density is between 620 and $820 \mathrm{~kg} / \mathrm{m}^{3}$ due to that the ratio of carbon atoms to hydrogen atoms is higher in the molecular structure of alkenes. Alkenes have high ignition resistance. Alkenes are less resistant to oxidation than alkanes so that they can easily react with oxygen. Thus, oxygen causes to be gummed to alkenes and consequently block the fuel pipeline. Alkenes contain double bonds between carbon atoms, one of which is sigma ( $\sigma)$ and the other is pi $(n)$. For this reason, it breaks down more difficult than alkanes with a single sigma bond. Alkenes can be used as fuel for gasoline engines due to high ignition resistance. Besides, it can be used as a diesel fuel by increasing autoignition temperature. The most important properties of alkenes give addition reactions with $\mathrm{H}_{2}, \mathrm{X}_{2}, \mathrm{HX}$, and $\mathrm{H}_{2} \mathrm{O}$ compounds. Carbon atoms of alkenes are not fully saturated with hydrogen. Therefore, alkenes can be more easily associated with elements such as hydrogen, chlorine, and bromine due to it being more chemically reactive than alkanes and naphthenes. With this reactive structure, they are used as raw materials to obtain better quality fuels by methods such as hydrogenation, polymerization, and alkylation. While alkenes are present in very small amounts in crude oil, generally they can be obtained by thermal and catalytic cracking methods which are heat or catalyst by means of large molecular product decomposition. Alkenes are present in large quantities in the gasoline obtained by these methods. The high ignition resistance of the alkenes makes them a good gasoline engine fuel, but they can also be diesel engine fuel by increasing the ignition tendencies [1-3, 5, 9]. Figure 4 shows the molecular structure of some alkenes.

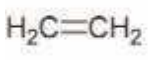

Ethylene<smiles>C=CC</smiles>

Propylene<smiles>C=CCC</smiles>

Butene-1<smiles>C=CCCC</smiles>

Pentene

Figure 4.

The molecular structure of some alkenes [5]. 


\subsection{Alkynes (acetylenes)}

Alkynes are compounds which having the general closed formula $\mathrm{C}_{n} \mathrm{H}_{2 n-2}$ and having at least one triple bond $(\mathrm{C} \equiv \mathrm{C})$ between carbon atoms. Alkynes are unsaturated hydrocarbons due to all carbon atoms not having enough bonds with hydrogen. Besides, alkynes have "-in" suffix which is added to the end of the compound and entitled according to the number of carbon atoms in the longest chain. The simplest and most known compound is acetylene $\left(\mathrm{C}_{2} \mathrm{H}_{2}\right)$. Alkynes may also be referred to as acetylene derivatives. Alkenes are more reactive than alkanes and naphthenes because they are unsaturated. Thus, they can be more easily reacted with elements such as hydrogen, chlorine, and bromine to form a compound $[3,5,9]$. Figure 5 gives the molecular structure of some alkenes.

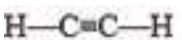

Acetylene
$\mathrm{H}_{3} \mathrm{C}-\mathrm{C} m \mathrm{C}-\mathrm{H}$

Methylacetylene

Figure 5 .

The molecular structure of some alkynes [5].

\subsection{Aromatics (benzene derivatives)}

At the end of the nineteenth century, organic compounds were divided into two classes as aliphatic and aromatics. Aliphatic compounds meant that the compounds exhibited "liparoid" chemical behavior, while aromatic compounds meant low hydrogen/carbon content and "fragrant." Aromatics are unsaturated hydrocarbons having double bonds between carbon atoms that have a closed general formula $\mathrm{C}_{\mathrm{n}} \mathrm{H}_{2 \mathrm{n}-6}$. Aromatic compounds are bonded to each other by aromatic bonds, not single bonds. In other words, aromatics are also called arenes. Although aromatics are unsaturated compounds, they have different chemical properties than other aliphatic unsaturated compounds. Unlike alkenes and alkynes, aromatics do not give an addition reaction which is the characteristic reaction of unsaturated compounds. Furthermore, aromatics carry out displacement reactions especially specific to saturated hydrocarbons. Because of these reasons and aromatics are more stable than other unsaturated compounds, aromatics have been categorized as a separate class of hydrocarbons. Due to the presence of more than one double bonded carbon atoms and cyclic structure, they have strong bond structures and highly resistant to ignition. Densities of aromatics range between 800 and $850 \mathrm{~kg} / \mathrm{m}^{3}$. Higher densities in the liquid state cause them to have a high-energy content per unit volume but have a low thermal value per unit mass. The bonds between carbon atoms are strong; aromatics have a high resistance to knocking. Therefore, because of the high octane number of aromatics, they can be a good gasoline fuel with the addition of gasoline to increase knocking resistance, but they are not suitable to use as diesel engine fuel because of their low cetane numbers. The simplest aromatic compound is benzene with the chemical formula $\mathrm{C}_{6} \mathrm{H}_{6}$. The main structures of other aromatics are also constituted by benzene. Generally, they can be obtained artificially from coal and can be used as a gasoline additive to improve the knocking resistance of gasoline. The aromatics must be used carefully because they are carcinogenic, cause exhaust pollution, have high solubility, and have corrosive effects on fuel supply systems $[1-3,5,6,9]$. Figure 6 shows the molecular structure of some important aromatics. 


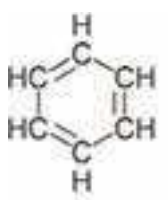

Benzene

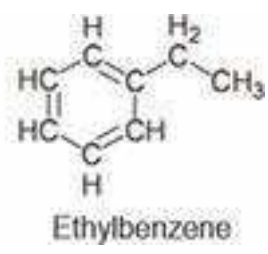

Figure 6.

Molecular structure of some aromatics [5].

\section{Fuels of internal combustion engine}

Gasoline and diesel fuels, which are derivatives of crude oil, are generally used in internal combustion engines. The approximate elemental structure of an average crude oil consists of $84 \%$ carbon, $14 \%$ hydrogen, $1-3 \%$ sulfur, and less than $1 \%$ nitrogen, oxygen atoms, metals, and salts. Crude oil consists of a wide range of hydrocarbon compounds consisting of alkanes, alkenes, naphthenes, and aromatics. These are very small molecular structures such as propane $\left(\mathrm{C}_{3} \mathrm{H}_{8}\right)$ and butane $\left(\mathrm{C}_{4} \mathrm{H}_{10}\right)$ but can also be composed of mixtures of various structures with very large molecules such as heavy oils and asphalt. Therefore, crude oil needs to be distilled to be used in internal combustion engines. As a result of heat distillation of crude oil, petroleum derivatives such as petroleum gases, jet fuel, kerosene, gasoline, diesel, heavy fuels, machine oils, and asphalt are obtained. In general, the distillation of crude oil resulted in an average of 30\% gasoline, $20-40 \%$ diesel, and $20 \%$ of heavy fuel oil, and heavy oils from 10 to $20 \%$ are obtained [2, 5].

During the distillation of crude oil, gasoline is obtained between 40 and $200^{\circ} \mathrm{C}$, and diesel fuel is obtained between 200 and $425^{\circ} \mathrm{C}$. In order to use these fuels in engines, some of the important physical and chemical properties such as specific gravity of the fuel, structural component, thermal value, flash point and combustion temperature, self-ignition temperature, vapor pressure, viscosity of the fuel, surface tension, freezing temperature, and cold flow properties are required. The specific mass, density of the fuel decreases with increasing hydrogen content in the molecule. The density of gasoline and diesel fuels is generally given in $\mathrm{kg} / \mathrm{m}^{3}$ at $20^{\circ}$ C. The American Petroleum Institute (API) number is an international measurement system that classifies crude oil according to its viscosity according to the American standards. The specific gravity can be defined as the ratio of the weight of a given volume of a given substance at $15.15^{\circ} \mathrm{C}\left(60^{\circ} \mathrm{F}\right)$ to the weight of the water at the same volume and temperature. The relationship between API number and specific gravity is expressed as follows $[1,2,5]$ :

$$
\begin{gathered}
\text { Specific weight }\left(15.15^{\circ} \mathrm{C} / 15.15^{\circ} \mathrm{C}\right)=\frac{\rho_{\text {specimen }}\left(15.15^{\circ} \mathrm{C}\right)}{\rho_{\text {water }}\left(15.15^{\circ} \mathrm{C}\right)} \\
\text { API }=\frac{141.5}{\text { Specific weight }\left(15.15^{\circ} \mathrm{C} / 15.15^{\circ} \mathrm{C}\right)}-131.5
\end{gathered}
$$

According to the API number, crude oil is divided into three groups as heavy, medium, and light, and as the number of the API increases, crude oil becomes thinner. The API degree of diesel fuels varies between about 25 and 45 . The viscosity, color, main component, and definition of crude oil according to the API grade are given in Table $\mathbf{1}[1,5]$. 
Fuels of the Diesel-Gasoline Engines and Their Properties

DOI: http://dx.doi.org/10.5772/intechopen.89044

\begin{tabular}{lllll}
\hline API grade & Definition & Viscosity & Color & Composition \\
\hline $0-22.3^{\circ}$ & Heavy & Too viscous & Dark & Asphalt \\
\hline $22.3-31.3^{\circ}$ & Medium & Medium & Brown & Diesel + gasoline \\
\hline $31.3-47^{\circ}$ & Light & Fluid & Light yellow & Gasoline \\
\hline
\end{tabular}

Table 1.

Classification of crude oil according to API grade [5].

While the density of gasoline is $\rho=700-800 \mathrm{~kg} / \mathrm{m}^{3}$, it varies between $\rho=830$ $950 \mathrm{~kg} / \mathrm{m}^{3}$ for diesel fuel. While the carbon content in alkane and naphthene fuels is $86 \%$, it is around $89 \%$ for aromatics. In addition to carbon and hydrogen atoms, sulfur, asphalt, and water can be found in gasoline and diesel fuels. In particular, sulfur can cause corrosion in engine parts, and the combustion products of sulfur have a negative impact on the environment. The asphalt adheres to the valve on the piston surfaces and causes wear. The water causes corrosion and reduces the thermal value of the fuel. These are undesirable components in the fuel. The thermal values of liquid fuels are given as unit mass energy $(\mathrm{kJ} / \mathrm{kg}$ or $\mathrm{kcal} / \mathrm{kg})$, while the thermal values of gas fuels are given as unit energy $\left(\mathrm{kJ} / \mathrm{l}, \mathrm{kJ} / \mathrm{m}^{3}\right.$ or $\left.\mathrm{kcal} / \mathrm{m}^{3}\right)$. Thermal values of fuels are expressed in two ways as lower and higher heating value. If the water in the fuel is in the vapor state at the end of the measurement, it gives the lower thermal value of this fuel. When the water in the fuel condenses at the end of the measurement, it gives the evaporation heat to the system, and the measured value gives the higher heating value of the fuel. As a result, the single-phase steam is obtained in the calorimeter capsule as a result of the thermal value measurement so that the lower heating value is measured. The dual phase (liquid-vapor phase) is obtained so that the higher heating value is measured. When the temperature of an air-fuel mixture is sufficiently heated, the fuel starts to ignite by itself without external ignition. This temperature is referred to as the self-ignition temperature (SIT) of the fuel and the delay time for the combustion of the fuel to be the ignition delay (ID). The terms SIT and ID are important features of engine fuels. SIT and ID values vary depending on variables such as temperature, pressure, density, turbulence, rotation, air-fuel ratio, and presence of inert gases. Self-ignition is the basic rule of the combustion process in diesel engines. SIT value is desired to be high in gasoline engines and low in diesel engines. The autoignition temperature of the gasoline is $550^{\circ} \mathrm{C}$ and higher temperatures $[1,2,4]$.

Depending on the type of gasoline or diesel engine, the desired properties of fuels vary. The most important properties of gasoline fuels are properties such as volatility and knocking resistance, whereas diesel fuels are required to have important fuel properties such as viscosity, surface tension, and ignition tendency. In gasoline fuels, volatility and knock resistance are one of the most important parameters affecting engine performance. The volatility of gasoline fuel affects the rate and amount of evaporation of the fuel in the intake channel and in the cylinder. The low volatility of the fuel influences the formation of sufficient air-fuel mixture, but when it is very volatile, it can prevent the flow of fuel by creating vapor bubbles in the suction channel with the local temperature increases. When the flame front advances during combustion, with the increasing temperature and pressure inside the cylinder, it compresses the air-fuel fill which the flame front cannot yet reach. Thus, the fuel can constitute another combustion front due to the fuel spontaneously reaches the ignition temperature to heat and radiation. The combustion speeds of the flame fronts at these different points can be $300-350 \mathrm{~m} / \mathrm{s}$, and 
cylinder pressures may reciprocate to as high as 9-12 MPa. At these high speed and pressure values, the flame fronts are damped by hitting each other or against the walls of the combustion chamber. These damping are not only cause loss of energy but also increase the local heat conduction. As a result of this situation, engine performance decreases. This phenomenon is called a knock in gasoline engines and is an undesirable situation. The chemical structure of the fuel has a considerable effect on the autoignition temperature. Octane number (ON) is defined as the property of fuel to knocking resistance or how well the fuel itself ignites. The octane number is inversely proportional to the chain length of the fuel molecules. The shorter the molecular chain length of the fuels has, the higher the octane number is. However, the octane number is directly proportional to the branched side chain component. The higher the branching in the molecule chain leads to the higher octane number of the fuel. In other words, it causes higher knocking resistance of fuels. Generally, increasing the number of carbon atoms in the composition of the fuel has higher impact resistance. However, the octane numbers of cyclic molecules, naphthenes, alcohols, and aromatics are high. In order to scale the octane number of gasoline, two reference points are taken, which represent points $0-100$. The octane number of normal heptane $\left(\mathrm{C}_{7} \mathrm{H}_{16}\right)$ is assumed to be 0 , while the octane number of isooctane $\left(\mathrm{C}_{8} \mathrm{H}_{18}\right)$ is considered to be 100 . The reason of these two fuels as a reference point is that both fuel compounds have almost the same volatility and boiling point values. The reason as a reference point of these two fuels is that both fuel compounds have almost the same volatility and boiling point values. Fuels such as alcohols and benzenes with an octane number higher than the top octane number of this measure are also available. In gasoline engines, additives are used to increase the knocking resistance of the fuel to prevent knocking. The two most commonly used methods for determining the octane number of fuels are engine method and research method. The octane numbers determined by these methods give the values of motor octane number (MON) and research octane number (RON), respectively. Table 2 gives the test conditions for determining the octane number of fuel $[1,2,4,5]$.

\begin{tabular}{lcc}
\hline Properties & RON & MON \\
\hline Engine speed $(\mathrm{rpm})$ & 600 & 900 \\
\hline Intake air temperature $\left({ }^{\circ} \mathrm{C}\right)$ & $52\left(125^{\circ} \mathrm{F}\right)$ & $149\left(300^{\circ} \mathrm{F}\right)$ \\
\hline Cooling water temperature $\left({ }^{\circ} \mathrm{C}\right)$ & $100\left(212^{\circ} \mathrm{F}\right)$ & 100 \\
\hline Oil temperature $\left({ }^{\circ} \mathrm{C}\right)$ & $57\left(135^{\circ} \mathrm{F}\right)$ & $13-19^{\circ} \mathrm{KMA}$ (before TDC) \\
\hline Ignition time & $13^{\circ} \mathrm{KMA}($ before TDC $)$ & 0.508 \\
\hline Spark plug nail range & $0.508(0.020$ inç $)$ & \multicolumn{2}{c}{ Atmospheric pressure } \\
\hline Intake air pressure & \multicolumn{2}{c}{ Adjusted for maximum knock } \\
\hline Air-fuel ratio & \multicolumn{2}{c}{ Adjusted to achieve a standard knock } \\
\hline Compression ratio & \multicolumn{2}{c}{} \\
\hline
\end{tabular}

Table 2.

Test conditions for octane number measurement [4].

Since the inlet air temperature of the MON method is higher than the RON method, the post-combustion temperature reaches higher values. Thus, the fuel spontaneously ignites and knocks. Therefore, the octane number obtained by the MON method is lower than the octane number obtained by the RON method because it is operated at lower compression ratios in the MON method. The value difference between these two octane number determination methods is called fuel sensitivity (FS). When the number of fuel sensitivities is between 0 and 10, it is stated that the knock characteristic of the fuel does not depend on engine geometry, 
and if it is higher than these values, the knock characteristic of the fuel is highly dependent on the combustion chamber geometry of the engine. YD is calculated as in Eq. (3):

$$
\mathrm{FS}=\mathrm{RON}-\mathrm{MON}
$$

Combustion chamber geometry, turbulence, temperature, and inert gases are the parameters that affect the octane number. The octane number is highly dependent on the flame velocity in an air-fuel charge. As the flame velocity increases, the air-fuel mixture above the spontaneous ignition temperature immediately burns during the ignition delay. Thus, there is a direct correlation between the flame speed and the octane number, as the flame speed will allow the fuel to run out without knocking. Alcohols have high flame speeds, so their octane numbers are high. The ID period does not depend on the physical properties of the fuel such as density and viscosity in a hot engine at steady state. It is strongly dependent on the components of the fuel chemistry. Therefore, additives such as alcohols or organic manganese compounds are added to increase the octane number of the fuel $[4,5]$. It is possible to work at higher compression ratios by increasing the octane number of fuels. Thus, high compression ratio increases engine power and provides fuel economy [10].

Diesel fuels are divided into two main categories as light diesel and heavy diesel fuels. The chemical formula of light diesel is approximately $\mathrm{C}_{12.3} \mathrm{H}_{22.2}$, while heavy diesel is considered as $\mathrm{C}_{14.06} \mathrm{H}_{24.8}$. The molar weights of light and heavy diesels are approximately 170 and $200 \mathrm{~g} / \mathrm{mol}$, respectively. Viscosity, surface tension, and ignition tendency of fuel are important fuel property parameters in diesel fuels. Light diesel fuel has a lower viscosity and requires less pumping work. Since low viscosity also reduces the surface tension of the fuel, the fuel has a smaller droplet diameter during spraying. In contrast to gasoline engines, it is desirable to have a high ignition tendency in diesel engines, since combustion in the diesel engines is based on the spontaneous combustion of the air-fuel mixture. At this point, the cetane number, which is a measure of the fuel's ignition ability, emerges as a fuel feature. In other words, it is a quantity that quantifies the ignition delay period. Hexadecane $\left(\mathrm{C}_{16} \mathrm{H}_{34}\right)$, a straight-chain fuel of the alkane group, is considered to be the highest reference point of the cetane number, which is the measure of the ignition tendency. The other reference point is cetane number 15 as heptamethylnonane (HMN) $\mathrm{C}_{12} \mathrm{H}_{34}$, or the lowest reference point was accepted zero as the cetane number value of alpha-methyl naphthalene $\mathrm{C}_{11} \mathrm{H}_{10}$ fuel. First of all, fuel with unknown cetane value is run in the adjustable compression ratio engine. Then, the engine test is carried out until the compression rate at which the first knock starts for determining compression ratio of the fuel. Then, the mixture of these two reference fuels in various ratios is tested at the specified compression ratio, and the reference fuels are mixed until the knocking begins. The percentage of hexadecane at the moment of the knock, in the heptamethylnonane or alphamethyl naphthalene fuel mixture, gives us the cetane number of the measured fuel. Several empirical equations have been developed by using the physical properties of the fuel since the engine tests are very laborious and costly in determining the cetane number. These methods, which measure the fuel propensity to ignite, are called cetane index, aniline point, or diesel index. Aniline is an aromatic compound which is very easily mixed with compounds of its group even at low temperatures, while it is more difficult to form mixtures with alkanes (paraffins). Therefore, hexadecane $\left(\mathrm{C}_{16} \mathrm{H}_{34}\right)$ which is an alkane group and has a high ignition tendency has a high mixing temperature with the aniline. The mixture of the sample fuel with the same amount of aniline is heated to find the diesel index. Then, all of the aniline is dissolved in the fuel. After that the mixture is cooled for allowing to aniline to separate from the fuel. This temperature, where the aniline is separated from the 
fuel, is called the aniline point. The diesel index is calculated with the aniline point and API grade specified in Eq. (4):

$$
\text { Diesel index }=\frac{\text { Aniline point }\left({ }^{\circ} \mathrm{F}\right) \times \text { API }\left(\text { at } 60^{\circ} \mathrm{F}\right)}{100}
$$

The higher the diesel index value, the fuel is more alkane (in paraffinic structure), and it has the higher ignition tendency. Increasing volatility in diesel fuels causes acceleration of fuel evaporation and decrease in viscosity. This is generally undesirable since the fuel causes a reduction in the cetane number $[1,2,4]$.

Some fuels commonly used in engines are presented in Table 3. Some of the important properties of fuels such as the closed formulas, molar weight, lower heating value and higher heating value, stoichiometric air/fuel and fuel/air ratios, evaporation temperature, motor octane number $(\mathrm{MON})$, research octane number (RON), and cetane number are given.

The cetane index can be calculated from Eq. (5) which is shown by distilling the fuel. It is calculated from the temperatures and the density of the vaporized fuel at 10,50 , and $90 \%$ volumetric ratios by the distillation of the fuel:

$$
\begin{aligned}
S I= & 45.2+0.0892\left(T_{10}-215\right)+0.131\left(T_{50}-260\right)+0.523\left(T_{90}-310\right)+0.901 B\left(T_{50}-260\right) \\
& -0.420 B\left(T_{90}-310\right)+0.00049\left(T_{10}-215\right)^{2}-0.00049\left(T_{90}-310\right)^{2}+107 B+60 B^{2}
\end{aligned}
$$

The values of $\mathrm{T}_{10}, \mathrm{~T}_{50}$, and $\mathrm{T}_{90}$ are the temperatures at which the fuel evaporates in volume ratios of 10,50 , and $90 \%$, respectively. $B=-\exp [-3500(\rho-850)]-1$, where $\rho=$ density in $\mathrm{kg} / \mathrm{m}^{3}$ at $15^{\circ} \mathrm{C}$. This formula is related to the number of cetane, unless cetane-enhancing additives are added to the fuel. Otherwise, the cetane number of doped fuels can be measured by engine test experiments. Another method used to calculate the cetane index is the empirical equation given in Eq. (6), which is calculated using some physical properties of the fuel [5]:

$$
\begin{aligned}
S I= & -420.34+0.016 G^{2}+0.192 G\left(\log _{10} T_{g n}\right)+65.01\left(\log _{10} T_{g n}\right)^{2} \\
& -0.0001809 T_{g n}{ }^{2}
\end{aligned}
$$

where $G=\left(141.5 / \mathrm{S}_{\mathrm{g}}\right)-131.5$ is the API degree of the fuel. $\mathrm{S}_{\mathrm{g}}$ and $\mathrm{T}_{\mathrm{gn}}$ are the relative boiling point temperature in ${ }^{\circ} \mathrm{F}$ and relative density, respectively.

The semiempirical expression that predicts ID duration based on cetane number and other operating parameters is as follows:

$I D=\left(0.36+0.22 U_{p}\right) \exp \left(E_{A}\left[\left(1 / R_{u} T_{e m} \varepsilon^{k-1}\right)-(1 / 17.190)\right]\left[(21.2) /\left(P_{e m} \varepsilon^{k}-12.4\right)\right]^{0.63}\right)$

ID $\left({ }^{\circ} \mathrm{CA}\right)$ is a time in crankshaft angle, $E_{A}=(618.840) /($ cetane number +25$)$ activation energy, $R_{u}=8.314 \mathrm{~kJ} / \mathrm{kmol} \mathrm{K}$ universal gas constant, $T_{\mathrm{em}}$ and $P_{\mathrm{em}}$ temperature at the beginning of compression time, respectively, $(\mathrm{K})$ and pressure (bar), $\varepsilon=$ compression ratio, and $k=\mathrm{cp} / \mathrm{cv}=1.4$ are the values used in air standard cycle analysis. ID is calculated by the formula given in Eq. (8). It is expressed in milliseconds for an engine at $\mathrm{n}$ rpm [4]:

$$
I D(\mathrm{~ms})=D\left({ }^{\circ} C A\right) /(0.006 n)
$$

The low cetane number of diesel engines leads to an increase in ID time, which in turn reduces the time required for combustion and CA. An increased TG time 
Fuels of the Diesel-Gasoline Engines and Their Properties

DOI: http://dx.doi.org/10.5772/intechopen.89044

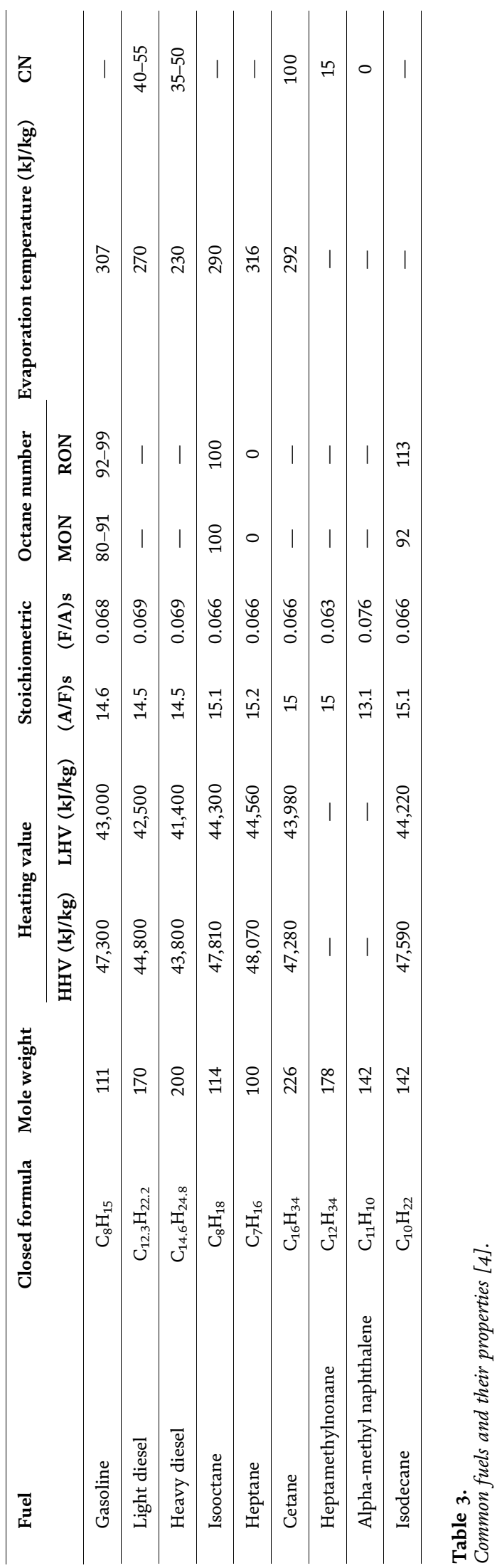


leads to accumulate more fuel in the combustion chamber than required. Thus, this excess fuel causes sudden and high-pressure increases during the onset of combustion. These sudden pressures increase cause mechanical stresses and hard engine operation, which is known as diesel knocking [2,4].

In brief, the number of cetane and the number of octane refer to the spontaneous combustion of fuels. A higher cetane number indicates that diesel fuel burns suddenly and easily. The high octane number defines the resistance of gasoline to sudden ignition. Generally, if the cetane number is high, the octane number is low. There is an inverse relationship between these two properties, so that the cetane number is low if the octane number is high [5].

\section{Natural gas and liquefied petroleum gas (LPG)}

Natural gas is a gas mixture containing methane, ethane, propane, pentane, and hexane in a lighter content than air, without color, smell, and taste. However, it contains a small amount ( $0-0.5 \%$ by volume) of carbon dioxide, nitrogen, helium, and hydrogen sulfide gas. Generally, this gas composition contains about 70-90\% of methane, $0-20 \%$ ethane, and slightly less propane than ethane. The natural gas used in the market is refined and separated from other gases and used as almost pure methane gas $\left(\mathrm{CH}_{4}\right)$ [5]. Natural gas can be stored as compressed natural gas (CNG) at high pressures such as 16-25 MPa or liquid natural gas at low pressures such as $70-210 \mathrm{kPa}$ and at very low temperatures such as $-160^{\circ} \mathrm{C}$. Natural gas can be stored by these methods and generally used as compressed natural gas (CNG) in internal combustion engines with a single-point spray system. The single-point spraying system allows for the most efficient use of natural gas as it provides a longer mixing time than required for natural gas [4]. Table 4 shows the compounds that form natural gas and boiling points.

\begin{tabular}{lccc}
\hline Composition & Boiling point $\left({ }^{\circ} \mathrm{C}\right)$ & Composition & Boiling point $\left({ }^{\circ} \mathrm{C}\right)$ \\
\hline Methane & -161.6 & Isopentane & 28 \\
\hline Ethane & -88.6 & n-Pentane & 36.1 \\
\hline Propane & -42.1 & Hexane & 69 \\
\hline Isobutane & -11.7 & Heptane & 98.4 \\
\hline n-Butane & -0.5 & & \\
\hline
\end{tabular}

Table 4 .

Compounds and boiling points in natural gas [5].

There are dual fuel diesel engines in which natural gas and diesel fuels work together. Natural gas is supplied to the combustion chamber at approximately sound speed. This leads to high turbulence and high flame speeds. Natural gas has lower combustion temperatures than diesel fuel, and with late spraying, the combustion chamber temperature can be further reduced. Decrease in combustion chamber temperature significantly reduces $\mathrm{NO}_{\mathrm{x}}$ formation. However, the low carbon content in natural gas leads to less $\mathrm{CO}_{2}$ emissions and much less solid particulate matter [4].

Dump gas engines, converting methane gas into energy, are one of the most common natural gas applications. Gases produced in landfills generally contain between 45 and $65 \%$ methane. In addition to methane, these landfill gases contain highly polluting and variable quality gases such as fluorine, chlorine, silicon, and solid particles. Especially due to the corrosive and abrasive effect of these gases, special piston and valve materials must be used in the engines. The thermal value of 
natural gas is between 33.4 and $40.9 \mathrm{MJ} / \mathrm{m}^{3} . \mathrm{CO}_{2}, \mathrm{H}_{2} \mathrm{O}$, and $891 \mathrm{~kJ}$ of energy are obtained when $1 \mathrm{~mol}$ of methane gas is fully combusted. The combustion equation of $1 \mathrm{~mol}$ of methane is as described in Eq. (9) as follows:

$$
\mathrm{CH}_{4}(\mathrm{~g})+2 \mathrm{O}_{2}(\mathrm{~g}) \rightarrow \mathrm{CO}_{2}(\mathrm{~g})+2 \mathrm{H}_{2} \mathrm{O}(\mathrm{l})+891 \mathrm{~kJ}
$$

The high flame velocity and octane number 120 of the natural gas enable the natural gas to operate at high compression rates. This ensures that natural gas is a good gasoline engine fuel. Furthermore, natural gas has low exhaust emissions. In addition, the most important advantage of natural gas fuel is that natural gas can be produced from a source such as coal that has a lot of reserves all over the world. However, since the low-energy capacity of natural gas is in the form of gas, its low volumetric efficiency leads to reductions in engine performance. The disadvantages of this fuel are that natural gas requires high-pressure fuel storage tanks; refueling takes time and has variable fuel components in the content of natural gas [4].

Table 5 presents the properties of natural gas and its comparison with other fuels as thermal values.

\begin{tabular}{lccc}
\hline Properties & Natural gas & Fuel types & Heating value (kcal/kg) \\
\hline Volume by composition $(\%)$ & $95-98$ & 1 kg of diesel oil & 10,200 \\
\hline Mole weight $(\mathrm{kg} / \mathrm{mol})$ & 16.04 & $1 \mathrm{~kg}$ no: six fuel oil & 9200 \\
\hline Density $\left(\mathrm{kg} / \mathrm{m}^{3}\right)$ & 0.82 & $1 \mathrm{~kg}$ LPG & 11,000 \\
\hline Thermal value $\left(\mathrm{MJ} / \mathrm{m}^{3}\right)$ & 36.14 & $1 \mathrm{~kg}$ imported lignite coal & $4700 / 6500$ \\
\hline Highest flame speed $(\mathrm{m} / \mathrm{s})$ & 0.39 & $1 \mathrm{~m}^{3}$ natural gas & 8250 \\
\hline
\end{tabular}

Table 5 .

The properties of natural gas and its comparison with other fuels [11].

LPG, a liquefied petroleum gas, is produced as a by-product from natural gas production processes or during the distillation of oil in refineries. In general, it contains $90 \%$ propane, $2.5 \%$ butane, and a small amount of ethane and propylene with heavy hydrocarbons. These propane and butane gas ratios in LPG may vary according to the regions and areas of use [5]. In recent years, propane-butane mixtures in different ratios ( $80 \%$ propane $/ 20 \%$ butane, $70 \%$ propane $/ 30 \%$ butane, $50 \%$ propane/ $\%$ butane) have been tested as fuel in vehicles. LPG gas used in Turkey consisted of $30 \%$ propane and $70 \%$ butane. LPG is the most preferred fuel type after gasoline and diesel fuels, since LPG is much easier to store and transport than natural gas $[1,4]$.

LPG is a colorless, odorless, nontoxic, and easily flammable gas. LPG is a mixture of propane and butane gas, which is gas at normal pressures and temperatures. However, LPG is a liquid at moderate pressure. Besides, it is two times heavier than air and half weight of water. Therefore, LPG leaks to the floor in case of leakage. LPG in liquid state expands to approximately 273 times its liquid volume. This is called sudden expansion and cooling of the sudden temperature drop with the very rapid evaporation of the liquid fuel as it passes into the gaseous state. Since this can cause cold burns, the gas should not be touched with bare hands. Although LPG is a noncorrosive gas, it can melt paint and oil and also inflate natural rubber materials, causing them to lose their properties. Therefore, the use of LPG compatible materials in autogas systems using LPG is very important for safety [1, 5]. LPG system is widely used in gasoline vehicles. With respect to this, the comparison of physical and chemical properties of propane and butane gases which are components of LPG and the gasoline fuel is given in Table 6. 


\begin{tabular}{lccc}
\hline Properties & Propane & Butane & Gasoline \\
\hline Volumetric mass at $15^{\circ} \mathrm{C}(\mathrm{kg} / \mathrm{l})$ & 0.508 & 0.584 & $0.73-0.78$ \\
\hline Gas pressure at $37.8^{\circ} \mathrm{C}(\mathrm{bar})$ & 12.1 & 2.6 & $0.5-0.9$ \\
\hline Boiling temperature $\left({ }^{\circ} \mathrm{C}\right)$ & -42 & 0.5 & $30-225$ \\
\hline RON & 111 & 103 & $96-98$ \\
\hline MON & 97 & 89 & $85-87$ \\
\hline Lower heating value $(\mathrm{MJ} / \mathrm{kg})$ & 46.1 & 45.46 & 44.03 \\
\hline Lower heating value $(\mathrm{MJ} / \mathrm{l})$ & 23.4 & 26.5 & 32.3 \\
\hline Stoichiometric ratio & 15.8 & 15.6 & 14.7 \\
\hline
\end{tabular}

Table 6.

Properties of LPG and gasoline [1].

\section{Conclusions}

Fossil-based fuels such as diesel, gasoline, natural gas, and LPG have been commonly used in engines as a fuel. However, the internal combustion engines show differences in the fuel types depending on the thermodynamic cycles. Therefore, fuels can be demonstrated in different properties with each other. For example, gasoline fuels should have a high ignition resistance, while diesel fuels should have well self-ignition. For these reasons, hydrocarbon fuels can be converted by some chemical process depending on the engine types or by improving fuel properties. Thus, new fuel formulas or various fuel properties can be improved by converting hydrocarbons each other via some of the chemicals process.

Diesel and gasoline engine fuel properties such as cetane number, octane number, viscosity, and density can be improved by fuel additives. One of the most promising fuel additives are alternative fuels in the future. High octane number and low density propensities of the alcohols lead to be improved the fuel properties such as increases the octane number of gasoline and decreased the viscosity, density properties of the diesel fuel. Besides, the diesel fuel cetane number can be improved by biodiesel, which has a high cetane number.

\section{Nomenclature}

$\begin{array}{ll}\text { API } & \text { American Petroleum Institute } \\ \text { bTDC } & \text { before top dead center } \\ \text { CN } & \text { cetane number } \\ \text { HHV } & \text { higher heating value }(\mathrm{kJ} / \mathrm{kg}) \\ \text { FS } & \text { fuel sensitivity } \\ \text { ID } & \text { ignition delay }(\mathrm{ms}) \\ \text { LHV } & \text { lower heating value }(\mathrm{kJ} / \mathrm{kg}) \\ \text { LPG } & \text { liquefied petroleum gas } \\ \text { MON } & \text { motor octane number } \\ n & \text { engine speed }(\mathrm{rpm}) \\ \text { RON } & \text { research octane number } \\ \text { rpm } & \text { revolution per minute } \\ \text { SI } & \text { cetane index } \\ \text { SIT } & \text { self-ignition temperature } \\ \theta & \text { crank angle }\left({ }^{\circ} \mathrm{CA}\right) \\ \gamma & \text { specific heat ratio } \\ \rho & \text { density }\left(\mathrm{kg} / \mathrm{m}^{3}\right)\end{array}$


Fuels of the Diesel-Gasoline Engines and Their Properties

DOI: http://dx.doi.org/10.5772/intechopen.89044

\section{Author details}

Selçuk Sarıkoç

Energy Division, Department of Mechanical Engineering, Bayburt University, Bayburt, Turkey

*Address all correspondence to: sarikocselcuk@gmail.com

\section{IntechOpen}

(C) 2020 The Author(s). Licensee IntechOpen. Distributed under the terms of the Creative Commons Attribution - NonCommercial 4.0 License (https://creativecommons.org/ licenses/by-nc/4.0/), which permits use, distribution and reproduction for non-commercial purposes, provided the original is properly cited. (cc))BY-NC 


\section{References}

[1] Yardım MH. Motor Teknolojisi "Engine Technology". 3.Basım ed. Ankara/Türkiye: Nobel Akademik Yayıncılık; 2017. p. 418

[2] Safgönül B et al. İçten Yanmalı Motorlar. İstanbul: Birsen Yayınevi; 1995. p. 218

[3] Altural B. Organik Kimya "Organic Chemistry". Kayseri: Erciyes Üniversitesi Yayınları No: 159; 2008. p. 473

[4] Pulkrabek WW. In: Yaşar H, editor. İçten Yanmalı Motorlar Mühendislik Temelleri. 1. Baskı ed. İzmir: İzmir Güven Kitabevi; 2016. p. 480

[5] Beşergil B. Yakıtlar Yağlar "Fuels Oils". İzmir: Ege Üniversitesi Yayını; 2009. p. 462

[6] Solomons TWG, Fryhle CB. Organik Kimya. İstanbul, Türkiye: Literatür Yayınc1l1k; 2002. p. 1346

[7] Clancy C. 12 Chemistry Academic Highschool Textbook. 2011th ed. Whitby, Ontario/Canada: McGraw-Hill Ryerson; 2011. p. 832

[8] Chang R. In: Timp TD, editor. Chemistry. 10th ed. New York, NY: McGraw-Hill; 2010. p. 1170

[9] Haşimoğlu C. Düşük Isı Kayıplı Bir Dizel Motorunda Biyodizel Kullanımının Performans ve Emisyon Parametrelerine Etkisi. Sakarya: Fen Bilimleri Enstitüsü, Sakarya Üniversitesi; 2005

[10] Stone R. Introduction to Internal Combustion Engines. 2nd ed. London: The Machillan Press Ltd.; 1992. p. 574

[11] Küçükçalı R. Yenilenebilir Enerjiler Alternatif Sistemler Isısan Çalışmaları No: 375. İstanbul, Türkiye: Isısan Akademi; 2008. p. 704 


\title{
Chapter 3
}

\section{Compressed Bio Gas (CBG) in Diesel Engine}

\author{
Hasan Köten
}

\begin{abstract}
In this chapter, as an alternative to conventional engines, compressed biogas (CBG)-fueled compression ignition (CI) engine was evaluated. Biogas fuel is considerably economic due to the local product fuel compared to that of CNG and LPG fuels for many countries. In addition, due to the higher octane rate, biogas is considerably adaptable for the diesel engines. In this issue, CBG diesel-fueled engine was investigated using full geometry 3D computational fluid dynamics (CFD) simulations including intake and exhaust ports were used in optimization process to get the optimum design parameters of the CBG-diesel engine. Usage of CBG fuel in the optimized CBG engine without any constructive change in cylinder block will considerably decrease the cost. During the engine design, one-dimensional (1D) and three-dimensional (3D) CFD codes and multi-objective optimization code were employed by coupling codes. CBG and diesel fuels were defined as leading reactants using user-defined code in dual-fuel diesel engine modeling. CBG and diesel mass flow rates, start of pilot diesel fuel injection, compression ratio, valve timing, and engine speed were defined as input variables in different engine loads and evaluated about 20,000 cases to define the proper operating conditions. CBG-diesel engine and significantly lower $\mathrm{NO}_{\mathrm{x}}$ emissions were emitted under dual-fuel operation for all cases compared to single-fuel mode at all engine load conditions. Moreover, CBG-diesel engine provided superior performance in reductions of $\mathrm{NO}_{\mathrm{x}}$ and particulate matter (PM) emissions.
\end{abstract}

Keywords: CBG, biogas, CFD, emission, diesel engine

\section{Introduction}

This chapter is intended to give an overview of the CBG-fueled diesel engine performance and emission characteristics. The optimum design parameters of the CBG-diesel dual-fueled engine were studied using CFD techniques and experimental work. Also the motivation for IC engine research is presented, and the combustion process for the SI and CI engine was shortly overviewed. In addition to that, new alternative combustion concepts for $\mathrm{CI}$ engines were discussed, and the research background and objective of the present work were presented. CBG fuel air mixture is compressed in a PPCI mode in achieving its simultaneous ignition by pilot diesel fuel inside the combustion chamber to get the best performance and emission results.

Part load, especially direct injection systems used to perform partially premixed charge, allows for optimized fuel consumption and a low level of emissions. During 
like this process, the engine has quite more homogeneous air fuel mixture and low in-cylinder temperature which caused lower $\mathrm{NO}_{\mathrm{x}}$ emissions. Also, the use of a pilot injection has become an effective way for reducing combustion noise.

In PPCI, combustion concepts have been recently developed with the purpose to strive the problem of the high emission levels of conventional direct injection diesel engines. A good example is the PPCI combustion, a strategy in which early fuel injections are used, causing a burning process in which more air fuel is burned in premixed conditions, which affects combustion performance and exhaust emissions.

Experimental studies due to the extreme conditions inside a typical IC engine such as high combustion temperatures and pressures, precipitation of PM, other combustion products, etc. are sometimes limited in approaching exhaust emission problem. However, CFD software offers the opportunity to carry out and optimize repetitive parameter studies with clearly defined boundary conditions in order to investigate various configurations.

In this book, effects of dual-fuel combustion characteristics were investigated on the combustion performance and the reduction of exhaust emissions for a CI engine fueled with CBG-diesel dual fuel. Different approaches for alternative diesel combustion systems are also investigated by CFD and optimization software. This combustion system is investigated in homogenous CBG fuel air mixture with early and late pilot diesel injection strategy.

\section{Usage of CBG fuel in diesel engine}

The intention of this investigation is to find out the effects of CBG-diesel dualfuel combustion characteristics on the $\mathrm{CI}$ engine performance. The rate of heat release (ROHR) and other performance parameters were investigated in different modes of combustions. Moreover, combustion performance and indicated mean effective pressure (IMEP), exhaust gas temperature, and also the concentrations of $\mathrm{PM}, \mathrm{NO}_{\mathrm{x}}, \mathrm{HC}, \mathrm{CO}$, and $\mathrm{CO}_{2}$ exhaust emissions were also investigated under various engine operating conditions to compare the exhaust emission and engine performance of single-fuel and CBG-diesel fuel modes experimentally and numerically. Within this framework, the combustion processes and performance of a commercial four-cylinder, turbocharged compression ignition engine are analyzed and improved the exhaust emission values of the engine by proposing some modifications for advance mode of combustion system by using CFD and multi-objective optimization codes.

In accordance with this purpose, first;

- Overall thermodynamic cycle simulation for one cylinder,

- In-cylinder fluid motion,

- Including inlet, exhaust manifold and valves are analyzed in 3D.

Therefore,

- To perform a detailed analysis in-cylinder cold flow,

- Fuel spray atomization,

- The combustion and emissions are investigated numerically and experimentally. 
Second part of this work included optimization for an advance combustion mode needed for the following parameters:

- Valve timing.

- Compression ratio.

- Pilot diesel fuel injection timing was optimized.

Lastly, selected cases which were optimized by CFD and multi-objective optimization code analyzed and compared with existing experimental single-fuel and CBG-diesel dual-fuel diesel engine combustion performance and exhaust emissions.

In this project, methodology was designed to accomplish the objectives described in objective parameters.

The first task was to carry out an overall and critical research of available literature in the dual-fuel diesel engine field. This review was done to fully understand the progress of dual-fuel combustion process in this particular field of research; also this is aided with the identification of issues/areas of further research.

The survey considered published books, journals, and papers. It was broadened to consider information published on the Ohio State University database and on the Center for Automotive Research Laboratories.

Full geometry model: After the study of the commercial CFD software documentation, some applications were carried out to aid with the meshing of the geometry.

Simulation: A preliminary simulation in commercial CFD software was carried out in order to build confidence levels, since combustion of spray droplets involves complex models both of pilot diesel fuel and CBG fuel injectors. The main simulations were divided into four main configurations as follows:

- Cold flow (no liquid fuel)

- Air/liquid spray mixture

- Combustion simulation using turbulence-controlled eddy breakup

- Dual-fuel combustion simulation using non-premixed and partially premixed model

For each model, these five turbulence models were investigated (k- $\varepsilon / \mathrm{high}$ Reynolds, k- $\varepsilon /$ RNG, k- $\varepsilon /$ Chen, k- $\varepsilon /$ Speziale/high Reynolds, and k- $\varepsilon /$ Standart/High Reynolds models). The method adopted for this simulation generally follows the steps outlined in commercial CFD software studies.

The analysis of the results was based on the post-processed data from all analyses carried out. In combustion modeling, two leading reactants CBG and diesel fuel are defined by using user-defined code. The predicted results by commercial CFD code were compared with each other. Detailed specifications of engine were summarized in Table 1. CBG fuel properties and operating conditions are given in

Tables 2 and 3.

\subsection{Computational grid}

The engine that is modeled is a commercial four-cylinder 1.51 light-duty diesel real engine. The geometrical specifications of the engine, as well as the engine's original valve timings, are summarized before chapter. The computational grid is 


\begin{tabular}{ll}
\hline Engine parameters & Value \\
\hline Type & 4 Cylinder-four stroke \\
\hline Bore $\times$ stroke & $76 \times 80.5 \mathrm{~mm}$ \\
\hline Connecting rod length & $131.2 \mathrm{~mm}$ \\
\hline Displacement & $1461 \mathrm{~cm}^{3}$ \\
\hline Compression ratio & $18.25: 1$ \\
\hline Max. lift (exhaust) & $10.1 \mathrm{~mm}$ \\
\hline Max. lift (intake) & $9.7 \mathrm{~mm}$ \\
\hline Operating speed & $2000 \mathrm{rpm}$ \\
\hline Maximum power & $48 \mathrm{~kW}$ at $4000 \mathrm{rpm}$ \\
\hline Maximum torque & $160 \mathrm{Nm}$ at $2000 \mathrm{rpm}$ \\
\hline
\end{tabular}

Table 1.

Engine specifications.

\begin{tabular}{ll}
\hline Properties & Value \\
\hline Chemical formula & Mixture \\
\hline $\mathrm{CH}_{4}$ & $65-70 \%$ by volume \\
\hline $\mathrm{CO}_{2}$ & $25-35 \%$ by volume \\
\hline $\mathrm{H}_{2}$ & $1-2 \%$ by volume \\
\hline Self-ignition temperature & $630-810^{\circ} \mathrm{C}$ \\
\hline Lower heating value & $26 \mathrm{MJ} / \mathrm{kg}$ \\
\hline F/A ratio & 0.058 \\
\hline Octane number & 135 \\
\hline Density & $0.79 \mathrm{~kg} / \mathrm{m}^{3}$ \\
\hline
\end{tabular}

Table 2.

Properties of $C B G$ fuel.

\begin{tabular}{ll}
\hline RPM & $2000 \mathrm{rev} / \mathrm{min}$ \\
\hline Test fuels & Diesel and CBG \\
\hline Single fuel & Diesel \\
\hline Dual fuel & Diesel + CBG \\
\hline Gas injection pressure & $0.3 \mathrm{MPa}$ \\
\hline Gas injection type & Port injection \\
\hline Injected gas mass & $30 \mathrm{mg} / \mathrm{cycle}$ \\
\hline Pilot diesel injection pressure & $13 \mathrm{MPa}$ \\
\hline Start of injection & 120,18 0CA bTDC \\
\hline
\end{tabular}

Table 3.

Operating conditions.

given in Figure 1. The mesh domain has about 700,000 elements at TDC. A finer grid could include the top-land crevice. In addition, a crevice model could be introduced in commercial CFD software, in order to simulate flow in the crevices and blow-by. Nevertheless, even though the low-temperature regions are not captured well, commercial CFD software can still provide reasonable predictions for the bulk temperature in the cylinder and the overall temperature and composition distributions. 


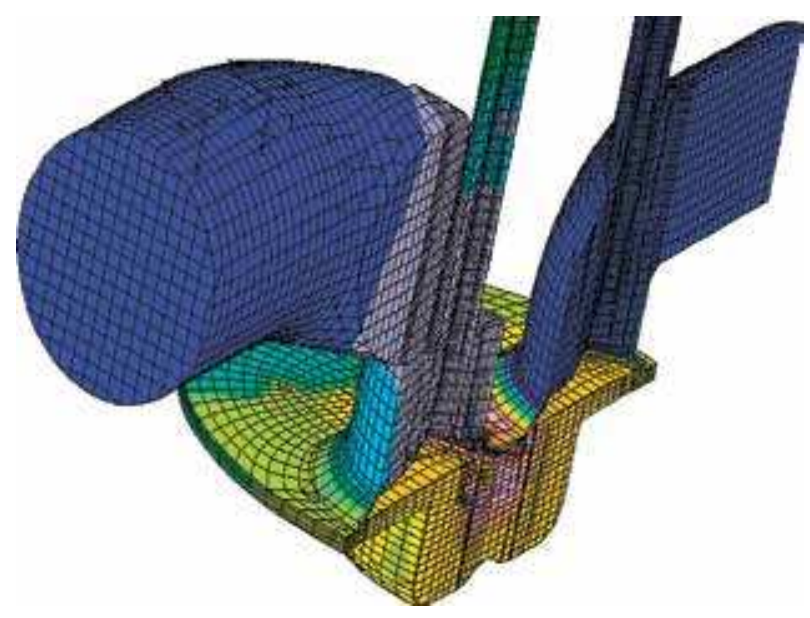

Figure 1.

Example of volume mesh.

In the CFD simulations before the experimental work, combustion chamber including intake and exhaust ports and valves was modeled in the development software. Mesh elements reached 1,700,000 at the BDC. In order to initialize the run, the pressure and the temperature in the cylinder at the start of the calculation were adjusted. Heat transfer and other physical models were selected according to real engine operating conditions. Complete combustion products were also defined using the user-defined code.

\section{Results and discussions}

\subsection{Dual-fuel engine spray modeling}

Recent researches show that it is possible to decrease the emissions considerably by modifying the geometrical sub-systems of the engine that affect the turbulence generation and spray formation. It is important to define the proper turbulence model in diesel CFD studies in terms of the exact representation of the combustion phenomenon. During these studies, a lot of turbulence models have also been analyzed to select the proper turbulence model for diesel combustion. In an attempt to improve the predictive ability of the standard $k-\varepsilon$ models, a number of alternatives have been offered. Among them the RNG k- $\varepsilon$ model $[18,19]$, anisotropic k- $\varepsilon$ model of Speziale [15], Morel and Mansour version of the k- $\varepsilon$ model [10], Chen's $\mathrm{k}-\varepsilon$ model [3], and the $\mathrm{k}-\omega$ model of Wilcox are well-known [17]. The RNG k- $\varepsilon$ model turbulence has been used in order to predict the compressed turbulence in IC engines.

In this investigation, combustion is modeled via a new combustion model (ECFM-3Z) developed at IFP and 1D thermodynamic model. Wiebe function for 1D approximation and ECFM for 3D CFD solution were used to carry out combustion modeling. ECFM-3Z is the member of the coherent flame model (CFM) family, and it is extended to nonhomogeneous turbulent premixed and unpremixed (diffusion) regions. In dual-fuel mode, extra definitions analyze the conventional diesel combustion and partially premixed compression ignition (PPCI) cases. In a diesel combustion, NOx formation is an important challenge instead of other emissions such as smoke which is gas and carbon mixtures. Conglomeration of carbon particles calls as PM, and dust airborne particles call as a particulate matter (PM). They 
are produced during incomplete combustion process. Real engine geometry was remodeled to find out dual-fuel flow structure inside the combustion chamber. In dual-fuel engine cases, air and CBG fuel mixture was ingested into the combustion chamber, and it was ignited with pilot diesel fuel at the end of compression stroke. First injector was located on the intake port as a main fuel CBG using cylindrical
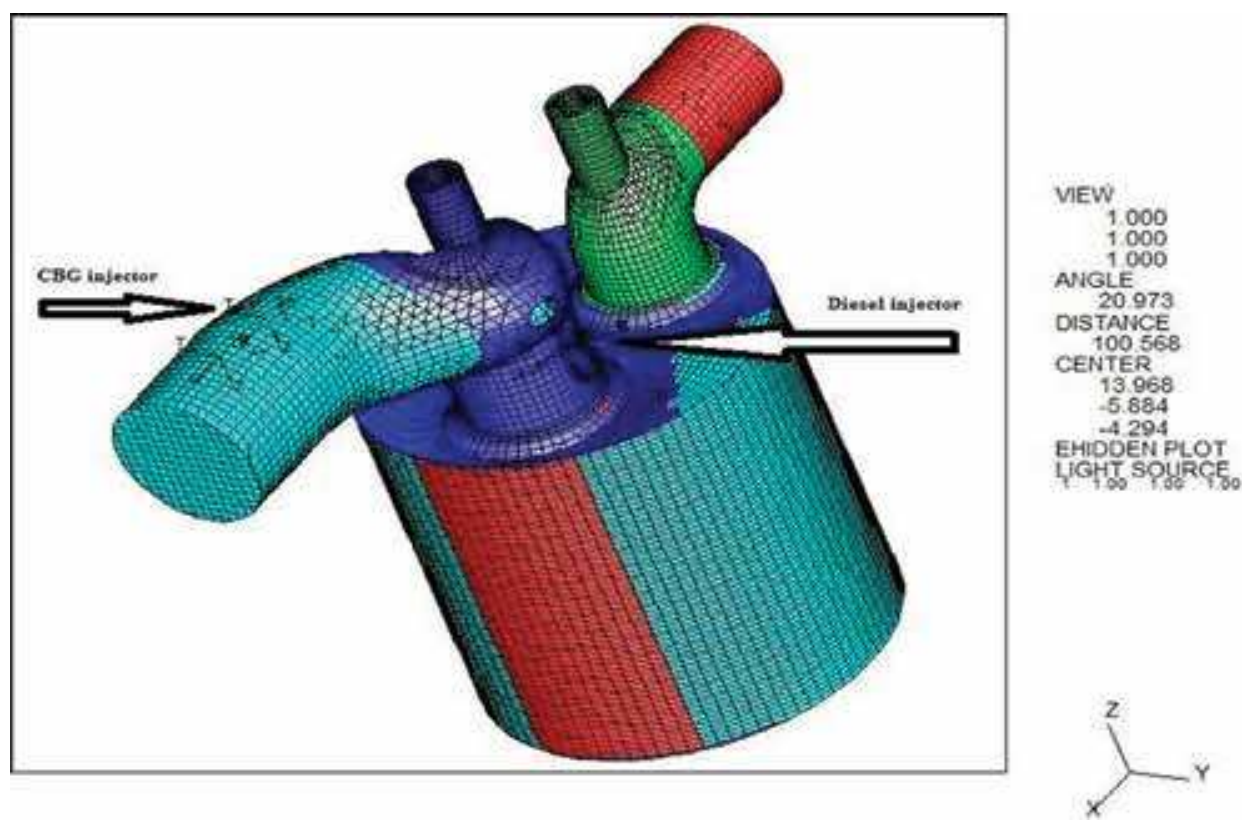

Figure 2.

CBG-fueled diesel engine mesh structure.

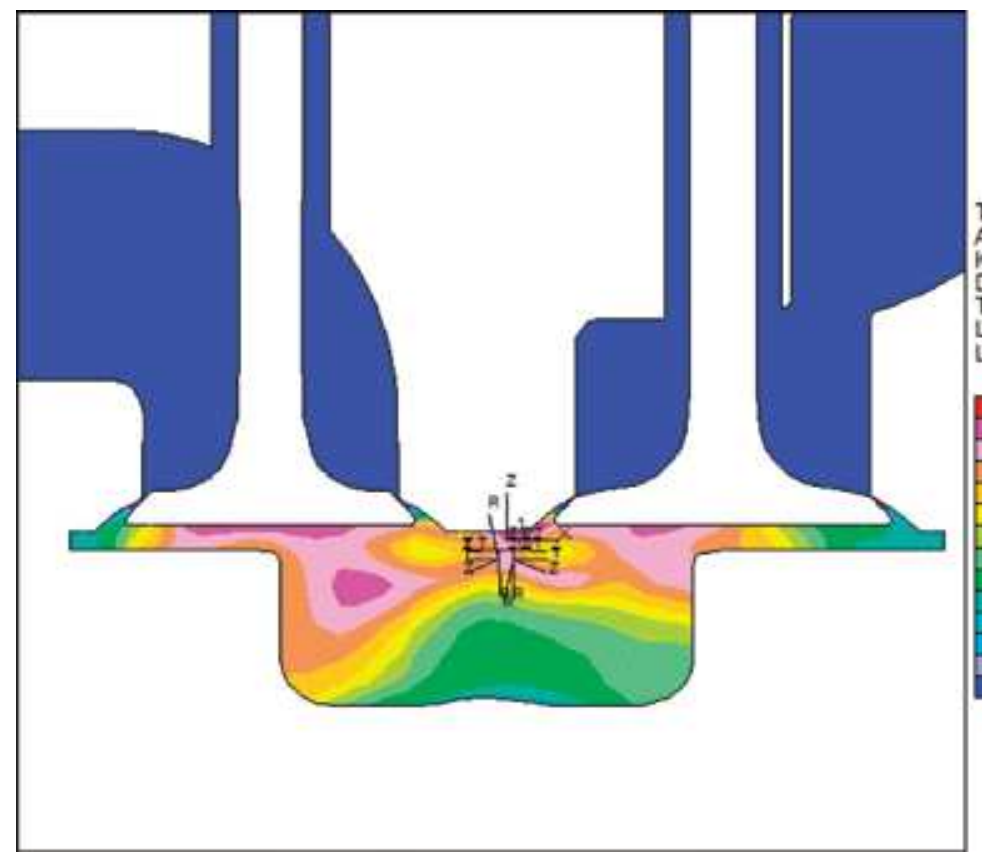

Temperature ABSOLUTE

$\mathrm{K}$ DEGCA $=72000$ TIME $=0.289394 \mathrm{E}-01$ LOCAL MX $=2448$. LOCAL MNV $=307.1$

Figure 3.

${ }_{3} D$ NOx emission contours for $S F$ case 3 at TDC in $+Y$ direction. 
coordinate system as shown in Figure 2. Second injector for pilot diesel fuel was retained on the cylinder head. Injector hole diameter, cone angle, hole number, start of CBG fuel injection, and duration were entered on the CFD code.

Because of the shifting of combustion event to earlier side, this causes the increase of negative operating conditions for a conventional diesel engine. These trends are regarded as typical problems of injection strategies and injection rates that lower the thermal efficiency and increase the incomplete combustion products such as the HC and CO emissions [6-9, 11-14, 16, 20].

The effects of the engine load and dual-fuel combustion mode on the NOx emissions with different engine configurations were shown in Figure 3. NOx emissions showed a strong dependence on the type of combustion at constant injection

\begin{tabular}{ll}
\hline Engine type & Single-cylinder direct injection diesel engine \\
\hline Engine speed & $2000 \mathrm{RPM}$ \\
\hline Valves per cylinder & 2 \\
\hline Bore & $86 \mathrm{~mm}$ \\
\hline Stroke & $76 \mathrm{~mm}$ \\
\hline Injection system & Common-rail \\
\hline Number of nozzle holes & 4 \\
\hline Nozzle diameter & 0.170 mm \\
\hline Valve overlapping & 39 CAD and 19 CAD \\
\hline Compression ratio & 17.6 \\
\hline Start of injection & 18 CAD bTDC \\
\hline
\end{tabular}

Table 4.

Specification of modified dual-fuel combustion chamber.

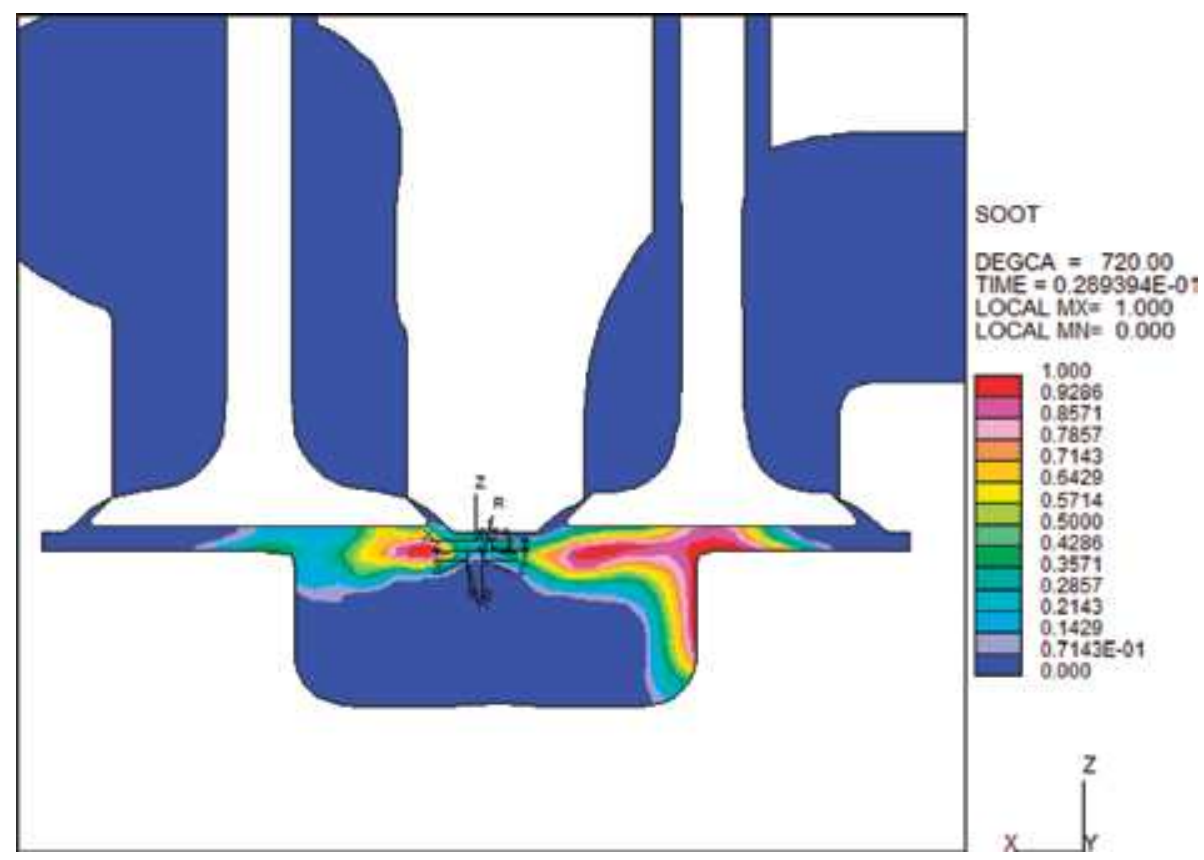

Figure 4.

Soot emission contours for SF case 3 at TDC. 
timing. The peaks of the NOx emissions occurred on the single-fuel cases at the same operating conditions. When the CBG fuel was increased, the NOx formations reached undetectable levels. This is due to the prolonged the ignition delays and premixed fuel/air mixture. In the dual-fuel modes, lower NOx formations were obtained compared to that of the conventional cases. The modified dual-fuel combustion chamber parameters are listed in Table 4.

1D, 3D, and multi-objective optimization codes were employed for single-diesel fuel (dodecane) and dual-fuel (CBG-diesel) cases. Case1, case2, case3, case4, and case 5 were investigated at $20,40,60,80$, and $100 \%$ engine loads, respectively for both single fuel and dual fuel. Soot emissions and combustion characteristics of engine can be seen in Figures 4 and 5. The combustion pressures and rates of heat release (ROHR) for the single-fuel mode with diesel fuel in a constant engine speed of 2000 (rev/min) were provided in Figure 6. The figures showed similar patterns for combustion pressure and ROHR at different engine loads. The combustion pressures and ROHRs increased for both fuels, since engine load increased at constant engine speed. At low engine load (20\%), the peak pressure and also heat release were slightly lower than other cases as depicted in Figure 6a. The lower diesel fuel consumption $(2.14 \mathrm{~kg} / \mathrm{h})$ resulted in the decrease on the combustion performance. In the $60 \%$ load, shown in Figure $6 a$, the pressure is $P \max =8.4 \mathrm{MPa}$, and peak heat release was obtained compared to CBG-diesel case, Pmax $=8.3 \mathrm{MPa}$. Simultaneously, a greater indicated mean effective pressure (IMEP) was resulted for the conventional diesel-injected fuel mass reached $5.3 \mathrm{~kg} / \mathrm{h}$. In Figure 7, NOx and soot emissions are given in detail.
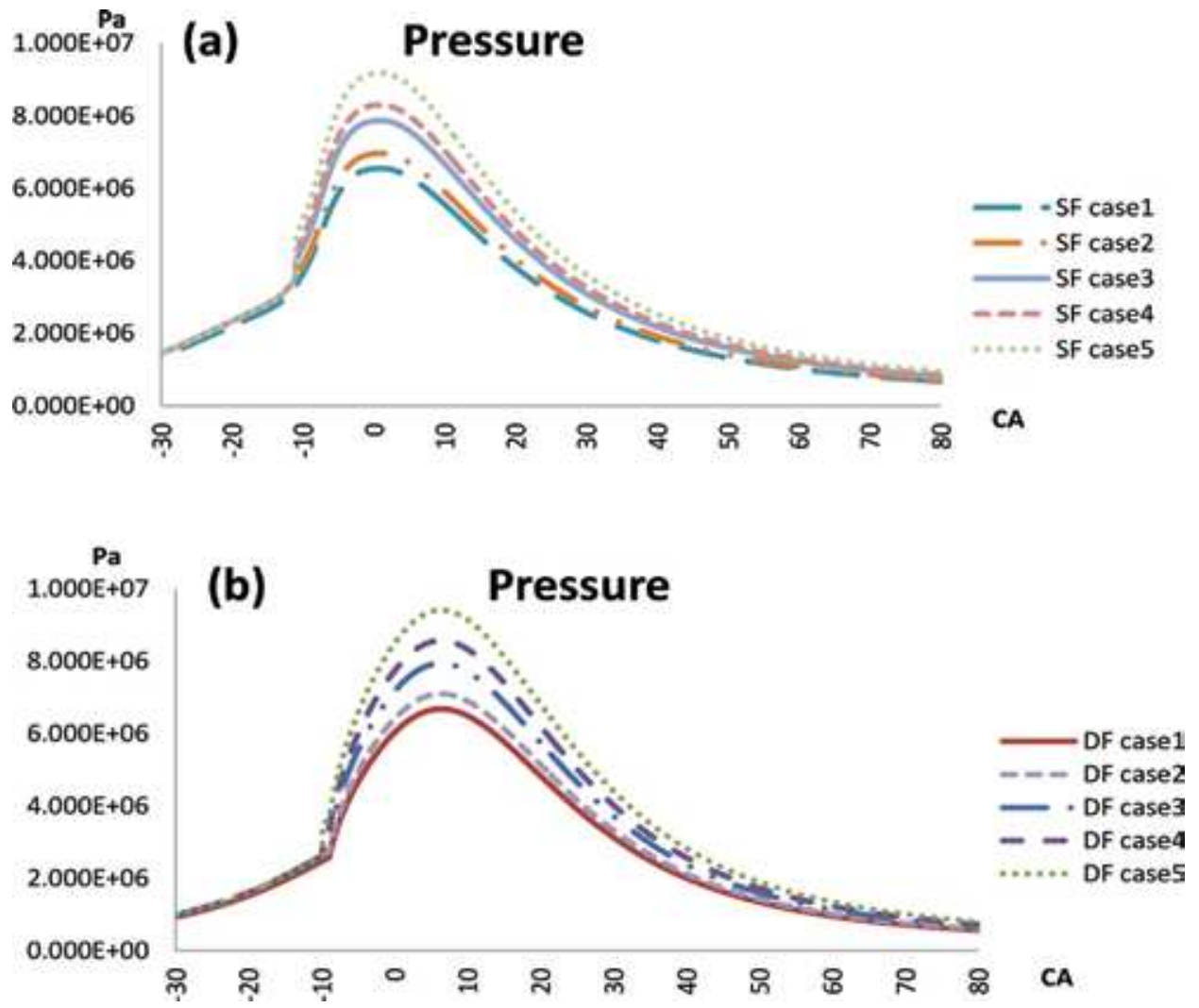

Figure 5.

Combustion characteristics at different engine loads. (a) Single-fuel (dodecane) cases and (b) dual-fuel (CBG-dodecane) cases. 


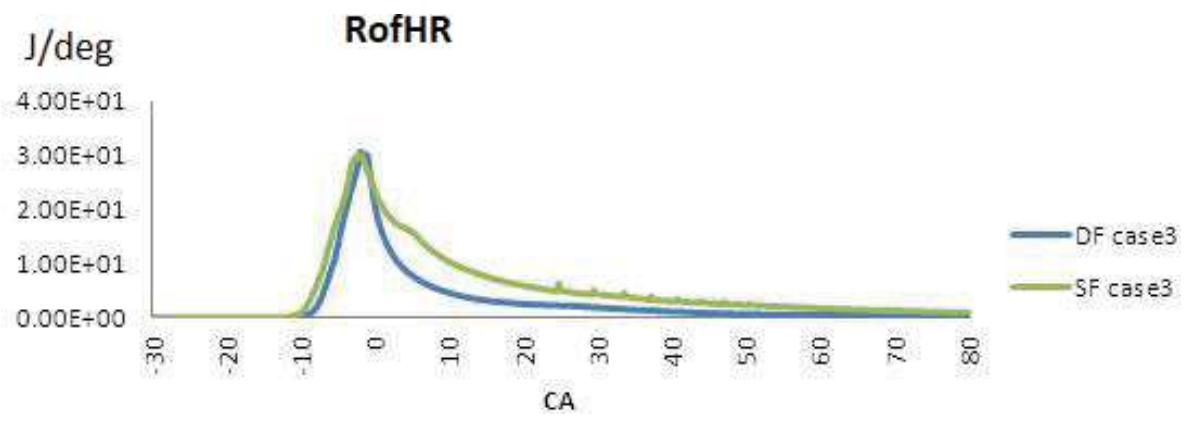

Figure 6.

Effect of fuel types on rate of heat release inside cylinder at $60 \%$ engine load.

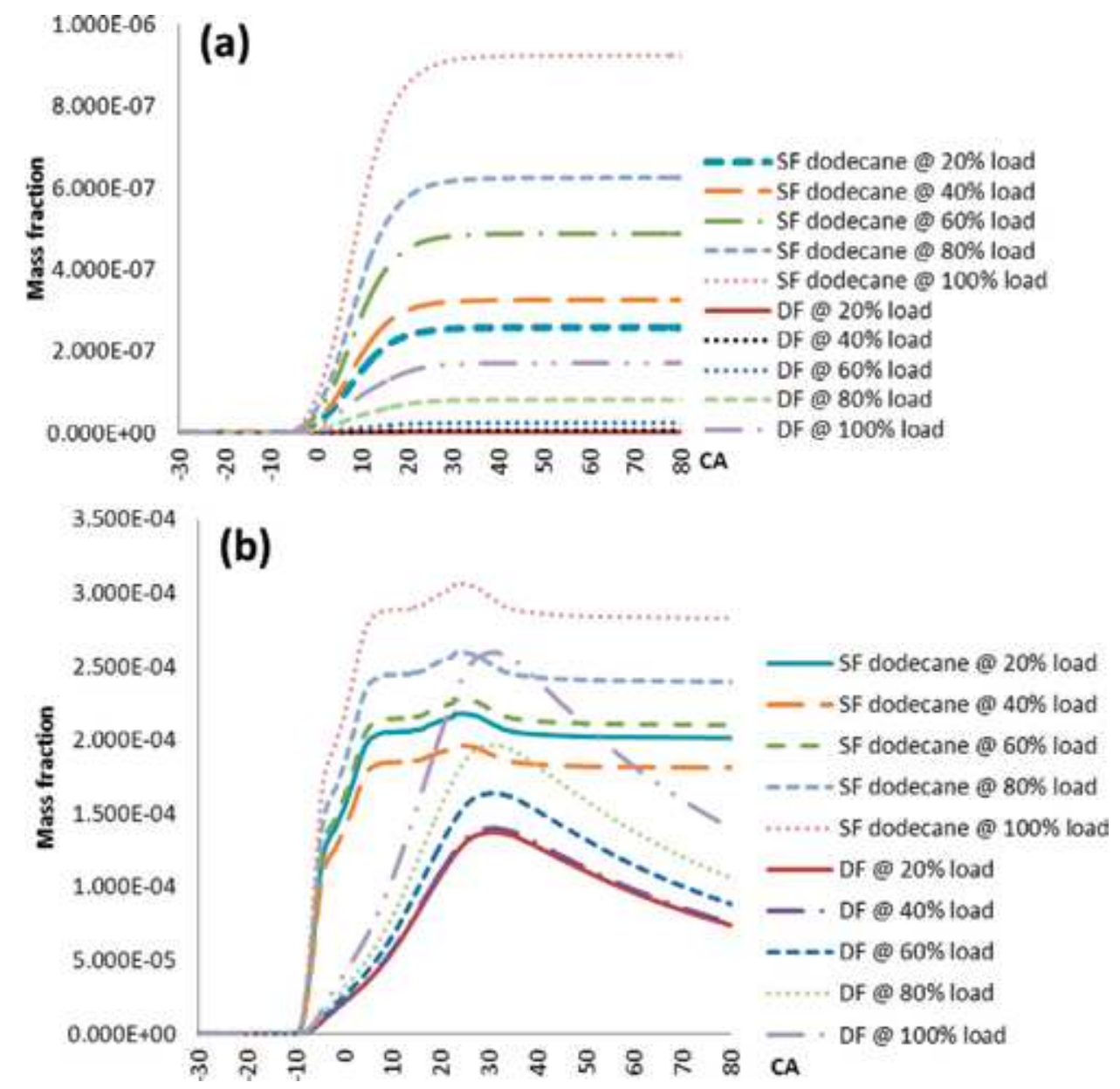

Figure 7.

NOx and soot emissions for single-and dual-fuel cases versus CA. (a) NOx emissions and (b) soot emissions.

In terms of the ignition delay, conventional diesel combustion has shorter time due to the air fuel mixture process. Ignition ability in a diesel engine is mainly relying on caffeine and physical fuel properties such as structure of fuel composition, density, bulk module, cetane number, oxygen content, and aromatic content of the fuel. Meanwhile, the oxygen amount of the air fuel mixture plays an important role in short ignition delays. Engine parameters such as SOI need to adjust for different 
operating conditions. Additionally, the diesel fuel used in the works has a long carbon chain, and it has important role for the short ignition delay. $\mathrm{CO}_{2}, \mathrm{HC}$, and $\mathrm{CO}$ concentrations were shown in Figure 8a-c for single- and dual-fuel cases at various engine loads [5].
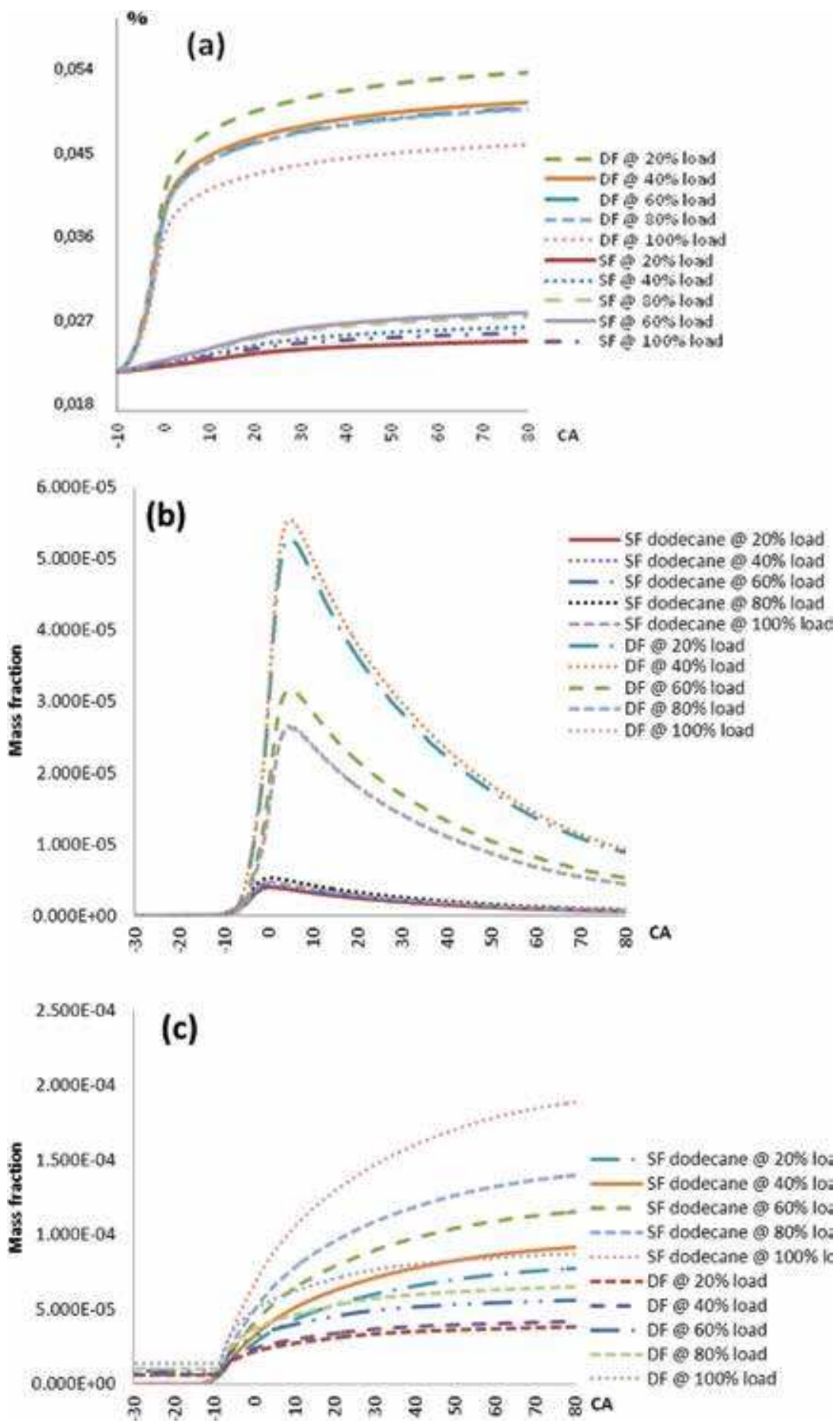

Figure 8.

Exhaust emissions for single-and dual-fuel cases with different engine loads. (a) Unburned HC; (b) CO; (c) $\mathrm{CO}_{2}$ 


\subsection{Optimization for CBG combustion}

In final simulation, compression ratio of simulated engine was reduced from 18.25:1 to $17.6: 1$ by widened engine bore diameter to keep more heat inside the cylinder due to the lower heating value of CBG fuel. According to optimization results, larger and smaller valves overlapped engines more suitable for CBG-diesel dual-fuel combustion. Because of the surface to volume ratio effect on combustion temperature, heavy-duty dual-fueled $\mathrm{CI}$ engines have better results on combustion performance and unburned $\mathrm{HC}$ emissions than light-duty dual-fueled CI engines. Real engine geometry cases have low thermal efficiency due to the valve overlap characteristics of conventional diesel engines. Valve overlap process facilitates scavenging between the intake and exhaust valves. However, in dual-fuel combustion, valve overlapping caused an increase in unburned $\mathrm{HC}$ emissions due to leaving of unburned CBG-diesel air fuel mixture from cylinder. At the same time, low valve overlap for dual-fuel CI engine caused incomplete combustion inside the combustion chamber due to the insufficient scavenging process. Valve overlap values also were optimized in final CFD simulation. Because of compression ratio effects on temperature and pressure during the compression phase, the engine compression ratio has an influence on the autoignition phase of the combustion: a reduction prolongs the air/fuel mixing process before combustion. In optimization study, compression ratio was limited in 19:1 due to the knock phenomenon during the compression stroke of CBG-air mixture. Higher compression ratio resulted in lower power due to the autoignition of air fuel mixture. Different works [1, 2, 4] studied on experimental single-cylinder engines showed this significant advantage. Another optimization parameter is SOI for modified dual-fuel engine geometry. In dual fuel-modified engine geometry cases, SOI was reduced to about $18^{\circ} \mathrm{CA}$ bTDC by optimization study due to the late ignition delay of CBG-air fuel mixture. Single-fuel cases have low ignition delay compared to that of the CBG-diesel dualfuel combustion as seen in ignition delay figure. In single-fuel cases, diesel fuel has higher cetane number, and this allowed faster combustion than dual-fuel engine cases. Optimized dual-fuel engine cases resulted in better combustion performance by changing SOI, compression ratio, modified engine size, and valve overlap values.

The peaks of pressure and temperature values occurred in DF case6 and DF case7 cases which have lower valve overlap, $19^{\circ} \mathrm{CA}$. Therefore, these two cases have indicated that the high temperature reaction (HTR) occurs at around 1200-1300 K. Calculated peak gas temperature for reduced valve overlap cases as shown in Figure 9a was $1790 \mathrm{~K}$ such as conventional single-fuel diesel combustion; also these cases have lower $\mathrm{CO}$ formation and slightly higher NOx formation but quite under acceptable emission standards.

As the valve overlap reduced, the peaks of heat release in-cylinder pressure and temperature rapidly increased, and the initiating timings of the reaction were also fastened. In real engine geometry cases, the ignition delay was very long, and ignition had begun very late after pilot started at $12^{\circ}$ bTDC. After SOI started at $18^{\circ}$ bTDC and valve overlap reduced to $19^{\circ} \mathrm{CA}$ in optimization study, this led to significant development in engine performance and better combustion control during combustion for CBG-diesel dual-fuel cases. In addition to engine performance development, $\mathrm{CO}$ emissions were decreased to very low levels by means of exact combustion. NOx emissions resulted in higher DF case6 and DF case7 than other DF cases, but these NOx emission values are very low in regard to international emission standards. Similarly, PM emissions resulted in better optimized DF case6 and DF case7 than other DF cases and kept in a reduction trend. Furthermore, it can be said that CBG fuel was burned effectively in regard to other cases (Figure 9f) especially for $\mathrm{DF}$ case7 which has $19^{\circ} \mathrm{CA}$ valve overlap value. Besides valve overlap 

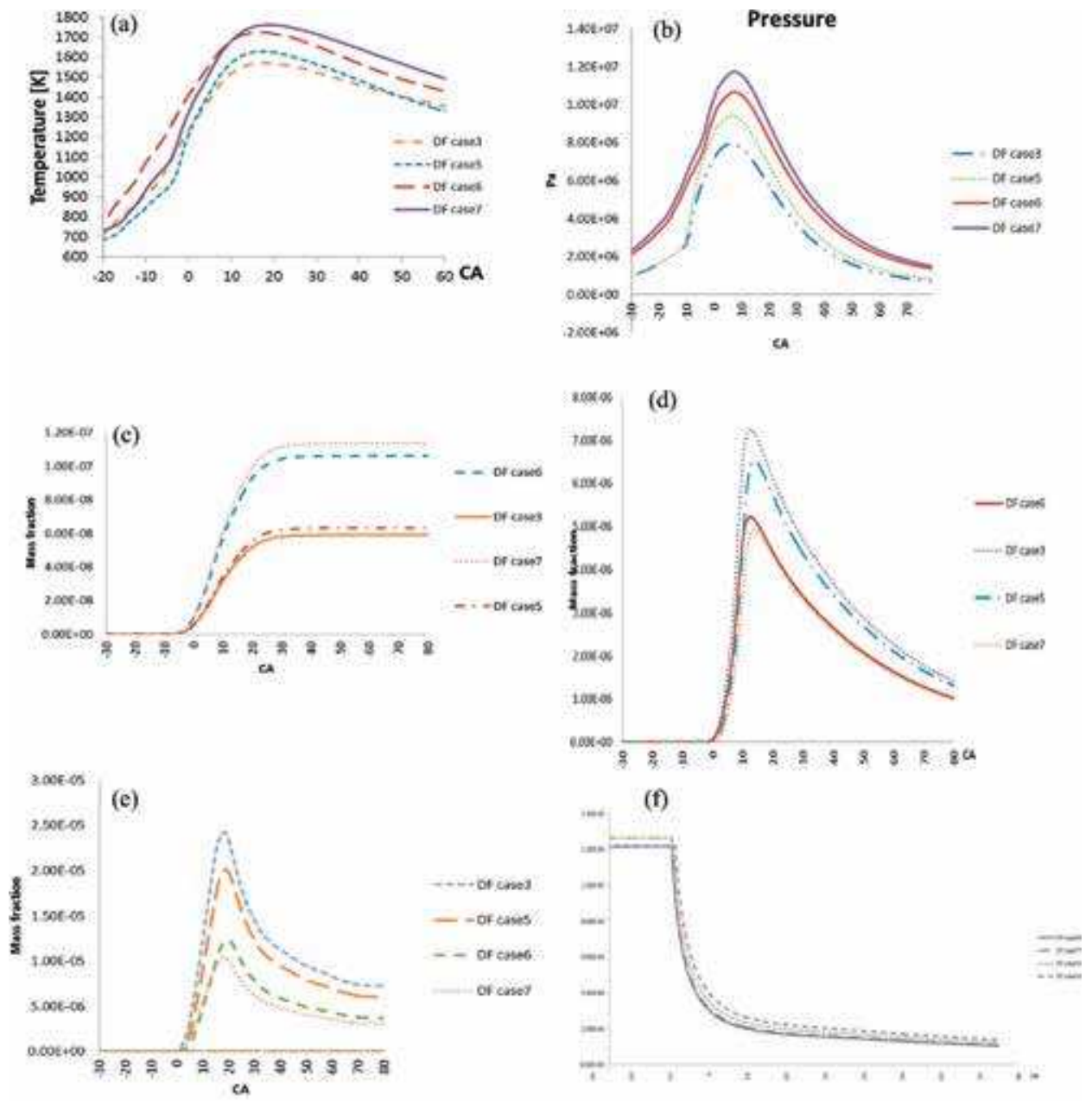

Figure 9.

Effects of valve timing on the dualfuel combustion performance. (a) In-cylinder calculated temperature; (b) In-cylinder calculated pressure; (c)NOx emissions; (d) CO emissions; (e) soot emissions; and ( $f$ ) total fuel mass.

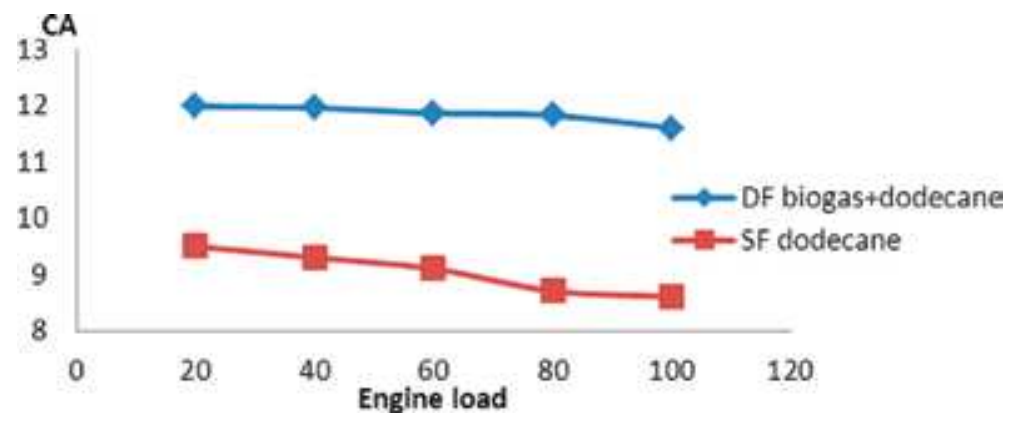

Figure 10.

Effect of single and dual fuel combustion mode on the ignition delay.

value, optimization results showed that larger $\mathrm{CI}$ engines which have big surface to volume ratio have better combustion performance according to light-duty CI engines. It can be concluded that CBG-diesel dual-fuel process with these optimization parameters is more proper for heavy-duty CI engines (Figure 10). 


\section{Conclusion}

In this chapter, the engine performance and emission results were studied and compared for the conventional diesel and CBG-diesel dual-fuel operations. CBG and diesel fuels were defined as leading reactants by writing user-defined code. In this work, conventional diesel combustion and dual-fuel pilot diesel combustion were examined. Obtained differences in the results between SF and DF are the result of fuel mixture ratios in the calculation, and this affects the efficiency of the engine. Combustion time is calculated by the software according to chemical compounds and gradients. Fuel ratio can be seen in Table 5. International emission standards were taken into consideration in the studies for the wide automotive market, and further studies can be evaluated the next regulations. Although $\mathrm{CO}_{2}$ is an inert gas in the mixture of air fuel, it is expected that $\mathrm{CO}_{2}$ ratio affects the emissions. However this is due to the mixture of biogas formation. Higher cetane number of diesel and the faster injection timing shortened the ignition delay, and this reduction is related to a decrease in fuel-rich zone throughout the combustion process.

Due to the volumetric efficiency, in the dual-fuel case concentrations, $\mathrm{CO}$ emissions were considerably higher than others under all test conditions. In the dual-fuel cases, CBG gas fuel is replaced by air which causes more $\mathrm{CO}$ emissions. The concentrations of $\mathrm{CO}_{2}$ emissions for dual-fuel cases are obtained under those regarding single-fuel diesel combustion modes. In terms of the ignition delays, conventional diesel combustion exhibited better performance with respect to CBG-diesel cases because of the overall specific heat capacity and oxygen rate. Also, exhaust gas temperature has lower value in dual-fuel cases. BSFC and PM results have better value in the CBG-diesel dual-fuel cases. More oxygen rate in single-fuel cases allowed more $\mathrm{CO}$ emissions to oxidize into $\mathrm{CO}_{2}$ and resulted in higher concentrations of $\mathrm{CO}_{2}$ emissions.

\begin{tabular}{lcccc}
\hline Case \# & CBG rate $(\mathbf{k g} / \mathbf{h})$ & Diesel fuel $(\mathbf{k g} / \mathbf{h})$ & Engine load $\mathbf{( \% )}$ & SOI CA \\
\hline SF case1 & - & 2.12 & 20 & -12 \\
\hline SF case2 & - & 3.13 & 40 & -12 \\
\hline SF case3 & - & 5.22 & 60 & -12 \\
\hline SF case4 & - & 8.54 & 80 & -12 \\
\hline SF case5 & - & 11.44 & 100 & -12 \\
\hline DF case1 & 2.27 & 1.62 & 20 & -12 \\
\hline DF case2 & 2.33 & 2.63 & 40 & -12 \\
\hline DF case3 & 2.61 & 4.37 & 60 & -12 \\
\hline DF case4 & 2.76 & 6.48 & 80 & -12 \\
\hline DF case5 & 3.25 & 7.88 & 100 & -12 \\
\hline
\end{tabular}

Table 5.

Case studies. 


\section{Author details}

Hasan Köten ${ }^{1,2}$

1 Mechanical Engineering Department, Istanbul Medeniyet University, Istanbul, Turkey

2 CEDPS, Brunel University, United Kingdom

*Address all correspondence to: hasan.koten@medeniyet.edu.tr

\section{IntechOpen}

(C) 2020 The Author(s). Licensee IntechOpen. Distributed under the terms of the Creative Commons Attribution - NonCommercial 4.0 License (https://creativecommons.org/ licenses/by-nc/4.0/), which permits use, distribution and reproduction for non-commercial purposes, provided the original is properly cited. (cc) BY-NC 


\section{References}

[1] Albrecht A, Grondin O, Le Berr F, Le Solliec G. Towards a stronger simulation support for engine control design: A methodological point of view. Les Rencontres Scientifiques de l'IFP—New Trends in Engine Control, Simulation and Modelling; 2006

[2] Chauvin J, Corde G, Petit N, Rouchon P. Experimental air path control of a diesel engine. Les Rencontres Scientifiques de l'IFP-New Trends in Engine Control, Simulation and Modelling; 2006

[3] Chen YS, Kim SW. Computation of Turbulent Flows Using an Extended K-E Turbulence Closure Model. NASA CR; 1987. p. 179204

[4] Gatellier B, Ranini A, Castagné M. New development of the NADITM concept to improve operating range, exhaust emissions and noise. Combustion Oil and Gas Science and Technology. 2006;61(1):7-23

[5] Köten H. Compressed biogas-diesel dual-fuel engine optimization study for ultralow emission. Advances in Mechanical Engineering. 2015;6:1-8. DOI: $10.1155 / 2014 / 571063$

[6] Helmantel A, Denbratt I. HCCI Operation of a passenger car common rail DI diesel engine with early injection of conventional diesel fuel. SAE Paper 2004. 2004-01-0935

[7] Kook S, Bae C. Combustion control using two-stage diesel fuel injection in a single-cylinder PCCI engine. SAE Paper 2004. 2004-01-0938

[8] Köten H. Experimental investigation and multidimensional modeling of biogas effects on the diesel engine combustion characteristics [PhD thesis]; 2014

[9] Lechner GA, Jacobs TJ, Chryssakis CA, Assanis DN, Siewert RM.
Evaluation of a narrow spray cone angle, advanced injection timing strategy to partially premixed compression ignition combustion in a diesel engine. SAE

Paper 2005. 2005-01-0167

[10] Morel T, Mansour NN. Modeling of turbulence in internal combustion engines. SAE Technical Paper Series, 820040. In: International Congress and Exposition, Detroit, Mich.; February 22-26; 1982

[11] Mueller CJ, Martin GC, Briggs TE, Duffy KP. An experimental investigation of in-cylinder processes under dual-injection conditions in a DI diesel engine. SAE Paper 2004; 2004-01-1843

[12] Neely GD, Sasaki S, Leet JA. Experimental investigation of PCCI-DI combustion on emissions in a lightduty diesel engine. SAE Paper 2004. 2004-01-0121

[13] Pekalski AA, Zevenbergen JF, Pasman HJ, Lemkowitz SM, Dahoe AE, Scarlett B. The relation of cool flame and auto-ignition phenomena to process safety at elevated pressure and temperature. Journal of Hazardous Materials. 2002;93:93-105

[14] Shibata G, Oyama K, Urushihara T, Nakano T. Correlation of low temperature heat release with fuel composition and HCCI engine combustion. SAE Paper 2005. 2005-01-0138

[15] Speziale CG. On nonlinear k-l and $k-\varepsilon$ models of turbulence. Journal of Fluid Mechanics. 1987;178:459-475

[16] Walter B, Gatellier B. Near zero NOx emissions and high fuel efficiency diesel combustion: The NADITM concept using dual mode combustion. Oil \& Gas Science and Technology. 2003;58(1):101-114 
[17] Wilcox DC. Turbulence Modelling for CFD. 2nd ed. DCW Industries, Inc; 1998

[18] Yakhot V, Orszag SA.

Renormalization group analysis of turbulence-I: Basic theory. Journal of Scientific Computing. 1986;1:1-51

[19] Yakhot V, Orszag SA, Thangam S, Gatski TB, Speziale CG. Development of turbulence models for shear flows by a double expansion technique. Physics of Fluids. 1992;A4(7):1510-1520

[20] Zhao H. HCCI and CAI Engines for the Automotive Industry. UK:

Woodhead Publishing; 2007 
Section 2

Fuel and Combustion 



\title{
Hydrogen Fumigation on HD Diesel Engine: An Experimental and Numerical Study
}

\author{
Emad Monemian and Alasdair Cairns
}

\begin{abstract}
The currently reported work was concerned with experimental and numerical evaluation of the potential to partially replace diesel with hydrogen fuel, which continues to attract attention as an alternative longer-term fuel solution. The experimental work was involved with the fumigation of hydrogen on a single cylinder HD diesel engine under two real-world driving conditions at low and mid loads. Highest practical hydrogen substitution ratios could increase indicated efficiency by up to 4.6 and $2.4 \%$ while reducing $\mathrm{CO}_{2}$ emissions by 58 and $32 \%$ at low and mid loads, respectively. Soot and $\mathrm{CO}$ emissions were reduced as more hydrogen was supplied, particularly at low load. The numerical study was made by using two distinct phenomenological models being run in parallel. While, an in-depth evaluation of the unique dual fuel combustion was possible, the arising errors were largely associated with lack of dual fuel burning velocity data, which will remain a key barrier to dual-fuel simulation.
\end{abstract}

Keywords: hydrogen, diesel, dual-fuel combustion, $\mathrm{CO}_{2}$ reduction, simulation

\section{Introduction}

The climate change issue as the most obvious challenge of our era is threatening million lives around the world. Notwithstanding the treaties such as Kyoto [1] and Paris agreement [2] adopted during last decades to hinder the greenhouse gas (GHG) emissions, the promises were not kept fully due to rapid rate of industrialisation and trade races between countries. However, the recent environmental threats have gone off the alarm louder as several European countries have put deadlines to end urban utilisation of diesel engines. This call out could be carried out by gradual replacement of diesel fuel with alternative clean fuels like hydrogen particularly in the heavy goods vehicles (HGVs) as one of the main contributors of $\mathrm{CO}_{2}$ emission.

Regarding the latest UK government target in 2019, GHG emissions will be cut to almost zero by 2050 within $\mathrm{UK}$ [3]. While the total $\mathrm{CO}_{2}$ was reduced significantly ( $\sim 30 \%$ ) since the baseline year 1990 until 2014, the $\mathrm{CO}_{2}$ emission in transport sector was almost unchanged representing $27.5 \%$ of total $\mathrm{CO}_{2}$ in 2014 [4]. In that year, $\mathrm{HGVs} \mathrm{CO}_{2}$ emission has experienced a $9 \%$ improvement compared with 1990. Despite the fact that UK is on track to meet the second "carbon budget" regarding the Climate Change Act 2008 [5], transport sector has not contributed 
a major impact on $\mathrm{CO}_{2}$ emission due to increase of motor vehicles sales in recent years [6]. As HGVs are accounted for $15.7 \%$ of UK transport sector's $\mathrm{CO}_{2}$ emission, the vehicle manufacturers have been required to additionally focus upon Heavy Duty (HD) vehicles [4].

On the other hand, there is no economically viable single solution for HD longhaul applications and the internal combustion engine (ICE) is foreseen to remain as the key in the global marine, rail and continental truck markets albeit operating on lower carbon fuels. As HD diesel engine can hardly take advantage of the conventional measures applicable to the passenger car engine, it can be dual-fuelled with various fuels like natural gas (NG), ethanol, hydrogen, etc. Indeed, a pathway has been opened in recent years by the dual-fuel combustion to the sustainable operation of $\mathrm{HD}$ engines in the transport sector by significant reduction of $\mathrm{CO}_{2}$ emission.

In this chapter, we aim to study the effect of substituting the diesel fuel with hydrogen in a HD diesel engine. Ameliorating the performance and decarbonisation of this engine is the main targets. Finally, a numerical study of $\mathrm{H}_{2}$-diesel combustion was done in GT-Power.

\section{Hydrogen usage in internal combustion engines}

Hydrogen is conventionally seen being used as an energy carrier rather than fuel itself in ICEs. Typically, there are two main methods of supplying hydrogen: NG steam reforming (supplying $\sim 95 \%$ of industrial $\mathrm{H}_{2}$ ) and electrolysis of water (which is a zero-carbon method but very costly). Alternatively, an innovative acquirement of hydrogen is via on-board steam reformation of part of the liquid hydrocarbon fuel, which improves the overall system efficiency by $\sim 5 \%$ via waste exhaust heat recovery [7]. Nevertheless, the vision of a "hydrogen economy" is only foreseeable when its required production energy is totally supplied from green renewable sources. If so, transportation and electrical needs can be fulfilled using hydrogen fuel cells [8].

Storage is among the main areas for development of hydrogen power due to the relevant safety issues and physical properties of hydrogen (Table 1). Although distinct crystalline materials have been suggested for hydrogen storage, hydrides are used for storing significant quantities of hydrogen gas. In 2008, a hydrogen tank using an alloy found by Robin Gremaud could have $60 \%$ less weight than a battery

\begin{tabular}{lcc}
\hline Parameter & Hydrogen & Diesel \\
\hline Density at $0^{\circ} \mathrm{C}\left[\mathrm{kg} / \mathrm{m}^{3}\right]$ & 0.089 & 830 \\
\hline Stoichiometric air $/$ fuel ratio & 34.3 & 14.5 \\
\hline LHV $[\mathrm{MJ} / \mathrm{kg}]$ & 120 & 42.5 \\
\hline Mixture calorific value at $\lambda=1\left[\mathrm{MJ} / \mathrm{m}^{3}\right]$ & 3.2 & 3.83 \\
\hline Boiling temperature $\left[{ }^{\circ} \mathrm{C}\right]$ & -253 & $180-360$ \\
\hline Ignition limits $[$ vol $\%, \lambda]$ & $4-75 \%, 0.2-10$ & $0.6-5.5 \%, 0.5-1.3$ \\
\hline Min ignition energy at air $(\lambda=1)[\mathrm{mJ}]$ & 0.02 & 0.24 \\
\hline Auto-ignition temperature $\left[{ }^{\circ} \mathrm{C}\right]$ & 585 & $\sim 250$ \\
\hline Laminar flame speed at $\lambda=1[\mathrm{~m} / \mathrm{s}]$ & 2.0 & $0.4-0.8$ \\
\hline Carbon content $($ mass $\%)$ & 0 & 86 \\
\hline
\end{tabular}

Table 1.

Physical properties: hydrogen and diesel [9]. 
pack [10]. Besides, cryogenic tanks have other preferences which attempt to improve compatibility, expense and volumetric capacity. As an example of efforts in this area, BMW previously adopted cryogenic tanks for a 7-series mini-fleet to demonstrate improved driving range. The distribution of hydrogen for vehicles at filling stations needs remarkable infrastructure and huge investment. As of 2019, there are 46 public hydrogen stations in the US, with 41 of those located in California [11]. Thus, hydrogen would be a more sustainable fuel if its supplying and storage problems could be solved.

Several automotive manufacturers including BMW, Ford and Mazda have attempted to utilise hydrogen as an alternative fuel for the IC engine. The BMW Hydrogen 7, powered by a hydrogen IC engine, was developed by BMW between 2005 and 2007. This demonstrator adopted the same 6L V12 engine as the gasoline production model but with modifications to allow for dual fuel operation. Overall, the combustion system matched the efficiency values of a baseline turbo-diesel engine at a maximum of $42 \%$ [12].

Elsewhere, Ford also developed the first vehicle in North America exclusively powered by a hydrogen fuelled IC engine (H2ICE). A Zetec-based 2-liter H2ICE with a port fuel injection (PFI) system was integrated into a P2000 passenger sedan. Comparing with gasoline powered $2 \mathrm{~L}$ Zetec, hydrogen powered $\mathrm{CO}_{2}$ emissions were reduced to $0.4 \%$ of that of the gasoline case with $18 \%$ higher metro cycle fuel economy [13]. In later work, to achieve the stringent 2010 Phase II Heavy Duty emission standards, Ford re-designed a V10 Triton engine with the aim of running an E-450 bus with hydrogen. Following this, the Ford Focus fuel cell vehicle (FCV) was developed as an alternative hydrogen fuel cell vehicle. Such FCV vehicles are widely considered to offer considerable promise but only provided the current high costs of fuel cell technology can be reduced in the longer term. Hence, in the medium term (at least), the ICE remains dominant [14].

There have been numerous other attempts to adopt hydrogen in IC engines. Revolve UK modified the engine of a Ford Transit 2.2L Puma Diesel to operate with PFI of hydrogen as the main fuel. As the ignition source, diesel pilot injection was used to allow a permanent dual-fuel mode [15]. More recently, Alset developed a hybrid hydrogen-gasoline system that allowed the vehicle to use both fuels individually or at the same time. This technology was implemented on the Aston Martin Rapide S, which was the first vehicle completing the 24-h Nürburgring race with hydrogen technology [16].

The injection strategy has considerable influence on the hydrogen mixture's homogeneity and stratification at ignition. Hydrogen direct injection (DI) could have further benefits rather than PFI due to providing more volumetric efficiency and avoiding irregular combustion such as backfire [17].

Lund university researchers have had the earliest attempt of hydrogen HCCI combustion [18]. Although $\mathrm{H}_{2}$ HCCI operating range is much limited than SI hydrogen operation, HCCI mode showed better efficiency. In an optical study by Aleiferis et al. at UCL, hydrogen HCCI combustion was characterised by sweeping various equivalent ratios and intake air temperatures [19]. This combustion was initiated by PFI of $n$-heptane prior to the main DI of hydrogen in a low compression ratio combustion chamber. The intake air needed to be preheated as the autoignition temperature of hydrogen is too high. Considering significant ability of hindering $\mathrm{CO}_{2}$ and nitrogen oxides (NOx) intensely, the ideal zero emission engine can be realised as a rival to the fuel cell.

The unique physical properties of hydrogen make it quite different from conventional fuels, as indicated in Table 1. Due to the very low density, hydrogen's volumetric energy density is small relative to that of diesel even in a compressed storage tank or in liquid state. Hence, a large volume is needed for storing sufficient 
hydrogen to perform a requisite driving range [20]. This fact highlights the benefits of hydrogen production through on-board reformation. According to Table 1, vast ignition limits (4-75\% volumetric concentration in air), enables combustion over a wide domain of fuel-air mixtures including high efficiency lean operation. Furthermore, hydrogen has a relatively high flame speed that leads to higher efficiency [21].

Hydrogen's high diffusivity facilitates forming a uniform fuel-air mixture readily. This is also advantageous in the case of a hydrogen gas leakage, with rapid dispersion [20]. Low ignition energy of hydrogen and high burning speed makes the mixture of diesel/hydrogen easier to ignite, hence, mitigating misfire and improving performance and emissions. Besides, by increasing the $\mathrm{H} / \mathrm{C}$ ratio, hydrogen enhances the mixture's energy density at lean mixtures. However, the full load must be supplemented by some means of volumetric efficiency compensation, such as compound boosting [20].

Comparing with diesel, hydrogen has meaningfully higher specific energy by mass, lower heating value (LHV), enabling a significant proportion of required diesel fuel be substituted by hydrogen in a more cost-effective way. However, diverse challenges remained are including high in-cylinder pressure rise rates and the occurrence of pre-ignition and flashback within the intake system, particularly under heavy loads. The high flame speed of hydrogen is favourable in terms of knock [20]. However, in-cylinder hotspots exposed during the intake stroke can serve as ignition sources for causing pre-ignition and flashback due to hydrogen's very low ignition energy. In addition, lubricant deposits or the sparkplug electrodes are also thought to initiate flashback [20].

\section{Dual-fuel diesel combustion}

Dual-fuel engine operation relies on method of introducing gaseous fuel which is hydrogen in our work. The conventional approach is adding gaseous fuel into the intake air flow like SI engines. The enrichment can also be done at start of compression stroke allowing fuel gas be mixed with air before diesel injection. Both these ways can be named as premixed dual-fuel engines with fumigation mode of enrichment. Other method of enrichment includes direct injection of fuel gas both whether prior to or after liquid fuel injection. In all approaches, gaseous fuel does not auto-ignite on its own via compression ignition, but usually burns with the assistance of the injected liquid-fuelled ignition processes [8].

In current work, fumigation of hydrogen into intake port of a heavy-duty diesel engine was applied, allowing a premixed dual-fuel combustion. The progress of conventional dual-fuel combustion (with diesel injection at near TDC), is depicted in Figure 1.

The complicated interaction of liquid fuel spray and bulk premixed gaseous fuelair is not only thermal but has chemical kinetic feature which tends to extend the ignition delay and emissions. Thus, very precise control on timing of both fuel gas introduction and liquid fuel injection is essential [8].

Fuel type and concentration (in air) are important factors in premixed combustion as these parameters control chemical reaction rates. However, local flame velocity is affected heavily by mass and heat transfer. It is worthwhile to note that extra fuel or oxidant is needed for initiating burn process in partially premixed regions. These instances present complicated interaction among many chemical and physical reactions which are expressed on burn process in ICEs generally and in dual-fuel engines specifically. Chemical processes are generally governing in conditions relatively slower than physical mixing processes such as at low temperatures. 

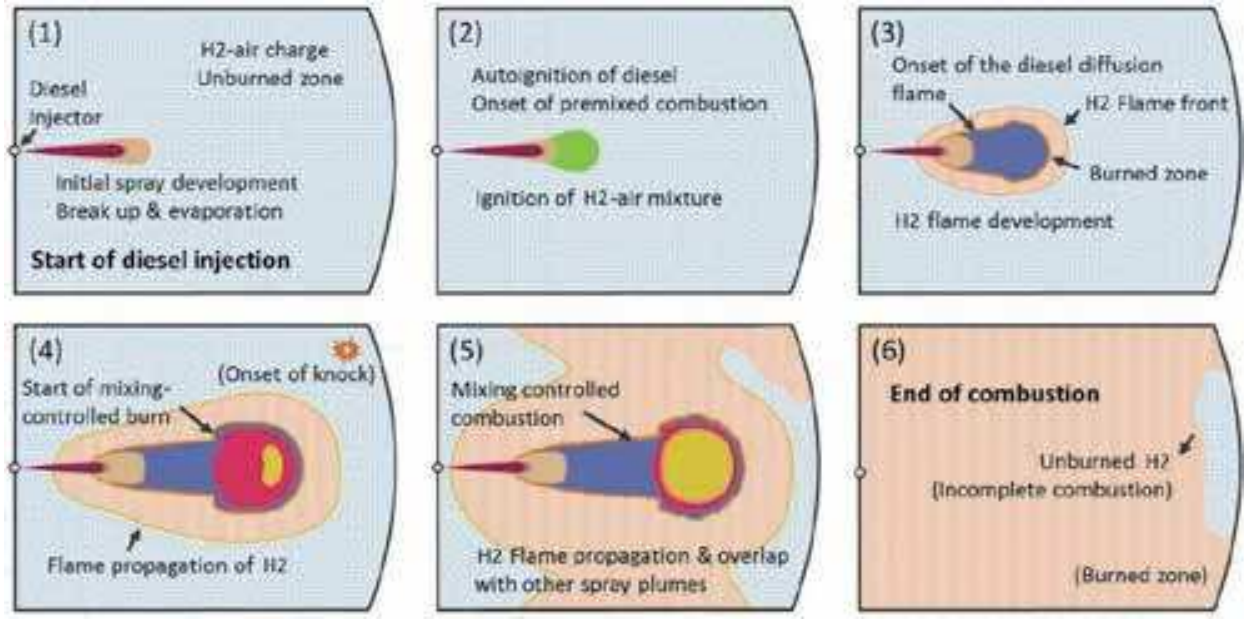

Figure 1.

Progress of conventional $\mathrm{H}_{2}$-diesel dual-fuel combustion.

However, oxidation is altering exponentially on temperature which makes it happen more rapid than other physical processes. Sometimes for simplification, its effect on burn rate might be undermined or dismissed. Diffusion flame length requires to be regulated ensuring no extreme impingement and heat transfer would result in intolerable high temperature surfaces [8].

Fumigating gaseous fuel into intake air of a dual-fuel engine makes alteration in mixture's physical and transport properties such as specific heat ratio and heat transfer features. In addition, varying partial oxygen pressure resulted from gaseous fuel displacement, affects pre-ignition activity and its associated heat release which can be altered by residual gas effects. Therefore, ignition delay trend in dual-fuel engine is distinguished from conventional diesel engine. This delay extends with higher gaseous fuel fumigation up to a specified peak and later reduces to a value well before approaching the stoichiometric ratio based on combination of gaseous and liquid fuels with available air [8].

Some of the characteristics of dual-fuel combustion which make is more complicated than conventional SI and diesel combustion are as follow [8]:

- The gaseous fuel has low tendency to get oxidised completely at low loads which results in higher fuel consumption, $\mathrm{HC}$ and $\mathrm{CO}$ emissions.

- Since significant pre-ignition occurs sporadically within gaseous fuel-air mixture, fast heat release and pressure rise is observed.

- The knock threshold at high loads is characterised by uncontrolled auto-ignition and very fast partial combustion subsequently.

Mixing process within CI engines is important for leading combustion process properly. For instance, injecting low-amount pilot makes ignition occur after end of injection allowing mixture of pilot injected fuel with premixed gas fuel-air. Earlier pilot injection if not too early (pre-ignition), might start lean mixture combustion permitting more time for mixing of pilot with gas fuel.

It is worthwhile to mention that lower flammability limit (LFL) plays as a turning point in dual-fuel combustion as the mechanism is affected depending on which side of LFL, the hydrogen concentration is. To clarify this point, a conceptual 
model proposed within a relevant work by [7] including the following three modes was considered:

1. When hydrogen concentration is above its LFL, hydrogen is pre-ignited resulting in an auto-ignition like homogeneous charge compression ignition (HCCI) mode or knocking combustion type.

2. In case of lean hydrogen (below LFL), hydrogen just burns in existence of diesel diffusion flame in a mixing-controlled mode.

3. If hydrogen concentration is over the LFL and in-cylinder conditions are not providing the hydrogen burn prior to diesel fuel ignition, the premixed hydrogen-air combustion develops in laminar mode encircling the diesel diffusion flame.

\section{Experimental methodology}

The test engine used for the experiments was an externally boosted single cylinder HD diesel engine which resembles the engine of a typical current European HGV, Table 2.

Supplying from a gas cylinder, hydrogen was fumigated downstream of the intake surge tank by mass flow controller. Gas detector and emergency shutdown circuit were embedded in the test cell with aim of protecting the operator and test facility against hydrogen leakage. In order to avoid risk of ignition in the intake system, a flashback arrestor was fitted to the hydrogen supply line, Figure 2.

As indicated in Table 3, two specific operating points were chosen for the hydrogen enrichment. The first corresponds to $1200 \mathrm{rpm}$ and 6 bar net indicated mean effective pressure (IMEPn), equivalent to $25 \%$ load representing operating point \#7 of the ESC13 i.e. A25. The second operating point was $1200 \mathrm{rpm}$ and $12 \mathrm{bar}$ IMEPn, equivalent to $50 \%$ load close to point \#5 of the ESC13 i.e. A50.

\begin{tabular}{lc}
\hline Parameter & Value \\
\hline Bore $\times$ stroke & $129 \times 155 \mathrm{~mm}$ \\
\hline Connecting rod length & $256 \mathrm{~mm}$ \\
\hline Swept volume & $2.026 \mathrm{dm}^{3}$ \\
\hline Number of valves & 4 \\
\hline Compression ratio & $16.8: 1$ \\
\hline $\begin{array}{l}\text { Max in-cylinder } \\
\text { pressure }\end{array}$ & 180 bar \\
\hline Diesel injection system & Bosch common rail, 220 MPa max injection pressure, 8 holes, 150 spray \\
& angle \\
\hline Diesel fuel & Diesel-off-road “red” diesel (LHV = 42.9 MJ $/ \mathrm{kg})$ \\
\hline Hydrogen enrichment & Continuous fumigation into intake port \\
\hline Hydrogen material & BOC $^{\circledR}$ CP grade hydrogen N5.0 (LHV = 120 MJ $\left./ \mathrm{kg}\right)$ \\
\hline
\end{tabular}

Table 2.

Test engine specifications. 


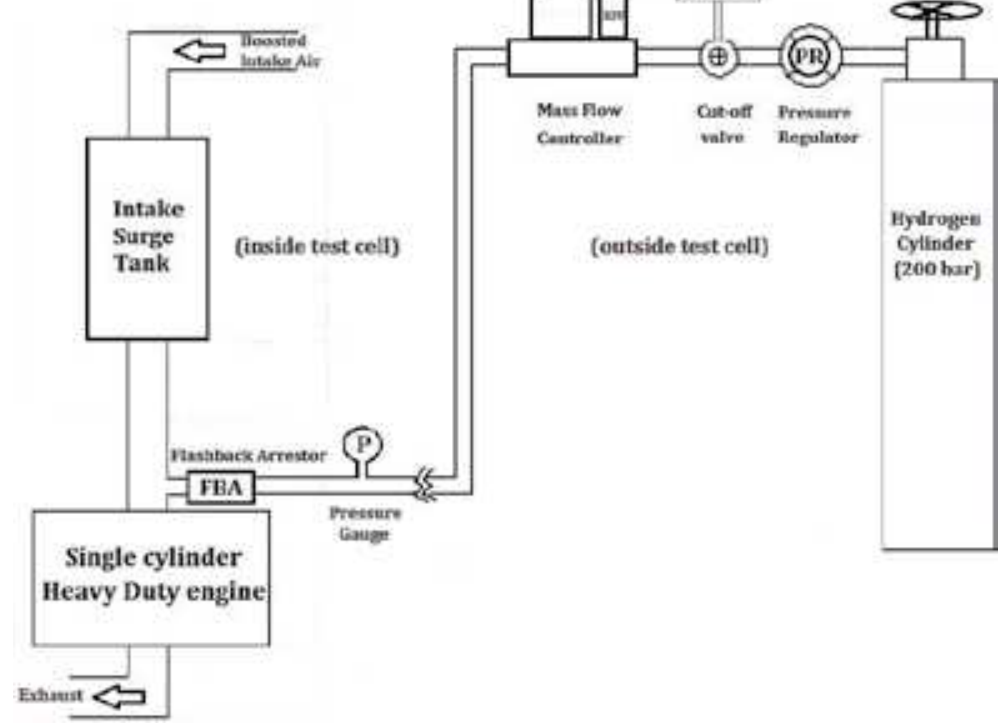

Figure 2.

Experimental setup.

\begin{tabular}{lcc}
\hline Parameter & Operating point 1(A25) & Operating point 2 (A50) \\
\hline Engine speed & $1200 \mathrm{rpm}$ & $1200 \mathrm{rpm}$ \\
\hline Load (IMEPn) & $6 \mathrm{bar}$ & $12 \mathrm{bar}$ \\
\hline Intake air temperature & $309 \mathrm{~K}$ & $318 \mathrm{~K}$ \\
\hline Intake pressure & $125 \mathrm{kPa}$ & $190 \mathrm{kPa}$ \\
\hline Exhaust pressure & $135 \mathrm{kPa}$ & $200 \mathrm{kPa}$ \\
\hline EGR rate & $25 \%$ & $25 \%$ \\
\hline EGR temperature & $339 \mathrm{~K}$ & $367 \mathrm{~K}$ \\
\hline Rail pressure & $1250 \mathrm{bar}$ & $1400 \mathrm{bar}$ \\
\hline Diesel injection strategy & Pre-injection & Pre-injection \\
\hline $\mathrm{H}_{2}$ energy fraction range & $0-65 \%$ & $0-35 \%$ \\
\hline
\end{tabular}

Table 3.

Engine operating conditions.

Based on energy input, the hydrogen fraction (HF) ratio was calculated, Eq. (1):

$$
H F=\frac{\dot{m}_{\text {hydrogen }} L H V_{\text {hydrogen }}}{\dot{m}_{\text {hydrogen }} L H V_{\text {hydrogen }}+\dot{m}_{\text {diesel }} L H V_{\text {diesel }}} \times 100
$$

With aim of simplification in writing, it is convectional to use " $\mathrm{H}$ " plus a number to refer to a specific hydrogen fraction ratio (e.g. H20 means HF $=20 \%$ ).

By optimising the start of injection (SOI) and its pressure, it was aimed to obtain the best indicated efficiency and indicated specific (IS) soot trade-off. While $\mathrm{H}_{2}$ substitution ratio was altered with 10 and 5\% increments at A25 and A50, 
respectively; it is worthwhile to note that highest hydrogen fraction in each operating point, was limited by the maximum flow rate of $\mathrm{H}_{2}$ mass flow controller (100 lit/min). Also, cyclic variation was defined by the coefficient of variation (COV) of the net IMEP averaged over 200 sampled cycles. The peak average pressure rise rate (PRR) and COV_IMEPn limits were set to 20 bar/deg and 5\%, respectively.

\section{Numerical methodology}

GT-Power as a user-friendly and powerful engine simulation tool is used by many engine manufacturers and research centres. Based on one-dimensional fluid dynamics, flow and heat transfer are represented in all flow components of an engine unit. GT-Power is an object-oriented graphical user interface with robust modelling capabilities. This has minimised the input data amount since only specific geometrical elements are required. Hence, this commercial package was utilised for processing our numerical modelling of dual-fuel combustion using its phenomenological models.

The following assumptions are common for all of Gamma Technologies (GT) phenomenological models:

- The behaviours of all gases are assumed similar to that of the ideal gas.

- In whole engine cycle excluding combustion process (IVC to EVO), content of cylinder is assumed as a lump single-zone which is homogenously mixed.

- The heat transfer between burned and unburned zones is neglected.

- Cylinder pressure is assumed uniform $\left(\mathrm{P}_{\mathrm{u}}=\mathrm{P}_{\mathrm{b}}=\mathrm{P}_{\text {cyl }}\right)$.

- Each zone has homogeneous temperature and chemical composition.

- The unburned zone composition is frozen and the composition of burned zone is kept in chemical equilibrium.

\subsection{Three pressure analysis (TPA)}

This section introduces the methodology of a reverse-run known as "three pressure analysis" (TPA) method for exploiting trapped in-cylinder condition and burn rate calculation. Regarding its name, this approach requires three measured pressures as inputs: in-cylinder, intake and exhaust. Thus, the corresponding engine model included valves and ports connected to a single cylinder crank case with all three required pressure curves versus crank angle degree (CAD) fed into it.

TPA approach is a multi-cycle simulation. For cycle 1, a mock burn rate is used with no pressure analysis. In next cycles, the forward-run will calculate the burn rate (Eq. (2)) using the trapped conditions at intake valve closure (IVC) and measured pressure profile at the start of each cycle. The injection profile and the heat transfer rate are imported from the previous cycle results. The burn rate will be iterated until the calculated cylinder pressure matches the measured cylinder pressure [22].

In the two-zone combustion model, the following energy equation is solved for the burned zone which determines burn rate $\left(\frac{d m_{f}}{d t}\right)$ [22]: 


$$
\frac{d\left(m_{b} e_{b}\right)}{d t}=-p \frac{d V_{b}}{d t}-Q_{b}-\left(\frac{d m_{f}}{d t} h_{f}+\frac{d m_{a}}{d t} h_{a}\right)
$$

The main benefit of TPA is prediction of all of the cylinder trapped quantities particularly the residual fraction. Another benefit is providing the burn rate input data consistency check, as there is always some amount of error in calculation of burn rate from cylinder pressure due to sort of inaccuracies and/or assumptions in the model. All of these potential errors add to a single "cumulative error" which results in mismatching of the predicted burned fuel with total in-cylinder fuel mass. With aim of handling this problem, GT-POWER adjusts the fuel energy content (LHV) until the available fuel is consumed right at the end of the predicted burn rate. The amount of this fuel energy adjustment which is reported as "fuel energy (LHV) multiplier", indicates the amount (and direction) of the cumulative error [22].

One of the beneficial results of TPA method is presenting a detailed energy analysis. As seen in Figure 3, the "in-cylinder energy balance" provides a comparison of following measured and predicted results thus can be used as a calibration tool:

- "Total fuel”

- "Burned fuel"

- "Cumulative energy" as the sum of internal energy, work and heat transfer.

\subsection{GT “DIPulse” combustion model}

In DIPulse model, the cylinder contents are divided into three thermodynamic zones including: the main unburned zone (all cylinder mass at IVC), the spray unburned zone (injected fuel and entrained gas) and the spray burned zone (combustion products). Using four calibration multipliers below, DIPulse is aimed to track the fuel as it was injected, evaporates and mixes with surrounding gas and burns. This model must be calibrated with experimental cylinder pressure analysis.

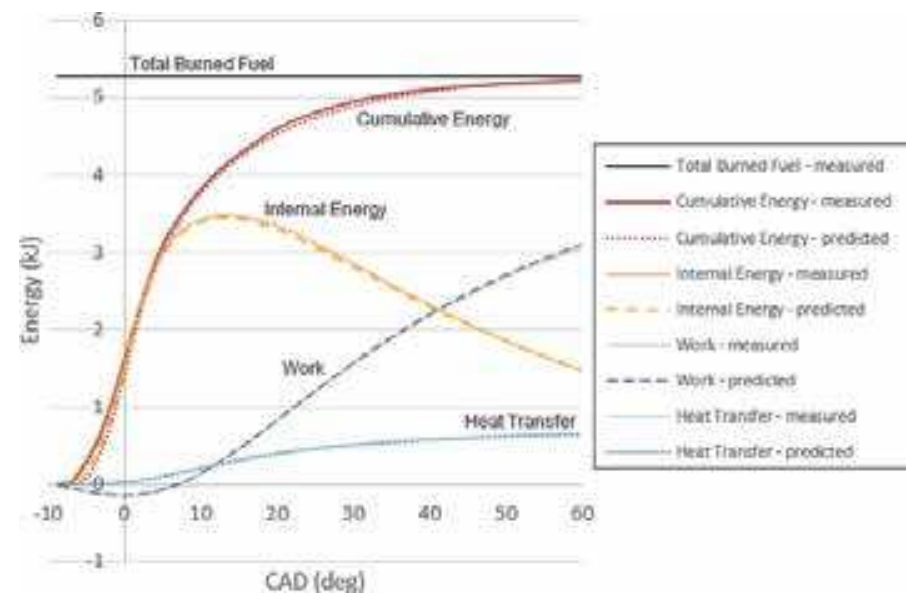

Figure 3.

In-cylinder energy balance, $H F=15 \%$. 
Furthermore, in order to achieve acceptable correlation results, an absolute requirement is precise injection profiles for each test case:

- entrainment rate multiplier (entrain)

- ignition delay multiplier (igndelay)

- premixed combustion rate multiplier (premix)

- diffusion combustion rate multiplier (diff)

The physical processes during injection and combustion are simulated by several sub-models within DIPulse, as summarised in below flowchart (as the GT uses some proprietary equations for calculating these parameters, those are not mentioned here) (Figure 4):

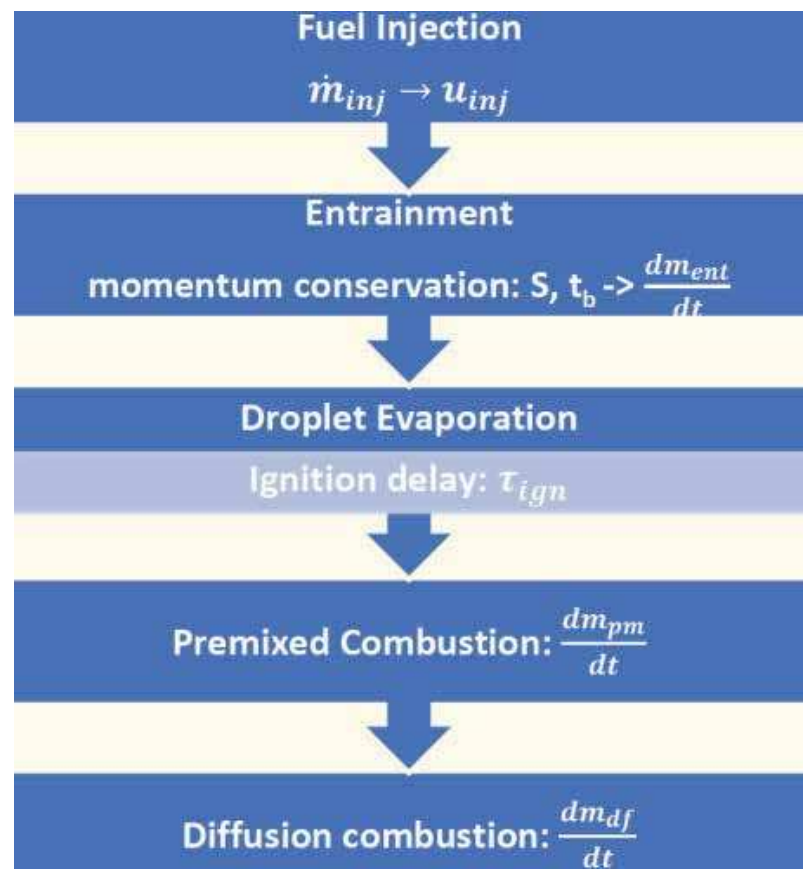

Figure 4.

Flowchart of DIPulse calculations process.

\subsection{GT “SITurb” combustion model}

The rate of transferring the unburned gas into the flame front and converting to combustion products under laminar conditions is specified by laminar burning velocity $\left(u_{L}\right)$. In laminar mode, the Taylor microscale $(\lambda)$ is defined as the average distance of vortex sheets where the burn process takes place.

As the threshold velocity of combustion initiation, (unstretched) laminar burning velocity $\left(u_{L}\right)$ has a dominance over whole combustion due to persisted interaction of initial combustion and charge motion. The laminar burning velocity is calculated by empirical correlations derived from pressure rise measured within constant-volume bombs or burners. Among those, the [23] correlation of " $u_{\mathrm{L}}$ " is 
acknowledged to be the most comprehensive one incorporating the effects of unburned gas pressure, temperature, composition and residuals.

This correlation for various hydrocarbons and methanol and those at high pressure and temperatures can be fitted in form of a power law [24]:

$$
\mathrm{u}_{\mathrm{L}}=\mathrm{u}_{\mathrm{L}, \mathrm{o}}\left(\frac{\mathrm{T}_{\mathrm{u}}}{\mathrm{T}_{\mathrm{o}}}\right)^{\alpha}\left(\frac{\mathrm{P}}{\mathrm{P}_{\mathrm{o}}}\right)^{\beta}
$$

where $\mathrm{T}_{\mathrm{o}}=298 \mathrm{~K}$ and $\mathrm{P}_{\mathrm{o}}=1 \mathrm{~atm}$ are the reference temperature and pressure, and $\mathrm{u}_{\mathrm{L}, \mathrm{o}}, \alpha$ and $\beta$ are constants for a given fuel, equivalence ratio and burned gas diluent fraction. $T_{u}$ is the temperature of unburned gas. For laminar burning velocity of hydrogen, the GT solver uses a proprietary equation similar to this equation with slight modification.

Since the turbulence parameters such as integral length scale (L), rms turbulent velocity $\left(u^{\prime}\right)$ and laminar burning velocity $\left(u_{L}\right)$ are difficult to measure experimentally under engine conditions, a numerical model must be used to estimate these parameters. The GT premixed combustion model, named as "SITurb" is based on the Blizzard and Keck model [25] which is the most applicable "turbulent entrainment model" used for SI engines [24]. The computational steps for this model are depicted in Figure 5:

This model is formed on three principle equations (Eqs. (4)-(6)) explained below. Regarding the fact that at the beginning, the flame is in laminar mode and then through the transition process which takes the time order of $\tau_{b}$, it evolves to the turbulent flame, the burning law is defined [22]:

$$
\tau_{b}=\frac{\lambda}{u_{L}}
$$

The entrainment rate of unburned mass into the turbulent flame is given by [22]:

$$
\frac{d M_{e}}{d t}=\rho_{u} A_{F F} u_{t e}
$$

$\mathrm{M}_{\mathrm{e}}$ : entrained mass; $\rho_{\mathrm{u}}$ : unburned density; $\mathrm{A}_{\mathrm{FF}}$ : flame front area; $\mathrm{u}_{\mathrm{te}}$ : turbulent entrainment velocity.

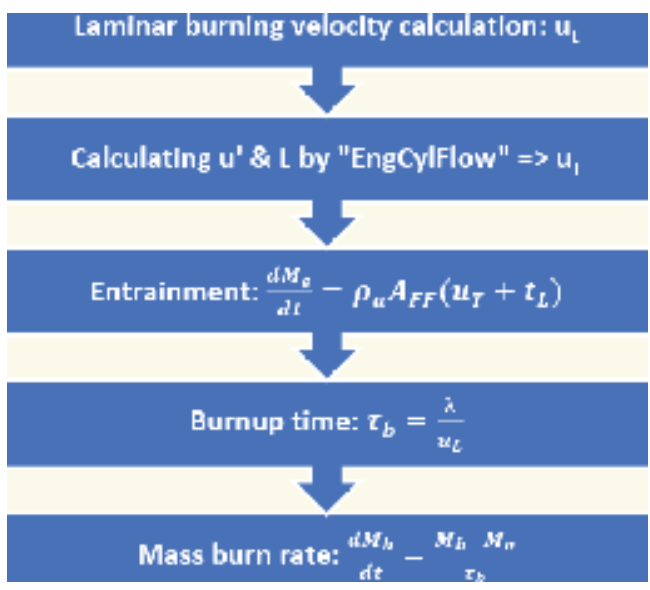

Figure 5 .

Flowchart of SITurb calculations process. 
The rate of mass burning is determined as [22]:

$$
\frac{d M_{b}}{d t}=\frac{M_{e}-M_{b}}{\tau_{b}}
$$

where $\left(M_{e}-M_{b}\right)$ is the mass of entrained yet unburned gas and $\tau_{b}$ is the burning characteristic time defined in Eq. (4).

In GT-Power, the turbulent entrainment velocity in Eq. (4) has been replaced with $\left(\mathrm{u}_{\mathrm{T}}+\mathrm{u}_{\mathrm{L}}\right)$ in accordance with improvements applied to Keck and Blizzard model by Hires et al. [26]. This was aimed to split the effects of laminar burning velocity component normal to the flame surface and the turbulent distortion of flame surface.

By adjusting the effects of these parameters via three multipliers of SITurb model which are highlighted in red in the below equations, the premixed combustion can be calibrated [22]:

$$
\begin{gathered}
u_{T}=C_{T F S} u^{\prime}\left(1-\frac{1}{1+C_{F K G}\left(\frac{R_{f}}{L}\right)^{2}}\right) \\
\lambda=\frac{C_{T L S} L}{\sqrt{\operatorname{Re}_{t}}} \\
\operatorname{Re}_{t}=\frac{\rho_{u} u^{\prime} L}{\mu_{u}}
\end{gathered}
$$

$\mathrm{C}_{\mathrm{TFS}}$ : turbulent flame speed multiplier; $\mathrm{Re}_{\mathrm{t}}$ : turbulent Reynolds number; $\mathrm{C}_{\mathrm{TLS}}$ : Taylor length scale multiplier; $\mu_{\mathrm{u}}$ : unburned zone dynamic viscosity; $\mathrm{C}_{\mathrm{FKG}}$ : flame kernel growth multiplier; $\rho_{\mathrm{u}}$ : unburned density.

\subsection{GT “DualFuel” combustion model}

The conventional spark ignition models are not precisely applicable for premixed dual-fuel combustion particularly during the ignition and early stages of combustion as the pilot injection is applied. Indeed, the prospect model for dualfuel combustion would divide the burn process into two dedicated regimes: pilot spray auto-ignition and the subsequent burning of premixed charge.

The "DualFuel" combustion model of GT-Power was used for predicting the burn rate for the dual-fuel engines where a pilot injection was used to ignite a premixed gaseous fuel/air mixture. This model combines the two distinct combustion models of DIPuse and SITurb. In this model, DIPulse handles the burning of the direct injected fuel and any premixed fuel that is entrained by the fuel spray and SITurb will model the resulting flame propagation for the premixed mixture. Both these two models take effect in parallel with an interaction between them.

Regarding optical observations, at the beginning of combustion, the spray shaped flames are formed. Then the flame front propagates into the unburned zone and ultimately will dominate the whole combustion chamber. Although, the flame front area for SITurb will initially use the conical area of the spray from DIPulse but the flame will finally transit to a spherical flame. A linear transition function will model this transformation [27]:

$$
A_{F F}=\left(1-\frac{R_{f}}{l_{k 0}}\right) A_{F F \text { jet }}+\left(1-\frac{R_{f}}{l_{k 0}}\right) A_{F F \_ \text {hemispherical }}
$$


The schematic of dual-fuel engine modeled in GT-Power is seen in Figure 6.

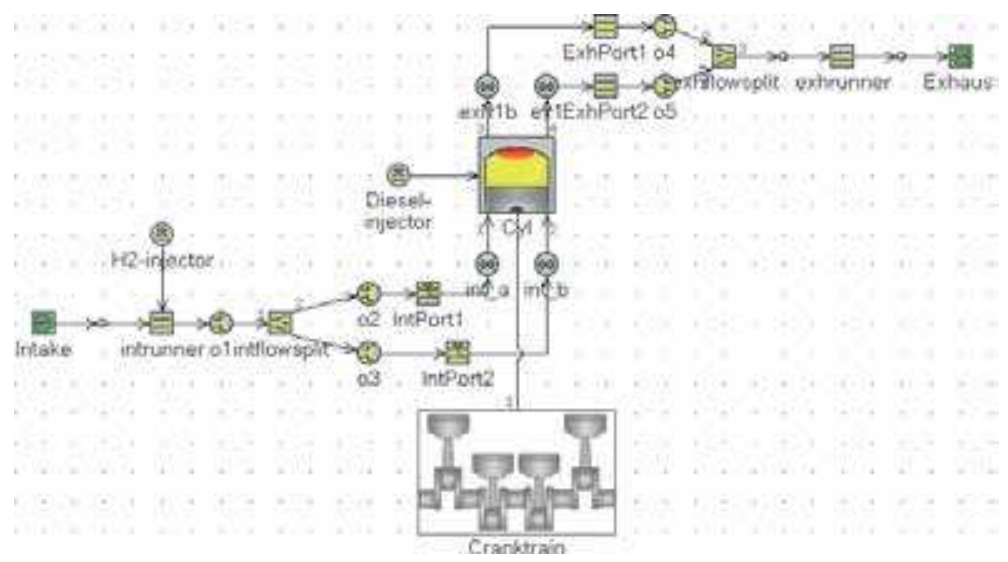

Figure 6.

Schematic of dual-fuel engine model in GT-power.

\section{Experimental results and analysis}

\section{1 $\mathrm{H}_{2}$-diesel combustion analysis}

According to the conceptual model proposed by [7] (explained at the end of Section 2), for experimental studying effect of hydrogen enrichment on diesel combustion, in each two operating points, specific hydrogen substitution ratios were selected regarding their $\mathrm{H}_{2}$ concentration in air. Their corresponding burn rate

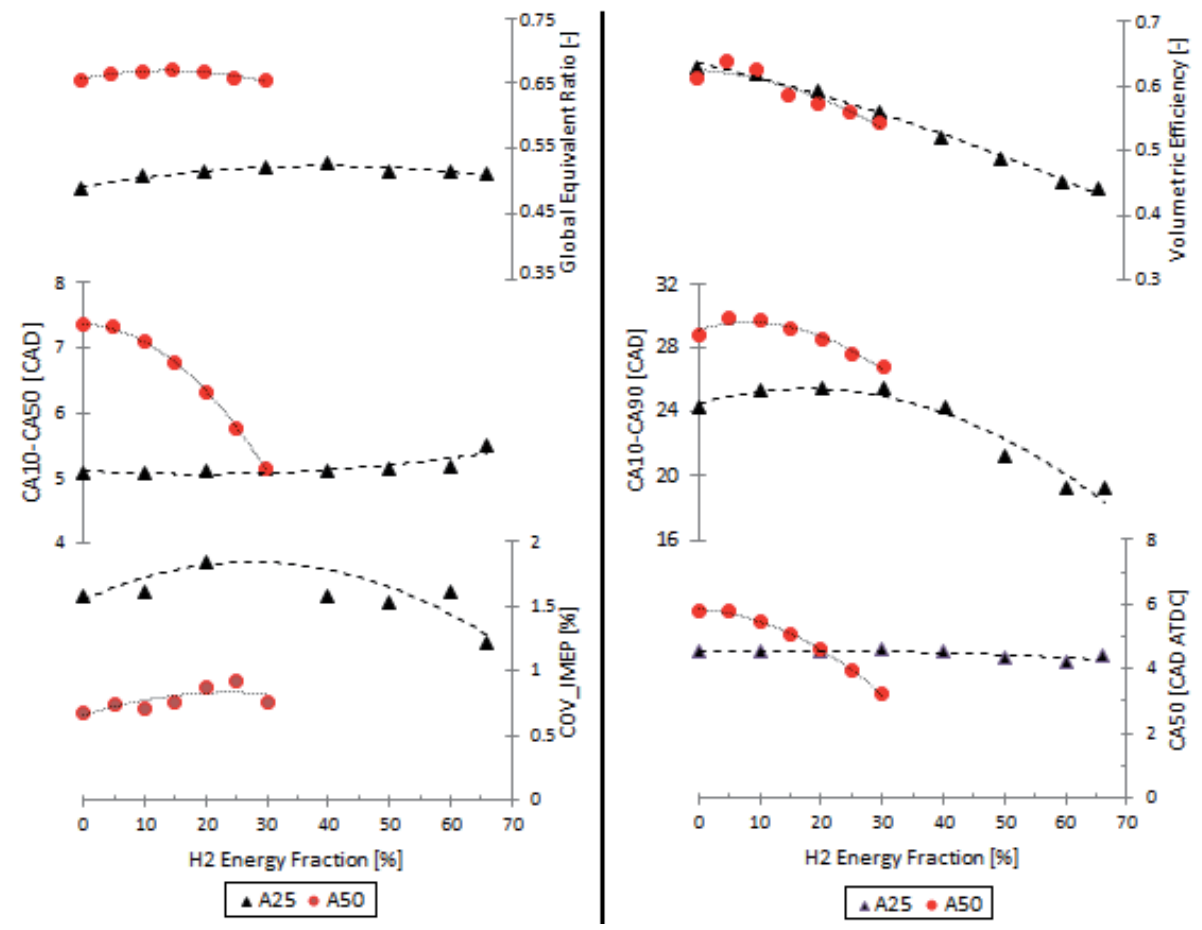

Figure 7.

$\mathrm{H}_{2}$-diesel: combustion characteristics [17]. 
and cylinder pressure plus the key attributes were post-processed by the TPA reverse-run calculation (explained in Section 5.1) on the measured test results. Four specific test cases chosen in the A25 operating point were: H0, H20, H40 and H65 and three ones chosen in the A50 were: H0, H15 and H30.

Combustion characteristics affected by hydrogen enrichment over two test operating points are presented in Figure 7. While $\phi_{\text {global }}$ was kept fairly constant for both loads, it was leaner at low load compared to mid load. Evaluating in-cylinder flow, it was observed that volumetric efficiency dropped drastically as expected. This is because significant amount of intake air was displaced with hydrogen which although has higher LHV but low molecular weight.

The key parameter, CA10-CA50, represents the premixed combustion part which set out and dominates the entire combustion process. While it was almost reluctant at $\mathrm{A} 25$, it was reducing monotonically by $\mathrm{H}_{2}$ enrichment at $\mathrm{A} 50$. This phenomenon is felt well in burn rate comparisons presented in Figure $\mathbf{8}$ as there is no variation at A25 while significant change is seemed at A50. The same trend was seen for combustion timing (CA50). These prove stimulating effect of hydrogen enrichment which was more pronounced at mid load in comparison to low load. In addition, as presented later, the flame radius and mass fraction burned for all selected cases at A25 except $\mathrm{H} 65$, are fairly reluctant to $\mathrm{H}_{2}$ enrichment.

Nevertheless, combustion duration (CA10-CA90) was descending for both loads with shorter combustion for A25 cf. A50. A similar trend is reported in [28].
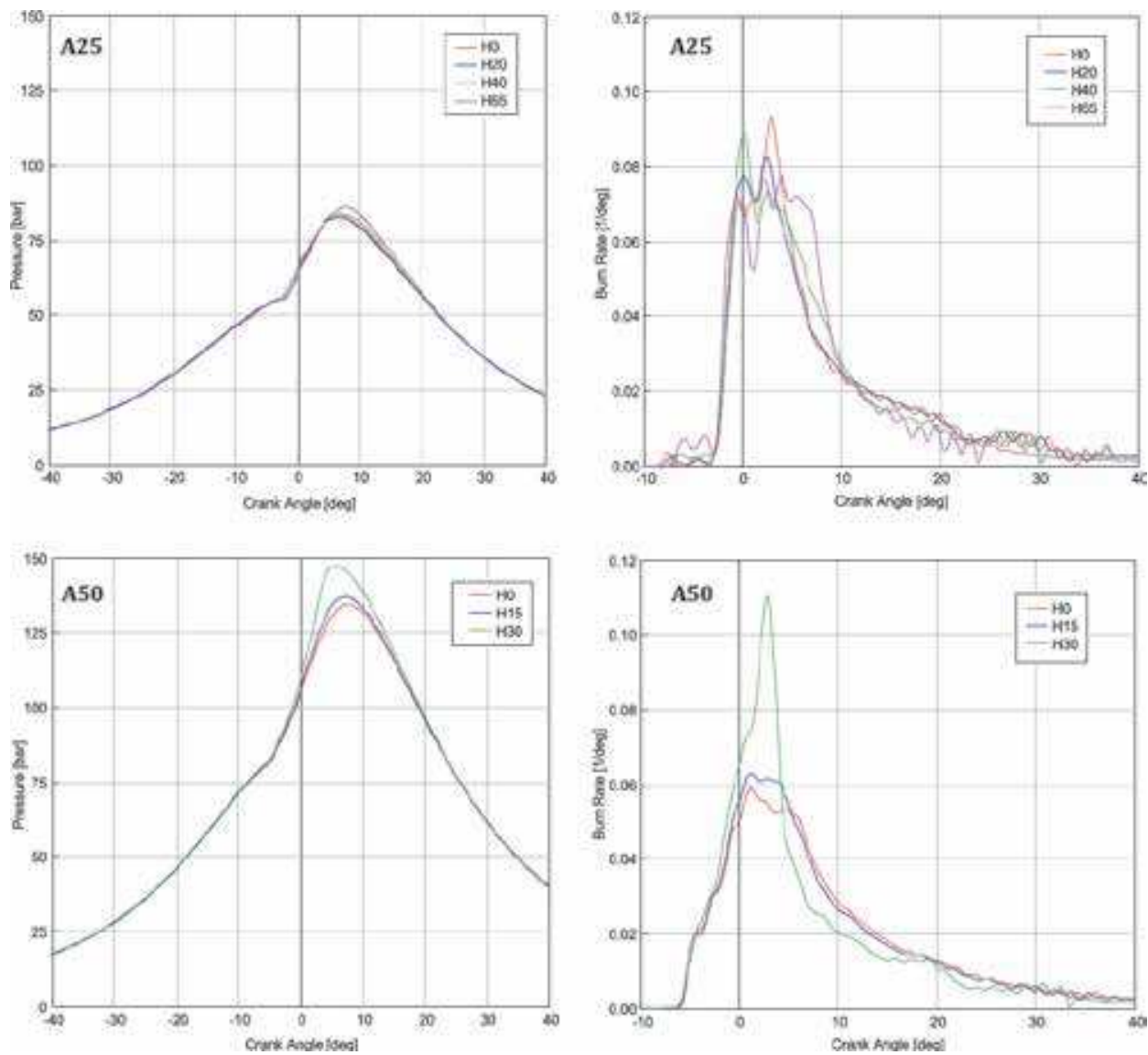

Figure 8.

Cylinder pressure (left) and burn rate (right) for $\mathrm{H}_{2}$-diesel dual-fuel combustion cases at $A_{25}$ (top) and $A_{50}$ (down). 
Ultimately, despite higher cyclic variation at A50, the COV_IMEPn was slightly affected by HF change, resulted in reasonable COV $(<5 \%)$ for both loads.

Despite the variations in key attributes of selected test cases, the cylinder pressure and burn rate trends are pretty similar for various HFs at A25. The reason can be related to low load characteristics which impede the hydrogen enrichment influence.

In contrast, the $\mathrm{H}_{2}$ enrichment influence has evolved the combustion process for A50 cases. This claim is affirmed in Figure 8 particularly for $\mathrm{H} 30$ where all key attributes were changed for both corresponding cylinder pressure and burn rate. Indeed, the mode 1 of the proposed conceptual model [7] is well presented in H30 whereas hydrogen pre-ignition prior to diesel fuel injection has been a game changer.

This phenomenon resulted in higher maximum pressure and PRR. In addition, combustion timing is advanced and burn duration is shortened significantly. More importantly, indicated efficiency has increased up to $46.44 \%$ i.e. $2.3 \%$ increase cf. HO case, Figure 9. This is because less heat was transferred to cylinder wall due to faster combustion.

\subsection{Exhaust emissions and performance of $\mathrm{H}_{2}$-diesel combustion}

Hydrogen enrichment had a positive effect on all carbon-related pollutants specially $\mathrm{CO}_{2}$. According to Figure 9, ISSoot, ISCO and ISCO2 all decreased abruptly by increasing $\mathrm{HF}$ for both loads due to reduction of the $\mathrm{C} / \mathrm{H}$ ratio. This trend of dropping $\mathrm{CO}_{2}$ emissions within dual-fuel $\mathrm{HD}$ diesel engine is very rewarding as the conventional $\mathrm{HD}$ diesel engines suffer from high $\mathrm{CO}_{2}$ emission seriously.

On the other hand, nitrogen oxides emission rate increased with higher mass flow of hydrogen, as $\mathrm{H}_{2}$ stimulates the combustion leading to higher temperatures.
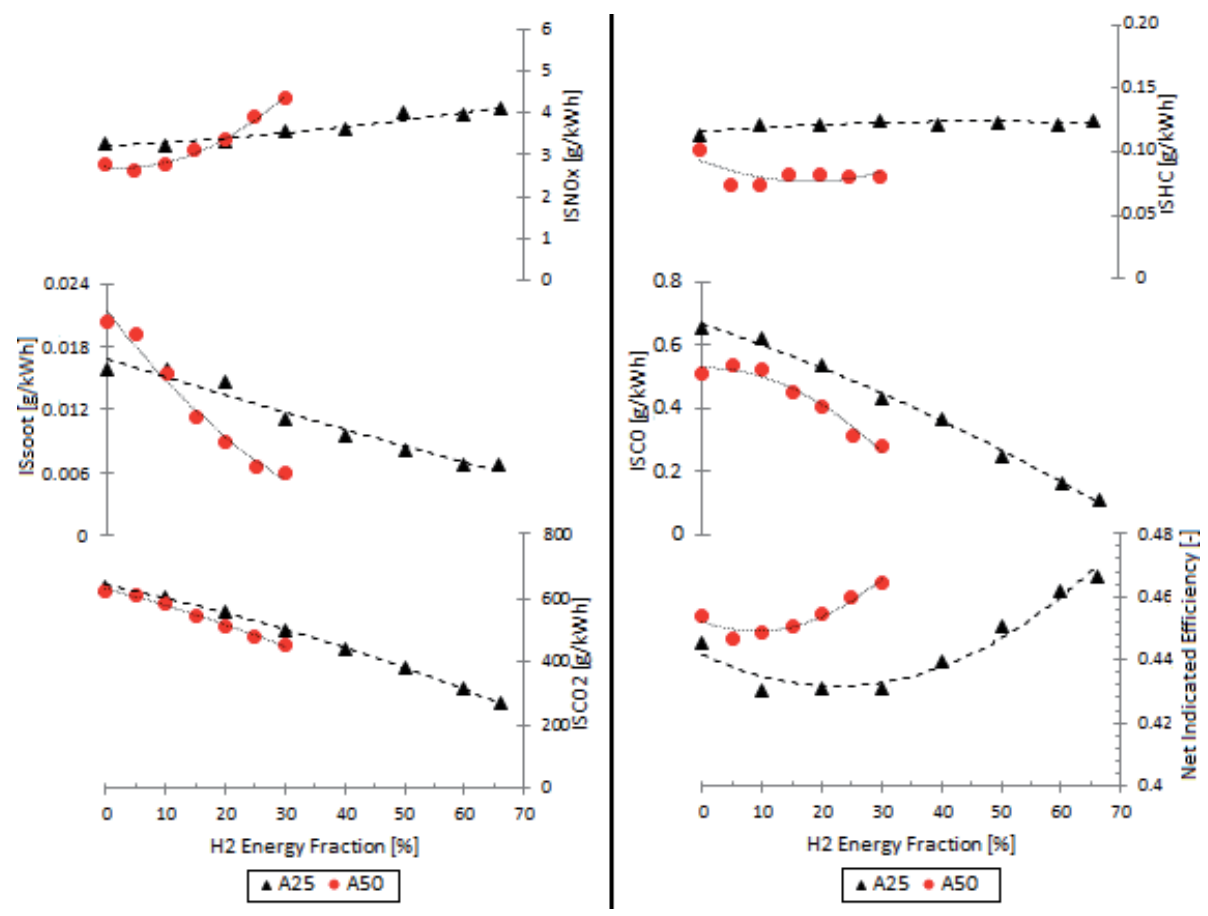

Figure 9.

Exhaust emissions and performance (A25 and $\left.A_{50}\right)$ [17]. 


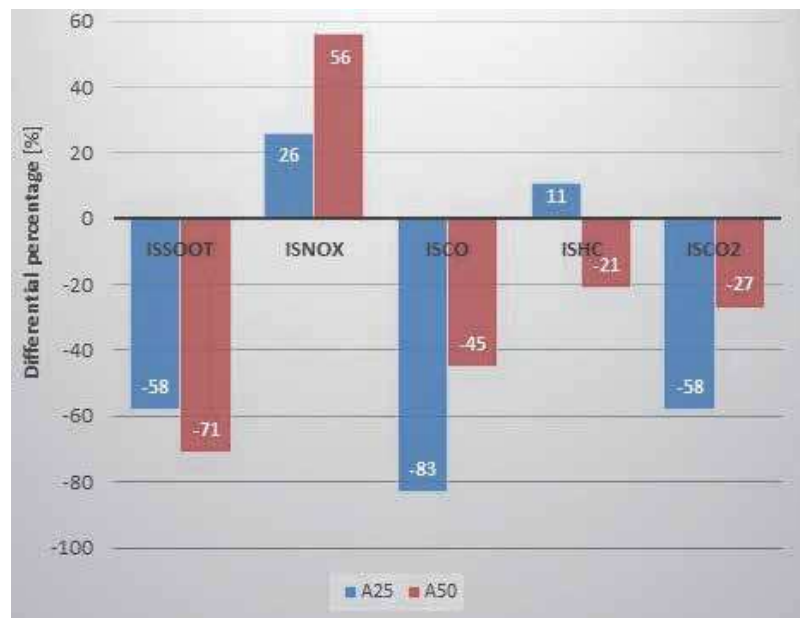

Figure 10.

Emissions alteration of highest HFs ( $\mathrm{H}_{5}$ at $\mathrm{A}_{25}$ and $\mathrm{H}_{35}$ at $\mathrm{A}_{50}$ ) to diesel baseline.

NOx-phi correlation presented in [29] can justify the ISNOx trends presented in Figure 9. As average equivalence ratio at A25 was near NOx rising threshold $(\phi=0.5)$, this resulted in relatively low increase of NOx emission ( $\sim 26 \%$ c.f. dieselonly) in 6 bar IMEPn. However, the NOx increase was significant at 12 bar IMEPn which exceeded $56 \%$ as the equivalence ratio was higher $(\phi=0.66)$ at A50. A same NOx trend was observed by relevant work in [29].

One interesting characteristic with hydrogen fumigation was remaining the ISHC fairly reluctant, particularly at A25, where it was unchanged. This can be due to constant combustion timing.

Adding small amounts of hydrogen led to slight reduction in indicated efficiency, potentially associated with reduced ratio of specific heats due to displacement of air. The reason for initial drop in efficiency could be due to "hydrogen slip" (incomplete combustion of hydrogen) as claimed in [7]. This issue was more pronounced at low load as the diesel fuel injected was relatively small, hence the gaseous fuel could not fully burn by entraining into the liquid fuel. However, at higher substitution ratio the faster combustion of hydrogen outweighed this effect and led to improved efficiency especially after hydrogen's lower flammability limit $(\mathrm{LFL}=4 \% \mathrm{Vol})$. At $\mathrm{A} 25, \eta_{\text {ind }}$ has a detrimental effect in the small hydrogen fractions until $\mathrm{HF}=30 \%$, where after efficiency starts to rise significantly until $\eta_{\text {ind }}=46.5 \%$. For A50, elevated $\eta_{\text {ind }}$ starts to recover at $\mathrm{HF}=10 \%$ and reaches a peak of $46.4 \%$ at the highest attainable HF.

The emission alteration for highest hydrogen fractions in two test points regarding the diesel-only baseline is presented in Figure 10.

\section{7. $\mathrm{H}_{2}$-diesel "dual-fuel" numerical analysis and results}

Numerical analysis concludes the full assessment of the GT "DualFuel" modelling of measured $\mathrm{H}_{2}$-diesel results considering the performance of the model. Initially, the multipliers of GT "DIPulse" and "SITurb" models were characterised using "Latin Hypercube" Design of Experiments (DOE) method within ranges recommended by GT. In association with TPA, the "Burn rate RMS" error can represent the error between the predictive burn rate and experimental burn rate measured by TPA. Our aim was minimising this error. With this aim, the threshold 
of 0.005 was determined for the burn rate RMS which the values lower than that give acceptable burn rate correlation.

Following the DIPulse and SITurb characterisation, it was concluded the following influential multipliers for 'DualFuel' burn rate prediction in order of importance:

\section{Diffusion multiplier}

\section{Entrainment multiplier}

3. Turbulent flame speed multiplier

4. Ignition delay multiplier (featured by SOI)

Thus, it was attempted to achieve the best fit of dual-fuel model for simulating $\mathrm{H}_{2}$-diesel combustion in the A25 as seen in Figure 11.

For overall evaluation of DualFuel model capability of simulating $\mathrm{H}_{2}$-diesel combustion, the mass burned fraction (MBF) for the selected case at A25 were calculated. As seen in Figure 12, the rate of turbulent premixed combustion could not be predicted precisely. This is the result of a source of error which appeared mostly at the end of mass burning. The reasons for this source of error could include:

- De-developing turbulence is not taken into account in the SITurb model.

- The flame-wall interactions and associated physical phenomena are also not directly accounted for (i.e. quench).

- Considerable scatter in the burning velocity correlations.
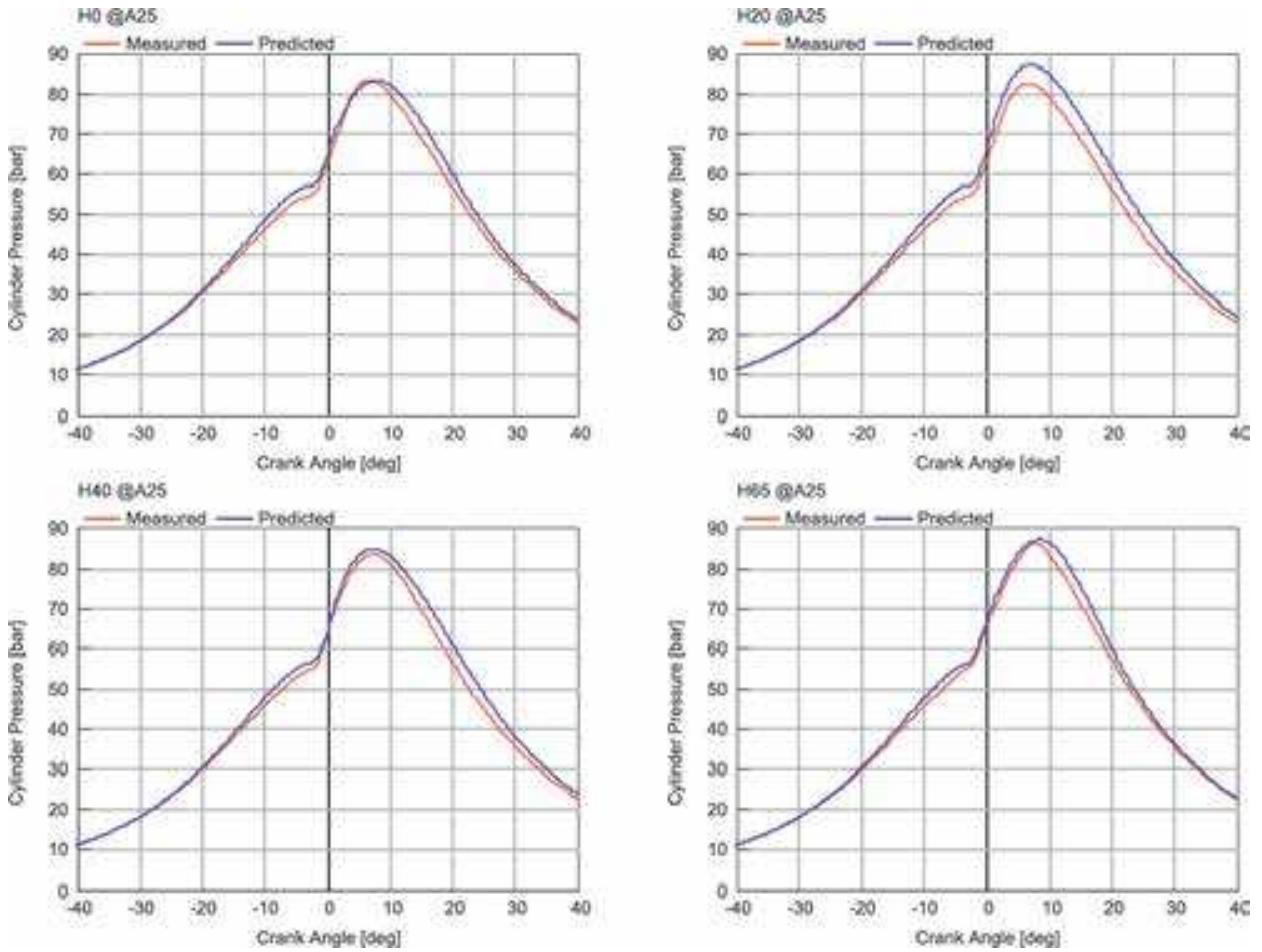

Figure 11.

Cylinder pressure prediction at A25. 

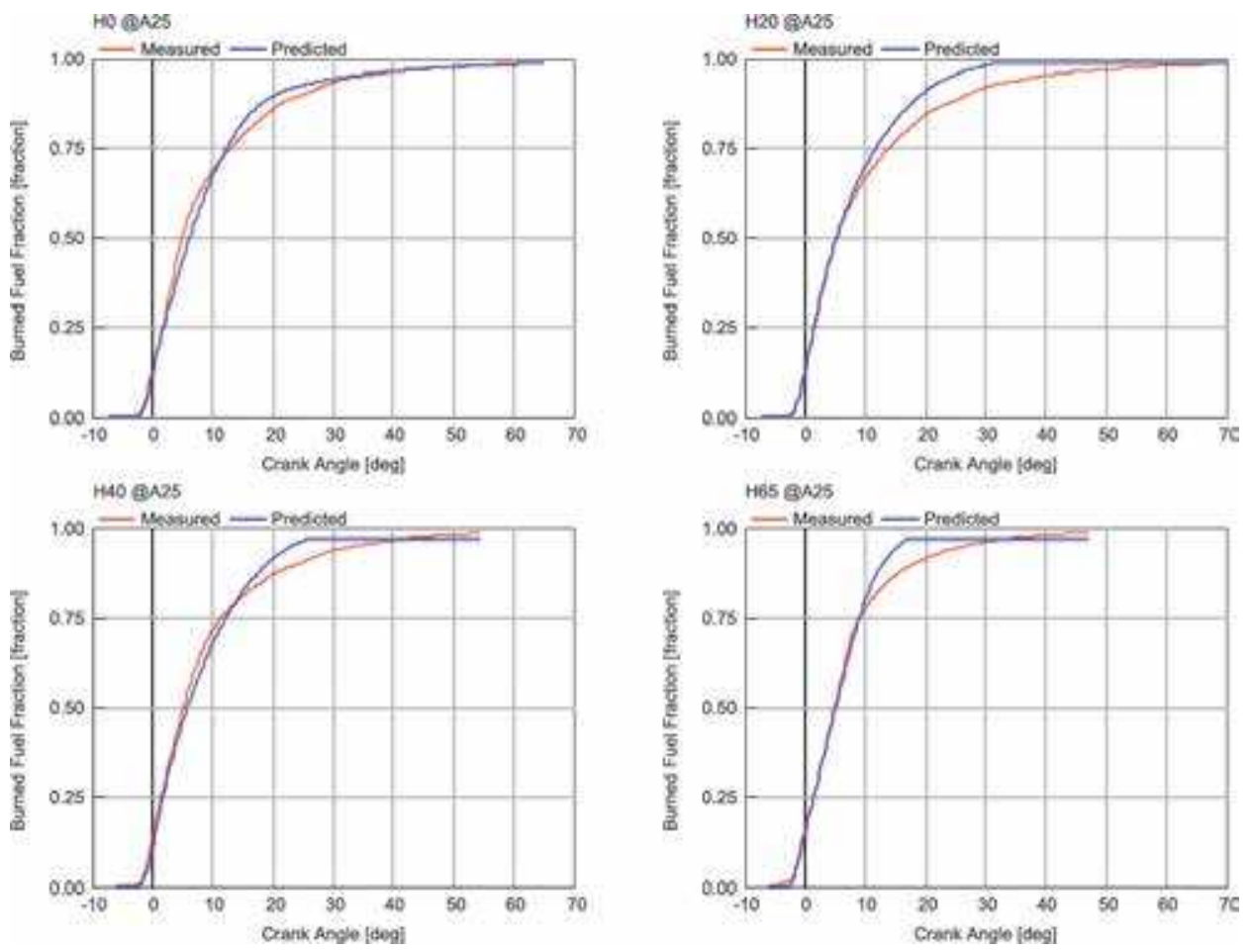

Figure 12.

Mass burned fraction for selected cases at A25.

The empirical flame speed ratio (FSR) as ratio of turbulent flame speed to laminar flame speed, was employed in the DualFuel model in order to define the flame propagation rate. FSR usefully indicates if the combustion is most affected by chemical factors (laminar flame) or turbulence. Indeed, FSR is a useful metric for comparing the ability of the flow field to increase the rate of unburned mass entrainment.

As seen in Figure 13, both laminar and turbulent flame speeds were increased by enriching more hydrogen in the dual-fuel combustion mode. These changes are all explainable regarding the conceptual model proposed by [7], within which the hydrogen volumetric concentration in air has a key role in dual-fuel combustion of hydrogen and diesel. In fact, the hydrogen LFL plays as a turning point where exceeding this limit leads to hydrogen pre-ignition in the hydrogen/air premixed charge.

Despite the enhancement of flame speeds in both laminar and turbulent regimes for H65, this case has the lowest FSR comparing with other HFs, Figure 13. This can be interpreted that combustion process was mostly influenced by the laminar chemical reactions rather than turbulence. However, the combustion was shorter in this case than other HFs. In addition, Figure 13 shows the highest FSR curve for $\mathrm{H} 20$ (lowest $\mathrm{H}_{2}$ fraction). This represents that influence of turbulence was more robust than effect of the chemical reactions initiated the flame at earliest stage of combustion. Therefore, hydrogen enrichment contributed mostly in accelerating the early chemical reactions rather than enhancing the turbulence level.

As depicted in Figure 14, the significant rise of laminar flame speed for H65 is related to its extra-ordinary rise of the in-cylinder temperature (Eq. (3)). This significance can also be assessed by the specific heat ratio $\left(\gamma=\frac{c_{p}}{c_{v}}\right)$ as the indicator 
Hydrogen Fumigation on HD Diesel Engine: An Experimental and Numerical Study DOI: http://dx.doi.org/10.5772/intechopen.89425
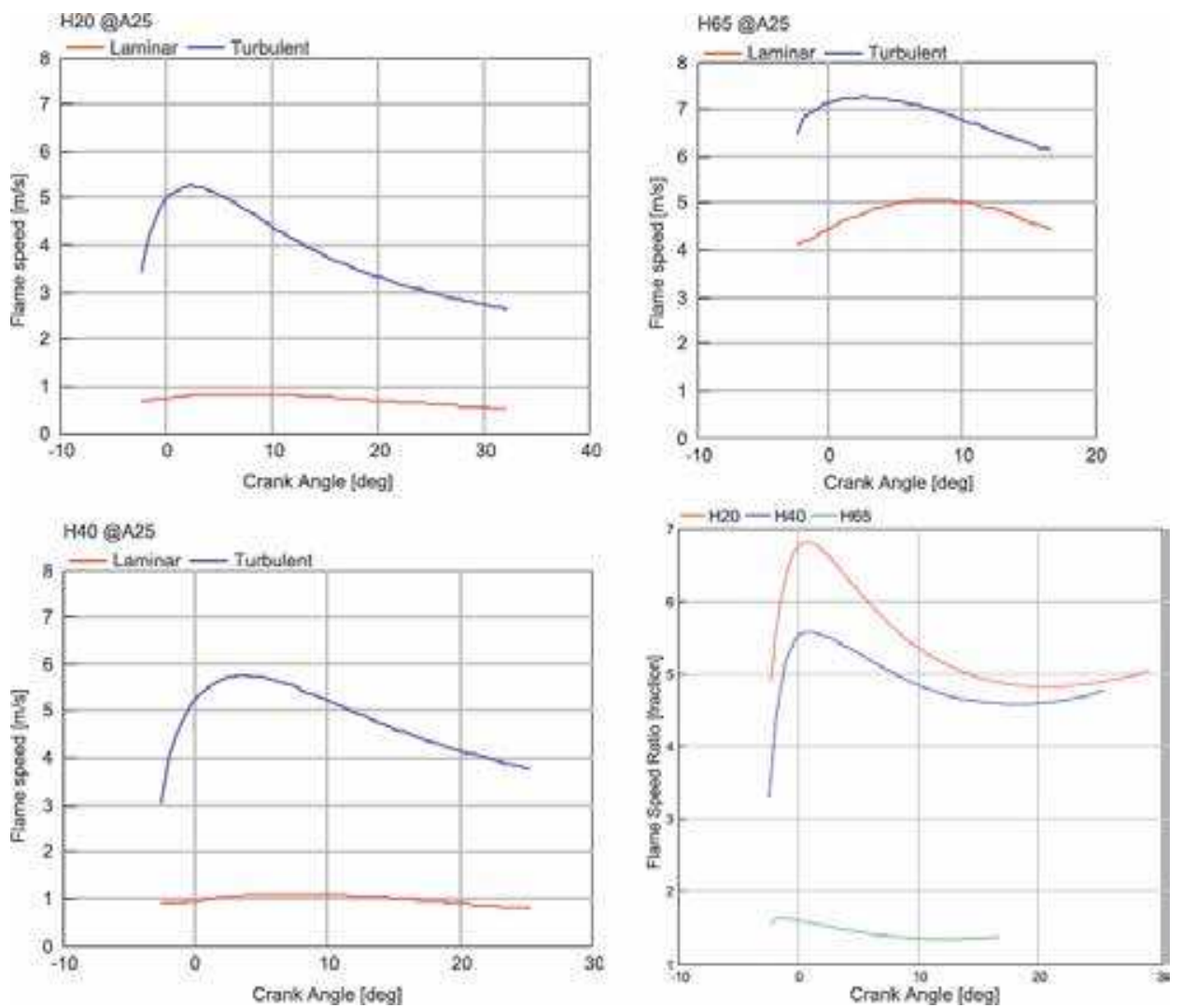

Figure 13.

Flame speeds of selected test cases at A25.
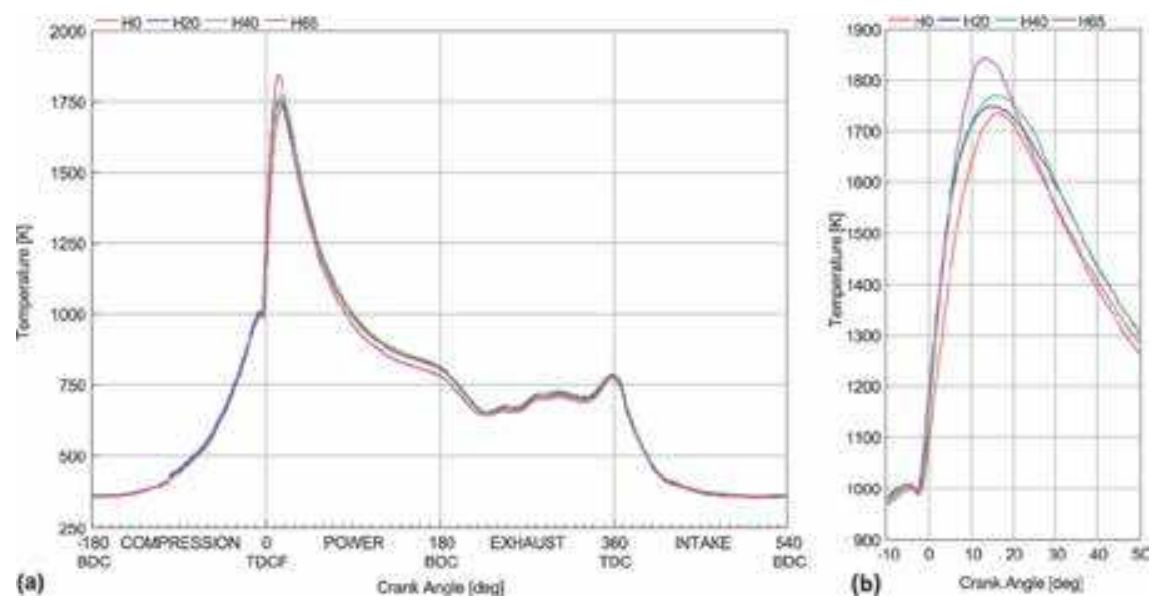

Figure 14.

In-cylinder temperature during (a) entire cycle (b) combustion process at $A 25$.

of sources of efficiency [24] during the engine cycle. As seen in Figure 15, this case has the highest $\gamma$ over the engine cycle in comparison to other test cases. This can contribute in achieving the highest indicated efficiency among all HFs at A25, as depicted in Figure 9. 


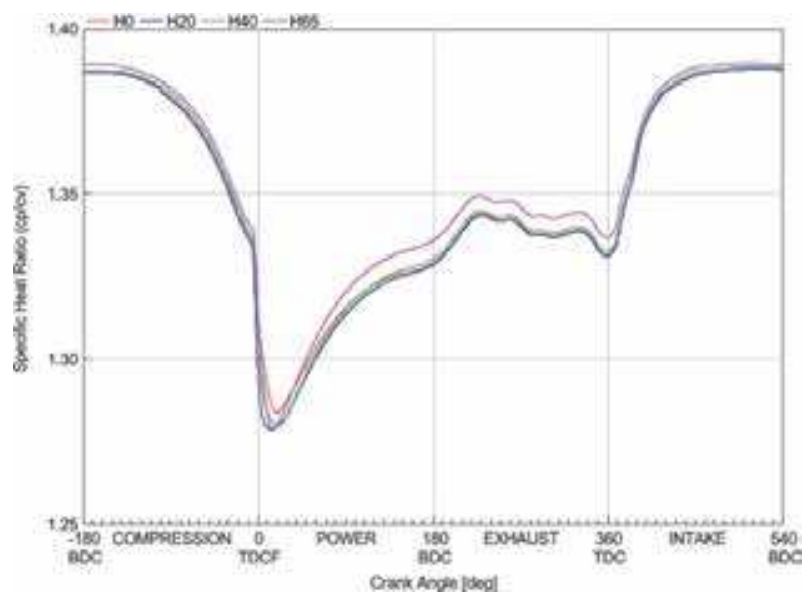

Figure 15.

Specific heat ratio at A25-DualFuel model.

\section{Conclusions}

\subsection{Experimental tests conclusions}

Comparing to the baseline diesel-only test results on our two targeted operating points (A25 and A50), it was aimed to achieve the best indicated efficiency-ISSoot trade-off. The following main points were concluded:

- Highest hydrogen substitution ratios increased indicated efficiency by up to $4.6 \%$ at 6 bar IMEPn and $2.4 \%$ at 12 bar IMEPn.

- ISCO2, ISCO and ISsoot were reduced by 58, 83 and 58\% respectively at 6 bar IMEPn. At 12 bar IMEPn, the reduction of these pollutants was 27, 45 and 71\% respectively compared to the diesel-only baseline.

- $\mathrm{H}_{2}$-diesel dual-fuel combustion with fixed SOI resulted in an increase of NOx emissions $(\sim 26 \%)$ at 6 bar IMEPn. This increase was significant at 12 bar IMEPn, which exceeded $56 \%$, but is an inherent feature of the elevated temperatures incurred. NOx emission could meet the $0.4 \mathrm{~g} / \mathrm{kWh}$ limit of Euro VI with NOx after-treatment of $90 \%$ conversion efficiency.

\subsection{Numerical study conclusions}

For the first time, in the currently reported work, two distinct phenomenological sub-models, "DIPulse" and "SITurb" were run in parallel in the form of a DualFuel model, to simulate the $\mathrm{H}_{2}$-diesel combustion. Although, the sub-models showed good capability of predicting the in-cylinder pressure, the DualFuel model suffers from insufficiencies in modelling of dual-fuel combustion particularly in high HFs. Despite its novelty, this current model may contain some pitfalls as follow:

- The model is in its infancy to be applied for dual-fuel modelling due to its oversimplified assumptions (e.g. single-zone homogeneous turbulence model with averagely-sized eddies). 
- The model relies heavily on correlations to engine data (flame images, cylinder pressure and burn rate) to have an inclusive predictive performance.

- The laminar burning velocity correlation for hydrogen does not include the effects of flame instabilities which result in an apparent rise in $u_{L}$ and hence pressure. Besides, the necessity of experimentally measuring the burning velocity of hydrogen within the premixed diesel charge is greatly acknowledged to allow us to have better insight of dual-fuel combustion physics. Although, this dual-fuel flame speed measurement has been mostly overlooked by fellow researchers, this can be very beneficial as premixing diesel could typically extend the lean burn limit with enhancing combustion efficiency of dual-fuel engines.

- The interaction between DIPulse and SITurb within DualFuel model is not yet known exactly in detail. Indeed, those might be able to predict the "trend" of combustion process rather than prediction of corresponding variables accurately.

Despite these barriers, the predictive model could be used for calculating the flame speeds (laminar and turbulent) in addition to other turbulent parameters for each test case. The results of our numerical study can be concluded as follow:

- The influential multipliers for 'DualFuel' burn rate prediction in order of importance are: diffusion, entrainment, turbulent flame speed and ignition delay.

- The laminar flame speed is increasing by enriching more hydrogen in dual-fuel combustion mode. This enhancement is more pronounced for highest HF (H65) as it is related to its extra-ordinary rise of the in-cylinder temperature.

- The H65, has the fastest flame propagation. This is in accordance with MFB curve of this case which resulted in shortest combustion duration among all cases. Nevertheless, H65 has the lowest FSR comparing with other HFs emphasising that its combustion process was mostly affected by the chemical activities rather than turbulence.

- The highest FSR was obtained by lowest HF (H20). Hence, hydrogen addition was mainly pronounced in expediting the early stage chemical reactions instead of turbulence level enhancement.

- As a proof for achieving the highest indicated efficiency by H65 at A25, the highest specific heat ratio was obtained by this test case over entire engine cycle.

\section{Acknowledgements}

The financial support of VN-Automotive Ltd. is acknowledged for commissioning the experimental work.

\section{Conflict of interest}

The authors declare there is no conflict of interest for publishing this chapter. 


\section{Acronyms}

$\begin{array}{ll}\text { CAD } & \text { crank angle degree } \\ \text { COV } & \text { coefficient of variation } \\ \text { DI } & \text { direct injection } \\ \text { DOE } & \text { design of experiments } \\ \text { FCV } & \text { fuel cell vehicle } \\ \text { FSR } & \text { flame speed ratio } \\ \text { GHG } & \text { greenhouse gas } \\ \text { GT } & \text { Gamma Technologies } \\ \text { H2 } \\ \text { HCE } & \text { hydrogen fuelled IC engine } \\ \text { HCCI } & \text { homogeneous charge compression ignition } \\ \text { HD } & \text { heavy duty } \\ \text { HF } & \text { hydrogen fraction } \\ \text { HGV } & \text { heavy goods vehicles } \\ \text { HRR } & \text { heat release rate } \\ \text { ICE } & \text { internal combustion engine } \\ \text { IMEPn } & \text { net indicated mean effective pressure } \\ \text { IS } & \text { indicated specific } \\ \text { IVC } & \text { intake valve closure } \\ \text { LFL } & \text { lower flammability limit } \\ \text { LHV } & \text { lower heating value } \\ \text { MBF } & \text { mass burned fraction } \\ \text { NG } & \text { natural gas } \\ \text { NOx } & \text { nitrogen oxides } \\ \text { PFI } & \text { port fuel injection } \\ \text { PRR } & \text { pressure rise rate } \\ \text { SOI } & \text { start of injection } \\ \text { TPA } & \text { three pressure analysis } \\ \text { UCL } & \text { University College London }\end{array}$

\section{Author details}

Emad Monemian* and Alasdair Cairns

University of Nottingham, Nottingham, UK

*Address all correspondence to: emad.monemian@gmail.com

\section{IntechOpen}

(C) 2020 The Author(s). Licensee IntechOpen. Distributed under the terms of the Creative Commons Attribution - NonCommercial 4.0 License (https://creativecommons.org/ licenses/by-nc/4.0/), which permits use, distribution and reproduction for non-commercial purposes, provided the original is properly cited. (cc) BY-NC 


\section{References}

[1] Kyoto Protocol. Available from: h ttps://en.wikipedia.org/wiki/Kyoto_ Protocol [Accessed: 15 August 2019]

[2] Adoption of the Paris Agreement, United Nations, Framework Convention on Climate Change, UN Doc FCCC/CP/ 2015/L.9/Rev.1 [Adopted: 12 December 2015]

[3] Climate Change: UK Government to Commit to 2050 Target. BBC News. Available from: https://www.bbc.co.uk/ news/science-environment-48596775 [Released: 2019-06-19]

[4] Final UK Greenhouse Gas Emissions National Statistics 1990-2014. Available from: https://assets.publishing.service.g ov.uk/government/uploads/system/ uploads/attachment_data/file/496946/ 2014_Final_Emissions_Statistical_ Summary_Infographic.pdf [Accessed: 15 August 2019]

[5] Climate Change Act 2008. Available from: http://www.legislation.gov.uk/ ukpga/2008/27/pdfs/ukpga_20080027_e n.pdf [Accessed: 15 August 2019]

[6] Provisional New CV Registrations or Sales (2014), OICA statistics. Available from: http://www.oica.net/category/sale s-statistics/ [Accessed: 10 July 2017]

[7] Morgan R, Atkins P, Atkins A, Lenartowicz C, Heikal M. Effect of Hydrogen Fumigation in a Dual Fueled Heavy Duty Engine. SAE Technical Paper 2015-24-2457. 2015

[8] Karim GA. Dual-Fuel Diesel Engines. Boca Raton: CRC Press; 2015

[9] Wimmer A, Wallner T, Ringler J, Gerbig F. $\mathrm{H}_{2}$-Direct Injection-A Highly Promising Combustion Concept. SAE Technical Paper, 2005-01-0108. 2005

[10] Light Weight Hydrogen 'Tank' Could Fuel Hydrogen Economy, Science
Daily. Available from: https://www.scie ncedaily.com/releases/2008/11/ 081104084215.htm [Released: 5 November 2008]

[11] Alternative Fueling Station Counts by State, Alternative Fuels Data Center, US Dept. of Environment. Available from: https://www.afdc.energy.gov/fue ls/stations_counts.html [Retrieved: 15 August 2019]

[12] BMW Hydrogen 7. Available from: $h$ ttp://en.wikipedia.org/wiki/BMW_Hyd rogen_7 [Accessed: 15 August 2019]

[13] Szwabowski SJ, Hashemi S, Stockhausen WF, et al. Ford Hydrogen Engine Powered P2000 Vehicle. SAE Technical Paper 2002-01-0243. 2002

[14] Natkin RJ, Denlinger AR, Younkins MA, et al. Ford 6.8L Hydrogen IC Engine for the E-450 Shuttle Van. SAE Technical Paper 2007-01-4096. 2007

[15] Low Carbon Vehicle Partnership. Innovations in UK road transport: Driving the economy, cutting carbon [Reported: 9 March 2015]

[16] Alset Global “Our Solutions”. Available from: http://alset.at/oursolutions/ [Accessed: 15 August 2019]

[17] Monemian E, Cairns A, Gilmore M, et al. Evaluation of intake charge hydrogen enrichment in a heavy-duty diesel engine. Proceeding of IMechE Part D: Journal of Automobile Engineering. 2017;232:139-147

[18] Stenlåås $O$, Christensen M, Egnell R, et al. Hydrogen as Homogeneous Charge Compression Ignition Engine Fuel. SAE Technical Paper 2004-01-1976. 2004

[19] Rosati MF, Aleiferis PG. Hydrogen SI and HCCI Combustion in a Direct- 
Injection Optical Engine. SAE Technical Paper 2009-01-1921. 2009

[20] Lanz A et al. Hydrogen Fuel Cell Engines and Related Technologies. CA, USA: College of the Desert; 2001

[21] Cassidy JF. Emissions and Total Energy Consumption of a Multicylinder Piston Engine Running on Gasoline and a Hydrogen-Gasoline Mixture.

Springfield, Virginia, USA: National Technical Information Service; 1977

[22] Engine Performance Application Manual (v2018), Gamma Technologies. Westmont, IL, USA; 2018

[23] Metghalchi M, Keck JC. Burning velocities of mixtures of air with methanol, iso-octane, and Indolene at high pressure and temperature.

Combustion and Flame. 1982;48:191

[24] Heywood JB. Internal Combustion Engine Fundamentals. 1st ed. New York, NY: McGraw-Hill; 1988

[25] Blizard NC, Keck JC. Experimental and Theoretical Investigation of a Turbulent Burning Model for Internal Combustion Engines. SAE Technical Paper 740191. 1974

[26] Hires SD, Tabaczynski RJ, Novak JM. The Prediction of Ignition Delay and Combustion Intervals for a Homogeneous Charge, Spark Ignition Engine. SAE Technical Paper 780232. 1978

[27] Walther H, Schlatter S, Wachtmeister G, Boulouchos K. Combustion Models for Lean-Burn Gas Engines with Pilot Injection, MTZ Paper 02I2012. 2011

[28] Dhole AE, Yarasu RB, Lata DB. Investigations on the combustion duration and ignition delay period of a dual fuel diesel engine with hydrogen and producer gas as secondary fuels.
Applied Thermal Engineering. 2016;107: 524-532

[29] Verhelsta S, Wallnerb T. Hydrogenfueled internal combustion engines. Progress in Energy and Combustion Science. 2009;35(6):490-527. Available from: https://biblio.ugent.be/publica tion/818298 


\title{
Planar Drop-Sizing in Dense Fuel Sprays Using Advanced Laser Diagnostic Techniques
}

\author{
Aniket P. Kulkarni and D. Deshmukh
}

\begin{abstract}
A reliable measurement of drop sizes and liquid fuel distribution in a spray is essential for best combustion efficiency and exhaust emission from I.C. engines. The droplet size and fuel distribution control air-fuel mixture formation and, hence, combustion characteristics. The chapter gives a concise summary of recent advances and developments in the LSD technique as a planar drop-sizing technique. The LSD technique relies on the principle that a ratio of planar laser-induced fluorescence (PLIF) and Mie signals is proportional to Sauter mean diameter (SMD). PLIF signal can also be used to determine the distribution of liquid in a spray. This makes LSD an attractive technique in dense spray characterization that can also provide liquid volume fraction distributions. A brief review of laser-based drop-sizing methods and working principle of LSD measurements are first discussed. Different approaches and limitations of the LSD technique are also summarized. Further, sources of error and ways to compensate these errors are explained in detail. Previous studies on LSD measurements in different fuel sprays of stationary combustion devices and I.C. engines are summarized. Finally, improvements in the LSD techniques are suggested, including structured laser illumination planar imaging (SLIPI) measurements, for reliable measurements in dense sprays.
\end{abstract}

Keywords: PLIF, Mie, LSD, liquid volume fraction, SLIPI

\section{Introduction}

Internal combustion (I.C.) engines are widely used in many applications including automobile, transport, power generation, etc. Delivery of liquid fuel in I.C engines is achieved by injecting liquid in the form of droplets into a combustion chamber, as in diesel or GDI engines, or into an intake manifold. It is recognized that atomization of liquid fuel and spray characteristics have critical impact on combustion processes and emission formation [1, 2]. Figure 1 explains the role of spray characteristics in air-fuel mixture formation processes of a combustion engine. The liquid fuel is injected into a combustion chamber in the form of a spray. Fuel droplets evaporate due to available heat in the combustion chamber that controls the mixing of air and fuel and, hence, physical ignition delay. Vaporized fuel then mixes with the surrounding air to form a combustible air-fuel mixture and 


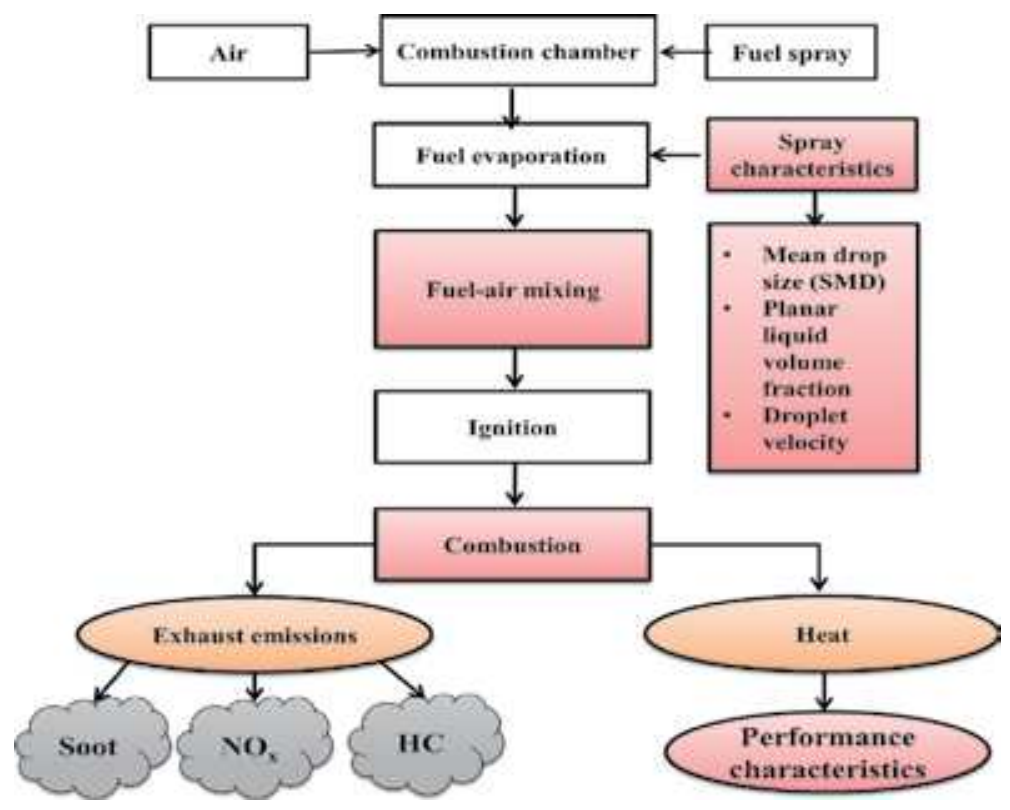

Figure 1.

Dependence of combustion performance on atomization characteristics of fuel spray.

initiate combustion reaction. Thus, distribution of liquid fuel droplets in the combustion chamber governs air-fuel mixture distribution and, thus, the temperature distribution. The combustion of fuel liberates heat and also produces undesirable exhaust gases as products. One of the exhaust gas emissions, nitrogen oxides $\left(\mathrm{NO}_{x}\right)$, is mainly formed due to high combustion temperature according to Zeldovich's mechanism [1]. Unburnt hydrocarbons and soot emissions are results of incomplete combustion of fuel. Soot and $\mathrm{NO}_{x}$ emissions can be controlled simultaneously with appropriate distribution of air-fuel mixture which is mainly governed by atomization of fuel and spray characteristics. Moreover, combustion efficiency is also controlled by the resultant distribution of air-fuel mixture [3]. Thus, various spray characteristics such as droplet size and its distribution, droplet velocity, and liquid volume fraction play an essential role in optimizing the combustion process along with minimum exhaust emissions.

Drop size and the distribution of liquid fuel (liquid volume fraction) in a spray have a considerable impact on the combustion efficiency. The Sauter mean diameter (SMD) is widely accepted as an average droplet size parameter in combustion applications that controls the evaporation rate $[2,4]$. Therefore, a reliable measurement of drop sizes and liquid volume fraction is necessary for optimizing air-fuel mixture formation in a combustion process.

\section{Laser-based drop sizing in sprays}

Laser-based techniques provide high spatial and temporal resolution in measurement and are preferred due to their nonintrusive nature. Drop sizes of micrometric fuel droplets moving with high velocities can also be measured by using laser-based drop-sizing techniques. Various laser-based drop-sizing techniques have been used to measure drop sizes in a spray. Most of the drop-sizing techniques are point measurement techniques and are limited to spray regions 
where droplet number density is low. Laser sheet drop sizing (LSD) is a planar drop-sizing method that has capability to be used even in dense fuel sprays. Some of the advanced laser-based drop-sizing techniques are discussed below:

- Laser-diffraction-based drop size measurements

- Particle/Droplet Imaging Analysis (PDIA)

- Phase Doppler Interferometry (PDI)

- Interferometric laser imaging for droplet sizing (ILIDS)

- Laser sheet drop sizing (LSD)

\subsection{Laser-diffraction-based drop size measurements}

This is a commonly used technique and is also known as Malvern particle sizer. The technique is based on Fraunhofer diffraction of a monochromatic laser beam [5]. Line-of-sight drop-size measurements are obtained using forward scattering. Thus, spatial variations along the line-of-sight cannot be determined. The technique also suffers from laser beam extinction and multiple scattering [6]. These limitations lead to erroneous drop-size measurements in dense sprays [5-7].

\subsection{Particle/droplet imaging analysis (PDIA)}

PDIA is a microscopic shadowgraphy-based direct imaging technique [8-11]. The microscopic shadowgraphs are captured using a high resolution CCD camera coupled to a microscope $[12,13]$. A long-distance microscope is used to probe into a very small field of view $(\sim 2 \times 2 \mathrm{~mm})$ with a pixel resolution of the order of a few microns per pixel. The microscopic images are analyzed using image processing tools to obtain statistically large number of droplets and mean drop size. The technique has a capability to consider nonspherical droplets and a presence of a number of droplets in a measurement volume [14, 15]. However, the technique is biased toward large size droplets as the resolution of the technique is diffractionlimited, and small droplets are neglected in the drop sizing $[10,14,16,17]$.

\subsection{Phase Doppler interferometry (PDI)}

PDI is an interferometry-based drop-sizing technique that uses Mie scattering theory to calculate drop size along with velocity at a point in a spray [5]. PDI is also known as Phase Doppler Anemometry (PDA) or Phase Doppler Particle Analyzer (PDPA). PDI is a widely accepted standard method in the spray diagnostics. However, single droplet occupancy, spherical droplets, and multiple scattering are some of the limitations of the PDI technique $[5,7,18]$. Therefore, drop sizing with PDI becomes questionable when spray is optically thick (optical density $>10$ ) such as in non-evaporative, high-pressure diesel sprays. The state of art of PDI technique for drop-size measurement is well documented in the literature $[7,19]$.

\subsection{Interferometric laser imaging for droplet sizing (ILIDS)}

ILIDS is also known as interferometric particle imaging (IPI) or planar particle image analysis (PPIA) [20-23]. Glare points are formed due to interference of 
reflection and refraction on the droplet surface. The glare points are imaged out of focus to calculate drop size. In this technique, micron-ranged droplets can be imaged in a relatively large field of view. However, interference fringes tend to overlap when droplet number density is high. Therefore, this technique is limited in sparse sprays where droplet number density is low. A comprehensive review of ILIDS technique can be found in the literature [7, 24-26].

\subsection{Laser sheet drop sizing (LSD)}

Laser sheet drop sizing (LSD, also called as Planar Drop Sizing, LIF/Mie ratio technique) is a combination of planar laser-induced fluorescence (PLIF) and Mie scattering imaging that gives a distribution of SMD in a plane of the spray [27-32]. The PLIF signal is proportional to the volume of the droplet, whereas the scattering signal is proportional to the surface area of the droplet [27-30]. The ratio of these two signals is then proportional to SMD. Initially, the basic principle was explained and applied to non-evaporative diesel sprays [31]. The accuracy of the technique has been verified with established drop-sizing methods such as PDPA [30, 32] and diffraction-based drop sizing [6].

Table 1 lists various laser-based drop-sizing techniques along with the measurement principle and limitation of the technique. Except for LSD, these techniques are either point measurement techniques (PDIA or PDI or ILIDS) or line-of-sight (diffraction-based techniques). These techniques also have limitations in sprays with high droplet number density. A large number of droplets in a small volume affect the travel of laser light and signal through a spray. The LSD technique is an attractive drop-sizing technique that provides SMD and liquid volume fraction distribution in a plane. Moreover, the technique can also be used in dense sprays where droplet number density is high. A detailed discussion on LSD technique, principles, assumptions, and limitations is given in the following section.

\section{Laser sheet drop sizing}

The LSD technique is a combination of a signal based on volume of a droplet and a signal based on surface area of a droplet. When a droplet of diameter $(D)$ is illuminated with a light of a wavelength $\lambda$, a relation between $D$ and $\lambda$ is given in terms of Mie parameter $\left(X_{m}\right.$, Eq. 1$)$. The Mie parameter $\left(X_{m}\right)$ can be used to

\begin{tabular}{llll}
\hline Technique & Principle & Type of measurement & Important limitation (s) \\
\hline $\begin{array}{l}\text { Particle/Droplet } \\
\text { Imaging Analysis } \\
\text { (PDIA) }\end{array}$ & $\begin{array}{l}\text { Microscopic } \\
\text { shadowgraphy }\end{array}$ & Point measurement & $\begin{array}{l}\text { Resolution is diffraction- } \\
\text { limited }\end{array}$ \\
\hline $\begin{array}{l}\text { Phase Doppler } \\
\text { Interferometry (PDI) }\end{array}$ & Interferometry & Point measurement & $\begin{array}{l}\text { Single droplet occupancy } \\
\text { in a measurement volume }\end{array}$ \\
\hline ILIDS & $\begin{array}{l}\text { Interferometry (glare- } \\
\text { point separation) }\end{array}$ & $\begin{array}{l}\text { Point measurement with } \\
\text { large field of view }\end{array}$ & $\begin{array}{l}\text { Can be applied only in } \\
\text { sparse sprays }\end{array}$ \\
\hline Diffraction & Interferometry & $\begin{array}{l}\text { Line-of-sight } \\
\text { measurement }\end{array}$ & $\begin{array}{l}\text { Attenuation of laser beam } \\
\text { in dense sprays }\end{array}$ \\
\hline Laser sheet drop sizing & Intensity ratio & Planar measurement & $\begin{array}{l}\text { Signal attenuation, laser } \\
\text { extinction, and multiple } \\
\text { scattering }\end{array}$ \\
\hline
\end{tabular}

Table 1.

Laser-based drop-sizing techniques used in spray diagnostics. 
estimate a relation between $D$ and scattering intensity $\left(I_{s}\right)[7,26,33]$. It is observed that the scattering intensity is proportional to square of Mie parameter $\left(X_{m}\right)$, i.e., $I_{s} \propto X_{m}^{2}$ for scattering angle of $90^{\circ}$ for spherical droplets of diameter $D \geq 1 \mu \mathrm{m} \mathrm{[7,26,}$ $33,34]$. This suggests that Mie scattering signal is proportional to the surface area of the droplet (Eq. 2).

$$
\begin{gathered}
X_{m}=\frac{\pi \cdot D}{\lambda} \\
I_{s} \propto D^{2}
\end{gathered}
$$

Laser-induced fluorescence signal is considered as volume-based signal. Rarely, Raman scattering signal can also be used for this purpose though the Raman signal is weak [35]. Laser-induced fluorescence (LIF) involves the excitation of liquid molecules by a laser followed by the detection of the subsequent emission of radiation from the liquid. Natural fluorescence of the liquid can be used if fluorophores are already present in the liquid. An external fluorophore, in the form of fluorescent dye, can be added in the liquid for generating PLIF signal. The radiation is necessarily inelastic and red-shifted according to Planck's law. The radiation can be distinguished from the incident laser wavelength using appropriate optical filters. The concentration of the dye is kept to a minimum to ensure low laser light absorption and all molecules of a droplet are equally illuminated. The linear regime of the PLIF signal with incident laser energy is ensured. Under these conditions, a relation between PLIF signal $\left(I_{f}\right)$ and a droplet with diameter $D$ can be expressed as

$$
I_{f} \propto D^{3}
$$

The signal (PLIF or Mie signal) from each pixel of the CCD array is obtained from the total droplets present in the measurement volume. The measurement volume of the LSD technique is defined using field of view of the CCD camera and a thickness of the laser sheet. The LSD signal is obtained by dividing the LIF signal by the scattering signal (Eq. 4), when a statistically large number of droplets are present in the measurement volume.

$$
\frac{I_{f}}{I_{s}} \propto \frac{\sum_{i} D_{i}^{3}}{\sum_{i} D_{i}^{2}} \propto S M D
$$

A constant of proportionality $(\mathrm{K})$ is introduced to get a quantitative SMD distribution in a plane.

$$
S M D=K \cdot \frac{I_{f}}{I_{s}}
$$

The constant of proportionality $(\mathrm{K})$ can be calculated at a location using an independent drop-sizing method (PDIA, PDI, ILIDS). In the LSD measurement technique, the proportionality between a droplet diameter and Mie and PLIF signals is mainly responsible for reliable drop-sizing measurements. $D^{3}$ and $D^{2}$ proportionality is well documented in the literature. Le Gal et al. [36] reported that a low concentration $(0.023 \mathrm{~g} / \mathrm{l})$ of p-terphenyl (PTP) in mineral spirit ensures the proportionality. Frackowiak et al. [37] reported that $\mathrm{D}^{3}$ proportionality is ensured for the low dye concentration of 3-pentanone in n-heptane. Domann et al. [27] reported a similar observation for Rhodamine 6G in water droplets when the signal was captured at an angle of $90^{\circ}$. An increase in dye concentration deviates $D^{3}$ 
proportionality, mainly because of the absorption of light by the dye molecules. Domann et al. [27] further demonstrated that $D^{2}$ proportionality is respected at detection angle of $90^{\circ}$. Charalampous et al. [28] performed a numerical study to investigate $D^{3}$ and $D^{2}$ proportionality as a function of detection angle from 60 to $120^{\circ}$ and various dye concentrations. The observations confirm $D^{3}$ proportionality at $90^{\circ}$ detection angle with the lowest dye concentration. Further, it was suggested to use $60^{\circ}$ detection angle instead of $90^{\circ}$, as Mie scattering fluctuations are minimum at $60^{\circ}$ detection angle [28]. However, the use of $60^{\circ}$ detection angle in Mie imaging may lead to Scheimpflug condition.

Assumptions made in the LSD technique are listed below [27, 28, 37, 38]:

1. Droplets are spherical and transparent.

2. The scattered photons undergo a single scattering event before reaching the detector.

3. Morphology-dependent resonances (MDR) in Mie and PLIF signals are neglected, or appropriate precautions are taken to avoid MDR [38].

4. The variation of fluorescence intensity with incident laser energy is in linear regime to ensure the non-saturated fluorescence signal.

5. Minimum dye concentration to avoid absorption.

6. Statistically large number of droplets are present in the measurement volume. This ensures drop size distribution in the independent drop-sizing technique is followed in the LSD technique at a location of the calibration.

7. The location of calibration must be accurately mapped in PLIF image, Mie image, and the independent drop-sizing technique.

8. The calibration constant $\mathrm{K}$ is constant over a range of drop sizes in the plane of the LSD measurements.

However, when LSD measurements are applied in real-life spray systems, these assumptions may lead to limitations of the technique.

- Mie scattering theory assumes that droplets are spherical. However, in the near-nozzle region, where the breakup of the liquid is in process, a large number of ligaments, liquid lumps, or nonspherical droplets are present. These nonspherical liquid droplets may lead to error in $D^{2}$ proportionality.

- It is assumed that the photon has undergone a single scattering event. This assumption may not be followed in the dense sprays where the droplet number density is high. The photons may undergo several scattering events leading to unreliable and unrealistic signals. This source of error is termed as multiple scattering or secondary emission. Therefore, LSD measurements may not provide reliable drop sizing in dense sprays.

- The quantitative SMD measurement in LSD technique further relies on an independent drop-sizing technique. An error involved in the independent drop 
sizing may propagate in the LSD measurements. Further, this dependence on the other drop-sizing technique adds additional cost to the LSD measurements.

- Laser extinction due to the scattering of the laser sheet and absorption of the laser sheet and signal attenuation may lead to error in the PLIF and Mie signals. These losses may lead to an error in the LSD measurements. The contribution of the error may be significant in dense sprays.

\section{Approaches used in the LSD measurements}

In the LSD technique, a combination of Mie and PLIF signals is used for droplet size measurements. Mie signals is elastic in nature (i.e., wavelength is the same as that of illumination), which helps to capture the Mie signal even without any optical filters. On the other hand, PLIF signals are red-shifted, thus inelastic in nature, which demands optical filters in PLIF imaging. For example, Rhodamine 6G dye is illuminated with $532 \mathrm{~nm}$ pulsed laser (green in color); it emits fluorescence signal in a window of 550-570 nm (orange in color). Thus, a band-pass filter is used to cover this window. Also, a notch filter can also be used to remove incident illumination of $532 \mathrm{~nm}$.

There are two approaches for droplet sizing in the LSD technique. In the first approach, PLIF and Mie signals are acquired simultaneously, whereas the second approach relies on the sequential imaging of the signals. Averaged PLIF and Mie images are then obtained in both the approaches. The number of images used must be sufficiently large to ensure enough number of droplets in the measurement volume. This ensures that similar drop size distributions are observed in LSD measurement and the independent drop-sizing measurement at a location of the calibration.

\subsection{Simultaneous imaging of PLIF and Mie signals}

In simultaneous imaging, PLIF and Mie signals are obtained simultaneously using appropriate optical filters and two separate camera systems or by a single camera fitted with appropriate image-splitting optics. The two-camera method involves simultaneous and independent imaging of Mie and PLIF signals as shown in Figure 2 [30-32, 35, 36, 39-41]. Both the cameras are focused on the same field of view that ensures pixel-to-pixel overlapping of the signals. The simultaneous imaging of the Mie and PLIF signals can also be obtained using a single camera system [35]. In this case, the CCD array of a single camera is used along with an imagesplitting arrangement to acquire simultaneous PLIF and Mie signals. However, this reduces the resolution of the LSD measurements. Further, a weak fluorescence signal may be reduced due to additional image-splitting arrangement. The simultaneous imaging approach is widely used in literature to get SMD distribution, including time-resolved SMD measurements [30-32, 35, 36, 39-41]. However, in this approach, the cost of the measurement is high due to two cameras or image splitter. Moreover, pixel-to-pixel overlapping may be an additional problem in instantaneous imaging.

\subsection{Sequential imaging of PLIF and Mie signals}

It is also possible to use a single camera to record the fluorescence and elasticlight-scattering images in sequence [27, 42-49]. This approach provides reliable SMD measurements where there is reasonable confidence that the flow or spray 


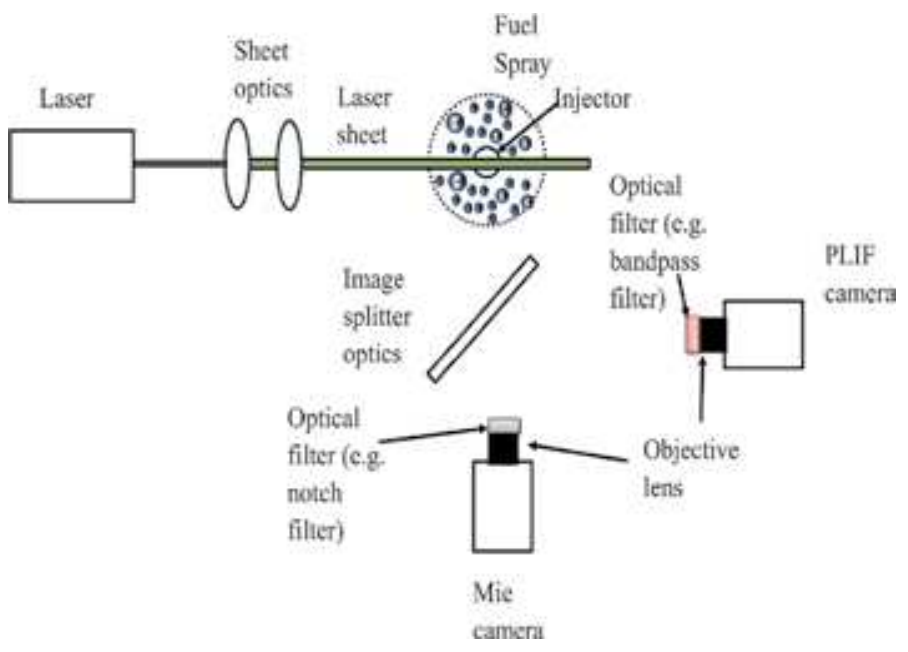

Figure 2.

Schematic representation of experimental setup for LSD measurements using simultaneous imaging of PLIF and Mie signals using two cameras.

characteristics do not change with time, steady spray $[43,44]$. This approach is used in the literature, and it is observed that results are consistent with SMD measurements from Phase Doppler Interferometry (PDI) [43-46].

Both simultaneous and sequential imaging have been widely used in the literature. However, it is necessary to compare the approaches with other independent drop-sizing techniques under a controlled environment to evaluate the reliability of the SMD measurements.

\section{Sources of error in the LSD measurements}

The Mie and PLIF signals suffer various losses due to interactions between spray droplets and the laser sheet. These losses affect signal-to-noise ratio (SNR) and the accuracy of the measurements. The losses can be categorized into three types, namely, laser extinction, signal attenuation, and multiple scattering. These sources of error in the LSD measurements are discussed in the following subsections.

\subsection{Laser extinction and signal attenuation}

The energy of the incident laser sheet is reduced as the laser sheet travels through the spray due to scattering by the droplets and as a part of the energy is absorbed by the droplets. This loss in the incident laser sheet reduces Mie and PLIF signals. The loss in the incident laser sheet due to scattering and the absorption by the medium is termed as laser sheet extinction loss $[5,18,50,51]$. The laser extinction loss is observed in both Mie and PLIF signals [18]. The contribution of laser sheet extinction can be different in Mie and PLIF signals which may lead to error in SMD measurements of the LSD technique. The laser extinction loss leads to asymmetry in the images [18]. Figure 3 shows SLIPI-PLIF image of an airblast spray for GLR of 4 when the laser sheet is traveling from left to right. It is expected that the spray is symmetrical about the spray axis [18]. However, a weak PLIF signal is observed on the right side due to loss in the incident laser sheet (laser extinction).

The PLIF and Mie signals travel from the plane of the laser sheet to the detector through ensembles of spray droplets. The spray droplets may absorb these signals 
Planar Drop-Sizing in Dense Fuel Sprays Using Advanced Laser Diagnostic Techniques DOI: http://dx.doi.org/10.5772/intechopen.90527

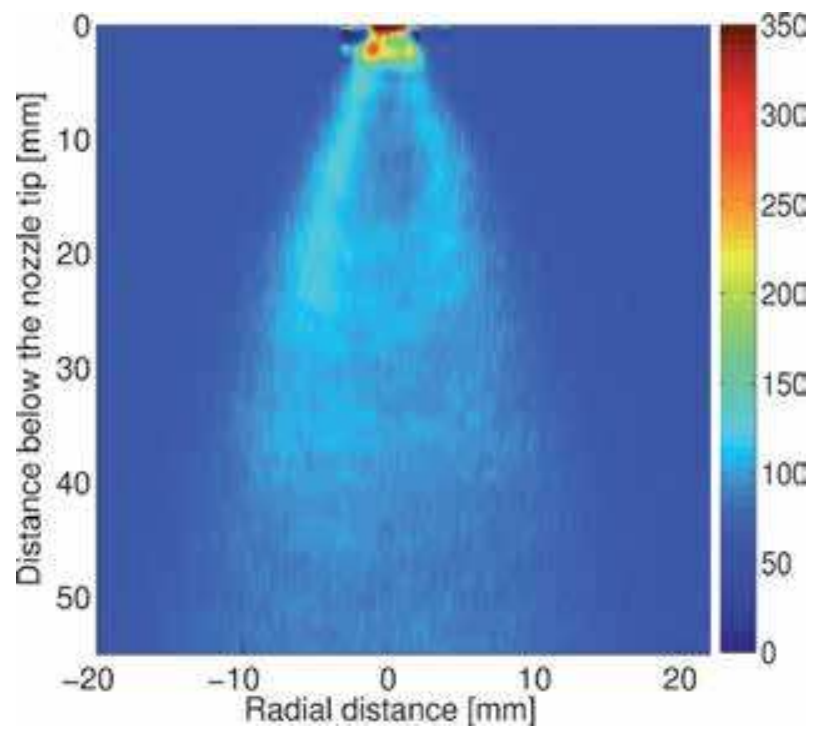

Figure 3.

Averaged SLIPI-PLIF signal in airblast spray at gas-to-liquid mass ratio (GLR) of 4 [49]. The intensity of signal is skewed due to various losses.

due to the overlapping of emission and absorption spectra of the liquid. This loss is termed as auto-absorption or self-absorption or re-absorption of the signal [52]. Auto-absorption is primarily observed in PLIF imaging. The laser sheet absorption and PLIF signal attenuation are mainly controlled by a dye concentration [52]. High dye concentration can increase the absorption and auto-absorption losses which will lead to deviations in $D^{3}$ proportionality [38].

\subsection{Multiple scattering}

The LSD technique assumes single scattering event of photons. However, many photons reaching the CCD camera are scattered more than once in a spray with high droplet number density. This phenomenon is referred to as multiple scattering or secondary emission. When a laser light interacts with a spray, a photon may follow

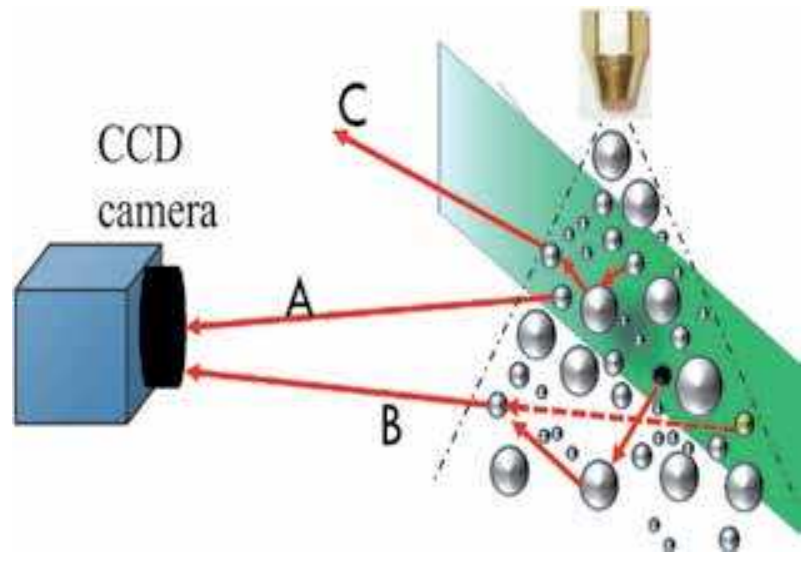

Figure 4 .

An illustration of possible scattering events in a spray with laser sheet imaging. (A) Single scattering event;

(B) multiple scattering that provides incorrect information about a droplet; (C) multiple scattering that results in the loss of the signals. 
several paths before it reaches a CCD camera. Figure 4 shows an illustration of possible scattering events in a spray with laser sheet imaging. Condition A explains a single scattering event. The laser light interacts with a droplet and reaches the CCD camera without interacting with any other droplet. This is the most ideal

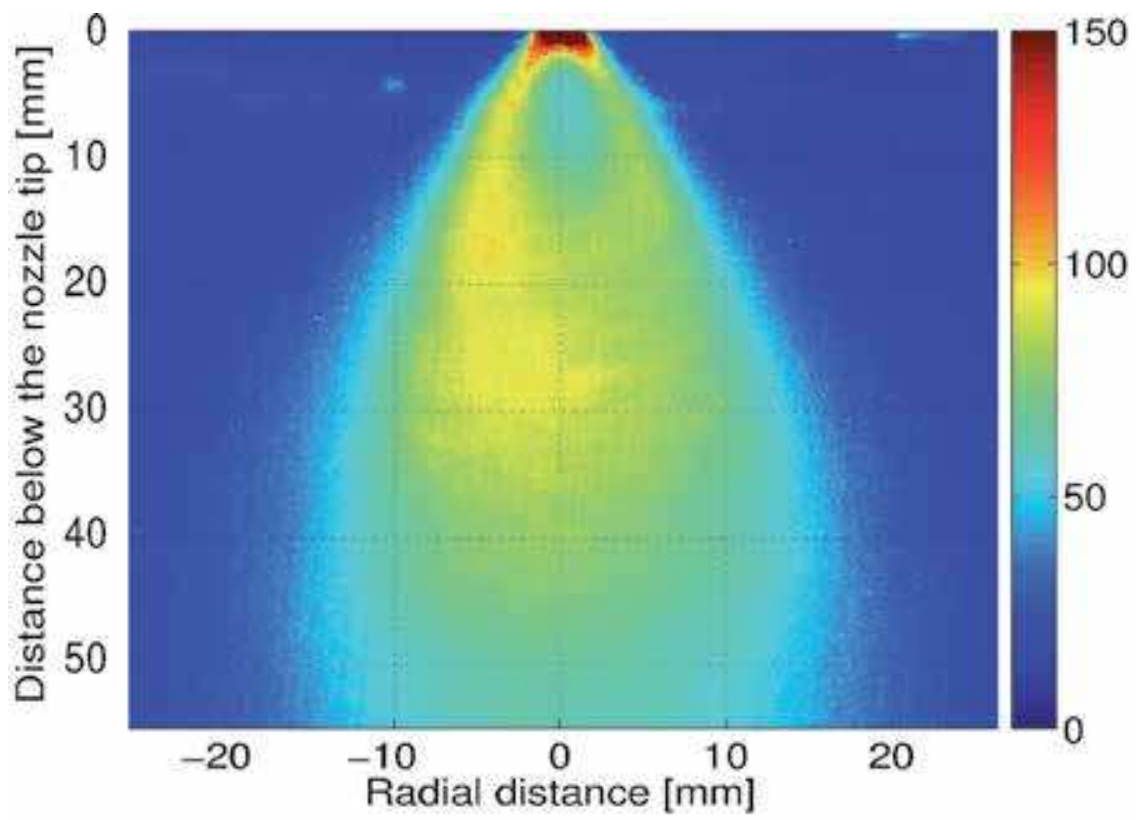

(a)

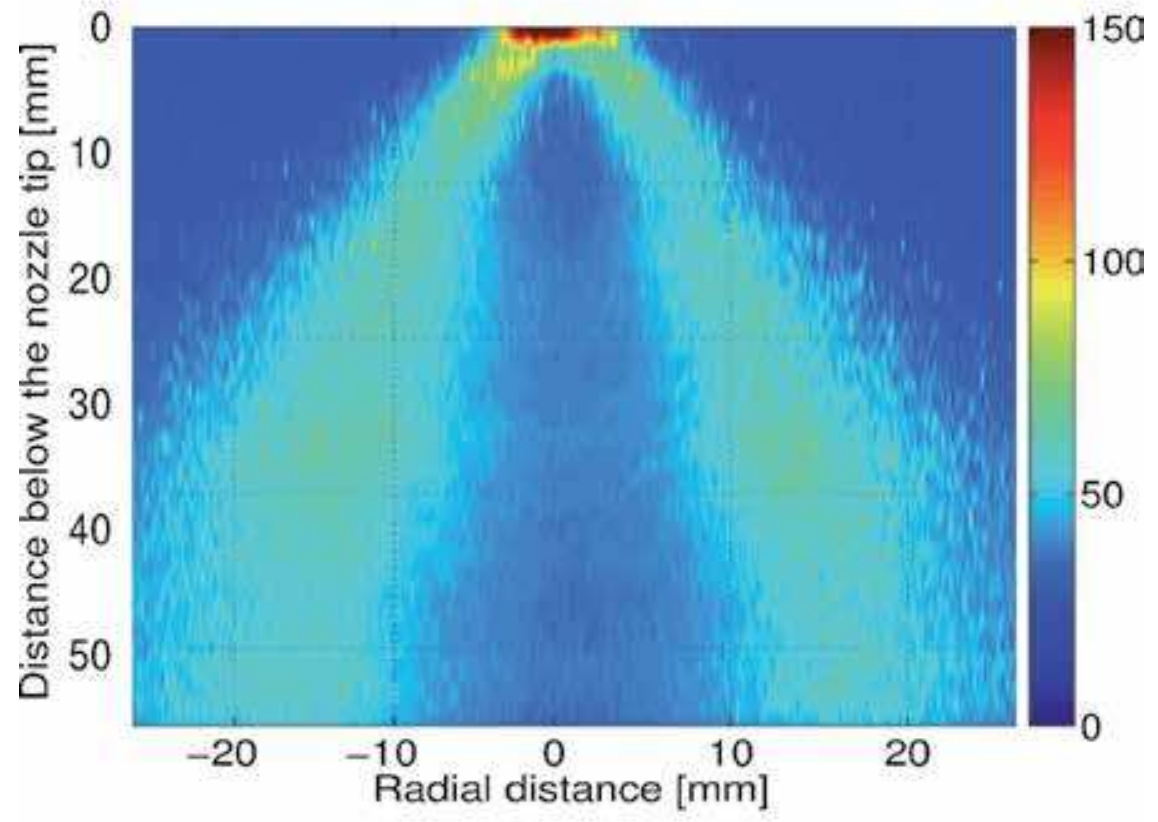

(b)

Figure 5.

A comparison of conventional and SLIPI-PLIF signals of airblast sprays at GLR 1. Conventional PLIF image shows a solid cone spray due to multiple scattering, whereas a hollow cone is observed in SLIPI-PLIF imaging [53]. The laser sheet travels from left to right. (a) Conventional PLIF signal. (b) SLIPI-PLIF signal. 
condition in the LSD measurement for reliable drop sizing. In Condition B, a photon starts traveling from a droplet illuminated with laser light. However, the photon interacts with several other droplets before its detection by the CCD camera sensor. This path causes misinterpretation of a false droplet (a yellow droplet with a dashed line). Condition $\mathrm{C}$ shows a path of a photon that interacted with a droplet; however, the photon is not recorded on the camera sensor leading to a loss in the signal. Conditions $\mathrm{B}$ and $\mathrm{C}$ are considered as multiple scattering, which may lead to error in the drop sizing of the LSD measurements. In the case of PLIF imaging, multiple scattered photons (path B) may induce additional errors due to absorption of the photon and reemission of the fluorescence signal. This suggests that the contribution of multiple scattering in Mie signal and PLIF signal may be different due to the absorption of the multiple scattering signal by the dye in the PLIF imaging. The unwanted multiple scattered photons lead to a blurred image or reduction in resolution of the image. Structured laser illumination planar imaging (SLIPI) technique is used to reduce multiple scattering in planar spray imaging. Conventional and SLIPI-PLIF signals of the airblast spray are compared for GLR 1 in Figure 5. The conventional imaging showed a solid cone spray as shown in Figure 5a. On the other hand, a hollow cone spray is observed in the SLIPI imaging (Figure 5b). The change in the spray geometry of the airblast spray was attributed to the presence of multiple scattering in the PLIF signal [53]. A similar observation was made by Linne [18]. It was observed that the conventional Mie image of a hollow cone spray shows the presence of liquid along the axis of the spray due to multiple scattering. Thus, the contribution of multiple scattering is significant in both Mie and PLIF signals [18].

Most of the LSD measurements neglect the contribution of the multiple scattering. Berrocal et al. [54-56] conducted Monte Carlo simulations to study the contribution of multiple scattering in a hollow cone spray with $\mathrm{OD}<1$, i.e., an optically dilute spray. It was reported that the contribution of multiple scattering is significantly high ( $\sim 76 \%)$, even in the optically dilute spray. Payri et al. [57] observed that LSD could be applied only at small particle concentrations where loss due to multiple scattering is low. At higher particle concentrations, loss due to multiple scattering is significant that reduces the accuracy of the LSD measurements. In few studies, it is assumed that the contribution of multiple scattering may be similar in Mie and PLIF signals, and it will be canceled while ratioing the signals. However, the contribution of multiple scattering may be different in Mie and PLIF signals. Mishra et al. [40] reported that multiple scattering has a significant impact on LSD technique even in optically dilute sprays $(O D \sim 1)$. Therefore, the contribution of multiple scattering may lead to unreliable drop-sizing measurements.

\section{Methods to reduce errors in the LSD measurements}

Many attempts have been made to compensate for the losses in the laser sheet imaging. Talley et al. [58] proposed a correction for laser extinction using counterpropagating laser sheets. Koh et al. [59] corrected signal attenuation using the geometric mean value of the intensities obtained using two cameras. The loss in the fluorescence signal due to auto-absorption of the fluorescence signal and absorption of the laser sheet can be corrected using Beer-Lambert law [52]. Abu-Gharbieh et al. [60] proposed a numerical approach to compensate for a loss in a laser sheet due to scattering. Brown et al. [61] attempted to reduce multiple scattering by scanning the spray with a narrow laser beam, instead of a laser sheet. They observed that the results were consistent with Phase Doppler Anemometry measurements. However, this method involves a long measurement time. A planar technique, structured laser 
illumination planar imaging (SLIPI), reduces the contribution of multiple scattering in a planar imaging [62-66]. The SLIPI technique reduces the effect of multiple scattering in Mie and PLIF imaging which can be used in dense sprays to get more accurate measurements of droplet diameter, spray structure, liquid volume fraction, and temperature $[62,63,66,67]$.

A spatially modulated laser sheet is used in the SLIPI technique to reduce multiple scattering in PLIF and Mie signals. The spatial modulation of the structured laser sheet is obtained by using a Ronchi grating. Three spatially modulated sub-images $\left(I_{1}, I_{2}\right.$, and $\left.I_{3}\right)$ are acquired at the period of one-third of the modulation [62-66]. The SLIPI image is calculated using modulated images with Eq. (6).

$$
I_{S L I P I}=\frac{\sqrt{2}}{3} \cdot\left[\left(I_{1}-I_{2}\right)^{2}+\left(I_{2}-I_{3}\right)^{2}+\left(I_{3}-I_{1}\right)^{2}\right]^{1 / 2}
$$

SLIPI signals require corrections for laser extinction and signal attenuation for reliable measurements. Various losses in the laser sheet and the signals pose difficulties in extracting reliable quantitative information from these techniques. Loss in Mie and PLIF signals due to scattering of the laser sheet can be compensated using Beer-Lambert law as explained by Abu-Gharbieh et al. [60]. Similarly, the loss in the fluorescence signal due to absorption of the laser sheet and auto-absorption of the fluorescence signal can be corrected using Beer-Lambert law [52]. Thus, the SLIPI signal needs to be corrected further for losses due to laser sheet extinction and signal attenuation. Recently, this methodology is used to improve LSD measurements in dense sprays. More details on the methodology can be found in $[53,68]$.

\section{Applications and limitations of the LSD technique}

The LSD technique is well established in the spray diagnostics. The method has been used in many spray systems, including fuel sprays that include ensembled SMD measurements and time-resolved SMD measurements. The LSD measurements have been performed using both simultaneous and sequential imaging of the Mie and PLIF signals. The various sprays are studied at evaporative and nonevaporative conditions using the LSD technique [36, 43, 44, 69-72].

Yeh et al. [31, 73, 74] developed LSD technique using simultaneous imaging of the Mie and PLIF signals of transient diesel sprays at non-evaporative conditions. Sankar et al. [32, 75] termed the technique as optical patternator and applied it to study the spray characteristics of continuous pressure atomizer. They compared SMD measurements from the LSD technique with PDPA measurement and found a good agreement. It was noted that the technique is ideal for dense spray applications compared to that of the PDPA. A similar observation was reported by Le Gal et al. [36]. In this study, the LSD was applied to study a small pressure-swirl spray and a full size industrial air-spray injector. The SMD measurements from the LSD technique were compared with PDPA measurements, and good agreement was observed. These studies employed simultaneous imaging of PLIF and Mie signals. Zelina et al. [43, 44] showed that LSD measurements could be performed by recording Mie and PLIF signals in a sequence for a steady-state continuous spray. The SMD distribution of a prefilming airblast atomizer was studied in this work. A good agreement between SMD measurements of LSD and PDPA measurements was observed with the sequential imaging. Jermy et al. further used sequential imaging of the Mie and PLIF signals [76] to study a dense cooling spray of water. Park et al. [77] argued that sequential imaging cannot be applied to the transient spray, as the images are not taken simultaneously. Hence, they used the simultaneous imaging 
approach to get the time-resolved SMD distribution of a swirl-type GDI spray. The $D^{3}$ and $D^{2}$ proportionality was verified using a droplet generator.

Domann et al. [30] performed planar SMD measurement in a spray generated by a pressure-swirl atomizer in a liquid-fueled burner at isothermal conditions. An assumption that the calibration constant is independent of a droplet diameter was analyzed. They found that the assumption was incorrect and can lead to sizing errors up to $30 \%$. The discrepancies between LSD and PDA measurements were observed in dilute spray regions. These discrepancies were attributed to the increased statistical uncertainty of the LSD measurements due to the limited sampling period. It was suggested to acquire a large number of Mie and PLIF images to get reliable drop sizing in dilute sprays. Zimmer and Ikeda [78] performed LSD measurements to study droplet clusters in an industrial gun-type burner. In this study, the calibration constant $(\mathrm{K})$ was calculated along a line in the image of the ratio of PLIF and Mie signals and PDA measurements, instead of calculating the $\mathrm{K}$ at a point. It was observed that the use of a single constant for calibration underestimates the small droplets. Stojkovic and Sick [79] reported relative SMD measurements of an automotive hollow-cone, transient spray of isooctane with bidirectional laser sheet illumination in a real engine cylinder head. LSD measurements were performed to study an air-assisted fuel injector in a constant volume chamber and an optical engine $[47,48]$. The sequential imaging approach has been adopted in these works. Mie and PLIF signals were over separate injection events to obtain transient development of the ensemble averaged spray. Anand et al. [42] reported time-resolved quantitative SMD distributions of PFI sprays from two-hole and fourhole plate-type injectors using the sequential imaging. In this work, calibration constant (K) was determined using granulometry with an accuracy of $\pm 20 \%$. Deshmukh and Ravikrishna [80] adopted the sequential imaging approach to study high-pressure transient diesel sprays of straight vegetable oils under high pressure conditions. In this work, $\mathrm{K}$ was calculated at the edge of the spray using PDIA technique. Kannaiyan et al. [6] performed simultaneous LSD measurements in liquid-centered swirl coaxial (LCSC) injector. They argued that the use of point measurement techniques such as PDI may be difficult to calculate $\mathrm{K}$, as exact mapping of a small measurement volume $(\sim 500 \mu \mathrm{m})$ in a LSD image of the pixel resolution of the order of micrometer is difficult. On the other hand, a measurement diameter of around $10 \mathrm{~mm}$ in a line-of-sight measurement technique will be easy for the calibration. They suggested the use of a line-of-sight measurement over point measurement for the calibration. The SMD measurements were compared with that from diffraction-based method, and good agreement was reported. They observed that the use of line-of-sight measurement technique was more reliable, which ensures exact mapping of the calibration location in the independent drop sizing and PLIF and Mie images. Most of the researchers used PLIF signal as a volume-dependent signal. Malarski et al. [35] suggested using Raman scattering signal as an alternative to the PLIF signal. However, a weak Raman signal leads to low signal-to-noise ratio (SNR), which might cause an error in LSD measurements, particularly in dilute sprays. Pastor et al. [46] compared the influence of natural fluorescence and doped fluorescence on LSD measurements. Natural fluorescence gives a weak PLIF signal that may lead to erroneous drop sizing in dilute sprays. Recently, Mishra et al. [81] demonstrated that the three-dimensional distribution of SMD can be obtained using SLIPI-LSD method. Koegl et al. [71] studied DISI multihole gasoline sprays of biofuels, ethanol, and butanol in a constant volume chamber using the SLIPI-LSD measurements. The measurements were carried out at reactive and engine-relevant conditions using simultaneous approach of the LSD measurements. They observed larger spray tip penetration and bigger droplet SMD in butanol sprays than those of ethanol sprays, which was attributed to reduced 
atomization in butanol sprays due to lower evaporation rate and higher surface tension and viscosity of butanol fuel. Kapusta [70] adopted simultaneous approach of LSD measurements to study SMD distributions of urea-water solution (UWS) sprays for after-treatment devices in diesel engines. SLIPI technique was used to mitigate multiple scattering in Mie and PLIF signals.

Overall, sequential and simultaneous imaging approaches are employed in many continuous and transient sprays. It is also possible to get time-resolved SMD measurements using sequential imaging. The LSD measurements are well established at non-evaporative conditions. At evaporative conditions, it is expected that the loss due to laser extinction, signal attenuation, and multiple scattering will be less important than that at non-evaporative conditions due to low droplet number density. However, extensive studies, e.g., studies on the effect of evaporation rate on the calibration constant and dye selection, etc., are required to establish LSD measurements in evaporative conditions.

\section{Summary}

Laser sheet drop sizing is an attractive technique that can be used in dense fuel sprays. The LSD technique provides planar SMD and liquid volume fraction distributions in a spray plane. However, the technique suffers from various sources of error due to multiple scattering, laser extinction due to scattering and absorption of the laser sheet, and auto-absorption of the PLIF signal. These sources may lead to significant errors in the LSD measurements, especially in dense sprays due to high droplet number density. Further, the contribution of the sources in Mie and PLIF signals might be different, which may lead to error in SMD measurements. Therefore, it is essential to reduce the contribution of these sources of error to obtain reliable planar SMD and liquid volume fraction distributions using the LSD technique in dense sprays.

\section{Acknowledgements}

The authors acknowledge the support from DST-SERB (Grant number: DST SB/S3/MMER/0028) for this work.

\section{Abbreviations}

CCD

Conv. LSD

GLR

ILIDS

$\mathrm{K}$

LSD

MDR

OD

PDA

PDI

PDIA

PDPA

PLIF

SLIPI charge-coupled device

conventional LSD measurements

gas-to-liquid mass ratio

interferometric laser imaging for droplet sizing

constant of proportionality in the LSD technique

laser sheet drop sizing

morphology-dependent resonances

optical depth (-)

Phase Doppler Anemometry

Phase Doppler Interferometry

Particle/Droplet Imaging Analysis

Phase Doppler Particle Analyzer

planar laser-induced fluorescence

structured laser illumination and planar imaging 
Planar Drop-Sizing in Dense Fuel Sprays Using Advanced Laser Diagnostic Techniques DOI: http://dx.doi.org/10.5772/intechopen.90527

$\begin{array}{ll}\text { SLIPI-LSD } & \text { SLIPI-LSD measurements } \\ \text { SMD } & \text { Sauter mean diameter } \\ \text { SNR } & \text { signal-to-noise ratio } \\ \Delta \mathrm{P} & \text { gauge pressure of the atomizing gas }(\mathrm{Pa}) \\ \lambda & \text { wavelength of illumination }(\mathrm{nm}) \\ I_{1}, I_{2} \text {, and } I_{3} & \text { SLIPI sub-images } \\ I_{f} & \text { fluorescence intensity } \\ I_{s} & \text { scattering intensity } \\ X_{m} & \text { Mie parameter }\end{array}$

\section{Author details}

Aniket P. Kulkarni* and D. Deshmukh

Spray and Combustion Laboratory, Discipline of Mechanical Engineering, Indian Institute of Technology Indore, Indore, India

*Address all correspondence to: aniketkulkarni1509@gmail.com

\section{IntechOpen}

(C) 2020 The Author(s). Licensee IntechOpen. Distributed under the terms of the Creative Commons Attribution - NonCommercial 4.0 License (https://creativecommons.org/ licenses/by-nc/4.0/), which permits use, distribution and reproduction for non-commercial purposes, provided the original is properly cited. (cc) BY-NC 


\section{References}

[1] Heywood JB. Internal Combustion Engine Fundamentals. New York, USA: McGraw-Hill Mechanical Engineering; 1988

[2] Lefebvre A. Atomization and Sprays. Boca Raton, FL: CRC Press; 1988

[3] Zhao H. Laser Diagnostics and Optical Measurement Techniques in Internal Combustion Engines. Warrendale, PA USA: SAE International; 2012

[4] Lefebvre A. Airblast atomization. Progress in Energy and Combustion Science. 1980;6:233-261

[5] Coghe A, Cossali GE. Quantitative optical techniques for dense sprays investigation: A survey. Optics and Lasers in Engineering. 2012;50(1):46-56

[6] Kannaiyan K, Banda MVK, Vaidyanathan A. Planar Sauter mean diameter measurements in liquid centered swirl coaxial injector using laser induced fluorescence, Mie scattering and laser diffraction techniques. Acta Astronautica. 2016;123: 257-270

[7] Tropea C. Optical particle characterization in flows. Annual Review of Fluid Mechanics. 2011;43: 399-426

[8] Anand TNC, Mohan AM, Ravikrishna RV. Spray characterization of gasoline-ethanol blends from a multihole port fuel injector. Fuel. 2012;102: 613-623

[9] Kashdan JT, Shrimpton JS, Whybrew A. A digital image analysis technique for quantitative characterisation of high-speed sprays. Optics and Lasers in Engineering. 2007; 45(1):106-115

[10] Kashdan JT, Shrimpton JS, Whybrew A. Two-phase flow characterization by automated digital image analysis. Part 2: Application of pdia for sizing sprays. Particle $\&$ Particle Systems Characterization. 2004;21(1):15-23

[11] Deshmukh D, Ravikrishna RV. Studies on microscopic structure of diesel sprays under atmospheric and high gas pressures. International Journal of Spray and Combustion Dynamics. 2014;6(2):199-220

[12] Kashdan JT, Shrimpton JS, Whybrew A. Two-phase flow characterization by automated digital image analysis. Part 1: Fundamental principles and calibration of the technique. Particle \& Particle Systems Characterization. 2003;20(6):387-397

[13] Manin J, Bardi M, Pickett LM, Dahms RN, Oefelein JC. Microscopic investigation of the atomization and mixing processes of diesel sprays injected into high pressure and temperature environments. Fuel. 2014; 134:531-543

[14] Crua C, De Sercey G, Heikal M, Gold M. Dropsizing of near-nozzle diesel and rme sprays by microscopic imaging. In: 2th Triennial International Conference on Liquid Atomization and Spray Systems. Germany: Heidelberg; 2012

[15] Crua C, Heikal MR, Gold MR. Microscopic imaging of the initial stage of diesel spray formation. Fuel. 2015; 157:140-150

[16] Kulkarni AP, Dhimole VK, Deshmukh D. Mean drop size measurements with LSD, PDIA and PDA techniques in an airblast spray. In: 19th Proc. of the Inst. For Liquid Atomization and Spray Systems Conf. (ILASS Asia, Jeju, Korea). Jeju, Korea: ILASS Asia; 2017

[17] Kulkarni AP, Deshmukh D. Spatial drop-sizing in airblast atomization- an 
experimental study. Atomization and Sprays. 2017;27(11):949-961

[18] Linne M. Imaging in the optically dense regions of a spray: A review of developing techniques. Progress in Energy and Combustion Science. 2013; 39(5):403-440

[19] Albrecht H-E, Damaschke N, Borys M, Tropea C. Laser Doppler and Phase Doppler Measurement Techniques. Heidelberg, Germany: Springer Science \& Business Media; 2013

[20] König G, Anders K, Frohn A. A new light-scattering technique to measure the diameter of periodically generated moving droplets. Journal of Aerosol Science. 1986;17(2):157-167

[21] Glover AR, Skippon SM, Boyle RD. Interferometric laser imaging for droplet sizing: A method for dropletsize measurement in sparse spray systems. Applied Optics. 1995;34(36): 8409-8421

[22] Damaschke N, Nobach H, Tropea C. Optical limits of particle concentration for multi-dimensional particle sizing techniques in fluid mechanics.

Experiments in Fluids. 2002;32(2):143-152

[23] Cecil F. Hess. Planar particle image analyzer. In: 9th Int. Symp. On Appl. Of Laser Tech. To Fluid Mech., Lisbon, Portugal: Springer, Berlin, Heidelberg; 1998

[24] Damaschke N, Nobach H, Nonn TI, Semidetnov N, Tropea C. Multidimensional particle sizing techniques. Experiments in Fluids. 2005;39(2): 336-350

[25] Sahu S. Experimental study of isothermal and evaporative sprays. Ph.D. thesis; 2011

[26] Chengxu T, Yin Z, Lin J, Bao F. A review of experimental techniques for measuring micro-to nano-particle-laden gas flows. Applied Sciences. 2017;7(2):120
[27] Domann R, Hardalupas Y. A study of parameters that influence the accuracy of the planar droplet sizing (PDS) technique. Particle \& Particle Systems Characterization. 2001;18(1):3-11

[28] Charalampous G, Hardalupas Y. Numerical evaluation of droplet sizing based on the ratio of fluorescent and scattered light intensities (LIF/MIE technique). Applied Optics. 2011;50(9): 1197-1209

[29] Charalampous G, Hardalupas Y. Method to reduce errors of droplet sizing based on the ratio of fluorescent and scattered light intensities (laserinduced fluorescence/Mie technique). Applied Optics. 2011;50(20):3622-3637

[30] Domann R, Hardalupas Y. Quantitative measurement of planar droplet Sauter mean diameter in sprays using planar droplet sizing. Particle \& Particle Systems Characterization. 2003; 20(3):209-218

[31] Kamimoto T. Diagnostics of transient sprays by means of laser sheet techniques. In: International Symposium COMODIA. Vol. 94. Yokohama, Japan: JSME; 1994. pp. 33-41

[32] Sankar SV, Maher KE, Robart DM, Bachalo WD. Rapid characterization of fuel atomizers using an optical patternator. In: ASME 1997 Turbo Asia Conference, Pages V001T05A001V001T05A001. Singapore: American Society of Mechanical Engineers; 1997

[33] Tayali NE, Bates CJ. Particle sizing techniques in multiphase flows: A review. Flow Measurement and Instrumentation. 1990;1(2):77-105

[34] Hovenac EA. Performance and operating envelope of imaging and scattering particle sizing instruments. Journal of Laser Applications. 1987;174: 1-13

[35] Malarski A, Schürer B, Schmitz I, Zigan L, Flügel A, Leipertz A. Laser 
sheet dropsizing based on twodimensional raman and Mie scattering. Applied Optics. 2009;48(10):1853-1860

[36] Le Gal P, Farrugia N, Greenhalgh DA. Laser sheet dropsizing of dense sprays. Optics \& Laser Technology. 1999;31(1):75-83

[37] Frackowiak B, Tropea C. Numerical analysis of diameter influence on droplet fluorescence. Applied Optics. 2010;49(12):2363-2370

[38] Greenhalgh DA. Laser imaging of fuel injection systems and combustors. Proceedings of the Institution of Mechanical Engineers, Part A: Journal of Power and Energy. 2000;214(4): 367-376

[39] Yeh CN. A fluorescense/scattering imaging technique for instantaneous 2-d measurement of particle size distribution in a transient spray. In: The Third International Congress on Optical Particle Sizing. Vol. 9. Yokohama, Japan; 1993. p. 9

[40] Mishra YN, Kristensson E, Berrocal E. Reliable LIF/Mie droplet sizing in sprays using structured laser illumination planar imaging. Optics Express. 2014;22(4):4480-4492

[41] Düwel I, Kunzelmann T, Schorr J, Schulz C, Wolfrum J. Application of fuel tracers with different volatilities for planar lif/Mie drop sizing in evaporating systems. ICLASS-Europe, Paper. 2003;9:3

[42] Anand CTN, Deshmukh D, Madan MA, Ravikrishna VR. Laserbased spatio-temporal characterisation of port fuel injection (PFI) sprays. International Journal of Spray and Combustion Dynamics. 2010;2(2): 125-149

[43] Joseph Z, Allan R, Subra S. Fuel injector characterization using laser diagnostics at atmospheric and elevated pressure. American Institute of Aeronautics and Astronautics. 1993;59:568
[44] Zelina J, Rodrigue A, Sankar S. Fuel injector characterization using laser diagnostics at atmospheric and elevated pressures. In: 36th AIAA Aerospace Sciences Meeting and Exhibit. Reno, NV, USA: AIAA; 1998. p. 148

[45] Pastor JV, Payri R, Araneo L, Manin J. Correction method for droplet sizing by laser-induced fluorescence in a controlled test situation. Optical Engineering. 2009;48(1):013601

[46] Pastor JV, Payri R, Salavert JM, Manin J. Evaluation of natural and tracer fluorescent emission methods for droplet size measurements in a diesel spray. International Journal of Automotive Technology. 2012;13(5):713-724

[47] Jin S-H, Brear M, Watson H, Brewster S. An experimental study of the spray from an air-assisted direct fuel injector. Proceedings of the Institution of Mechanical Engineers, Part D: Journal of Automobile Engineering. 2008; 222(10):1883-1894

[48] Boretti AA, Jin SH, Zakis G, Brear MJ, Attard W, Watson H, et al. Experimental and numerical study of an air assisted fuel injector for a d.i.s.i. engine. In SAE Technical Paper. SAE International, 04 2007. doi: 10.4271/ 2007-01-1415

[49] Kulkarni AP, Chaudhari VD, Bhadange SR, Deshmukh D. Planar drop-sizing and liquid volume fraction measurements of airblast spray in crossflow using slipi-based techniques. International Journal of Heat and Fluid Flow. 2019;80:108501

[50] Verbiezen K, Klein-Douwel RJH, Van Vliet AP, Donkerbroek AJ, Meerts WL, Dam NJ, et al. Attenuation corrections for in-cylinder no lif measurements in a heavy-duty diesel engine. Applied Physics B. 2006;83(1):155-166

[51] Cooper CS, Laurendeau NM.

Comparison of laser-induced and planar 
laser-induced fluorescence

measurements of nitric oxide in a highpressure, swirl-stabilized, spray flame.

Applied Physics B. 2000;70(6):903-910

[52] Pastor JV, Lopez JJ, Juliá JE, Benajes JV. Planar laser-induced fluorescence fuel concentration measurements in isothermal diesel sprays. Optics Express. 2002;10(7): 309-323

[53] Kulkarni AP, Deshmukh D. Planar liquid volume fraction measurements in air-blast sprays using slipi technique with numerical corrections. Applied Physics B. 2018;124(9):187

[54] Berrocal E, Meglinski I, Jermy M. New model for light propagation in highly inhomogeneous polydisperse turbid media with applications in spray diagnostics. Optics Express. 2005; 13(23):9181-9195

[55] Berrocal E, Sedarsky DL, Paciaroni ME, Meglinski IV, Linne MA. Laser light scattering in turbid media part i: Experimental and simulated results for the spatial intensity distribution. Optics Express. 2007; 15(17):10649-10665

[56] Berrocal E, Sedarsky DL, Paciaroni ME, Meglinski IV, Linne MA. Laser light scattering in turbid media part ii: Spatial and temporal analysis of individual scattering orders via Monte Carlo simulation. Optics Express. 2009; 17(16):13792-13809

[57] Araneo L, Payri R. Experimental quantification of the planar droplet sizing technique error for micro-metric mono-dispersed spherical particles. In: Proc. of the Inst. For Liquid Atomization and Spray Systems Conf. (Como Italy). Como Lake, Italy: ILASS Europe; 2008

[58] Talley D, Verdieck J, Lee S, McDonell V, Samuelsen G. Accounting for laser sheet extinction in applying
PLLIF to sprays. In: 34th Aerospace Sciences Meeting and Exhibit, Page 469. Reno, NV, USA: AIAA; 1996

[59] Koh H, Jeon J, Kim D, Yoon Y, Koo J-Y. Analysis of signal attenuation for quantification of a planar imaging technique. Measurement Science and Technology. 2003;14(10):18-29

[60] Abu-Gharbieh R, Persson JL, Försth M, Rosén A, Karlström A, Gustavsson T. Compensation method for attenuated planar laser images of optically dense sprays. Applied Optics. 2000;39(8):1260-1267

[61] Brown CT, McDonnell VG, Talley DG. Accounting for laser extinction, signal attenuation, and secondary emission while performing optical patternation in a single plane. In: Fifteenth Annual Conference on Liquid Atomization and Spray Systems, Madison, WI, USA. Madison,WI, USA: ILASS Americas; 2002

[62] Kristensson E. Structured laser illumination planar imaging: SLIPI applications for spray diagnostics. Ph.D. thesis. Lund: Lund University; 2012

[63] Berrocal E, Kristensson E, Richter M, Linne M, Aldén M. Application of structured illumination for multiple scattering suppression in planar laser imaging of dense sprays. Optics Express. 2008;16(22):17870-17881

[64] Berrocal E, Kristensson E, Hottenbach P, Aldén M, Grünefeld G. Quantitative imaging of a noncombusting diesel spray using structured laser illumination planar imaging. Applied Physics B. 2012; 109(4):683-694

[65] Kristensson E, Araneo L, Berrocal E, Manin J, Richter M, Aldén M, et al.

Analysis of multiple scattering suppression using structured laser illumination planar imaging in scattering and fluorescing media. Optics Express. 2011;19(14):13647-13663 
[66] Mishra YN. Droplet size, concentration, and temperature mapping in sprays using SLIPI-based techniques. Ph.D. Thesis; 2018

[67] Mishra YN, Nada FA, Polster S, Kristensson E, Berrocal E. Thermometry in aqueous solutions and sprays using two-color LIF and structured illumination. Optics Express. 2016; 24(5):4949-4963

[68] Kulkarni AP, Deshmukh D. Improvements in laser sheet dropsizing using numerical and experimental techniques. International Journal of Multiphase Flow. 2019;110:273-281

[69] Corber A, Rizk N, Chishty WA. Experimental and analytical characterization of alternative aviation fuel sprays under realistic operating conditions. Journal of Engineering for Gas Turbines and Power. 2019;141(6): 061022

[70] Kapusta ŁJ. LIF/Mie droplet sizing of water sprays from SCR system injector using structured illumination. In: 28th Proc. of the Inst. For Liquid Atomization and Spray Systems Conf. (ILASS Europe, Valencia, Spain). Valencia, Spain: ILASS Europe; 2017

[71] Koegl M, Mishra YN, Storch M, Conrad C, Berrocal E, Will S, et al. Analysis of ethanol and butanol directinjection spark-ignition sprays using two-phase structured laser illumination planar imaging droplet sizing. International Journal of Spray and Combustion Dynamics. 2018;11: 1756827718772496

[72] Kulkarni AP, Deshmukh D. Planar liquid volume fraction and smd distribution of Jatropha vegetable oil spray: Effect of ethanol blending and glr. Sādhanā. 2019;44(2):46

[73] Yeh CN, Kosaka H, Kamimoto T. Measurement of drop sizes in unsteady dense sprays, chapter 12 . In: Recent
Advances in Spray Combustion: Spray Atomization and Drop Burning Phenomena. Reston Vergina: AIAA; 1996. pp. 297-308

[74] Yeh CN. Fluorescence/scattering image technique for particle sizing in unsteady diesel spray. JSME Transaction (B). 1993;59:568

[75] Sankar SV, Maher KE, Robart DM, Bachalo WD. Rapid characterization of fuel atomizers using an optical patternator. Journal of Engineering for Gas Turbines and Power. 1999;121(3): 409-414

[76] Jermy MC, Greenhalgh DA. Planar dropsizing by elastic and fluorescence scattering in sprays too dense for phase Doppler measurement. Applied Physics B. 2000;71(5):703-710

[77] Park S, Cho H, Yoon I, Min K. Measurement of droplet size distribution of gasoline direct injection spray by droplet generator and planar image technique. Measurement Science and Technology. 2002;13(6):859

[78] Zimmer L, Ikeda Y. Planar droplet sizing for the characterization of droplet clusters in an industrial gun-type burner. Particle \& Particle Systems Characterization. 2003;20(3):199-208

[79] Stojkovic BD, Sick V. Evolution and impingement of an automotive fuel spray investigated with simultaneous Mie/LIF techniques. Applied Physics B. 2001;73(1):75-83

[80] Deshmukh D, Ravikrishna RV. A method for measurement of planar liquid volume fraction in dense sprays. Experimental Thermal and Fluid Science. 2013;46:254-258

[81] Mishra YN, Koegl M, Baderschneider K, Hofbeck B, Berrocal E, Conrad C, et al. 3d mapping of droplet Sauter mean diameter in sprays. Applied Optics. 2019;58(14): 3775-3783 


\title{
Some Methods to Prevent the
} Wear of Piston-Cylinder When Using Low Sulphur Fuel Oil (LSFO) for All Ships Sailing on Emission Control Areas (ECAs)

\author{
Tien Anh Tran
}

\begin{abstract}
The IMO (International Maritime Organization) of MARPOL 73/78, Regulations for the Prevention of Air Pollution from Ships, has been adopted and took effect from May 2005 and had significantly to the present. The increases in a number of ships are leading to a large of number of exhaust gas emission into the environment. It is main reason that the Annex VI, MARPOL 73/78 is extremely necessary to require the ships need to comply. Furthermore, the marine fuel is used mainly for marine diesel engine nowadays, heavy fuel oil with high sulphur content. However, the IMO's regulations show that from January 1, 2020, fuel oil that is used on board should have no more than $0.50 \%$ sulphur content in order to protect the environment. Its benefit will have positive effect to the environment. On another side, the diesel engine operation especially the corrosion phenomenon for all piston-cylinder components will have negative effect due to the use of low sulphur fuel oil (LSFO). This chapter concentrates on researching the above phenomenon and gives some methods to restrict the negative influence on using the kind of low sulphur fuel oil. The results are fundamental knowledge for all vessels to comply the regulations of MARPOL 73/78 while sailing on ECAs.
\end{abstract}

Keywords: low sulphur fuel oil, corrosion, piston-cylinder, MARPOL 73/78, diesel engine

\section{Introduction}

Marine engines are generally compression ignited two- and four-stroke diesel engines. From the environmental and economic point of view, the Specific Fuel Oil Consumption (SFOC, measures unit in gram fuel oil $/ \mathrm{kWh}$ ) of engine is one of the important factors that contribute to the energy efficiency of ships [1]. On the other hand, the other important factors are the emissions of other gases such as $\mathrm{NO}_{\mathrm{x}}, \mathrm{SO}_{\mathrm{x}}$ and PM (particulate matter). Some factors depend on the quality of fuel oil and some on the combustion process in the combustion chamber of the engines [2].

The sulphur content of heavy fuel oil is determined through the content of $\mathrm{SO}_{\mathrm{x}}$ into the exhaust gas from diesel engine combustion process. In the combustion chamber, the sulphur content of heavy fuel oil is being oxidised into the primary $\mathrm{SO}_{2}$. A much smaller 
portion, some $3-5 \%$ is further oxidised into $\mathrm{SO}_{3} . \mathrm{SO}_{2}$ and $\mathrm{SO}_{3}$ together are called $\mathrm{SO}_{\mathrm{x}}$. The lubrication oil cylinder contains substances to neutralise the sulphur thus preventing the damage caused by sulphuric acid in the engine. Only a very small portion of $\mathrm{SO}_{\mathrm{x}}$ is neutralised into calcium sulphate and is considered insignificant.

The exhaust gas emissions are often directly related to the impurities contained in fuels that are being used. The high level of sulphur oxides $\mathrm{SO}_{\mathrm{x}}$ and nitrogen oxides $\mathrm{NO}_{\mathrm{x}}$ is an inevitable result of using heavy fuel oil (HFO). Maximum emissions of these oxides are regulated by IMO (International Maritime Organization). The requirements for reducing $\mathrm{SO}_{\mathrm{x}}$ emissions in certain areas of navigation have resulted in using low sulphur fuel oils in diesel engine operation. The use of HFO with high sulphur contents become unacceptable after adopting the regulations brought by Annex VI of International Convention for the Prevention of Pollution from Ships (MARPOL 73/78) at some sensitive areas (emission control areasECAs), and after introducing the monitoring of emissions from ships in ECAs. The maximum sulphur content in fuel oil is regulated in European ECAs that amounts to $0.10 \%$ for ships in ports and all inland waterways across the European Union.

Following the new requirements relate to sulphur content emissions that forced into all ships when sailing in emission control areas (ECAs) on January 2015, namely that ships trading have to use the heavy fuel oil and marine diesel oil with a low sulphur content of no more than $0.10 \%$, do not, strictly speaking, alter the regulatory environment.

However, using low sulphur content fuel oil will cause some troubles for technical engine condition.

At the request of California Air Resources Board, following a series of problems that occurred on ship due to fuel switching after the introduction of regulations on using low sulphur fuel oils within 24 miles of the California coastline, a research was conducted from 2009 to 2010; according to the research findings indicated, the fuel switching causes [3]:

- Loss of propulsion and operation instability as the engine reduces speed to come to dead slow or slow astern, resulting in revolution per minute (rpm) fluctuations or stopping the engine, whereas the engine operation was stable at high rpm.

- Failures to start events, including difficulties in starting the engine or inability to start the engine due to low pressures in fuel systems, low viscosity of fuel, problems related to high-pressure fuel pump operation, fuel injection, leakage of oil in the fuel systems, and leakage of sealing rings.

- Inability to reach maximum speed, inability to reserve the engine Ahead/ Astern, most commonly due to pressure of fuel injection.

This chapter is based on the effects of using low sulphur fuel oil to engine operation. It is significant to give the method to restrict the negative forces to the engine technique condition when operation.

\section{Literature review}

\subsection{Marine diesel engine}

The diesel engine is an internal combustion engine in which the fuel ignition has been conducted into the combustion chamber at high temperature. 
The ignition process of diesel engine takes place in the combustion chamber. The operational principle of diesel engines is carried out throughout 4 cycles: suction-compression-ignition-exhaust.

The compression-ignition engine has the highest thermal efficiency (engine efficiency) of any practical internal or external combustion engine due to its high expansion ratio and inherent lean burn which enables heat dissipation by the excess air. The low-speed compression-ignition engines (as used in ships and other applications, where overall engine weight is relatively unimportant) can have a thermal efficiency that exceeds $50 \%$.

The compression-ignition engines are manufactured in two-stroke and fourstroke versions. They were originally used as more efficient replacement for stationary steam engines. Since the 1910s, they have been used in submarines and ships. The use of locomotives, trucks, heavy equipment and electricity generation plants followed later. The structure of marine diesel engine is described in Figure 1. The main marine diesel engine is a two-stroke diesel engine type with large size, slow speed, high power engine that installed on large size ship.

In the true diesel engine, only air is initially introduced into the combustion chamber. The air is then compressed with a compression ratio typically between 15:1 and 23:1. The high compression causes the temperature of the air to rise. At about the top of the compression stroke, fuel is injected directly into the compressed air in the combustion chamber. This may be into a (typically toroidal) void in the top of the piston or a pre-chamber depending upon the design of the engine. The fuel injector ensures that the fuel is broken down into small droplets, and that the fuel is distributed evenly. The heat of the compressed air vaporises fuel from the surface of the droplets. The vapour is then ignited by the heat from the compressed

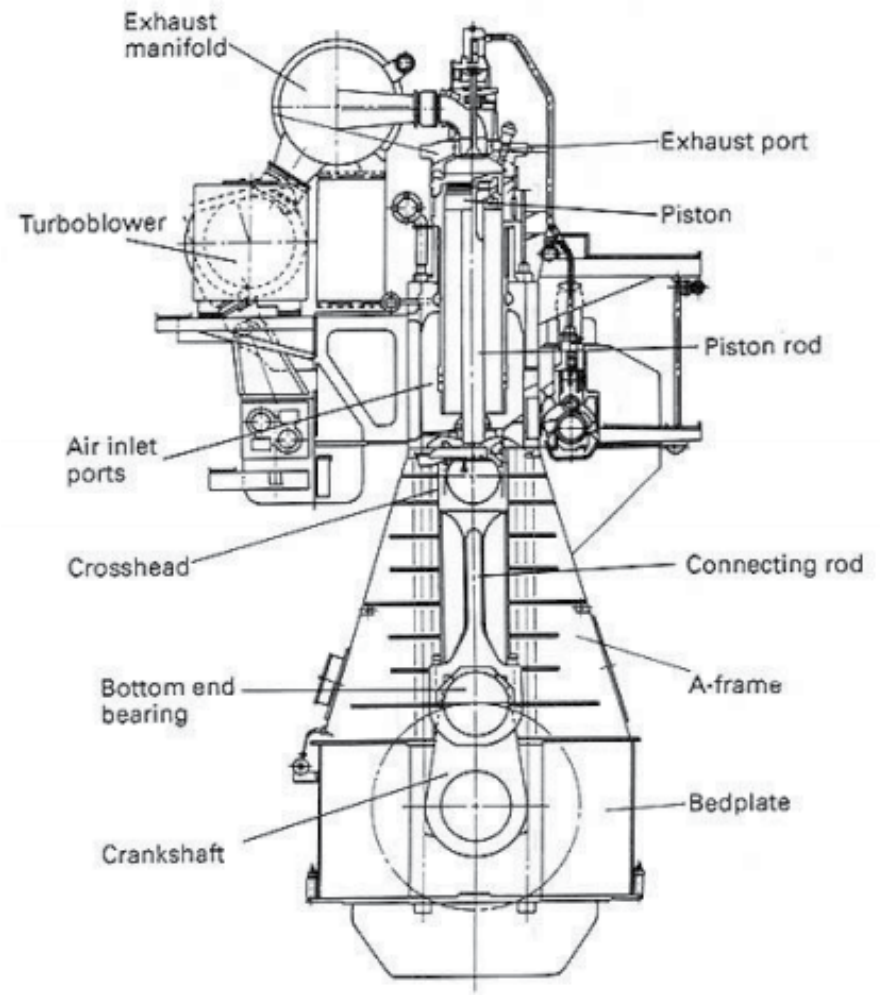

Figure 1.

The structure of diesel engine. 
air in the combustion chamber, the droplets continue to vaporise from their surfaces and burn, getting smaller, until all the fuel in the droplets has been burnt. Combustion occurs at a substantially constant pressure during the initial part of the power stroke. The start of vaporisation causes a delay before ignition and the characteristics diesel knocking sound as the vapour reaches ignition temperature and causes an abrupt increase in pressure above the piston (not shown on the P-V indicator diagram).

When the combustion process is complete, the combustion gases expand as the piston descends further, the high pressure in the cylinder drives the piston downward, supplying power to the crankshaft. The working cycle of two-stroke diesel engine has been described on P-V (pressure-volume) diagram in Figure 2.

As well as the high level of compression allowing combustion to take place without a separate ignition system, a high compression ratio greatly increases the engine's efficiency. Increasing the compression ratio in a spark-ignition engine where fuel and air are mixed before entry to the cylinders is limited by the need to prevent damaging pre-ignition. Since only air is compressed in a diesel engine and fuel is not introduced into the cylinder until shortly before top dead center (TDC), premature detonation is not a problem and compression ratios are much higher.

\subsection{Emission control areas}

The International Maritime Organization (IMO) member states acknowledged the low quality of heavy fuel oil in the field of connection with the high sulphur content of fuel on boards. Since the low quality of fuel oil will bring to producing exhaust gas fumes such as $\mathrm{SO}_{\mathrm{x}}$ that leads to acid rain phenomenon. So, it is main reason that the most straightway form of reducing acid rain effects is to life creatures due to change-over high sulphur content fuel oil to low sulphur content fuel oil at present.

MARPOL 73/78, Annex VI entered into force on May 19, 2005. Regulations 14 and 18 define the method of controlling sulphur oxide $\left(\mathrm{SO}_{\mathrm{x}}\right)$ emissions on a global basis and in defined protected areas called sulphur emission control areas (SECAs or ECAs).

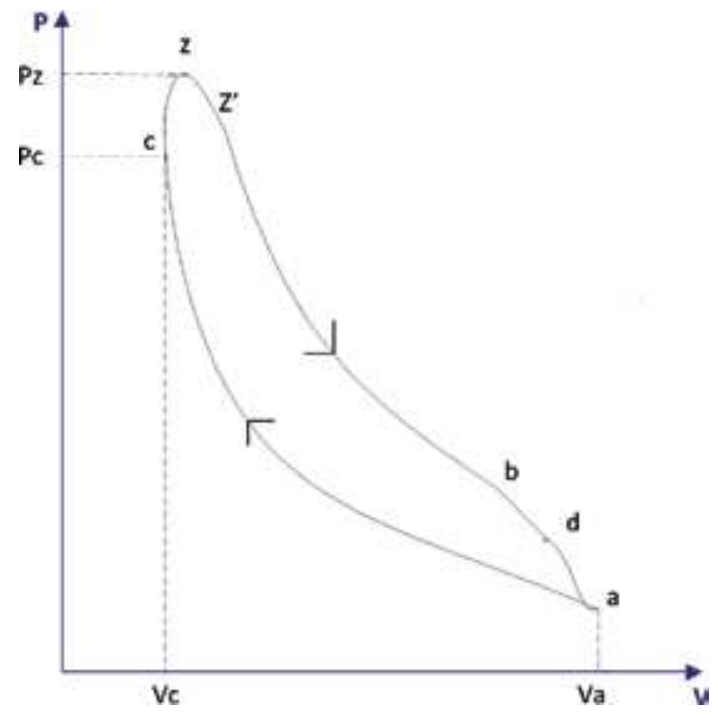

Figure 2.

$P$-V diagram of 2-stroke diesel engine. 
The aim of the legislation is to reduce $\mathrm{SO}_{\mathrm{x}}$ emissions from ships to reduce the acidification of the atmosphere and the resulting acid rain. This is to be achieved by setting a limit on the sulphur content in marine fuels.

Marpol Annex VI, Regulation 14 requires the following:

- A limit on the sulphur content on any fuel used onboard ship, this must not exceed 4.5\% m/m until January 1, 2012 (currently 3.5\% max sulphur).

- The sulphur content on any fuel used onboard a ship operating in a SECA must not exceed $1.5 \% \mathrm{~m} / \mathrm{m}$.

- Alternatively, an exhaust gas cleaning system or other approved technological method of reducing total $\mathrm{SO}_{\mathrm{x}}$ emissions from main and auxiliary engines and boilers to a maximum of $6.0 \mathrm{~g} \mathrm{SO}_{\mathrm{x}} / \mathrm{kWh}$ when operating in a SECA. Controls are also set on effluent discharges from such cleaning systems.

- Details of the change-over operation from high sulphur fuel to low sulphur fuel when entering a SECA are to be recorded in a log book and also when changing over to high sulphur fuel when leaving a SECA for an uncontrolled area. The procedure is to ensure that all fuels exceeding the $1.5 \%$ sulphur limit are flushed out of the fuel system prior to entering a SECA.

Marpol Annex VI, Regulation 18 establishes requirements for the quality, sampling and delivery of fuel oil and the keeping of bunker deliver note records.

On the other hand, Annex VI regulations include caps on sulphur content of fuel oil when ships sail on ECAs with the $\mathrm{SO}_{\mathrm{x}}$ emissions and indirectly, $\mathrm{PM}$ emissions. Special fuel quality provisions exist for $\mathrm{SO}_{\mathrm{x}}$ emission control areas $\left(\mathrm{SO}_{\mathrm{x}} \mathrm{ECA}\right.$ or SECA). The sulphur limits and implementation dates are listed in Table 1 and illustrated in Figure 3.

Heavy fuel oil (HFO) is used popularly but this fuel needs to meet the requirements of MARPOL 83/78 when sailing on ECAs. In addition, the alternative measures are also allowed (in the $\mathrm{SO}_{\mathrm{x}}$ ECAs and global) to reduce sulphur emissions, such as through the use of scrubbers.

Especially, the Marine Environment Protection Committee, session 69th (MEPC 69) on April 18-22, 2016 has adopted the limit of low sulphur content fuel oil used for marine engines through Table 1 and Figure 3. The MEPC 69 has supplied some contents such as mandatory system for collecting ships' fuel consumption data, reduction of Greenhouse Gas (GHG) emissions from ships, the establishment of effective dates for the Baltic Sea Special Area, the implementation of the BWM (Ballast Water Management) Convention, the energy efficiency of international

\begin{tabular}{|c|c|c|}
\hline \multirow[t]{2}{*}{ Date } & \multicolumn{2}{|c|}{ Sulphur limit in fuel $(\% \mathrm{~m} / \mathrm{m})$} \\
\hline & $\mathrm{SO}_{\mathrm{x}} \mathrm{ECA}(\%)$ & Global (\%) \\
\hline 2000 & 1.5 & 4.5 \\
\hline 2010.07 & 1.0 & \\
\hline 2012 & & 3.5 \\
\hline 2015 & 0.1 & \\
\hline 2020 & & 0.5 \\
\hline
\end{tabular}

Table 1.

Marpol annex VI fuel sulphur limits [4]. 


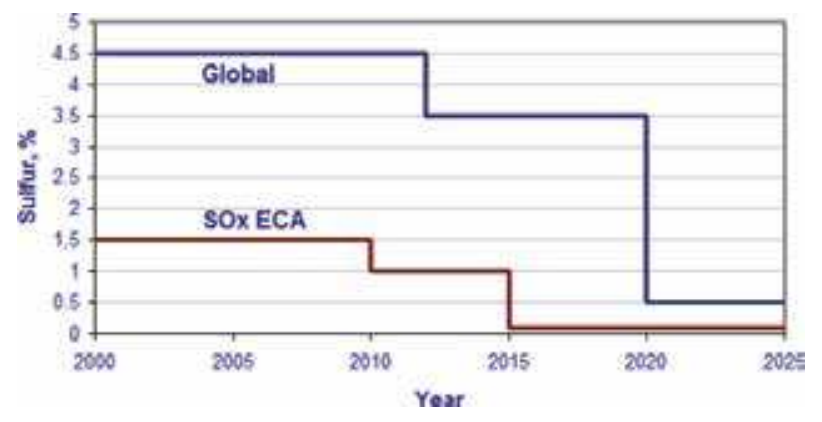

Figure 3.

Marpol annex VI sulphur content limit [4].

shipping, etc. [5]. In where, the fuel oil quality was concerned more since the cost of ship operation will be increased due to the requirement of high quality fuel oil. The low sulphur content fuel oil will be regulated detail in MEPC 69. Following that, to 2020 global sulphur cap implementation date decided in aims with sea environmental protection and human health. Due to, January 1st 2020 was confirmed as the implementation data for a significant reduction in the sulphur content fuel oil used on ships. In addition, the decision about limit of a global sulphur cap of $0.50 \% \mathrm{~m} / \mathrm{m}$ (mass $/ \mathrm{mass}$ ) in 2020 will be applied to all ships. Following discussion, the Committee encouraged the fuel oil supply industry to develop the draft best practice for fuel oil providers and submit this best practice to the Committee for consideration at a future session.

The date of 2020 was agreed in amendments adopted in 2008. In then, those amendments were adopted. If it was also agreed that a review should be carried out by 2018 in order to assess whether the sufficient compliant fuel oil would be available to meet the 2020. On the other hand, the review completed in 2016 and submitted to the Marine Environment Protection Committee, session 70th (MEPC 70 ) organised in London. So, the new global limit about sulphur content in fuel oil of no more than $0.50 \% \mathrm{~m} / \mathrm{m}$ in 2020 . It is contrasting the current limit of $3.50 \%$ applied from January 1, 2012 [6].

\subsection{MARPOL 73/78, Annex VI (Regulation 14)}

The following IMO's regulations about the International Convention for the Prevention of Pollution from Ships, 1974 as modified by the Protocol of 1978 (MARPOL 73/78) is one of the most important international marine environmental conventions. This convention was developed by the International Maritime Organization (IMO) with a lot of delegates from different country where the diversity of ships and nation's border lies on the sea.

$\mathrm{SO}_{\mathrm{x}}$ and particular matter (PM) emission controls are applied to all fuel oil, combustion equipment and devices due to both of main engine and auxiliary engine together generate the harmful gas emission in where contain a lot of other elements not only above ones but also carbon dioxide, nitrogen oxide, etc.

Among the $\mathrm{SO}_{\mathrm{x}}$ controls, the level of sulphur content must be controlled in fuel oil varies for designated emission control area (ECA). The existing controls are in Table 2.

Under the provisions of MARPOL 73/78, Annex VI, Regulation 14, the availability of fuel oil to meet the global $0.50 \%$ sulphur content in fuel oil used. It is determined by the Committee in 2018. Moreover, a Steering Committee (regionally represented by Member States) began reviewing of the availability of $0.50 \%$ 
sulphur fuel oil under terms of reference agreed at MEPC 68 with a report submitted to MEPC 70 held in October 2016 [7].

During the period of session time of MEPC 60 has been held from March 22 to 26,2010 , a lot of views were given out by delegates, a proposal has been adopted to amend the MARPOL Convention by designating the areas within 200 nautical miles from the coasts of North America and Canada (excluding a part of the areas such as the West Coast of Alaska) as the North American Emission Control Area for controlling the emissions of $\mathrm{NO}_{\mathrm{x}}, \mathrm{SO}_{\mathrm{x}}$ and $\mathrm{PM}$ (particulate matter) from August 1, 2012 (see Figure 4).

Besides that, IMO (International Maritime Organization) also has given out the latest emission control regulations about the limit of $\mathrm{SO}_{\mathrm{x}}$ content exhaust gas emission next time. Annex VI, MARPOL 73/78, Regulations for the Prevention of Air Pollution from Ships, has been applied since May 2005.

The emission control areas (ECAs) are the Baltic Sea, North Sea and English Channel, possibly Mediterranean in August 2007, 200 nautical mile zone at the US coast; Californian Air Resources Board (CARB), it is 24 nautical miles of the Californian baseline.

Thus, the sulphur oxides $\left(\mathrm{SO}_{\mathrm{x}}\right)$ limit applies to all vessels in the category of ships with an engine power output of more than $130 \mathrm{~kW}$. In the regulation 13 of Annex VI, MARPOL 73/78 has indicated that $\mathrm{NO}_{\mathrm{x}}$ emission control requirements for all ships installed $130 \mathrm{~kW}$ engine. So, the $\mathrm{SO}_{\mathrm{x}}$ emission control must be complied.

The international general limit on sulphur is reduced from $5 \%$ to $4.5 \%$ through the ISO 8217 fuel standard. International Maritime Organization has specified that in the future, this limitation will be imposed on $\mathrm{SO}_{\mathrm{x}}$ as well as the other components into exhaust gas.

\begin{tabular}{lcc}
\hline Effective date & $\begin{array}{c}\text { Area other than designated emission } \\
\text { control area }\end{array}$ & $\begin{array}{c}\text { Designated emission control } \\
\text { area }\end{array}$ \\
\hline Before 1 July 2010 & $4.50 \%$ & $1.50 \%$ \\
\hline On and after 1 July 2010 & $\downarrow$ & $1.00 \%$ \\
\hline On and after 1 January 2012 & $3.50 \%$ & $\downarrow$ \\
\hline On and after 1 January 2015 & $\downarrow$ & $0.10 \%$ \\
\hline On and after 1 January & $0.50 \%$ & $\downarrow$ \\
2020 & & \\
\hline
\end{tabular}

Table 2.

Controls on the concentration of sulphur content in fuel oil.
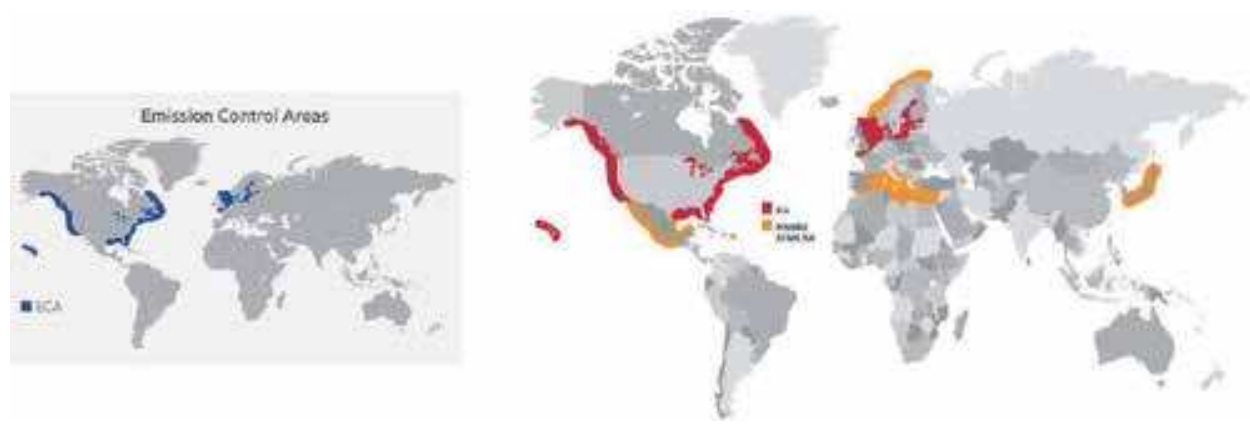

Figure 4.

The emission control area (ECA). 
Today, ECAs comprise the Baltic Sea, the English Channel and the North Sea, however, more areas will be added to these in the future.

California Air Resources Board (CARB) has introduced limits on the use of sulphur for distillates [8].

Ports in the European Union Area (European Union-EU) includes EU member states, Norway, the Faroe Islands and Iceland applied the regulations about using the low sulphur content in shipping transportation industries.

In addition, Ports in Turkey include Istanbul \& Marmara, Aegean, Mediterranean and Black Sea Regions also admit the limit of sulphur content fuel oil in the emission control areas (ECAs).

\subsection{Low sulphur fuel oil}

The sulphur content of marine fuel depends on the crude oil fuel and the refining process. In the combustion process of the engine, sulphur contains into the fuel, mixed with oxide after that converted into the sulphur oxides. These oxides are corrosive to engine piston liner and must be neutralised by the cylinder lubricant. If the correct lubricant is used, the sulphur content of marine fuels is technically not important, but sulphur oxides do have environmental implications. Fuel is the specification of ISO 8217:2010 that is not necessary for compliance with the regulations in force at the vessel's location. IMO sets the limitation regarding the sulphur content of any fuel oil used on board ships. However, the low sulphur content fuel oil may have a negative impact on different fuel properties depending on the fuel type. Table 3 shows the relation between fuel properties and fuel types.

The types of marine fuel are being used on vessels in order to meet the requirements of MARPOL 73/78 Annex VI about low sulphur content fuel oil limit including marine gas oil (MGO) and marine diesel oil (MDO). In where, the MGO includes DMA, DMX, and DMZ grade. The MDO has DMB grade according to ISO 8217. Especially, the ultralow sulphur fuel oil (ULSFO) is a new fuel type with sulphur content of no more $0.10 \%(\mathrm{~m} / \mathrm{m})$. It is not traditional distillates, but blended products are from refinery streams that have not previously been utilised extensively in marine fuel oils [9]. These main properties of fuels above are introduced in Table 4.

The characteristics of ultralow sulphur fuel oil (ULSFO) differ completely compared with types of fuel MGO and MDO [11]. There are some other characteristics of fuel oil but in Table 4 only uses the main characteristics include the sulphur content, viscosity at $40^{\circ} \mathrm{C}$, and flash point of fuel oil. In reality, the ultralow sulphur fuel oil is suitable to use low sulphur fuel oil for vessels with advantageous characteristics.

\subsection{Procedures of change-over HSFO to LSFO for main engine}

Emission control areas (ECAs) are designed at sea in order to follow the MARPOL 73/78 regulations about reducing of $\mathrm{SO}_{\mathrm{x}}$ and $\mathrm{NO}_{\mathrm{x}}$ emissions. In this researching, the article is referred to $\mathrm{SO}_{\mathrm{x}}$ emission into the environment by ships due to using the high sulphur content of heavy fuel oil for equipment.

Some local laws regarding air pollution are more stringent than those laid down by the IMO. For example, in Europe while the ship is at the port, all the running of machinery consumes the type of fuel oil must be less than $0.10 \%$ sulphur content.

As the $\mathrm{SO}_{\mathrm{x}}$ emission is purely dependent on the quality and sulphur content of the fuel, while entering emission control areas. It is required to change-over for a 
Some Methods to Prevent the Wear of Piston-Cylinder When Using Low Sulphur Fuel Oil... DOI: http://dx.doi.org/10.5772/intechopen.89400

\begin{tabular}{ll}
\hline Fuel properties & Fuel types \\
\hline Low viscosity & $\mathrm{MDO}$ \\
\hline Lubricity & $\mathrm{MGO} / \mathrm{MDO}$ \\
\hline Acidity & $\mathrm{MGO} / \mathrm{MDO} / \mathrm{HFO}$ \\
\hline Flash point & $\mathrm{HGO} / \mathrm{MDO} / \mathrm{HFO}$ \\
\hline Ignition and combustion quality & $\mathrm{HFO}$ \\
\hline Increased catalytic fines & $\mathrm{HFO}$ \\
\hline
\end{tabular}

Table 3.

Relation between the fuel properties and fuel types.

\begin{tabular}{lccccc}
\hline Grade & \multicolumn{3}{c}{ MGO } & MDO & ULSFO \\
\cline { 2 - 5 } & DMX & DMA & DMZ & DMB & \\
\hline Sulphur content $\%(\mathrm{~m} / \mathrm{m})$ & $\max .1 .00$ & $\max .1 .50$ & $\max .1 .50$ & $\max .2 .00$ & $\max .0 .10$ \\
\hline Viscosity at $40^{\circ} \mathrm{C}(\mathrm{cSt})$ & $\min 1.40$ & $\min .1 .50$ & $\min .3 .00$ & $\max .11 .0$ & $\min .40$ \\
& $\max 5.50$ & $\max 6.00$ & $\max .6 .00$ & & $\max .75$ \\
\hline Flash point $\left({ }^{\circ} \mathrm{C}\right)$ & $\min .43$ & $\min .60$ & $\min .60$ & $\min .60$ & $\min .70$ \\
\hline
\end{tabular}

Table 4.

Main properties of fuel oil defined in ISO 8217 (2010) [10].

low sulphur content fuel oil including flushing of fuel from the system with sulphur content more than $1.0 \%$ sulphur before entering the emission control areas (ECAs).

For the changing-over to low sulphur fuel oil for main engine is carried out under supervising of Chief Engineer. To consider that most of the ships today run at high sulphur fuel oil, changing over of fuel at the appropriate time is very important. Moreover, looking at today's economic condition of the industry, it s imperative to change over the fuel from high to low sulphur at the correct time as an early change-over will lead to loss of low sulphur oil, which is quite expensive, whereas a delay in the changeover procedure will lead to violation of MARPOL Annex VI. This is to be done along with using other technologies to reduce $\mathrm{SO}_{\mathrm{x}}$ and $\mathrm{NO}_{\mathrm{x}}$ from ships.

Almost all ships are usually installed one service tank and more setting tanks. The changing-over of fuel is conducted between tanks each other on ships. So, the mixture of two different grades of fuel oils will be happened in order to decrease the low sulphur content of fuel oil on ships nowadays [12].

On the other hand, it is provided with changing-over to low sulphur fuel oil calculator which tells the correct changing-over time at a certain case that before entering an emission control areas (ECAs). This system requires some important factors [3]:

- The sulphur content of high sulphur fuel currently in the system;

- The sulphur content of low sulphur fuel;

- The fuel capacities of the main engine system including setting tank, service tank, main engine piping and transfer piping from service tank to main engine;

- The capacity of transfer equipment-fuel oil transfers pump and fuel oil separators. 
Once the change-over time is computed which also accounts for the time of intermixing of two different sulphur grades oil (let us suppose $48 \mathrm{~h}$ ) following action are to be taken $48 \mathrm{~h}$ prior.

- Ensure that no transfer of high sulphur fuel is carried out any further to settling tank;

- Ensure that the low sulphur bunker tank steam is open for transfer and purification of fuel should not have any problem;

- If two separate settling tanks are present, once can be dedicated to low sulphur oil which will reduce the changeover period;

- Keep running the separator till the settling tank level reaches minimum;

- If filling of service tank with HSFO increases the calculated time period of changeover then stop the separator and drain the settling tank;

- Settling tank can be first drained into fuel oil overflow tank, and then the oil drained can be transferred to bunkers tanks containing same grade of oil;

- Once the settling tank is drained from heavy sulphur oil, fill the settling tank with low sulphur fuel oil via transfer pump;

- As the separator are stopped, service tank oil will be consumed by main engine system;

- Remember not to lower the level of service tank below which the fuel pumps cannot take suction;

- Start separators from settling to service tank which be now filling low sulphur fuel oil;

- Fill the low sulphur fuel oil into settling tank and service tank as per quantity required to cross the ECA calculated by the Chief Engineer as per the voyage plan.

\section{Impacts on piston-cylinder of main engine using LSFO}

\subsection{Impact of high sulphur content fuel oil on ship operation}

Firstly, to understand the effects of using low sulphur fuel oil to piston-cylinder liner component, need to regime of high sulphur content of fuel oil on ship operations [9].

The greatest environmental problem of maritime transport is heavy fuel oil (HFO) with high value of sulphur content and used popularly for diesel engine. Merchant vessels consume the heavy fuel for the marine engines and auxiliary engines in order to generate the energy for ship propulsion and electricity, respectively, on board. On the other hand, the unwanted properties elements like as incombustible transition metals, polycyclic aromatic hydrocarbons and sulphur also exist in heavy fuel oil which are residual oil from petroleum refining process to produce the marine diesel oil (MDO), marine gas oil (MGO) and other distillate oil. 
The unwanted properties make HFO price cheaper than distillate fuel oil. Intermediate Fuel Oil (IFO) 380 is the most commonly used for ocean-going vessels. Nowadays, some ships usually carry out bunkering oil in Singapore, China, Netherland, etc. In reality, the price of fuel oil at some places is different. For example, the price of IFO 380 is $\$ 311.50 /$ tonne in then the price of DO is $\$ 487.00$ / tonne in port of Singapore in the year 2017. Port of Rotterdam, the price of IFO 380 is $\$ 282.00 /$ tonne, DO is $\$ 460.00 /$ tonne in the year 2017 [13]. The cheaper price of $\mathrm{HFO}$ is an advantage for ship operators to lower fuel costs considering incremental fuel costs if the engine consumes distilled products. It is the main reason why HFO is used by most ocean going ships. In fact, fuel costs are a dominant proportion of voyage costs accounting for $47 \%$, while voyage costs contribute roughly $40 \%$ of the total operational costs [14]. Consequently, the fuel costs is the most important factor in the voyage costs which should be maintained as low as possible, otherwise it will bring negative effects on the total operational costs.

Nevertheless, HFO entails several drawbacks in shipping operation. For example, the heavy fuel oil must be heated before injected into the engine combustion chamber with the temperature approximately $140^{\circ} \mathrm{C}$ because of its viscous. Besides that it is necessary to equip the sludge tanks to accommodate the sludge of $\mathrm{HFO}$ which cannot be burnt during combustion process of engine and it must be moved on shore. The methods which are treated include as burning into an incinerator on ship or transferred to the reception facilities. So, the exhaust fumes are released from the combustion process using HFO in diesel engines which is vastly more harmful to human health and life environment.

Until now, marine low speed engines and their lubricants have been optimised for operation on heavy fuel oil (HFO) with a high sulphur S content. During the combustion process is happening, the sulphur $\mathrm{S}$ is converted to the sulphur trioxide $\left(\mathrm{SO}_{3}\right)$. In combination with water from the combustion and the scavenge air, $\mathrm{SO}_{3}$ forms sulphuric acid $\left(\mathrm{H}_{2} \mathrm{SO}_{4}\right)$ is be generated.

When the liner temperature drops below the dew point of sulphuric acid and water, a corrosive on the liner wall. The high alkaline lubricants (high-BN oils) neutralise the acid and prevent corrosion of piston rings and cylinder liner surfaces.

\subsection{Impact of low sulphur content on engine operation}

Secondly, when operating on fuels with less than $0.10 \% \mathrm{~S}$, such as distillates, ultra-low sulphur fuel oil (ULSFO) with less than $0.10 \% \mathrm{~S}$, LNG, methanol, ethane and LPG, only small amounts of sulphuric acid are formed in the combustion chamber. The cylinder lube oil additives are then not used for the designed purpose and they tend to build up as deposits. These deposits may disturb the lube oil film and obstruct the piston ring movement, which could lead to micro-seizures on the piston rings and liner and increase the risk of scuffing. Deposit formation and the total lack of corrosion increase the risk of bore-polishing, which could also lead to increased wear and scuffing. For engines operating continuously on fuels with less than $0.10 \% \mathrm{~S}$.

\subsection{Impact of emission control area (ECA) on the ship operation}

Emission control area (ECA) has been adopted by IMO members, the countries need follow the IMO's regulations about using low sulphur content fuel oil from now until 2020.

The availability of low sulphur fuel oil is a major issue in ECA implementation. For this purpose, EPA (Environmental Protection Agency) confirms LSFO under $1 \%$ available within the US ECA [15]. Therefore, Canada should also be able 
to provide adequate LSFO in the ports in its territorial waters. Since the scheme requires more stringent control of sulphur content in fuel to $0.10 \%$ from 2015 , due to the fuel consumption is the greatest problem for all ships and ship owners under pressure of high fuel price nowadays (Figure 5). Table 5 describes the cost of $\mathrm{SO}_{\mathrm{x}}$ and $\mathrm{NO}_{\mathrm{x}}$ emission regulation.

Table 5 shows that operating costs will attribute to the total costs to comply with ECA standard. For the existing ships, the changeable prices will be varied around $\$ 2.07$ billions in 2020 . In then, the new building ships will spend at least $\$ 3.2$ billions to install appropriate hardware and to use distillate fuel and urea in 2020.

\subsection{Impact of low sulphur fuel oil on diesel engine}

\subsubsection{Lack of lubricity}

Lubricity is the ability to generate a hydrodynamic lubrication film (oil wedge). To ensure that a given low sulphur marine gas oil, the significant value of the lubrication oil needs to provide enough. Following the fuel is tested under the ISO 12156-1 (EN 590) High Frequency Reciprocating Rig (HFRR) protocol. This standard is required at a maximum wear scare rate if $460 \mu \mathrm{m}$. However, the refineries add a lubricity additive in case of EN 590 requirements are not completed. The higher value of HFRR is showed in Figure 6.

The reduction of the lubricity in low sulphur fuel oil will be risked to the marine fuel oil pump system. Its result will be caused the excessive wear and premature failure. So, the special lubrication oil must be used to add lubricity and prevent carbon deposition that is called lacquering. On the other hand, the largest contribution to diesel engine lubricity system comes from the trace amounts of surface-active polar compounds forming a protective layer on the metal surface, thus enhancement of the boundary lubrication. The most active polar materials naturally occurring in diesel fuel are hetero-compounds containing nitrogen and oxygen. The hydro-desulphurization (HDS) process which removes sulphur content also removes these polar compounds, resulting in very poor lubricity characteristics and exposing pumping systems to damage and potential catastrophic failure. It is main reason that the lower fuel lubricity can be seen as abrasive wear of fuel system components. It is not sufficient fuel to supply to the plungers, barrels and injectors.

The proper lubrication in a marine plunger/barrel fuel pump depends on a balance between both hydrodynamic lubrication (Figure 7) and boundary lubrication (Figure 8). Hydrodynamic lubrication occurs when two surfaces are in motion to each other and are separated by a liquid film that carries the applied load. The result is collected to make a low friction and minimal wear between two surfaces (Figure 7).

\begin{tabular}{lcc}
\hline Type of cost & Compliance strategy & $\begin{array}{c}\text { Cost in 2020 } \\
\text { (billions USD) }\end{array}$ \\
\hline Operating costs (apply to all ships) & Fuel switching & $\$ 1.9$ \\
\cline { 2 - 3 } & $\begin{array}{c}\text { Urea consumption (for SCR-equipped } \\
\text { engines) }\end{array}$ & $\$ 0.17$ \\
\hline $\begin{array}{l}\text { Hardware costs (apply to ships built } \\
\text { in 2020) }\end{array}$ & Fuel switching & $\$ 0.03$ \\
\cline { 2 - 3 } & SCR & $\$ 1.1$ \\
\hline Total costs & & $\$ 3.2$ \\
\hline
\end{tabular}

Table 5.

The total of compliant $\mathrm{SO}_{x}$ and $\mathrm{NO}_{x}$ emission regulation. 
Some Methods to Prevent the Wear of Piston-Cylinder When Using Low Sulphur Fuel Oil... DOI: http://dx.doi.org/10.5772/intechopen.8940o

\section{MARPOL 73/78 IMO \& CARB Fuel-Sulphur Content Limits}

Equivalent methods may be used as altemative

\section{Sulphur limit}

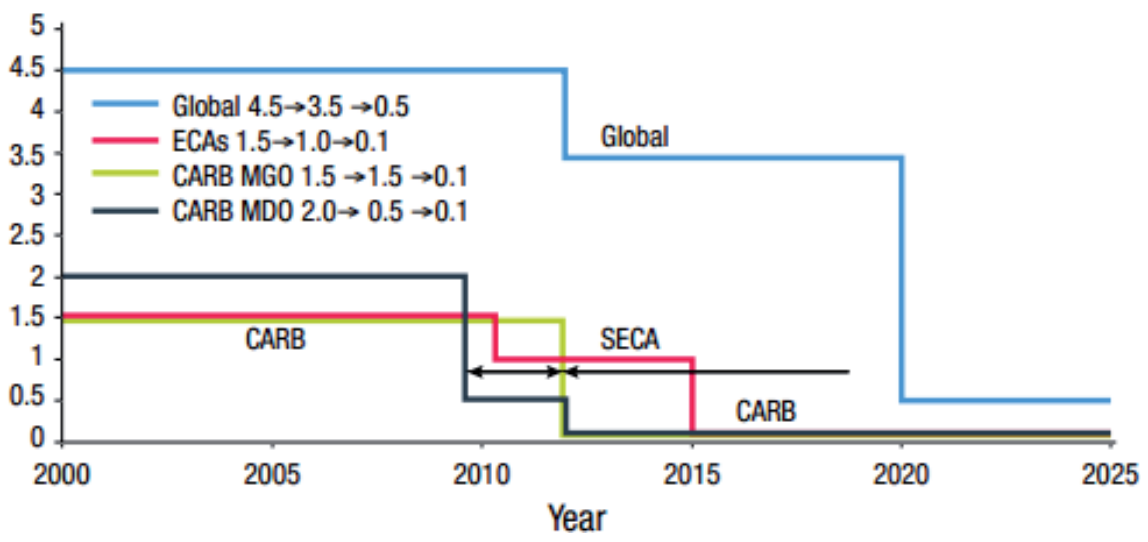

Figure 5.

The diagram of sulphur content limit in ECAs.

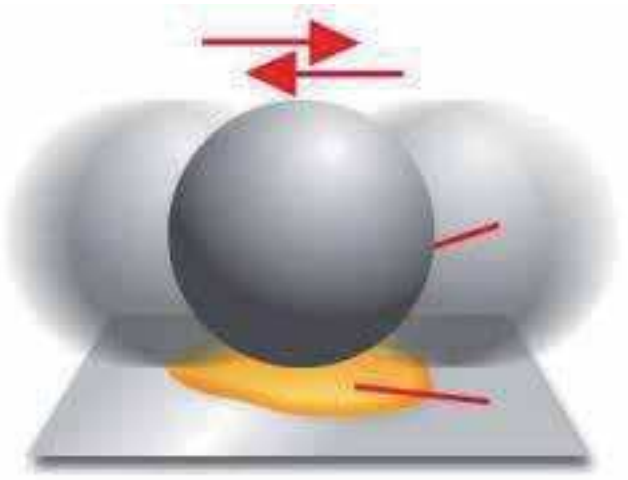

Figure 6.

HFRR test.

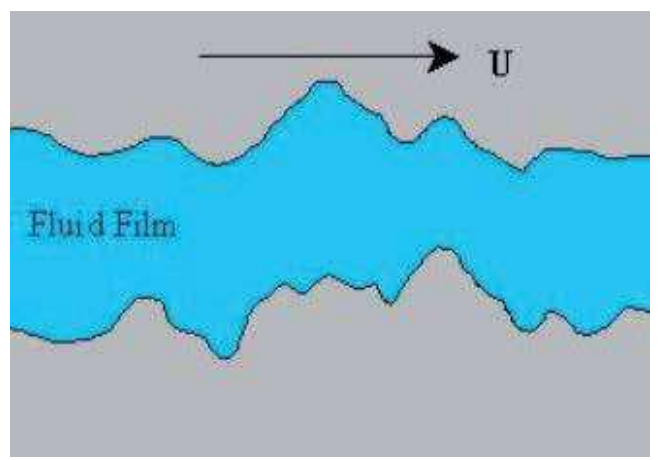

\section{Figure 7.}

Hydrodynamic lubrication.

In contrast, the boundary lubrication happens when the liquid film becomes thin to the point that it attains the same thickness as the surface roughness of the high points of the two interfacing solid surface contact, the fuel must have sufficient 


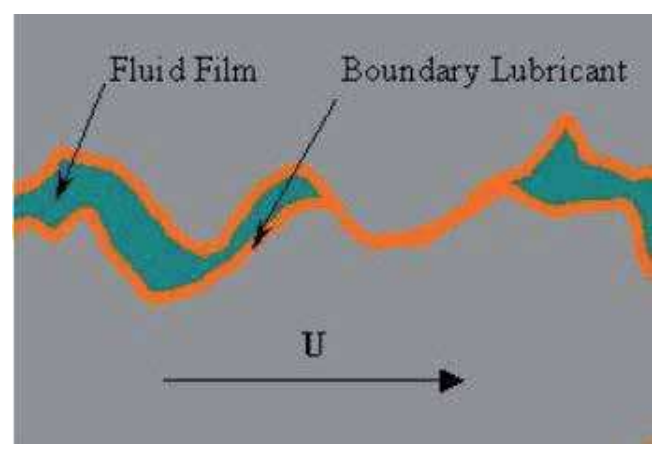

Figure 8.

Boundary lubrication.

lubricity to prevent increased friction and wear. The boundary lubrication is critical in three different situations, namely on initial start-up with insufficient liquid film, at low speed operations when not enough fuel is pumped to provide a satisfactory film and at very high speed operation when high pressure within the pump diminishes the film thickness (Figure 8).

A viscosity range 12-16 centistokes is sufficient to provide adequate hydrodynamic lubrication. Viscosity of low sulphur MGO varies from 1.5 to $3.0 \mathrm{cSt}$. In that case the protective fuel film between the surfaces of the barrel and plunger becomes dangerously thinner resulting is increased metal to metal contact even if fuel viscosity is increased through chilling or cooling. The difference between boundary and hydrodynamic lubrication is depicted.

Unfortunately the IMO regulation only regulates the sulphur content and no other fuel specifications are addressed. Low sulphur fuel with good lubricity characteristics is expected to be more expensive. Owners should not opt for less expensive fuel quantities, which will result in wear of fuel pump and injection components, bad combustion and engine wear and damages.

\subsubsection{Fuel stability}

The hydro-desulphurization (HDS) removes a large measure of aromatic content, resulting in reduced ignition quality. It also removes naturally occurring anti-oxidants that provide both physical and thermal stability of the fuel. Absence of natural anti-oxidants leads to the formation of hyper-peroxides, which can result in acid corrosion attach of fuel pump systems and pump seal failure. Especially, the formation of hyper-peroxide in fuel oil happens quickly at high temperature and it causes the negative influence on the fuel oil system. Oxidation process also produces gums, polymers and other insolubles. Standards to detect hyper-peroxide contamination are available.

The inherent instability of low sulphur fuel poses four critical threats to safe marine engine operation, namely degraded ignition quality, excessive engine deposits, an increase in visible particular emissions and excessive sludge production and fuel system fouling. Reduced stability of the fuel can also result increased emissions. Low sulphur marine fuels often produce excessive unburned hydrocarbon and visible particulate emissions (smoke opacity). Poor stability may result in the formation of gum and sludge during storage as well as deposit formation on injection nozzles and gumming of valves.

Poor physical stability can result in problems with fuel compatibility, particular when transitioning from operation on heavy fuel to low sulphur marine gas oil. Since some marine gas oils will be stored aboard the vessel for prolonged time 


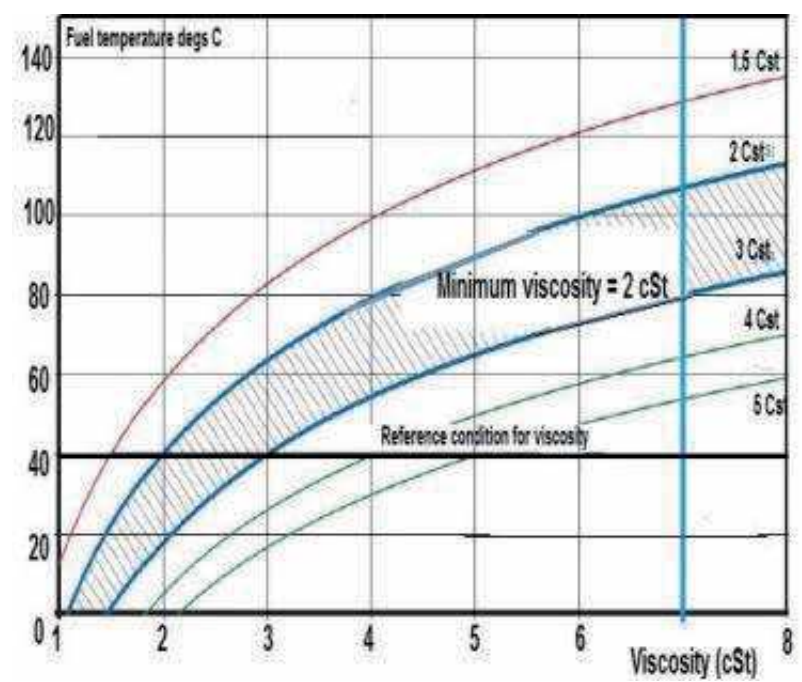

Figure 9.

Viscosity versus temperature [16].

periods, fuels of poor stability characteristics will suffer accelerated degradation, resulting in reduced ignition quality and degraded engine operation.

\subsubsection{Low fuel viscosity}

Low sulphur distillates have relatively low viscosity, ranging from 1.5 to $3.0 \mathrm{cSt}$. Fuel pumps depend upon an appropriate viscosity to meet required volumetric capacity, an especially important consideration in maintaining proper feed rates. ISO 8217 states minimum viscosities for DMX, Distillate Marine Oil of Class X, of $1.4 \mathrm{cSt}$ at $40^{\circ} \mathrm{C}$ and DMA, Distillate Marine Oil of Class A, of $1.5 \mathrm{cSt}$ at $40^{\circ} \mathrm{C}$. A rule of thumb value advised by the makers is $2 \mathrm{cSt}$ at engine inlet [10]. Ambient temperature in an engine room easily reaches $40^{\circ} \mathrm{C}$ and sometimes even higher-in some cases as much as $55^{\circ} \mathrm{C}$. Adding excessive heat from pipes and engines will raise the temperature even further and as consequence viscosity will fall, causing a significant change of operating conditions in the system. Mercifully, the lower the viscosity at $40^{\circ} \mathrm{C}$ the more gradual the fall of viscosity with temperature rise as depicted in Figure 9.

The lower viscosity will reduce the film thickness between the fuel pump plunger and casing and in the fuel valves leading to excessive wear and possible sticking, causing failure of the fuel pump. Special fuel injection pumps may be available that are more suitable for this type of fuel, such as tungsten carbide coated pumps, or a fuel pump lubrication system could be installed. Any new types of fuel injection equipment installed to address lubrication issues shall be certified by the engine maker to maintain engine compliance with emission standards and may require re-certification of engines.

\section{Methods to restrict from affectation of using low sulphur fuel oil (LSFO)}

Following the operation experience associates with the properties of the low sulphur fuel oil. The use of low sulphur fuel oil for marine diesel engine has caused the corrosion between piston-cylinder liner components due to the cylinder liner 
lubrication oil with low BN (Base Number). It is primarily obtained from stationary engines, operating at $100 \%$ load and $100 \%$ rpm in high ambient conditions.

\subsection{To provide the appropriate lubrication oil quality}

Using of low sulphur fuel oil for marine diesel engine will be momentum for causing the sulphuric acid $\left(\mathrm{H}_{2} \mathrm{SO}_{4}\right)$ in the combustion chamber. This process is made from the progress chain in Figure 10.

To neutralise the acid generated, the cylinder liner lubrication oil must contain alkaline components by mean of using calcium salts. Normally, the Base Number (BN or TBN) is a measure of the cylinder liner lubrication oil's ability to neutralise acid because the higher $\mathrm{BN}$, the more acid can be neutralised.

So the Base Number (BN) is very important parameter in controlling the corrosion on the cylinder liner surface. To control corrosion is not avoiding corrosion so it is important to ensure the proper tribology needed for creation of the lubrication oil film. It the neutralisation of the acid is too efficient, the cylinder liner surface has a risk of being polished. It is leading to the lubrication oil film damaged and the risk of the scuffing increases.

On the other hand, the operation of engine with an unmatched BN/fuel sulphur content could increase the risk of either scuffing or excessive corrosive wear.

To make a comparison between using of the different BN lubrication oil for the cylinder line with the same type of low sulphur fuel oil.

$\left[\mathrm{O}_{2}\right]$
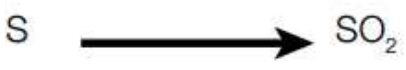

Fast $100 \%$ conversion
[0]

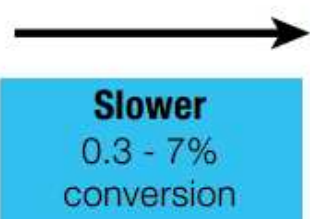

$\left[\mathrm{H}_{2} \mathrm{O}\right]$<smiles>C1=CO[Si]C1</smiles>

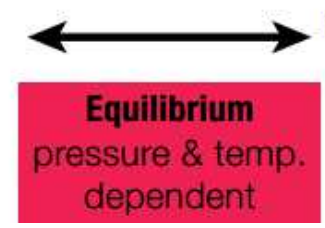

Figure 10.

Chemical conversion of sulphur to sulphuric acid.

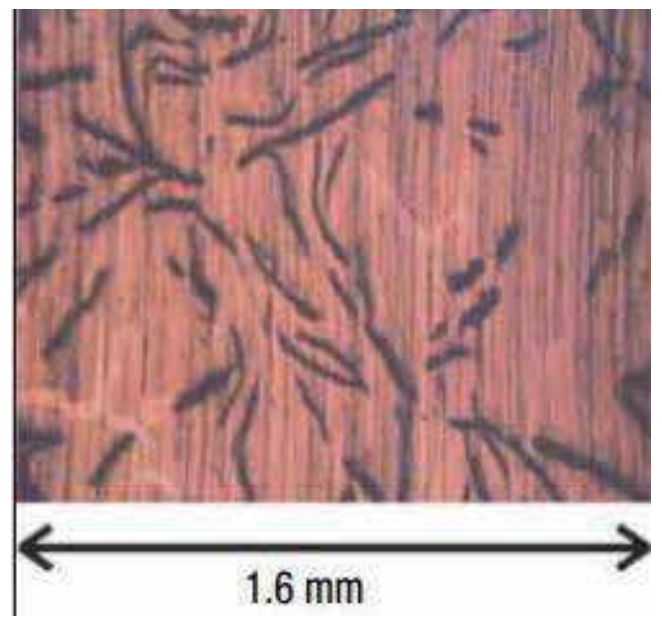

Figure 11.

Cylinder liner surface with BN40. 'Open' graphite structure with good tribological abilities. 
Like as Figures 11 and 12, it is used the different BN lubrication oil will make the changeable graphite structure on the cylinder liner surface. By using of BN40 lubrication oil will create the 'open' graphite structure with good tribological abilities in contrast to using BN70 lubrication oil has the 'closed' graphite structure with reduced tribological abilities.

It is essential for a good cylinder condition and performance that keeps an 'open' graphic structure on the cylinder liner surface so that a hydro-dynamic oil film is always kept between the piston-rings and cylinder walls at all times.

Therefore, it runs on low sulphur fuel oil that is considered more complex due to the relationship between liner corrosion and scuffing resistance, dry lubrication properties from elements in the fuel (or lack of same), the interaction between the BN in the cylinder oil and the detergency level, possible sulphur of alkaline additives, the piston ring pack, etc.

The appropriate operation of diesel engine is very important especially when it operate at the low sulphur fuel oil. Due to the selection of the low BN cylinder liner

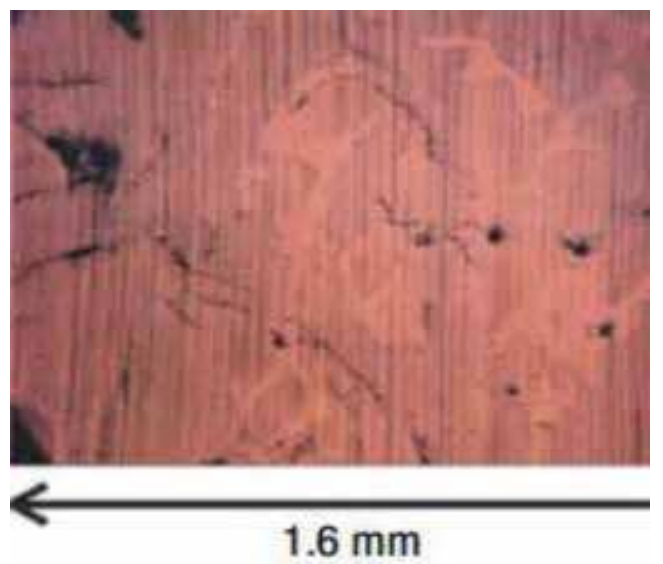

Figure 12.

Cylinder liner surface with BN70. 'Closed' graphite structure with reduced tribological abilities.

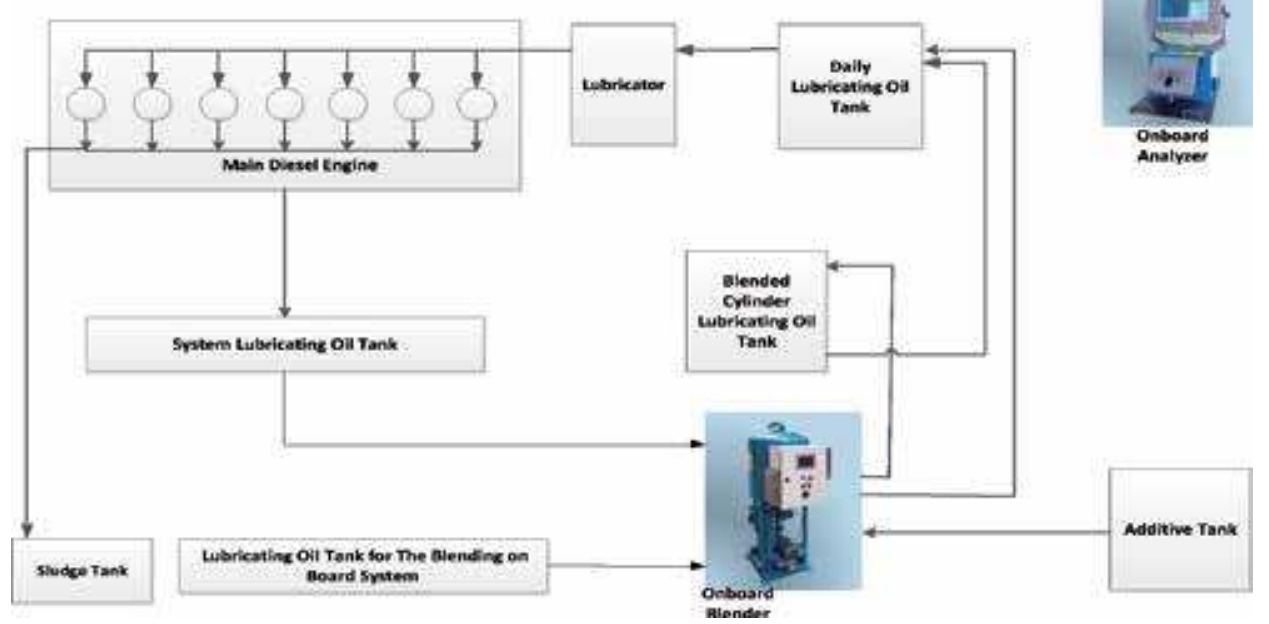

Figure 13.

The blend on board $(B O B)$ system for main diesel engine lubricating oil. 
lubrication oil is carried out carefully. In this research, OEMs (Original Equipment Manufactures) recommend the regular testing of scrape down oil for residual BN and Fe content and adjustments to BN of cylinder oil and feed rate to suit. They provide the charts showing the safe zones for the results of the testing and adjustments. In Figure 13, the blending on board system is given out in aim with regulating the lubricating oil quality for main diesel engines according to the use of low sulphur content fuel oil nowadays.

The lubricating oil for main diesel engine is regulated through onboard blender from using the system lubricating oil and additives. This task will meet the $\mathrm{BN}$ characteristics of lubricating oil in process of using low sulphur content fuel oil for main diesel engines. The scheme of blend on board system is represented in Figure 13.

The use of BOB system will get benefit to obtain the lubricating oil feed rate depending on variable $\mathrm{BN}$ characteristic. And then, it will increase the lubricity of lubricating oil for main diesel engines in case of using low sulphur content fuel oil onboards.

In a result, it is recommended for using the BN40-BN70 for cylinder liner lubrication oil at feed rate of large bore (Figure 14). The selection of appropriate lubrication oil depends on the low sulphur content in marine fuel.

\subsection{To equip the cooler in the fuel oil system}

The fuel oil viscosity is very important because it decides the ignition quality of fuel oil in diesel engine combustion chamber. Since the main engine must changeover to low sulphur fuel oil when the ship sails into the emission control areas (ECAs) with low viscosity. So, the best method that has solved this problem is the cooler in the fuel oil system.

It is necessary to instant cooler in the fuel oil system in order to maintain the required viscosity at the engine inlet fuel oil (Figure 15).

On the other hand, the hydrodynamic characteristics of fuel oil are completely dependent on the fuel oil temperature and fuel oil viscosity. The fuel oil system contains supporting equipment such as pumps (transfer pump, supply pump, booter pump, fuel oil pump, etc.), filters, heaters and coolers. So it is necessary to concern

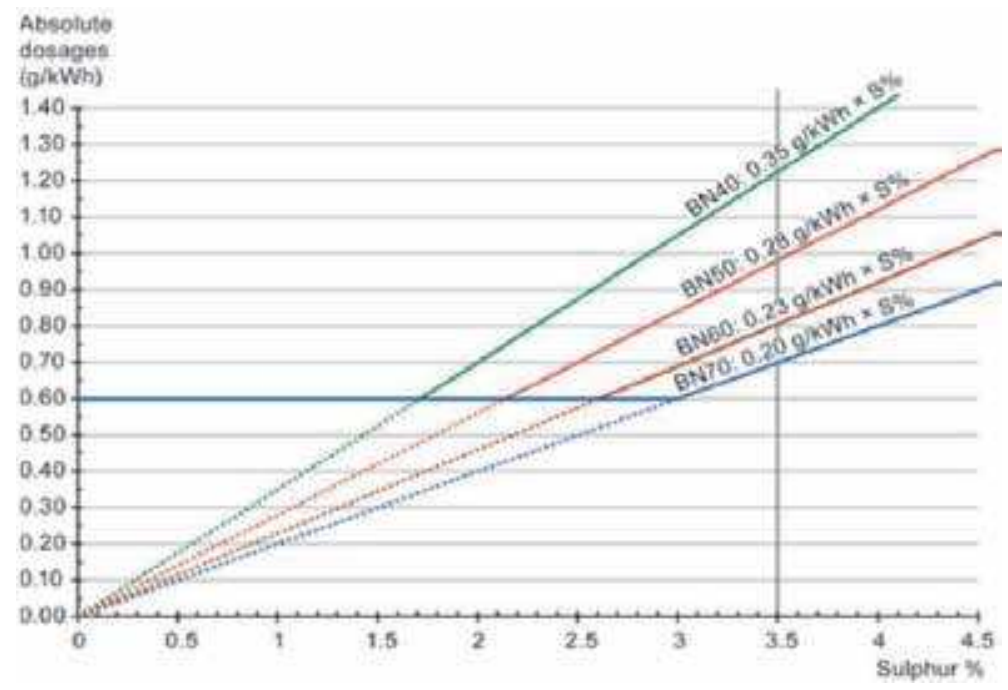

Figure 14.

Use of BN40, BN50, BN60 and BN70 for cylinder liner lubrication oil. 
about the fuel oil viscosity. In this chapter, it describes the depend between the fuel oil viscosity and temperature in Figure 16. It is useful to ensure the appropriate temperature of fuel oil flows in the system.

The horizontal axis shows the fuel viscosity in cSt. Its value is taken from the bunker analysis report. In the case if the temperature of the MGO (marine gas oil) is below the lower blue curve at engine inlet, the viscosity must be above $3 \mathrm{cSt}$.

Furthermore, the black thick line shows the viscosity at reference condition at $40^{\circ} \mathrm{C}$ according to ISO 8217. Minimum viscosity for marine distillate DMX, DMA, $\mathrm{DMB}$ and $\mathrm{DMZ}$ are indicated.

Moreover, there are a lot of factors that influence the viscosity tolerance during the engine operation during of the time from the start point to the normal operation. These include engine condition and maintenance, fuel pump wear, engine

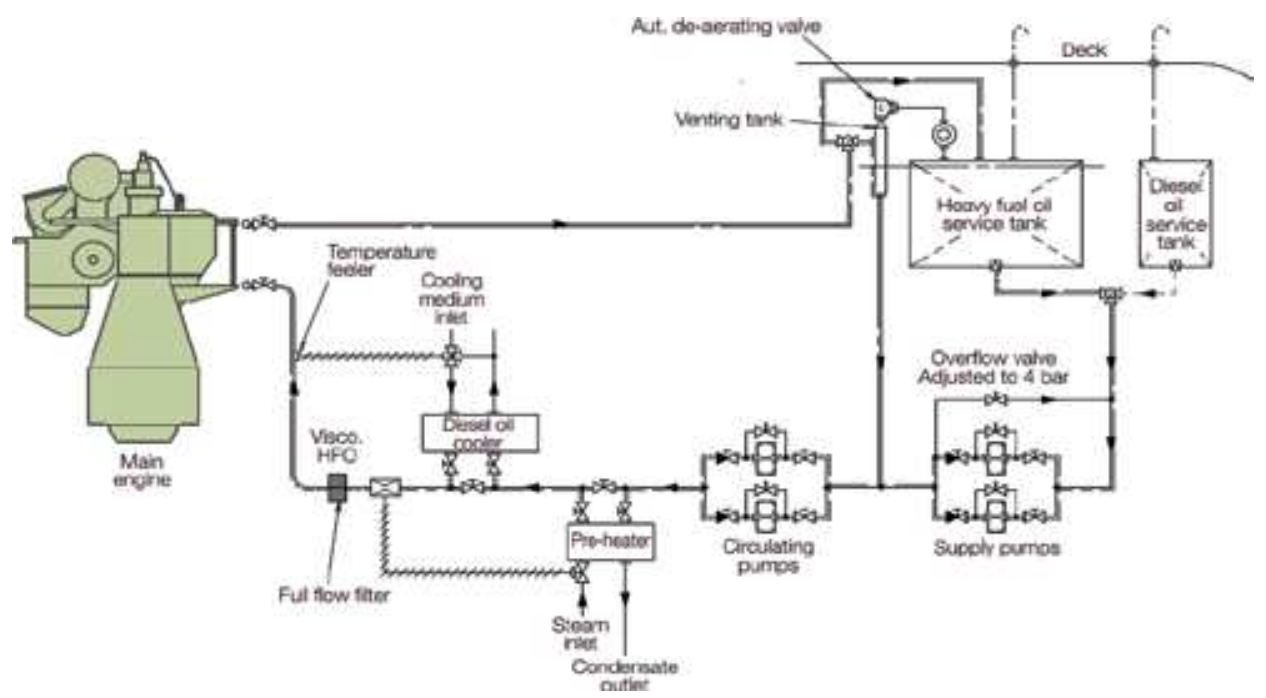

Figure 15.

Fuel oil system with fuel oil cooler.

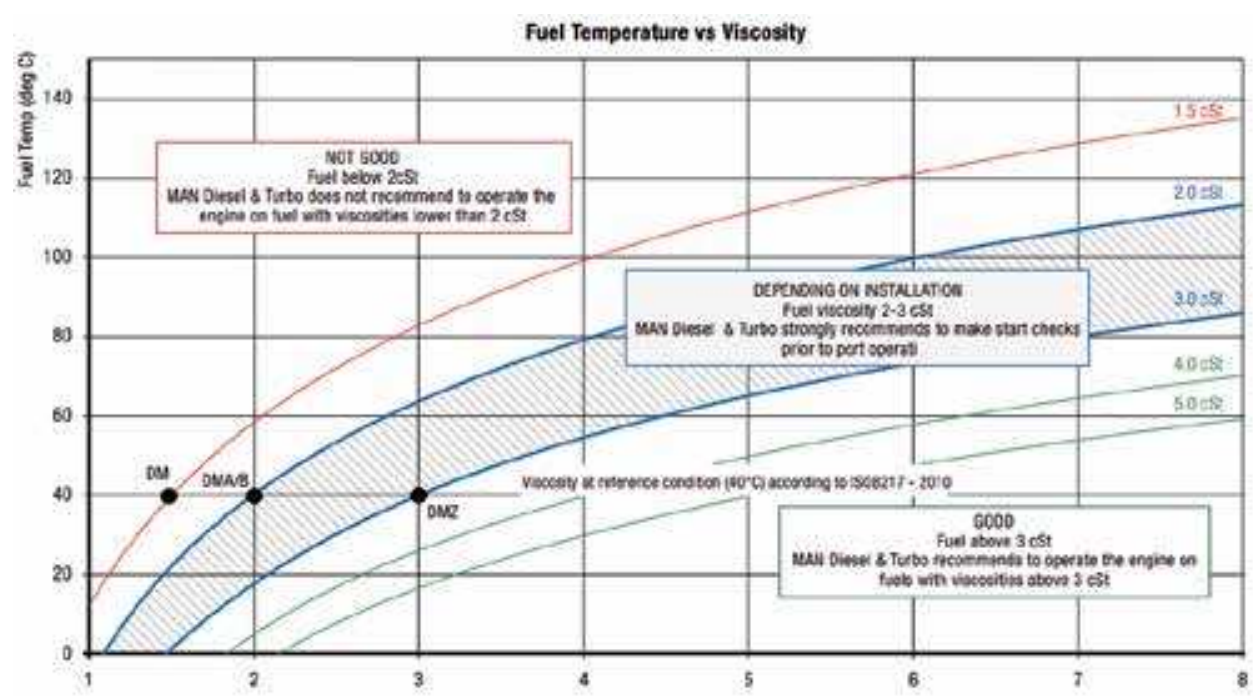

Figure 16.

Fuel oil temperature and viscosity [9]. 
pump wear, engine adjustment, actual fuel temperature in the fuel system, human factor, etc.

The effective operation plays an important role to maintain in good condition for devices and equipment in the fuel oil system. The makers of marine diesel engine (MAN B\&W) recommend to operate the engine with viscosity of fuel oil above 3 cSt when using the low sulphur content fuel oil.

\subsection{Lubricity-improvement additive for low sulphur diesel oil}

The use of low sulphur content fuel oil will be applied widely for all ships operate outside the emission control areas (ECAs) from 2020 with no more of $0.50 \%$ $\mathrm{m} / \mathrm{m}$. This regulation will impact positively on the environment due to the reduction of sulphur dioxide $\left(\mathrm{SO}_{2}\right)$ emissions from engine exhaust gas. However, there will be a lack of lubrication oil. Its effect includes abnormal friction and operational defects, crucial parts of engines such as the fuel-supply pumps and fuel-injection pumps. As a result, the additives for low sulphur diesel oil are used in order to improve the lubricity of low sulphur marine gas oils with aims in keeping the safe vessel operations as well as protecting the environment.

Yunic 700LS is used in order to improve the lubricity for low sulphur marine gas oil (LSMGO) and low sulphur marine diesel oil (LSMDO) with standard dosing rate of 1/2500 (Figure 17). Its effect is addressed to prevent the abnormal wear and stick the fuel injection pump and fuel pump of marine diesel engine by the low lubricity of fuel oil. There are lots of other similar products which are used for increasing the lubricity ability of low sulphur diesel oil. The comparison between other products is showed in Table 6.

In addition, the blending Yunic 700LS into the low sulphur, the low lubricity ability of marine gas oils (MGO) was verified through an HFRR (High Frequency Reciprocating Rig) test (Figure 18). The HFRR is currently approved and then it is a standard index for evaluating lubricative ability of low sulphur fuel oil.

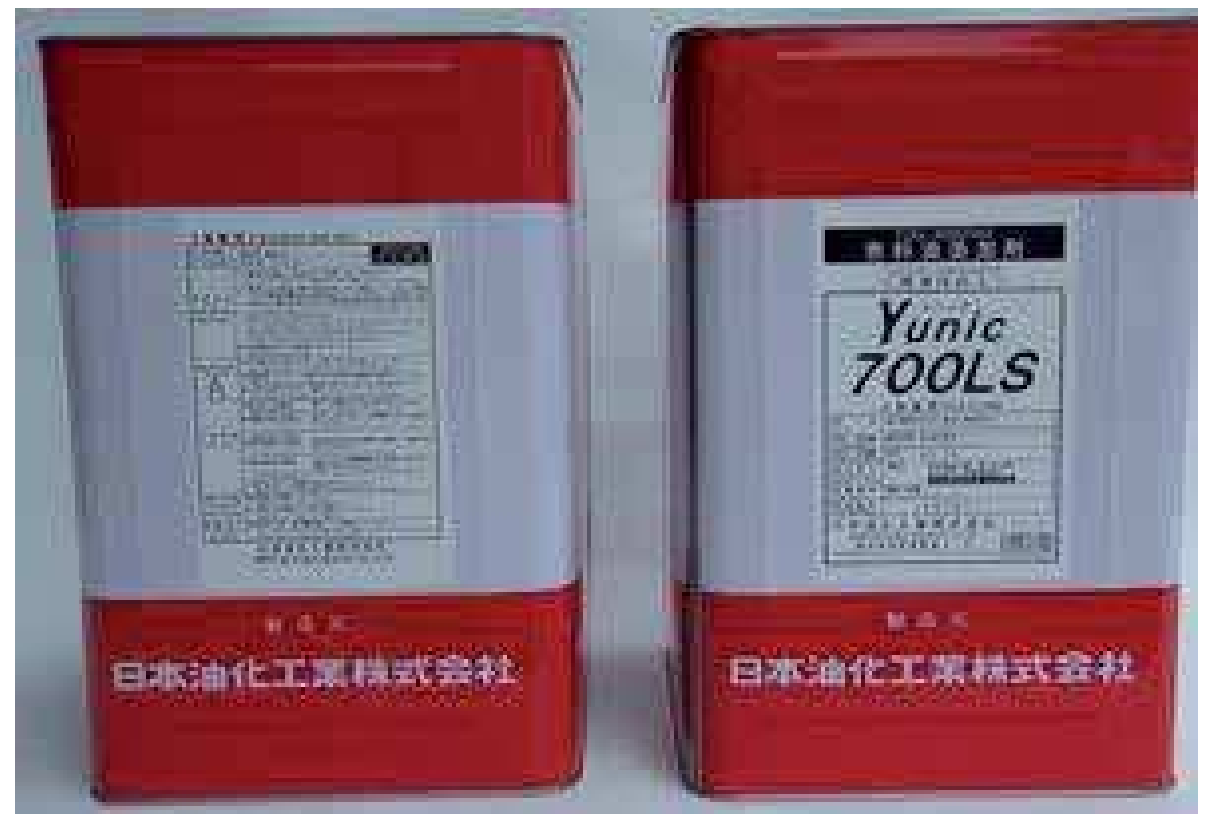

Figure 17.

Yunic $700 L S$. 
Some Methods to Prevent the Wear of Piston-Cylinder When Using Low Sulphur Fuel Oil... DOI: $h t t p: / / d x$.doi.org/10.5772/intechopen.8940o

\begin{tabular}{|c|c|c|}
\hline Products & Advantages & Inconvenients \\
\hline $\begin{array}{l}\text { Yunic } \\
700 L S\end{array}$ & $\begin{array}{l}\text { - Improve the lubricity of low sulphur fuel oil } \\
\text { - Prevent the stick phenomenon of fuel oil } \\
\text { injection pumps }\end{array}$ & $\begin{array}{l}\text { - Disable to prevent the emulsion } \\
\text { phenomenon } \\
\text { - Disable to prevent the sludge dispersion } \\
\text { of low sulphur heavy fuel oil } \\
\text { - Lower price than Yunic } 750 \text { LS-F }\end{array}$ \\
\hline Yunic 300 & $\begin{array}{l}\text { Separate the water out of oil from emulsion } \\
\text { phenomenon }\end{array}$ & $\begin{array}{l}\text { Disable to increase the lubricity ability of } \\
\text { low sulphur fuel oil }\end{array}$ \\
\hline $\begin{array}{l}\text { Yunic } \\
555 \mathrm{D}\end{array}$ & $\begin{array}{l}\text { - Increase the sludge dispersion of low } \\
\text { sulphur heavy fuel oil } \\
\text { - Improve the combustion process of diesel } \\
\text { engine when using low sulphur fuel oil }\end{array}$ & $\begin{array}{l}\text { Disable to increase the lubricity ability of } \\
\text { low sulphur fuel oil }\end{array}$ \\
\hline $\begin{array}{l}\text { Yunic } \\
650-\text { II }\end{array}$ & $\begin{array}{l}\text { - Increase the sludge dispersion of low } \\
\text { suphur fuel oil } \\
\text { - Increase the melting point of ash factor of } \\
\text { low sulphur fuel oil }\end{array}$ & $\begin{array}{l}\text { Disable to increase the lubricity ability of } \\
\text { low sulphur fuel oil }\end{array}$ \\
\hline $\begin{array}{l}\text { Yunic } \\
600 S-I I\end{array}$ & $\begin{array}{l}\text { - Increase the melting point of ash factor of } \\
\text { low sulphur fuel oil } \\
\text { - Decrease the gas leakage phenomenon from } \\
\text { exhaust valve of diesel engine }\end{array}$ & $\begin{array}{l}\text { Disable to increase the lubricity ability of } \\
\text { low sulphur fuel oil }\end{array}$ \\
\hline $\begin{array}{l}\text { Yunic } \\
600 S X\end{array}$ & $\begin{array}{l}\text { Prevent the slag formation with high content } \\
\text { of vanadium of low sulphur fuel oil }\end{array}$ & $\begin{array}{l}\text { Disable to increase the lubricity ability } \\
\text { of low sulphur fuel oil } \\
\text { - Normally used for marine boiler }\end{array}$ \\
\hline $\begin{array}{l}\text { Yunic } \\
\text { 750LS-F }\end{array}$ & $\begin{array}{l}\text { - Increase the lubricity ability of low sulphur } \\
\text { fuel oil } \\
\text { - Prevent the mould sludge of fuel oil }\end{array}$ & $\begin{array}{l}\text { - Disable to prevent the emulsion } \\
\text { phenomenon } \\
\text { - Disable to prevent the sludge dispersion } \\
\text { of low sulphur heavy fuel oil }\end{array}$ \\
\hline
\end{tabular}

Table 6.

The comparison between same other products.

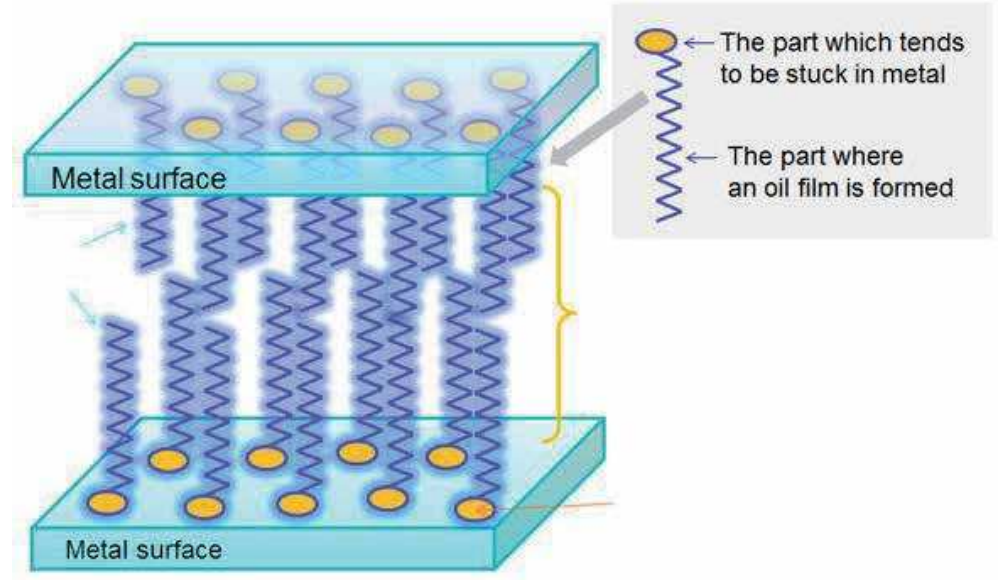

Figure 18.

High Frequency Reciprocating Rig (HFRR) test method.

In particular, the HFRR uses a ball in which a load is applied. Then, the ball will reciprocate on a metal surface immersed in the test of fuel oil. Finally, the size of the scars created on the ball is used to assess the lubricative ability of fuel oil. 
In HFRR test, the lubricity indexes of light fuel oil are tested, the wear scar diameter of low sulphur fuel oil is about $600 \mu \mathrm{m}$. Addition of $200 \mathrm{pm}$ with 1/5000 is standard addition rate of Yunic 700LS, the wear scar diameter is reduced to $460 \mu \mathrm{m}$ or less, which is the specification recommended by engine manufacturers (Figure 19).

So, the engine manufacturers suggest using with HFRR wear scar diameter of $460-520 \mu \mathrm{m}$ or less. In reality, the use of fuel oil has a lower lubricity that will lead to the corrosion of fuel injection pump and fuel pump of main diesel engine on ships.

\subsection{Alpha adaptive cylinder-oil control (alpha ACC)}

The Alpha Lubricator System is available for all MAN B\&W MC/MC-C twostroke diesel engines (Figure 20) [16].

The Alpha Lubricator System has an algorithm controlling cylinder oil dosage proportional to the sulphur content in the fuel. And, this algorithm is considered as Alpha Adaptive Cylinder-oil Control (Alpha ACC).

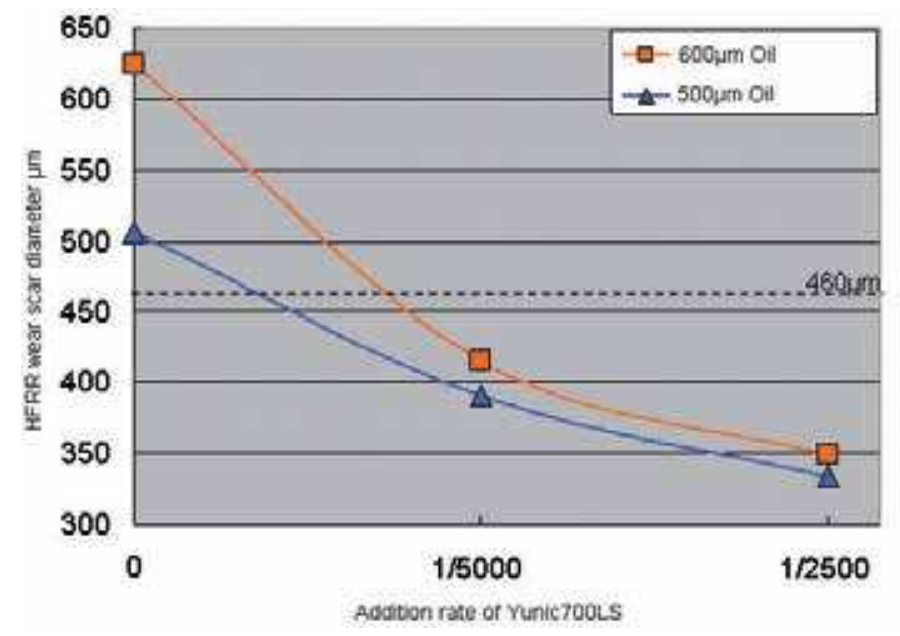

Figure 19.

Relationship of addition rate of Yunic $700 L S$ and HFRR.

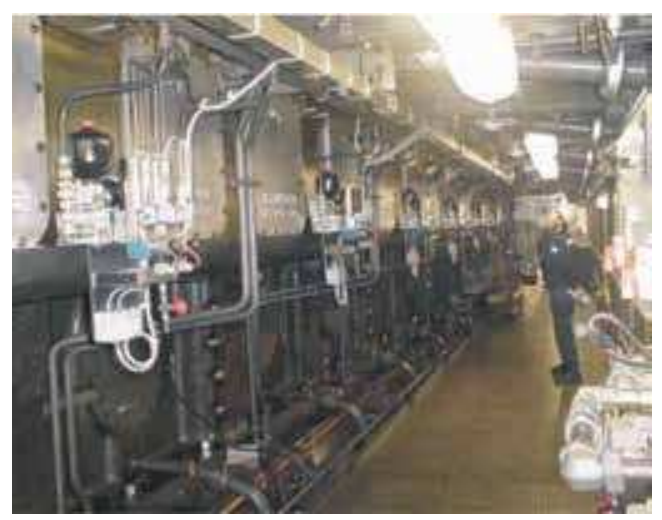

Figure 20.

Alpha lubricator system. 
The advantage of Alpha Adaptive Cylinder-oil Control (Alpha ACC) in field of saving cylinder oil then a large scale testing programme is in progress on MAN B\&W MC/MC-C type engines in service for a number of owners. In addition, to save the cylinder oil consumption will protect the environment from impacting on ship operation by Alpha Lubricator System.

The testing programme includes large bore engines for both container ships (K-MC/MC-C) and for VLCC propulsion (S-MC/MC-C), as well as small and medium bore MC/MC-C engines [16].

The cylinder oil dosage is proposed to an amount of sulphur content percentage in fuel oil. The cylinder oil dosage shall be proportional to the sulphur percentage in the fuel oil in Figure 21. On the other hand, the cylinder oil dosage shall be

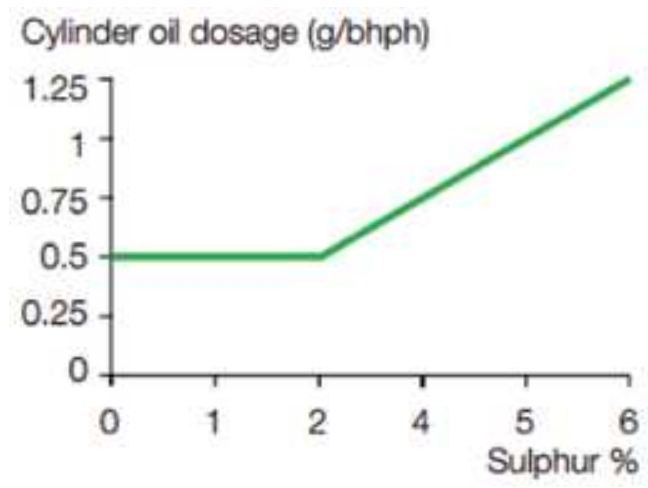

Figure 21.

Cylinder oil dosage versus sulphur percentage in the fuel oil.

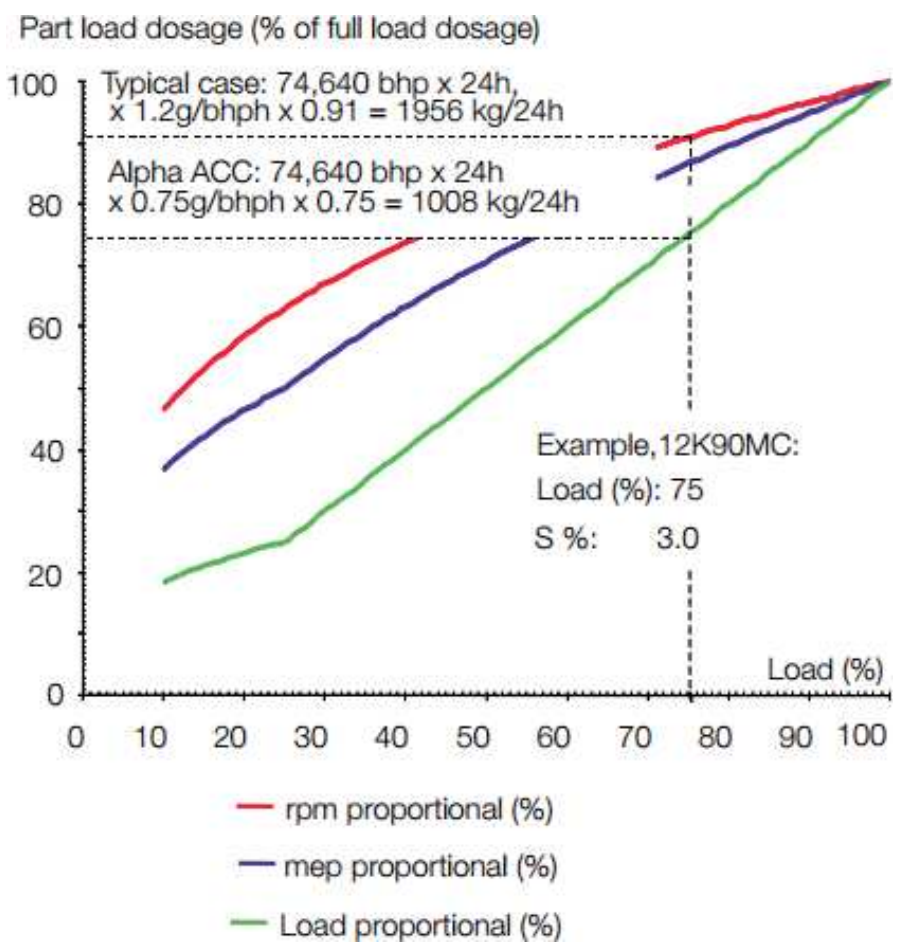

Figure 22.

Load-proportional cylinder oil dosage is used by alpha ACC. 
proportional to the engine load like this amount of fuel admitted into the cylinders. This one will decide an optimal cylinder oil dosage with sulphur content in the fuel oil admitted into the cylinders.

Furthermore, it is very important to determine the cylinder oil dosage admitted into the cylinder line in aims with saving amount of cylinder oil following the sulphur content percentage in fuel oil used.

In Figure 22, the control of cylinder oil dosage proportional to the engine load together with revolution per minute (rpm)-proportional and mep-proportional lubrication. In case of part load, load-proportional cylinder oil dosage will provide large cost saving and reduce environmental pollution due to excessive lubrication. Additionally, if it is below $25 \%$ load, the load-proportional lubrication will stop and rpm-proportional lubrication will take over.

\section{Conclusion}

In this chapter, the new regulations for sea environment protection have been introduced through IMO and MARPOL 73/78 for all vessels that operate on special areas (ECAs). Especially, the IMO decision of $0.50 \% \mathrm{~m} / \mathrm{m}$ sulphur content limit in marine fuel oil after 2020 is definite and no further decision till the date has happened. So, some methods have been represented including the use of an appropriate lubrication oil quality for diesel engine on ships, installing the cooler in fuel oil system, improving the additive for low sulphur fuel oil and using the alpha adaptive cylinder oil control (Alpha ACC). This research will be meaningful solutions for all ships to comply with the new regulations when sailing on ECAs.

\section{Acknowledgements}

The author wants to thank Chief Engineer, MSc, Thuy.H.V of M/V NSU JUSTICE, who gave meaningful suggestion to complete this study. Furthermore, I acknowledge all colleagues at Reliability Engineering Institute and Key Laboratory of Marine Power Engineering \& Technology (Ministry of Transportation), School of Energy and Power Engineering, Wuhan University of Technology, 430063 Wuhan, P.R. China. Finally, I would like to thank reviewers for valuable comments for revised manuscript.

\section{Nomenclature}

$\begin{array}{ll}\text { Alpha ACC } & \text { alpha adaptive cylinder oil control } \\ \text { BMW } & \text { Ballast Water Management } \\ \text { BN/TBN } & \text { Base Number/Total Base Number } \\ \text { CARB } & \text { California Air Resources Board } \\ \text { ECAs } & \text { emission control areas } \\ \text { EPA } & \text { Environmental Protection Agency } \\ \text { HSFO } & \text { high sulphur fuel oil } \\ \text { HFO } & \text { heavy fuel oil } \\ \text { HFRR } & \text { High Frequency Reciprocating Rig } \\ \text { HDS } & \text { hydro-desulphurization } \\ \text { IMO } & \text { International Maritime Organisation } \\ \text { ISO } & \text { International Standard Organisation } \\ \text { IFO } & \text { Intermediate Fuel Oil }\end{array}$


Some Methods to Prevent the Wear of Piston-Cylinder When Using Low Sulphur Fuel Oil...

DOI: $h$ ttp://dx.doi.org/10.5772/intechopen.8940o

$\begin{array}{ll}\text { GHG } & \text { Greenhouse Gas } \\ \text { LSFO } & \text { low sulphur fuel oil } \\ \text { LPG } & \text { liquefied petroleum gas } \\ \text { LNG } & \text { liquefied natural gas } \\ \text { MEPC } & \text { Marine Environment Protection Committee } \\ \text { MGO } & \text { marine gas oil } \\ \text { MDO } & \text { marine diesel oil } \\ \text { MARPOL 73/78 } & \text { International Convention for the Prevention of Pollution from } \\ & \text { Ships } \\ \text { PM } & \text { particulate matter } \\ \text { RPM } & \text { revolution per minute } \\ \text { SFOC } & \text { specific fuel oil consumption } \\ \text { ULSFO } & \text { ultra low sulphur fuel oil }\end{array}$

\section{Author details}

Tien Anh Tran ${ }^{1,2}$

1 Faculty of Marine Engineering, Vietnam Maritime University, Haiphong, Vietnam

2 Marine Research Institute, Vietnam Maritime University, Haiphong, Vietnam

*Address all correspondence to: trantienanhvimaru@gmail.com

\section{IntechOpen}

(C) 2020 The Author(s). Licensee IntechOpen. Distributed under the terms of the Creative Commons Attribution - NonCommercial 4.0 License (https://creativecommons.org/ licenses/by-nc/4.0/), which permits use, distribution and reproduction for non-commercial purposes, provided the original is properly cited. (cc) BY-NC 


\section{References}

[1] ABS. Fuel Switching Advisory Notice. USA: American Bureau of Shipping; 2010. pp. 1-32

[2] Fajar N. Effective implementation of emission control area towards cleaner shipping operations: Focusing on sulphur oxides ( $\mathrm{SOx}$ ) emission reducation [Master's dissertation]. Malmo, Sweden: World Maritime University; 2009

[3] ICCE, International Council on Combustion Engines. Guideline for the Operation of Marine Engines on Low Sulphur Diesel. Germany: CIMAC; 2013. pp. 1-23

[4] IMO, International Maritime Organization. 2009 Guidelines for Exhaust Gas Cleaning Systems. MEPC 59/24/Add.1, Annex 9, Adopted on 17 July 2009. 2009

[5] Marine Environment Protection Committee (MEPC). 69th Session. 2016. Available from: http://www.imo.org/en/ mediacentre/meetingsummaries/mepc/ pages/mepc-69th-session.aspx

[6] IMO, International Maritime Organization. IMO Sets 2020 Data for Ships to Comply with Low Sulphur Fuel Oil Requirement. 2016. Available from: http://www.imo.org/en/MediaCentre/ PressBriefings/Pages/MEPC-702020sulphur.aspx

[7] ABS. Marine Environment Protection Committee 69 Brief. USA: American Bureau of Shipping; 2016. pp. 1-6

[8] Laurie G. Exhaust emissions from ship engines in Australian waters including ports. Workshop on New South Wales Environment Protection Agency, Australia. 2014

[9] MAN Diesel\&Turbo. Operation on Low-Sulphur Fuels: MAN B\&W
Two-stroke Engines. Denmark: MAN; 2014

[10] MAN Diesel\&Turbo. Guidelines for Operation on Fuels with less than $0.1 \%$ Sulphur. Denmark: MAN; 2014. pp. 1-24

[11] Hazrat MA et al. Lubricity improvement of the ultra-low sulphur diesel fuel with the biodiesel. Energy Procedia. 2015;75:111-117

[12] Anish W. Fuel Oil Change over Procedure for Ship's Main and Auxiliary Engines. Marine Insight; 2016. Available from: https://www.marineinsight. com/main-engine/fuel-oil-changeover-procedure-for-ships-main-andauxiliary-engine/

[13] World Bunker Prices. 2017. Available from: http://shipandbunker.com/prices

[14] Stopford M. Maritime Economics. 3rd ed. New York: Rouyledg; 2009

[15] Sergey U et al. Effects of high sulphur content in marine fuels on particulate matter emission characteristics. Journal of Marine Engineering \& Technology. 2014;12(3):30-39

[16] MAN B\&W. Alpha Adaptive Cylinder-oil Control Alpha ACC. 2002. P.395-02.09 
Section 3

Diesel Engine and Pollutants 



\title{
Ecological Predictive Maintenance of Diesel Engines
}

\author{
António Simões, José Torres Farinha and Inácio Fonseca
}

\begin{abstract}
The ecological predictive maintenance (EPM) of diesel engines is a great contribution to improve the environment and to stimulate good practices with good impact in the human health. The ecology is a rapidly developing scientific discipline with great relevance to a sustainable world, whose development is not complete as a mature theory. There are, however, general principles emerging that may facilitate the development of such theory. In the meantime, these principles can serve as useful guides for EPM. According to the state of the art, it can be stated that through prediction algorithms, the equipment's performance can be improved. To support this approach, it is necessary to implement a good condition monitoring maintenance. The result permits to maximise the time spacing between interventions and to increase the reliability levels. The condition variables of each equipment can be monitored according to their specificity, such as temperature, humidity, pollutant emissions $\left(\mathrm{NO}_{\mathrm{x}}, \mathrm{CO}_{2}, \mathrm{HC}\right.$ and $\left.\mathrm{PM}\right)$, emitted noise, etc. The environment where the equipment is inserted also must be considered. The assessment of the equipment's condition can be done by Hidden Markov Models (HMM), namely diesel engines. This chapter presents two algorithms-Viterbi and Baum-Welch algorithms-that, through the prediction of the equipment's condition, help to increase the efficiency of the maintenance planning.
\end{abstract}

Keywords: ecological maintenance, predictive maintenance, ecological predictive maintenance, diesel engines, Hidden Markov Model

\section{Introduction}

The e-maintenance is expanding in many industrial domains. Diesel engines segment is being revealed as one of the most important in its application. eMaintenance is synonymous of effectiveness and efficiency, both by operators and the society in general. It permits to make anticipate diagnosis and prognosis conducting to a better organisation and people performance. This is the way to increase data precision and the decision confidence level.

To summarise, it can be said that e-maintenance allows to reduce human intervention, because it is a powerful mechanism, used in automatic mode to determine on-the-fly changes in the engine condition. This approach uses information and communication technologies (ICT) to provide, automatically, logistical support for the technicians.

The development presented in this chapter is supported on a distributed acquisition system with intelligent processing. This process helps to reduce engine 
emissions and, simultaneously, decreases costs for people, families, companies and organisations.

The solution can be extended to alert in general for the need of inspection of the vehicles that circulate in a certain street arch. This is one way to contribute to reduce the environmental impact and to improve the life quality in the urban centres.

An application was developed using MatLab, in which the algorithms based on HMM were coded. Other specific developments have been added by other languages such as PHP, SQL, etc. The sensing equipment includes vibration monitoring, emission gas analysis, sonometer, opacimeter and high-resolution digital camera. Some of these devices already integrate a remote transmission system.

Detection and decision of the action to be done and the alarm triggering are made in worthy time, allowing to schedule interventions before failures and high damages.

The equipment that emits pollutants can be monitored through the measurement of $\mathrm{HC}, \mathrm{CO}_{2}, \mathrm{NO}_{\mathrm{x}}, \mathrm{PM}$, vibration and noise, allowing to determine the state of the equipment [1].

The focus is to implement a model that aggregates the contributions of the information obtained from the monitored variables and their behaviour over time, in order to determine the current state and the next one. Usually, the following situations may happen: the sequence of states is linked; the current state can be predicted by the previous ones. The precedent cases are suitable to be managed by HMM that can handle many variables.

The positioning among well-defined objectives, like maintenance, costs and operational processes, is fundamental.

In the case of diesel engines, the usual is to use schedule maintenance based on distance travelled or time elapsed. Another less frequent, but available, hypothesis is to check the quality of the oil and replace it if necessary. Recent models of some brands already have an oil sensor that gives this information to the vehicle's computer and the driver's panel.

e-Maintenance is an e-management supporting tool based on several views and perspectives. It can be defined as:

- Intelligent system with resources for information gathering, processing and decision-making. It includes transmission technology, sensor technology, maintenance activities-logistics, maintenance plans, etc., as well as diagnostic and prognostic capabilities-sensors, computer power, digital information and smart algorithms.

- e-Maintenance gives access to maintenance aspects like the following:

\section{i. Remote maintenance}

ii. Predictive maintenance

iii. Real-time maintenance

iv. Collaborative maintenance

The increasingly technological development allows the construction of intelligent equipment with the capacity for sensing, processing and transmission, allowing alarms and real-time events depending on the diesel engine's state.

This digital information allows to use condition-based maintenance (CBM) as part of the e-maintenance solution. 
Maintenance information enables not only to increase the effectiveness and efficiency of the diesel engines but also to provide the persons with informative internet services. For example, the information about unexpected maintenance activities within a diesel engine and maintenance process enables opportunistic maintenance in order to reduce the negative impact [2].

Simultaneously, the same information can be correlated to spatial data in order to provide better decision support for a route planning aimed for the consumeroffering good information is essential about the services that support the performance contributing to greater consumer satisfaction of services. Managers and technicians recognise the relevance of the oil analysis applied to fleet predictive maintenance based on condition monitoring [3]. This considerably decreases the reaction time to solve critical problems of diesel engines and optimises overall equipment and vehicle trustworthiness [4].

The projected model (Figure 1) describes an integrated platform that is called the diesel engine e-maintenance (DEEM) that includes the items of the subsystem visible in Figure 1.

This model contains a sub-item called ecological predictive maintenance (EPM) based on environmental indicators [5].

In the EPM, the emission spectrum and the HMM are the innovative matter presented in this chapter. The motivation is based on the usefulness of the emission spectrum and its coherence, which can be used in a viable way by specialists who perform condition monitoring through wireless technology.

At present time, the new hardware and software solutions require a more complex integration and communication among the several pieces of this complex "puzzle".

One thing that concerns since the first time is the simplicity, friendliness and low cost of all system. The central system is based on a Linux server running Apache web server and PostgreSQL database. All system is available through IPv4 connectivity from the acquisition system level to the Linux server. Data acquisition can be done using special low-cost hardware, as also by high-performance acquisition systems, like National acquisition hardware using LabView, obtainable by IPv4 connectivity and Ethernet PLC's. It is also available by Transmission Control Proto$\mathrm{col} /$ Internet Protocol (TCP/IP) server for reception of data acquired from different

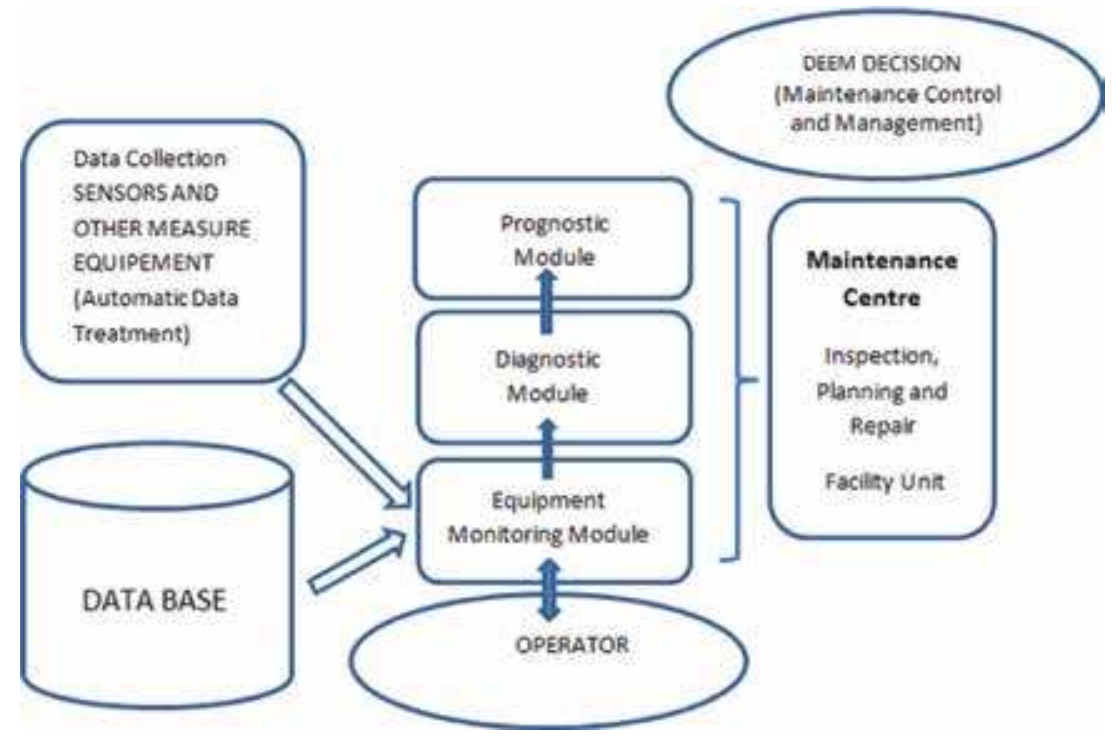

Figure 1.

Diesel engines e-maintenance. 
acquisition hardware, using Unreliable Datagram Protocol (UDP) packets with acknowledgement.

Nowadays, e-maintenance systems have new adding, like the following:

- Wireless communication to IP devices to receive measurements from diesel engines or any others

- Condition monitoring modules to predict interventions based on variables that are regularly measured by remote way, by physical connecting or by human reading

\section{Ecological diesel engines e-maintenance}

New trends in this new paradigm are to diminish faults and respect the environment.

The system has included a prediction algorithm for condition monitoring maintenance that uses a new forecast paradigm based on HMM $[6,7]$.

The use of artificial intelligence, as neural networks with the objective to maximise chances of success, is a great challenge. The presented model begins with the measure of condition variables as source data that will permit to forecast the condition monitoring indicators, now through HMM models, and after, predicts the new state.

To be able to measure the condition monitoring signals in an optimal approach and to support the diagnostic and prognostic phases of e-maintenance, the analysis of refined signals must be used.

The Ecological Maintenance Performance Indicators (EMPI) are based on safety, reduction of downtime, health, pollution mitigation, costs and waste and on improving productivity, capacity utilisation and quality [8].

Thus, using a specific group of statistics and reference conditions (requirements/targets), the EMPI evaluates the actual conditions.

Figure 2 shows an e-maintenance framework proposed for maintenance management. The local platform involves the condition monitoring system and the monitored systems and vehicles. Performance and health data for vehicles and systems are logged by the condition monitoring system [3].

The CPU processing power is very important, but some sensors already integrate processing capabilities, what provides information already processed for the analysis.

Based on reviews, it appears that, despite much research ongoing, several articles on various signal analysis techniques have been published, on essential methods, and have achieved viable success.

In order to implement the acquisition of monitored signals, an acquisition system is proposed in Figure 3.

The back-office server system runs Linux and MySQL to store the values of the physical variables in their digital format. The acquisition system installed on the vehicles has four possible options:

1. Beckhoff PLC with Ethernet and acquisition cards

2. ARM microcontroller with Ethernet and ADCs

3. National CompactRio with LabView for prototyping research

4. Compact PC for local installation 


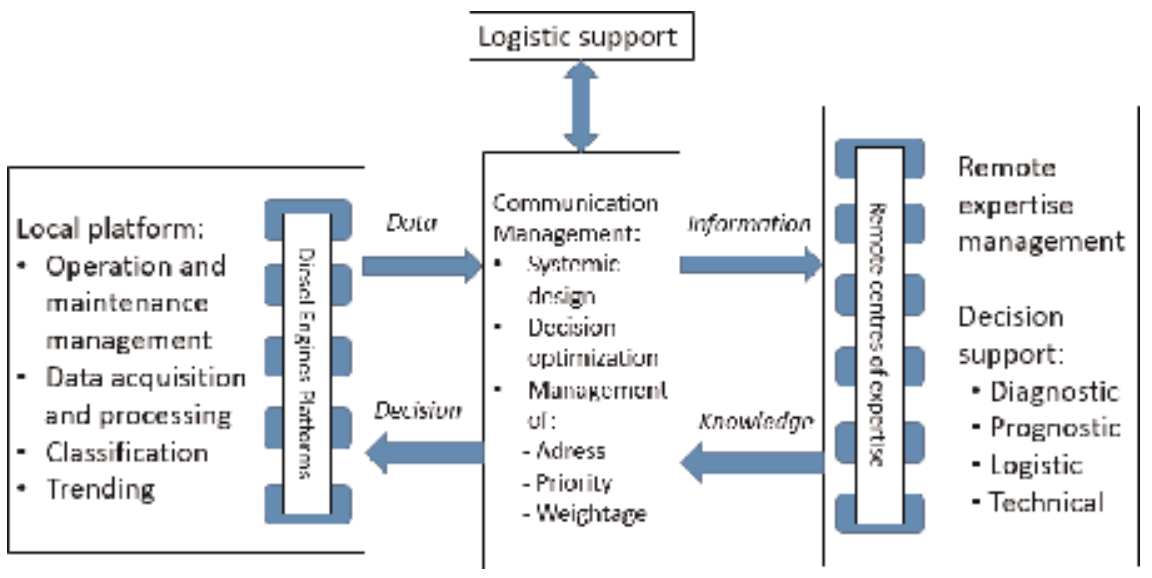

Figure 2.

Framework for e-maintenance [9].

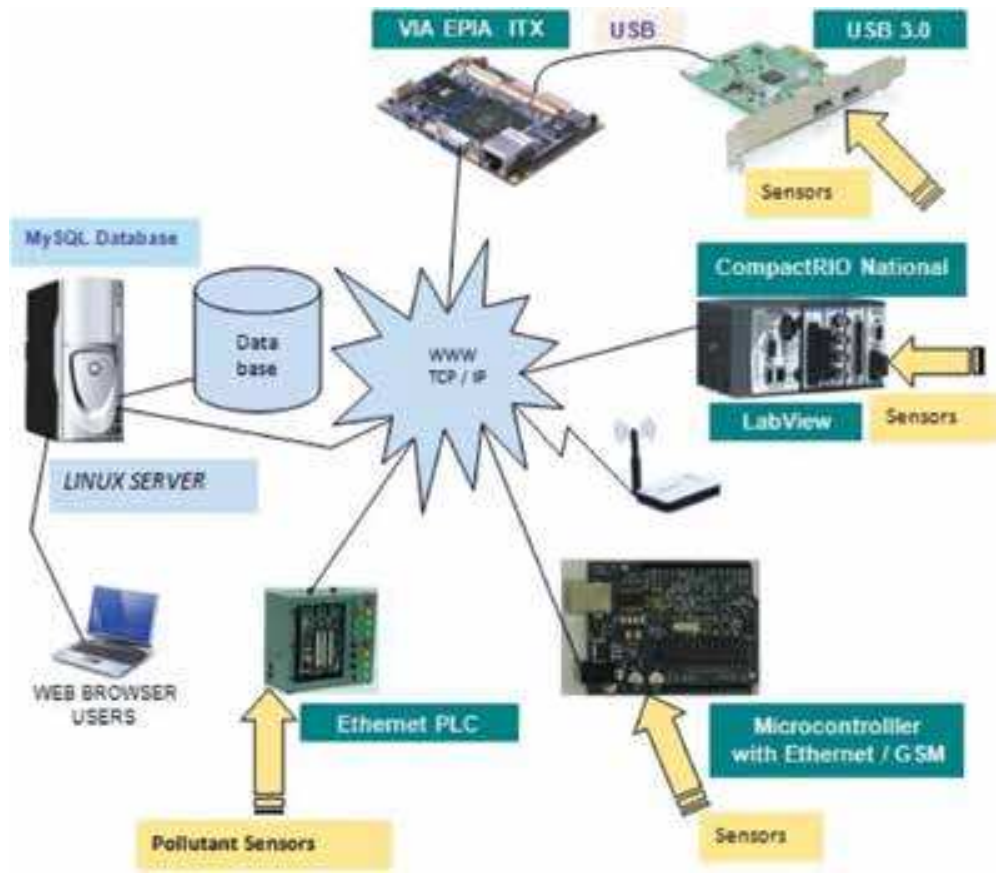

Figure 3.

Data acquisition system.

The physical variables can be acquired by each solution and transmitted via Ethernet to the back-office Linux server.

Typical key performance indicators used in fleet management include operating cost, asset availability and lost-time injuries.

In our analyses, we have defined an emission spectrum to characterise the pollution impact and to infer the engine vehicle class state (Figure 4). This matrix includes effluents and noise. At the same time, the Vehicle Specific Power (VSP) is used.

To reduce downtime, improve the environment, reduce waste and costs and increase process capability, emission spectra (ES) and overall equipment efficiency (OEE) evaluate the performance, as the main key performance indicators that the fleet maintenance needs for continuous improvement. 


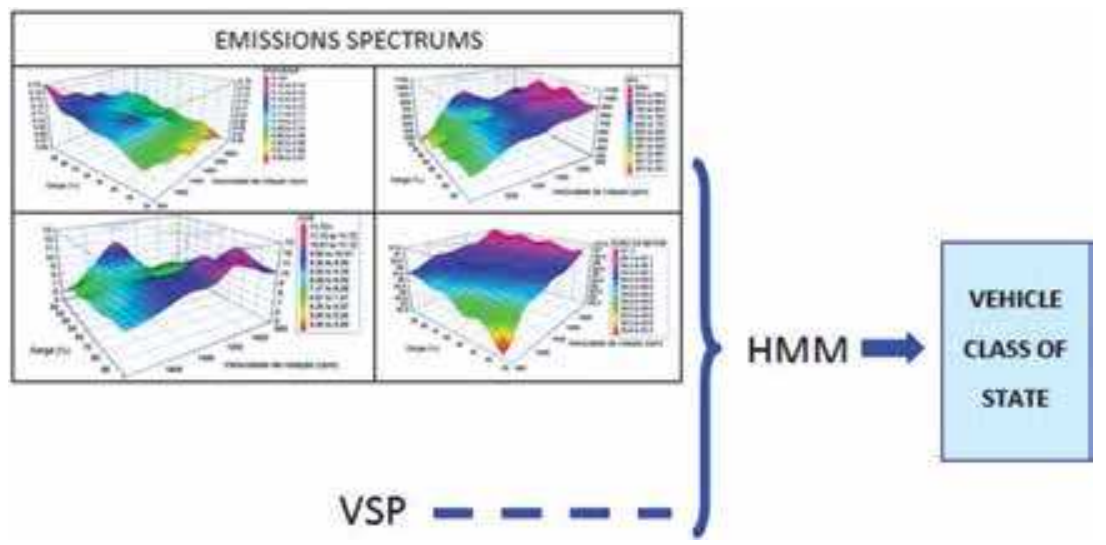

Figure 4 .

Vehicle class of state evaluation.

To determine the impact on the environment and performance for each individual vehicle, maintenance, OEE, the four ES elements (Noise, $\mathrm{NO}_{\mathrm{x}}$, Opacity (or $\mathrm{PM}$ ) and $\mathrm{CO}_{2}$ ), quality of service and availability are very important.

The important variable $\mathrm{CO}$ was not used because this pollutant is not significant in diesel engines. However, it is very relevant in spark ignition vehicles.

Preventive maintenance services and activities are driven by road side sensors or vehicle metre readings. To help and simplify the fleet maintenance management process, all e-maintenance features are combined.

The platform provides the fleet managers with the necessary tools to supervise the operation, such as report generation and others, anytime, anywhere. All those involved in the fleet management increase their degree of satisfaction.

In the development of diesel engines e-maintenance (DEEM), the platform uses the following modules/resources:

- Technical management: methods of condition monitoring and tools, prognosis and state diagnosis.

- Data acquisition and reporting: use of wireless internet when possible, the concepts of e-maintenance management, the newest information technologies, mobile communications for data collection and reporting of malfunctions.

- Analysis and modelling of technical data: tools with advanced techniques that allow to perform environmental impact analysis, HMM analysis, maintenance engineering analysis, reliability block diagram, cause and consequence analysis, life cycle cost, FTA, FMECA, ETA, part counting analysis and tolerance analysis. MatLab was used to construct the model matrix and the response matrix with the predicted values.

- Logistics and systems design: tools that streamline data and information between institutions and departments, aiming to assist management and business decisions. They also assure the project selection of variables and maintenance levels and evaluate diversity and redundancy, levels and factors, maintainability versus reliability, diagnosis and modularity, trade-off studies, ecological predictive maintenance versus preventive maintenance programme, replacement and part control programme. 
The relationship between dysfunctions and symptoms plays a relevant role in the understanding (i.e. diagnosis) of the health condition. A lot of work has been implemented, in order to anticipate the demand for spare parts in the future, almost always automatically.

The environmental specifications and regulations applicable to each case, as well as international standards, help to define the classes and thus adopting a set of limits.

Figure 5 shows DEEM's architecture.

There is a high correlation between the diesel engine states, the diagnosis obtained and the emissions spectra data. However, automatic diagnosis is still not the rule, despite countless successful research applications.

In the future, with data available from numerous sensors, their analysis will be done by automatic programmes to support diagnosis and prognosis. Determining the physical and ecological state of the fleets based on the mixing of emission signals and the dynamic signals of vehicles combined with the OEE is a major challenge. With the automatic acquisition of emissions spectra and traffic signals and advanced processing, even because the volume of data and its relationship cannot be perceived by humans in time, there is a new step in maintenance. So, for humans, this intelligent processing is like a black box: the inputs and the result are known-inside there are algorithms and technologies not noticeable. The future

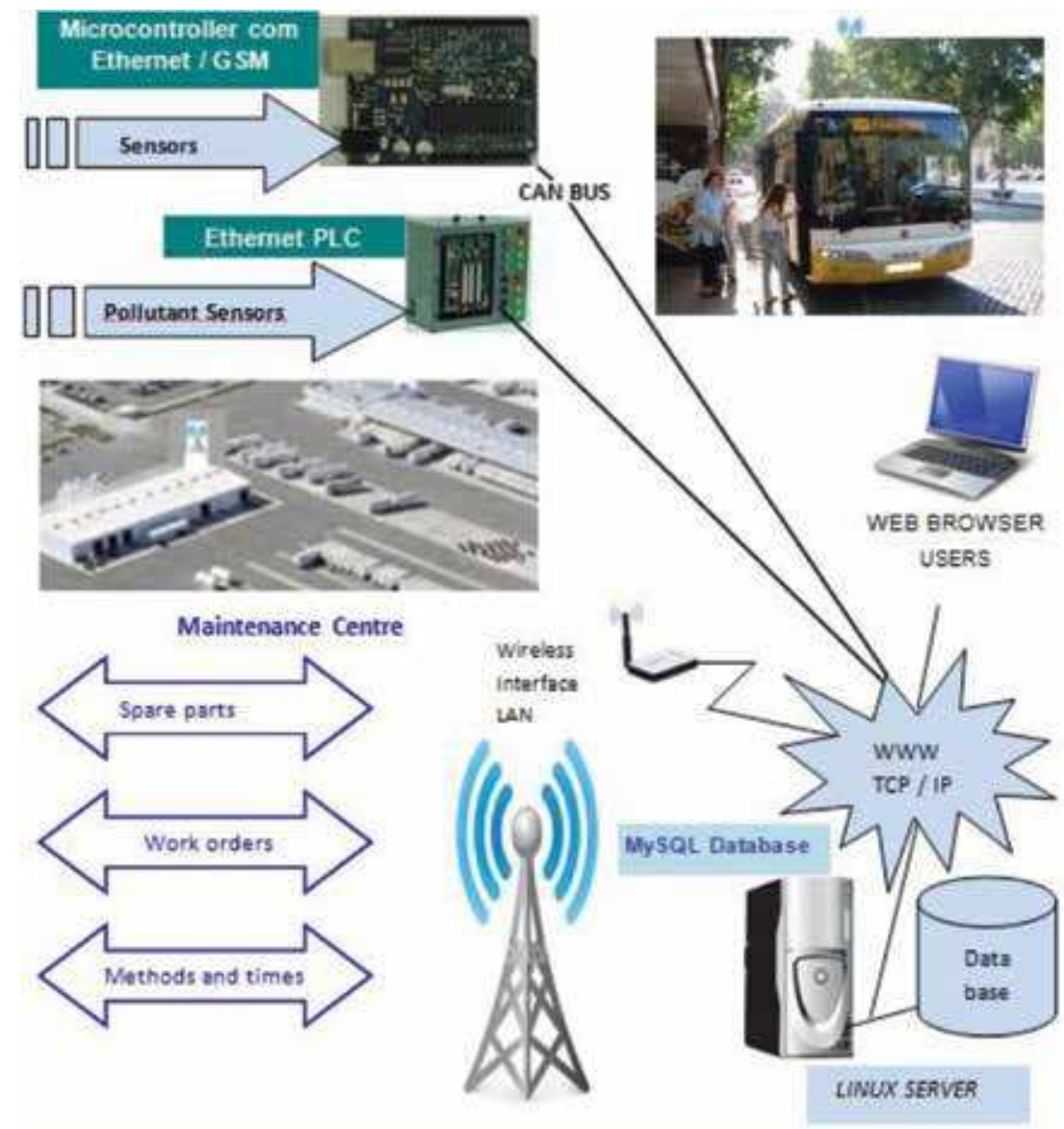

Figure 5 .

Diesel vehicle e-maintenance layout. 
goes in this direction of all digitization and entry of artificial intelligence in the study of the resolution of these problems.

Surprisingly, automatic diagnostics are little used in transport, although much research is done to solve the problem.

The central and municipal administrations have still adhered little, although there are strong indications of new ways. The big challenge is to tailor the entire infrastructure to install sensors and tools, communications and signal analysis to produce useful results.

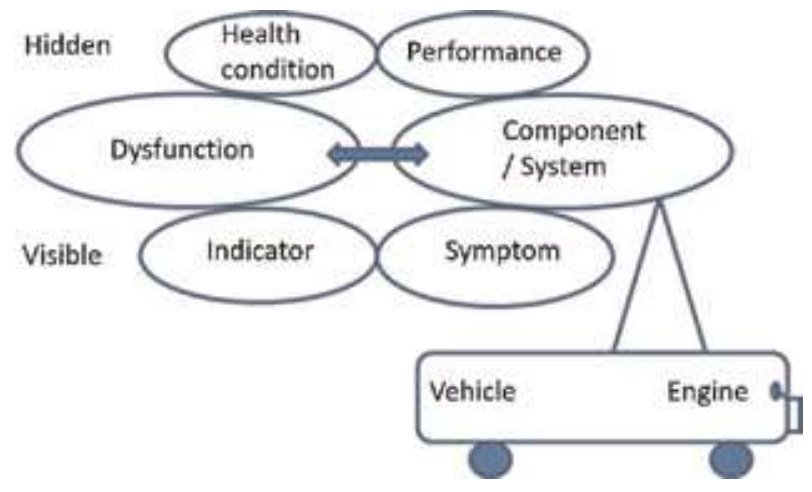

Figure 6.

Fleet model conceptualization.

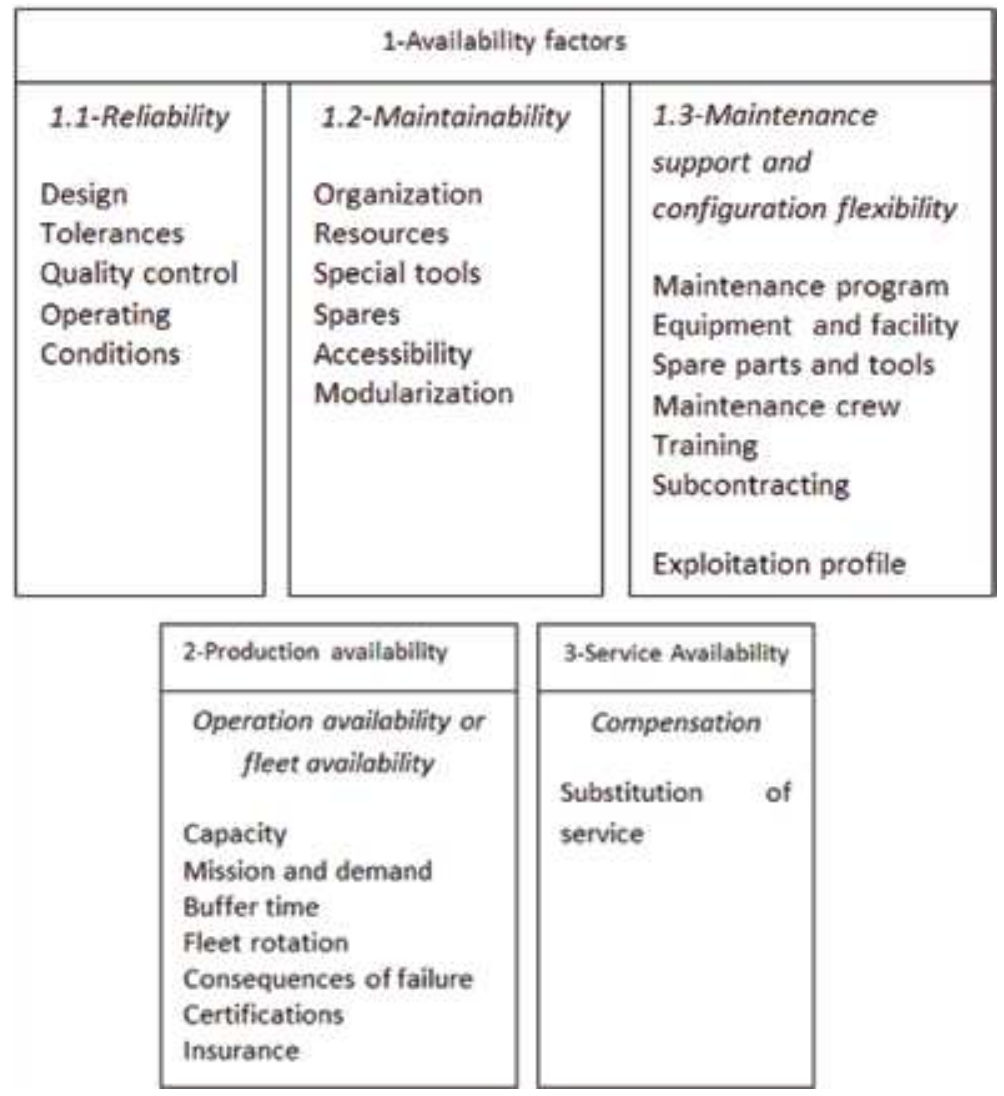

Figure 7.

Availability factors groups. 
Obviously, the correct sensors must be used with appropriate techniques, although the operators have not yet adhered to and facilitated this path.

As a result, continuous research and the obtained results point to obtaining usable knowledge in the scope of the component wear and the correct detection of the prognosis, with the possibility of automating the process. In the future, both the actual data and the simulations for the situations experienced will be available to support the prognosis, diagnosis and monitoring of the condition state.

Maintenance beyond tomorrow solutions can carry out the requests, the acts of management and allocation of the human resources, automatically. If there are errors, neural networks or HMM are important because they evaluate and adapt.

Each fleet has its own context, operational service and performance [10].

The corresponding component and context can define the meaningful health indicator. For example, the system environment may cause abnormal behaviour. In this case, contextual information does not only use technical or service level issues but also environmental issues.

Different criteria or contextualization can help assess the health status of a component. Abnormal behaviours can be defined by symptom indicators, representing the health condition.

The performance context is one of the main objectives in a fleet and is associated to the optimisation capacity (costs and equipment availability).

The relation between dysfunctions and symptoms helps to understand the health condition of the equipment designated by diagnosis (Figure 6).

Achieving the objectives of a company goes through the fleet to meet performance and availability goals, both now and in the future, and for this e-platform, there is a programme for systematic monitoring and evaluation of various aspects of technical activities and services for diesel engine management (Figure 7).

In the operation phase, observations of the fleet availability performance should be used to evaluate the need for corrective actions, that is, improvements and modifications. Feedback should identify [11]:

1. The performance of the fleet according to the established goals and requirements

2. In the case of goals and requirements not reached, where and why the deviations occur

3. The improvements implemented through reliable and low-cost solutions

The main conclusions reported in this article are the following: Why use HMM? How and what model to build? How the values observed can be read? How the model is trained? Why the model is appropriate and how to assess the perplexity index [12].

\section{Hidden markov model}

Markov processes are a class of probabilistic models used to study the evolution of systems along time. Transition probabilities help to identify the evolution of the system between periods. The Markov chain, within its logic, characterises the temporal behaviour of the system, as described in the probability matrix in the first state. 
In order to apply an HMM to the process, it must fall in the next requirements:

- The process must be stochastic.

- The probability to move from one to another state does not depend on the transitions of earlier times. Thus, in calculations only the previous state is necessary.

A Hidden Markov Model inherits from the Markov Model (first order) [13]:

- The states of the model are only observable indirectly and must be inferred (hidden states).

- The measurable variables (emissions, in the present case) depend on the probability of the hidden states.

- Hidden states inherited the behaviour of states from a first-order Markov process.

The next set of probabilities and states/emissions (in this approach) is a set of correlated states of the Hidden Markov Model, that is:

- The hidden states: represent the true state, referring to the Markov process.

- The observable variables (emissions): the visible face of the process, which allow to infer the hidden states.

- The probabilities of the states hidden in the initial step.

- The matrix of transition probabilities: related to hidden states.

- The probability matrix of the output symbol of the model: each element exposes the probability of generating an emission symbol, considering the state in which the model is the probability matrix of the observations.

The present chapter, in the next sections, both in the simplicity and performance of the model, shows that the Hidden Markov Model (HMM) can be used to predict the equipment condition.

There is an initial state probability vector, which represents the probability of the system starting in a given class that links to a state.

In practice, the emissions of a vehicle depend on many factors (variables), such as temperature and engine condition, but also driving, operating conditions and maintenance.

System planning performs cycles between interventions, starting at zero (new vehicle or repaired as new), evolving over time with maintenance and exploration leading to evolution in the states.

In some cases, it is interesting to apply the HMM to continuous densities of observations. For this to be possible, some constraints have to be applied to the probability density function of the model, thus ensuring a consistent re-estimation of the parameters of this function.

A discrete or continuous HMM have the following properties:

- The time of permanence in a state is Markovian (process without memory).

- The next state depends only on the instant of transition and the current state: Markovian property. 
The process can only be discrete (HMM) due to the following two reasons:

1. The dwell time in a state does not need to follow an exponential distribution.

2. In the present approach, this time depends on the climate, the acceleration and other changeable variables. In addition, it is not possible to continuously measure emissions.

The classification of the data introduces difficulties. Researchers using complex classifiers admit that they can solve almost the entire problem. It is a signal that a good classifier gives better performance and avoids system malfunction-which is not always the case.

The present work uses statistics, but the use of neural networks may be a good option.

\subsection{Emissions and states}

Emissions from a diesel engine is a specific situation assumed that there is an initial state (when the engine is new or rebuilt like new), referenced as the state at instant zero. Next states evolve until the limits imposed by international standards, environmental rules and some requisites of each real situation are reached. Figure 8 shows a generic evolution of states and observations in diesel engines context [14].

- $Q:\left\{q_{1} \ldots q_{N}\right\}$-Set of possible values for the hidden states, designated as "states vector" or "states library"

- $V:\left\{V_{1} \ldots V_{M}\right\}$-Set of possible values for the observations, designated as "observations vector" or "emissions collection"

The time evolution of vectors associated with the emission matrix and transition matrix is presented in Figure 9, that is:

- $A=\left\{\mathrm{a}_{i j}\right\}$-Probability matrix (state transition)

- $B=\left\{\mathrm{b}_{i k}\right\}$-Probability matrix (state observation)

The vector for the initial instant must be known as the start model:

- $\prod=\left\{\prod_{i}\right\}-$ Probability matrix (initial state)

The HMM Model comes as:

$$
\left\{Q, V, \prod, A, B\right\}
$$

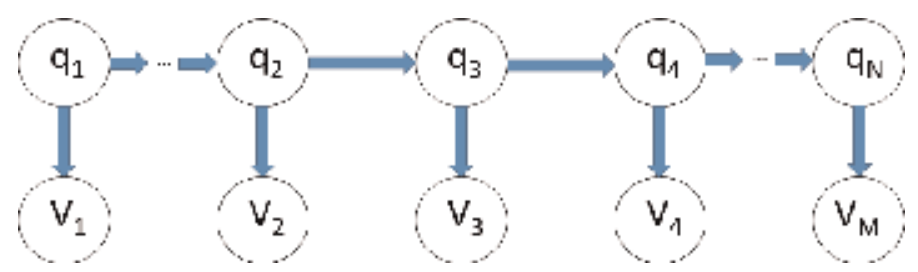

Figure 8.

Hidden states and observed symbols in a diesel engine. 
The implementation of HMM follows the following points:

1. To determine the probability of the observation sequence

2. To know the sequence of observations and to determine the most appropriate sequence of hidden states

3. To know the set of possible models and the observation sequence and to determine which model best fits the data

For a model and an observation sequence, the corresponding sequence probability is as follows:

$$
O=\left(o_{1} \ldots o_{T}\right), \lambda=(A, B, \Pi)
$$

One should calculate $P(O \mid \lambda)$. A hypothesis for this calculation, the sum of the probabilities of the possible state sequences (which lead to this state), is equal to the probability of the observation sequence. However:

- The calculation to the gross force takes time, because in the observations $T$ and $N$, there is $N^{T}$ sequence of possible states.

- If the HMM is small, e.g. $T=9$ and $N=9$, there are approximately 387.5 million hypotheses.

Dynamic programming is one way of solving the problem. The steps to achieve this solution are the following:

$$
\begin{aligned}
& P(O \mid S, \lambda)=b_{s_{1} O_{1}} b_{s_{2} O_{2}} \ldots b_{s_{T} O_{T}} \\
& P(S \mid \lambda)=\pi_{s_{1}} a_{s_{1} s_{2}} a_{s_{2} s_{3}} \ldots a_{S_{T-1} s_{T}} \\
& P(O \mid \lambda)=\sum_{S} P(O \mid S, \lambda) P(S \mid \lambda) \\
& P(O, S \mid \lambda)=P(O \mid S, \lambda) P(S \mid \lambda)
\end{aligned}
$$

that can be resumed by:

$$
P(O \mid \lambda)=\sum_{\left\{S_{1} \ldots S_{T}\right\}} \pi_{s_{1}} b_{s_{1} o_{1}} \prod_{t=1}^{T-1} a_{s_{t} s_{t+1}} b_{s_{t+1} o_{t+1}}
$$

which is the basis of the forward-backward algorithm described in the next section.

The HMM algorithm has quite a few unsolved problems that lead to many answers, giving to the succeeding actions:

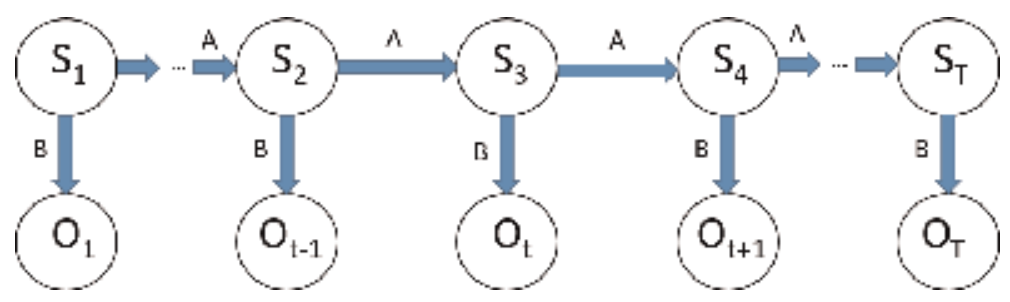

Figure 9.

HMM with transition probability matrixes. 
I. Assessment:

1. Problem: Are there several possible HMMs and a number of observations where HMM probably generate the given sequence?

2. Solution

- For each HMM calculates the probability of the observed sequences.

- The most likely sequence must be chosen.

- Reduce complexity through the Forward algorithm.

II. Interpreting:

1. Problem: For an observation sequence and a given HMM, determine the most likely sequence (underlying hidden sequence) that gave rise to the observations sequence.

2. Solution:

- In a possible sequence of underlying hidden states, determine the probability of the observed sequences.

- The most likely sequence must be chosen.

- Reduce complexity with the Viterbi algorithm.

III.Knowledge:

1. Problem: It does estimate the probabilities of the HMM from the training data.

2. Solution:

a. Train with labelled data [15]:

- To evaluate the transition probability

- $\mathrm{P}\left(q_{i}, q_{j}\right)=$ (number of transitions from $q_{i}$ to $\left.q_{j}\right) /($ total number of transitions of $\left.q_{i}\right)$

- The observation probability matrix $\mathrm{P}\left(q_{i}, V\right)=$ (number of symbol $V$ occurrences in state $q_{i}$ )/(number of all symbol occurrences in state $q_{i}$ )

b. Train with the unlabelled data:

- Baum-Welch algorithm basic idea:

i. To maximise the probability of the observation sequence, given the model

ii. To estimate new probability from the previous HMM until $P$ (current $\mathrm{HMM})-\mathrm{P}$ (previous $\mathrm{HMM})<e$ (a small number) 
3. Problem: Use training data to estimate HMM probabilities.

4. Solution:

a. Train using marked data [15]:

- Transition probability

- $\mathrm{P}\left(q_{i}, q_{j}\right)=\left(\right.$ transitions number from $q_{i}$ to $\left.q_{j}\right) /($ entire number of transitions of $q_{i}$ )

- Observation likelihood matrix $\mathrm{P}\left(q_{i}, V\right)=$ (number of symbol $V$ incidences in state $q_{i}$ )/(number of all symbol incidences in state $q_{i}$ )

b. Train with unmarked data:

- Basic idea-Baum-Welch algorithm:

i. For the model, maximise the probability of the observation sequence.

ii. Evaluate new probability from the preceding HMM until $P$ (current HMM) $-P$ (previous HMM) $<e$ (a lesser number).

For unmarked and marked data [16], the following sections provide a solution to solve this problem.

\subsection{Forward-backward algorithm}

Predicting hidden states is complex and requires efficient algorithms to solve the problem, which can be solved by applying the principles of dynamic programming through the forward-backward algorithm.

It uses the auxiliary variable forward $\alpha_{t}$ (i) that is the probability of observing the partial sequence "O1, O2, ..., Ot" and that at time t we have state Si. This can be defined by Eq. (5):

$$
\alpha_{t}(i)=P\left(O_{1}, O_{2}, O_{3}, \ldots \ldots, O_{t}, S_{t}=q_{i} \mid \lambda\right)
$$

that is the basis of the forward procedure.

The calculation of $\alpha_{t}(i)$ is achieved by the following steps:

$$
\begin{aligned}
& \alpha_{1}(i)=\pi_{i} b_{i}\left(O_{1}\right), \quad 1 \leq i \leq N \\
& \alpha_{t+1}(j)=P\left(O_{1}, \ldots \ldots, O_{t}, O_{t+1}, S_{t+1}=q_{j} \mid \lambda\right)= \\
& \sum_{i=1}^{N} P\left[O_{1}, \ldots ., O_{t}, O_{t+1}, S_{t+1}=q_{j} \mid S_{t}=q_{i}, \lambda\right] \cdot P\left[S_{t}=q_{i} \mid \lambda\right]= \\
& \sum_{i=1}^{N} P\left[O_{1}, O_{2} \ldots ., O_{t} \mid S_{t}=q_{i}, \lambda\right] \cdot P\left[S_{t}=q_{i} \mid \lambda\right] \cdot P\left[O_{t+1}, S_{t+1}=q_{j} \mid S_{t}=q_{i}, \lambda\right] .= \\
& \sum_{i=1}^{N} P\left[O_{1}, \ldots ., O_{t}, S_{t}=q_{i} \mid \lambda\right] . P\left[O_{t+1} \mid S_{t+1}=q_{j}, S_{t}=q_{i}, \lambda\right] \cdot P\left[S_{t+1}=q_{j} \mid S_{t}=q_{i}, \lambda\right]
\end{aligned}
$$




$$
\begin{gathered}
\alpha_{t+1}(j)=b_{j}\left(O_{t+1}\right)\left[\sum_{i=1}^{N} \alpha_{t}(i) a_{i j}\right] \\
\alpha_{t+1}(j)=\left[\sum_{i=1}^{N} \alpha_{t}(i) a_{i j}\right] b_{j}\left(O_{t+1}\right), \quad 1 \leq t \leq T, \quad 1 \leq j \leq N
\end{gathered}
$$

Given a known state at time $t$, the next step is the backward algorithm, which calculates the sequence of probabilities in the observations. The following equations formalise the process:

$$
\beta_{t}(i)=P\left(O_{t+1}, O_{t+2}, O_{t+3}, \ldots \ldots, O_{T} \mid S_{t}=q_{i}, \lambda\right)
$$

- Initialization:

$$
\beta_{T}(i)=1, \quad 1 \leq i \leq N
$$

- Induction:

$$
\beta_{t}(i)=\sum_{j=1}^{N} a_{i j} b_{j}\left(O_{t+1}\right) \beta_{t+1}(j), \quad t=T-1, T-2, \ldots 1 \text { and } 1 \leq i \leq N
$$

The final steps for decoding the solution are

$$
P(O \mid \lambda)=\sum_{i=1}^{N} \alpha_{T}(i)
$$

That is, the forward procedure, and

$$
P(O \mid \lambda)=\sum_{i=1}^{N} \pi_{i} b_{i}\left(O_{1}\right) \beta_{1}(i)
$$

that is, the backward procedure.

\subsection{Viterbi algorithm}

Now we will try to find the states sequence that best explains the observations. This can be done by the Viterbi algorithm, synthesised by Eq. (12):

$$
S^{*}=\arg \max _{S} P(S, O \mid \lambda)
$$

To evaluate this equation, an auxiliary variable $\delta_{t}(i)$ is defined. This variable corresponds to the maximum result (or higher probability) of the recorded sequence of observations, assuming that the end state is stage $q_{i}$ :

$$
\delta_{t}(i)=\underset{S_{1}, S_{2}, S_{3}, \ldots S_{t-1}}{\max } P\left[S_{1} S_{2} S_{3} \ldots \ldots S_{t-1}, S_{t}=q_{i}, \quad \mathrm{O}_{1} O_{2} O_{3} \ldots \ldots O_{t} \mid \lambda\right)
$$


The algorithm may be compactly stated by:

- Initialization:

$$
\begin{aligned}
& \delta_{1}(i)=\pi_{i} b_{i}\left(O_{1}\right), \quad 1 \leq i \leq N \\
& \psi_{1}(i)=0
\end{aligned}
$$

- Recursive computation:

$$
\begin{array}{r}
\delta_{t}(j)=\max _{1 \leq i \leq N}\left[\delta_{t-1}(i) a_{i j}\right] b_{j}\left(O_{t}\right), \quad 2 \leq t \leq T \text { and } 1 \leq j \leq N \\
\psi_{t}(j)=\arg \max _{1 \leq i \leq N}\left[\delta_{t-1}(i) a_{i j}\right], \quad 2 \leq t \leq T \text { and } 1 \leq j \leq N
\end{array}
$$

- Termination:

$$
\begin{gathered}
P^{*}=\underset{1 \leq i \leq N}{\max }\left[\delta_{T}(i)\right] \\
S_{T}^{*}=\arg \underset{1 \leq i \leq N}{\max }\left[\delta_{T}(i)\right]
\end{gathered}
$$

Next step consists of computing the most likely state sequence by backtracking:

$$
\begin{gathered}
S_{t}^{*}=\arg \max _{1 \leq i \leq N}\left[\delta_{t}(i) a_{i q_{t+1}^{*}}\right] \\
S_{t}{ }^{*}=\psi_{t+1}\left(S_{t+1}^{*}\right), \quad t=T-1, T-2, \ldots . ., 1
\end{gathered}
$$

The result is the generation of the sequence:

$$
S_{1}, S_{2}, S_{3} \ldots . . S_{t-1}, S_{t}
$$

\subsection{Baum-Welch algorithm}

The final step is the calibration of the parameters to fully define the HMM; for a sequence of observations, the question is: what is the corresponding model with the same behaviour? For a model and a sequence of observations, adjust the parameters of this model in order to more accurately approximate the observations.

$\xi_{t}(i, j)$ defines the probability of the system being in the state $q_{i}$ at time $t$ and in state $q_{j}$ at time $t+1$ :

$$
\xi_{t}(i, j)=\frac{\alpha_{t}(i) a_{i j} b_{j}\left(O_{t+1}\right) \beta_{t+1}(j)}{\sum_{i=1}^{N} \sum_{j=1}^{N} \alpha_{t}(i) a_{i j} b_{j}\left(O_{t+1}\right) \beta_{t+1}(j)}
$$

Eq. (19) gives the probability of to occur an $i-j$ transition.

$$
\gamma_{t}(i)=\sum_{j=1}^{N} \xi_{t}(i, j) \mathrm{t}=1 \ldots . \mathrm{T}
$$

Eq. (20) gives the probability of being in state $i$ at time $t$.

Now it is possible to compute new estimates for the model parameters:

$$
\begin{gathered}
\hat{\pi}_{i}=\gamma_{1}(i) \\
\hat{a}_{i j}=\frac{\sum_{t=1}^{T-1} \xi_{t}(i, j)}{\sum_{t=1}^{T-1} \gamma_{t}(i)} \\
\hat{b}_{j}(k)=\frac{\sum_{t=1}^{T} \gamma_{t}(j)_{\text {For } O_{t}=V_{k}}}{\sum_{t=1}^{T} \gamma_{t}(j)}
\end{gathered}
$$




\subsection{Perplexity measurement}

The performance of the HMM model can be measured in two ways:

1. By classification accuracy

\section{By perplexity}

The ratio of the number of correct predictions of the state vector hidden by the total number of hidden states (the analysed candidates) defines the accuracy of the classification. For a small sample, the classification accuracy is unreliable and is contaminated with noise, since a sample can be assigned to a single class. For this reason, the perplexity of the data set is a more appropriate alternative. This metric measures the confidence of the predictors of the classifier through the function of the average $\log$-likelihoods $L$ ( of $N$ data sequence), described by Eq. (24):

$$
L_{i}=\log p\left(q_{i} \mid o_{1 \ldots T_{i}}^{i}, \lambda\right) \operatorname{perp}=e^{-\frac{1}{N_{s}} \sum_{i=1}^{N_{s}} L_{i}}
$$

where $o_{1 \ldots T_{s}}^{i}$ represents for the $i$ th sequences of observations of length $T_{s}$ and $q_{i}$ is the type of hidden states $i$; $N_{s}$ is the number of sequences and $\lambda$ the model parameters. The value one is the best quantity for the perplexity, giving probability 1 for the correct task type. A perplexity of 3 means a random decision, with a probability of one-third for each hidden state [17].

\section{Implementation}

Maintenance performance indicators (MPI) are a metric to gauge how the system behaves, that is, measure availability, costs and wastes, process capacity, productivity, quality, health, safety and environmental impact. The objective allows a macro idea of the state of operation of the fleet [18].

The targets for each of the MPIs used can be established as a requirement to compare each measure during the operation period in the future.

The metric associated with OEE, consisting of three elements, Quality, Performance and Availability, allows to calculate the influence of the performance of an equipment's part. The concept of e-maintenance was used in cars and buses to automatically manage the fleet. Their particularities are the following:

a. Notifications of anomalies by email.

b. Detect problems in advance before they occur and undetectable for drivers.

c. Automated system, either at the level of requirements or at the level of consumables, indicates a loss of performance, parts to be replaced and so on.

It is possible to make a remote access to the computers of the buses-the technical assistance can unlock some anomalous situations.

In the case of diesel engines, as mentioned above, they can be represented by a matrix of states taking into account the following variables: $\left\{\mathrm{CO}_{2}, \mathrm{NOx}, \mathrm{PM}\right.$, NOISE, HC\}; the combinations/intercepts designate the observable emission variables $\left\{V_{1}, V_{2}, V_{3}, V_{4} \ldots \ldots . V_{M}\right\}$. 
Thus, including the initial, there are five possible states, and the boundaries to segment the states are:

1. Bad

2. Dysfunctional

3. Tolerable

4.Good

5. Excellent

As the transition matrix is $5 \times 5, \mathrm{q} 1, \mathrm{q} 2, \mathrm{q} 3, \mathrm{q} 4$ and $\mathrm{q} 5$, $\mathrm{t}$ is necessary to identify the four state classes.

Of course, the decision thresholds are four for each variable:

1. Poor or bad

2. Acceptable

3. Good

4. Excellent

At the moment, the model incorporates the variables $\left\{P M, N O_{x}\right.$ and NOISE $\}$.

If the equipment is new or after a maintenance intervention has gone into effect, the hidden and actual initial states may overlap. Generally:

$$
\pi_{i}=P\left[S_{1}=q_{i} \mid\right], \quad 1 \leq i \leq N
$$

where $\pi_{i}=$ Number of times in state $q_{i}$ at time $t=1$.

The elements of the matrix q must be calculated using

$$
\begin{aligned}
& a_{i j}=P\left[S_{t+1}=\mathrm{q}_{j} \mid S_{t}=\mathrm{q}_{i}\right]=\frac{\text { number of transitions from } \mathrm{q}_{i} \text { to } \mathrm{q}_{j}}{\text { number of times in state } \mathrm{q}_{i}} \\
& a_{i j}=P\left[S_{t+1}=\mathrm{q}_{j} \mid S_{t}=\mathrm{q}_{i}\right]=\frac{\text { number of transitions from } \mathrm{q}_{i} \text { to } \mathrm{q}_{j}}{\text { number of times in state } \mathrm{q}_{i}}
\end{aligned}
$$

There are 64 combinations for the 4 levels associated with each. These 64 combinations are grouped into 11 emission classes, namely: $V_{1}, V_{2}, V_{3}, V_{4}, \ldots . . V_{11}$.

$$
A=\left[\begin{array}{lllll}
a_{11} & a_{12} & a_{13} & a_{14} & a_{15} \\
a_{21} & a_{22} & a_{23} & a_{24} & a_{25} \\
a_{31} & a_{32} & a_{33} & a_{34} & a_{35} \\
a_{41} & a_{42} & a_{43} & a_{44} & a_{45} \\
a_{51} & a_{52} & a_{53} & a_{54} & a_{55}
\end{array}\right]
$$

The library of emissions is much more complex, since it integrates the environmental impact of different variables: 


$$
B=\left[\begin{array}{lllllllllll}
b_{1}(1) & b_{1}(2) & b_{1}(3) & b_{1}(4) & b_{1}(5) & b_{1}(6) & b_{1}(7) & b_{1}(8) & b_{1}(9) & b_{1}(10) & b_{1}(11) \\
b_{2}(1) & b_{2}(2) & b_{2}(3) & b_{2}(4) & b_{2}(5) & b_{2}(6) & b_{2}(7) & b_{2}(8) & b_{2}(9) & b_{2}(10) & b_{2}(11) \\
b_{3}(1) & b_{3}(2) & b_{3}(3) & b_{3}(4) & b_{3}(5) & b_{3}(6) & b_{3}(7) & b_{3}(8) & b_{3}(9) & b_{3}(10) & b_{3}(11) \\
b_{4}(1) & b_{4}(2) & b_{4}(3) & b_{4}(4) & b_{4}(5) & b_{4}(6) & b_{4}(7) & b_{4}(8) & b_{4}(9) & b_{4}(10) & b_{4}(11) \\
b_{5}(1) & b_{5}(2) & b_{5}(3) & b_{5}(4) & b_{5}(5) & b_{5}(6) & b_{5}(7) & b_{5}(8) & b_{5}(9) & b_{5}(10) & b_{5}(11)
\end{array}\right]
$$

Next step is to test the model as exemplified in (Table 3).

The challenge is to diagnose not just the state associated to a combination of emissions, but also to the prognoses of the next emission level and correspondent states of health.

Using the operating conditions, one can obtain the degradation models and thus update the initial state probability matrix [8].

The current monitoring systems are enough from the point of view of the predictive diagnosis because, depending on the case, they can anticipate the failure.

As soon as the monitoring system gives the alarm, according to what you read from the sensors, depending on the case, the time to correct the problem is short, otherwise the fault will happen-it requires a detailed analysis of the alarms before or after.

The present model can determine this monitoring data with the corresponding situation at different levels.

About diagnostic results for some of the buses of a fleet are proposed in summary form. A specialist, when using a system like this, in a specific situation, should first focus on the modes of degradation already observed that are re-incidents and/ or associate already solved cases that are similar to the case at hand. The system helps to perceive the behaviour without hiding its complexity, whenever different contextual information is available.

For each model a transition state matrix is created. At the same time, another matrix is created, which associates the probabilities of different classes of the emission indicators to each state.

As an example, if we consider four states and six different emission scenarios, the instructions in MatLab and outputs will be two matrixes " $4 \times 4$ " and " $4 \times 6$ ":

- seq1 = xlsread('inputsallbuses','ENGINE','b72:ao72')

- states1 = xlsread ('inputsallbusesenginesandparts','b18:ao18’)

- [TRANS_EST, EMIS_EST] = hmmestimate (seq1, states1)

In the present case study, the transition matrix is shown in Table 1.

And the emission matrix in Table 2.

\begin{tabular}{|l|l|l|l}
\hline 0,350 & 0,450 & 0,100 & 0,100 \\
\hline 0,125 & 0,000 & 0,875 & 0,000 \\
\hline 0,286 & 0,000 & 0,429 & 0,286 \\
\hline 0,571 & 0,000 & 0,000 & 0,429 \\
\hline
\end{tabular}

Table 1.

Transition matrix. 


\begin{tabular}{|l|l|l|l|l|l}
\hline 0,900 & 0,000 & 0,000 & 0,000 & 0,100 & 0,000 \\
\hline 0,300 & 0,200 & 0,000 & 0,250 & 0,000 & 0,250 \\
\hline 0,429 & 0,143 & 0,286 & 0,143 & 0,000 & 0,000 \\
\hline 0,125 & 0,000 & 0,000 & 0,000 & 0,375 & 0,500 \\
\hline
\end{tabular}

Table 2.

Emission matrix.

\begin{tabular}{lccccccc}
\hline Emission time & $\mathrm{t}=1$ & $\mathrm{t}=2$ & $\mathrm{t}=3$ & $\mathrm{t}=4$ & $\mathrm{t}=5$ & $\mathrm{t}=6$ & $\mathrm{t}=7$ \\
\hline Emissions classification & $\mathrm{V}_{4}$ & $\mathrm{~V}_{5}$ & $\mathrm{~V}_{7}$ & $\mathrm{~V}_{7}$ & $\mathrm{~V}_{4}$ & $\mathrm{~V}_{9}$ & $\mathrm{~V}_{10}$ \\
\hline Real hidden state & $\mathrm{S}_{1}=\mathrm{q}_{1}$ & $\mathrm{~S}_{2}=\mathrm{q}_{4}$ & $\mathrm{~S}_{3}=\mathrm{q}_{4}$ & $\mathrm{~S}_{4}=\mathrm{q}_{5}$ & $\mathrm{~S}_{5}=\mathrm{q}_{2}$ & $\mathrm{~S}_{6}=\mathrm{q}_{5}$ & $\mathrm{~S}_{7}=\mathrm{q}_{5}$ \\
\hline Hidden state classification & $\mathrm{q}_{1}$ & $\mathrm{q}_{4}$ & $\mathrm{q}_{5}$ & $\mathrm{q}_{5}$ & $\mathrm{q}_{2}$ & $\mathrm{q}_{5}$ & $\mathrm{q}_{5}$ \\
\hline
\end{tabular}

Table 3.

Main outputs of ecological HMM.

\begin{tabular}{|c|c|c|c|c|c|c|c|c|c|}
\hline \multicolumn{10}{|c|}{ Actual Stote Probabilities, defined by nine HMM models } \\
\hline & HMMMI & HaAs2 & HIviMs & HMMMA4 & HMAM's & HIN MG & HIv M/ & HMPS & Im:ay \\
\hline Morc probable atate & 2 & 2 & 1 & 3 & 3 & 3 & 3 & 4 & 3 \\
\hline State 3 protiatility & $P_{x, 1}$ & P.: & $P_{2,3}$ & $P_{3,4}$ & $P_{\alpha, 1}$ & $P_{3,1}$ & $P_{3, i}$ & $P_{3,3}$ & $P_{2, y}$ \\
\hline State $\triangle$ probabillty & $P_{i, 1}$ & $P_{\mathrm{a} . \mathrm{Z}}$ & $P_{4,1}$ & $P_{4,4}$ & $P_{\infty}$, & $P_{4,6}$ & $\mathrm{P}_{4, i}$ & $P_{4, y}$ & $\mathrm{P}_{4,3}$ \\
\hline
\end{tabular}

Table 4

Outputs of actual states.

In the present case, it is intended to determine the next health state and the respective level of emissions and also to diagnose the state associated to the combination of emissions as shown in Table 3.

We can to test several models to choose the better one. Table 4 exemplifies how different models generate different outputs of actual states. Each tested model generates the probability of the system to be in one of the possible four states. At the same time is finding the occurrence probability of unfavourable different states (Ps, m-s-state; m-model).

Therefore, the calibration of the model assumes as an important step in the construction of an asset management solution.

The model ends with a part of the forecast, in which the most probable sequence of future emissions and the corresponding states are generated. It calculates until two periods after the current remote sensing reading.

\section{Conclusions}

The chapter gives an overview of an open system approach to e-maintenance with an innovative proposal of how a conventional enterprise can be transformed to a fully automated e-maintenance solution based on an ecologic condition monitoring model. 
The chapter corresponds to a basis for a more in-depth study based on extensive literature review and a case study from which demonstrates how e-maintenance can influence the business model of an organisation and the improvement of the environment in the cities.

The application context of the model and case study presented allow to consider the fleet components' similarities and heterogeneities. Data of the monitored diesel vehicles are considered within their context and enhance the identification of the corresponding health condition. The case study points new ways for the future.

All the developments presented are supported on an information system. The new hardware and software solutions require complex integration and communication among the several pieces of these complex technological devices but are presented to the final user as a friendly solution.

The chapter also mentions the capabilities of the proposed architecture and addresses certain challenges faced in order to enable an open framework.

The findings suggest that the different traditional practices used in preventive and condition monitoring maintenance strategies require the building of customised solutions, according to the specificity of each organisation. An open system solution can tackle the associated problem in a fairly cost-effective way.

A new development, ubiquitous and intelligent system of e-maintenance using standards "on demand", shall facilitate interoperability with existing legacy systems.

The interval between interventions in diesel engines was improved through condition monitoring maintenance planning with the input of condition variables: $\mathrm{CO}_{2}, \mathrm{NO}_{\mathrm{x}}, \mathrm{HC}$, NOISE and PM. The HMM model has been shown to be adequate for maintenance planning based on these variables despite the complexity of it. The Viterbi and Baum-Welch algorithms are used in the present model.

For automatic detection of environmental impacts, the efficiency of the prediction model depends on the characteristics of the system and the sampling frequency of the measured physical variables.

Urban areas can improve environmental quality, if we reduce emissions-this is a new paradigm for building a better world.

The model has a potential versatility to be applied in various fields to evaluate the health status of the equipment.

The upcoming work will involve research towards a decision tool to assess the need for vehicle maintenance, as well as actions to be taken-an integrated application for urban transport. Remote sensor devices will be used by the system to measure emissions. The chapter also mentions the capabilities of the proposed architecture and addresses some challenges in order to enable an open framework.

\section{Acronyms}

$\begin{array}{ll}\text { CBM } & \begin{array}{l}\text { condition-based maintenance. } \\ \text { carbon dioxide }\end{array} \\ \mathrm{CO}_{2} & \begin{array}{l}\text { diesel engines e-maintenance } \\ \text { ecological maintenance performance indicators }\end{array} \\ \text { EMPI } & \begin{array}{l}\text { ecological predictive maintenance } \\ \text { EPM }\end{array} \\ \text { ES } & \text { emissions spectrums } \\ \text { ETA } & \text { estimated time for accomplishment } \\ \text { FMECA } & \text { failure mode, effects and criticality analysis } \\ \text { FTA } & \text { fault tree analysis } \\ \text { HC } & \text { hydrocarbons } \\ \text { HMM } & \text { Hidden Markov Model }\end{array}$


ICT information and communication technology

$\mathrm{NO}_{\mathrm{x}} \quad$ nitrogen oxides

OEE overall equipment effectiveness

PM particulate matter

TCP/IP transmission control protocol/internet protocol

UDP unreliable datagram protocol

VSP vehicle specific power

\section{Author details}

António Simões ${ }^{1,3 *}$, José Torres Farinha ${ }^{1,3}$ and Inácio Fonseca ${ }^{2,3}$

1 Department of Mechanical Engineering, Coimbra Polytechnic_ISEC, Coimbra, Portugal

2 Department of Electrical Engineering, Coimbra Polytechnic_-ISEC, Coimbra, Portugal

3 CEMMPRE (Centre for Mechanical Engineering, Materials and Processes), Coimbra, Portugal

*Address all correspondence to: assimoes@isec.pt

\section{IntechOpen}

(C) 2020 The Author(s). Licensee IntechOpen. Distributed under the terms of the Creative Commons Attribution - NonCommercial 4.0 License (https://creativecommons.org/ licenses/by-nc/4.0/), which permits use, distribution and reproduction for non-commercial purposes, provided the original is properly cited. (cc) BY-NC 


\section{References}

[1] Clark N, Gajendran P. Predictive Tool for Emissions from Heavy-Duty Diesel Vehicles. Department of Mechanical and Aerospace Engineering, Argonne National Laboratory; 2003

[2] Biswal M, Parida A. An integrated approach for open e-Maintenance: Opportunities and challenges. In: 1st international workshop and congress on eMaintenance; Luleå, Sweden. 2010

[3] Monnin M et al. Fleet-wide health management architecture. In: Annual Conference of the Prognostics and Health Management Society; Montreal, Canada. 2011

[4] Frey C et al. Comparing Real-World Fuel Consumption for Diesel and Hydrogen Fuelled Transit Buses and Implication for Emissions.

Transportation Research - Part D. ScienceDirecct/Elsevier; 2007. DOI: 10.1016/j.trd.2007.03.003. www.elsevie r.com/locate/trd

[5] Simões A et al. Ecological predictive maintenance in hospital equipment. In: Proceedings of 20th Congress of the International Federation of Hospital Engineering (IFHE), Barcelona; 19-22 October 2008

[6] Rabiner L et al. On the application of vector quantization and hidden markov models to speaker-independent, isolated word recognition. The Bell System Technical Journal. 1983;62(4):1075-1105

[7] Rabiner L. A tutorial on Hidden Markov Models and selected applications in speech recognition. Proceedings of the IEEE. 1989;77(2):257-286

[8] Simões A et al. Buses degradation based on exploration conditions. In: Proceedings of the 3rd WSEAS International Conference on Energy Planning, Energy Saving, Environmental Education; 2009. p. 141-149. ISSN: $1790-5095$, ISBN: 978-960-474-093-2

[9] Verma AK et al. A systemic approach to integrated E-maintenance of large engineering plants. International Journal of Automation and Computing. 2010;7 (2):173-179

[10] Monnin M et al. Fleet historical cases for predictive maintenance. In: PREDICT 19. Nancy Cedex, France: Centre de Recherche en Automatique de Nancy (CRAN), Nancy Université, UMR 7039 CNRS-UHP-INPL, Faculté des Sciences-1er Cycle - BP239; France: Vandoeuvre-Les-Nancy Cedex; 2012

[11] Ahmadi A et al. Prerequisites for a Business-oriented Fleet Availability Assurance Program in Aviation. In: 1st International Workshop and Congress on e-Maintenance; Luleå, Sweden. 2010

[12] Bilmes J. What HMMs Can Do. UWEE Technical Report Number WEETR-2002-0003. Seattle, Washington: Department of Electrical Engineering, University of Washington; 2009

[13] Cunha A. Métodos Probabilisticos para Reconhecimento de Voz. Technical Report TR-03-04. Brasil: Instituto de Matemática Pura e Aplicada, Laboratório VISGRAF; 2003

[14] Simões A. Manutenção Condicionada às Emissões Poluentes em Autocarros Urbanos-Diagnóstico por Cadeias Escondidas de Markov [Doctor Doctoral Thesis]. Lisbon's High Institute of Technology (IST); 2011

[15] Zhou D et al. Learning from Labeled and Unlabeled Data Using Random Walks. Tuebingen, Germany: Max Planck Institute for Biological Cybernetics; 2005 
[16] Seeger M. Learning with Labeled and Unlabeled Data. Edinburgh:

Institute for Adaptive and Neural

Computation. University of Edinburgh;

2002

[17] Simola J et al. Using hidden Markov Model to uncover processing states from eye movements in information search tasks. Cognitive Systems Research. 2008;9(4):237-251. Elsevier Science

[18] Simões A et al. Ecological predictive maintenance in urban fleets. In: Proceedings of the 5th IASME/WSEAS International Conference on Energy \& Environment (EE'10); 2010. pp. 46-53. ISSN: 1790-5095 384, ISBN: 978-960474-159-5 


\title{
$\mathrm{NO}_{\mathrm{x}}$ Pollutants from Diesel Vehicles and Trends in the Control Technologies
}

\author{
İbrahim Aslan Reşitoğlu
}

\begin{abstract}
Nowadays, climate change that caused from air pollution has become a major problem on the agenda of almost all countries around the world. Compared to other air pollutants, $\mathrm{NO}_{\mathrm{x}}$ emissions have an important share in climate change, and especially diesel vehicles are one of the most important sources for the formation of $\mathrm{NO}_{\mathrm{x}}$ pollutants. This chapter focused on $\mathrm{NO}_{\mathrm{x}}$ emissions from diesel vehicles and the trends in $\mathrm{NO}_{\mathrm{x}}$ control technologies; Exhaust Gas Recirculation (EGR), Lean $\mathrm{NO}_{\mathrm{x}}$ trap (LNT) and Selective Catalytic Reduction of $\mathrm{NO}_{\mathrm{x}}$ by ammonia $\left(\mathrm{NH}_{3}-\mathrm{SCR}\right)$ and hydrocarbons (HC-SCR). The reasons of the $\mathrm{NO}_{\mathrm{x}}$ emissions, environmental effects and damages on human health, $\mathrm{NO}_{\mathrm{x}}$ emissions from diesel engines and diesel engine parameters affecting $\mathrm{NO}_{\mathrm{x}}$ emissions are handled in detail. The EGR, LNT and SCR technologies that had large reduction rates of $\mathrm{NO}_{\mathrm{x}}$ emissions and the latest developments in these systems are comprehensively explained.
\end{abstract}

Keywords: air pollution, $\mathrm{NO}_{\mathrm{x}}$ emissions, diesel engine, EGR, LNT, SCR

\section{1. $\mathrm{NO}_{\mathrm{x}}$ emissions in the window of life cycle}

Air pollution causes serious damage to human health and the environment. The World Health Organization reported that 9 out of every 10 people in the world breathe polluted air and 7 million people lost their lives due to air pollution [1]. Harmful gases, which are released from industrial facilities, power plants, automobiles and other transport vehicles, threaten human health by entering the airways, the lungs and the bloodstream from there. In addition to human health, biodiversity and ecosystems are also endangered by air pollution. The damages of air pollution at financial level reach very serious figures [2]. It is reported that in 2015, air pollution caused USD 280 billion expense only in social assistance costs worldwide [3]. From past to present, dozens of reports on air pollution and its effects have been published by various organizations, and various policies and plans have been drafted and regulations and laws have been enacted in order to prevent air pollution [4-10].

$\mathrm{NO}_{\mathrm{x}}$ emissions are one of the most important pollutants causing air pollution and climatic change. $\mathrm{NO}_{\mathrm{x}}$ emissions are in the most effective pollutant class with $\mathrm{PM}$ and ozone $\left(\mathrm{O}_{3}\right)$ [8]. All kinds of sources where combustion is performed at high temperatures (internal combustion engines, gas turbines, power plants, industry etc.) create $\mathrm{NO}_{\mathrm{x}}$ emissions and $95 \%$ of $\mathrm{NO}_{\mathrm{x}}$ emission is made by these sources [4] 
$\mathrm{NO}_{\mathrm{x}}$ emissions are called nitrogen oxides and are usually in the form of nitrogen monoxide (NO) and nitrogen dioxide $\left(\mathrm{NO}_{2}\right)$. NO emission is a colorless and odorless gas and poisonous to humans. $\mathrm{NO}_{2}$ gas is a highly reactive gas in red-brown color and has a suffocating odor and high oxidizing property. Compared with NO gas, the toxic effect of $\mathrm{NO}_{2}$ gases is 5 times higher [11, 12].

The effects of $\mathrm{NO}_{\mathrm{x}}$ emissions on human health are on a frightening scale. Today, pollutant emissions and especially $\mathrm{NO}_{\mathrm{x}}$ emissions lie behind the problems, which about many individuals complain. The report of the European Environment Agency (EEA), published in 2017, shows the extent of the air pollution and the threat of global warming caused by $\mathrm{NO}_{\mathrm{x}}$ emissions. It is stated in this report that $\mathrm{NO}_{\mathrm{x}}$ emissions in 2014 caused about 80,000 premature deaths in Europe [8].

The effects of $\mathrm{NO}_{\mathrm{x}}$ gases on human health are directly proportionate to the density and inhalation period. Low rates or short-term inhalation of $\mathrm{NO}_{\mathrm{x}}$ emissions can cause health problems such as eye and throat irritation, chest tightness, nausea, headache and loss of strength. Long-term or large amount of exposure to $\mathrm{NO}_{\mathrm{x}}$ gases causes severe coughing, difficulty in breathing, asthma, cyanosis, and sometimes give rise to even death [13]. The World Health Organization (WHO) states that $80 \%$ of lung diseases and lung cancer are caused by air pollution, particularly by $\mathrm{NO}_{\mathrm{x}}$ [9]. A study found that $\mathrm{NO}_{\mathrm{x}}$ emissions causes premature birth resulting from asthma in pregnant women [14].

$\mathrm{NO}_{\mathrm{x}}$ pollutant emissions also play an important role in ground-level ozone formation, which has serious adverse effects on human health and the environment. In the natural process, ozone $\left(\mathrm{O}_{3}\right)$ is a very reactive form of oxygen formed in the upper layer of the atmosphere and protects the earth from the sun's ultraviolet rays. However, the ozone layer that takes place due to the pollutant emissions under the atmosphere is very dangerous. When $\mathrm{NO}$ emissions are released into the air, they react with $\mathrm{O}_{2}$ in the air and form $\mathrm{NO}_{2}$ and cause formation of undesirable groundlevel ozone. Ozone formed in this way leads to global warming, causing serious damage to human health and environment [15].

Ground-level ozone formation, which is caused by $\mathrm{NO}_{\mathrm{x}}$ emissions, invites global warming by increasing the greenhouse effect. Due to the undesirable ozone formation, the year 2015 has been the hottest year since the past [8].

Figure 1 shows the effect of $\mathrm{NO}_{\mathrm{x}}$ emissions on ozone and greenhouse gases. The rays coming on the Earth are reflected by the earth and are absorbed by the gases (mainly carbon dioxide $\left(\mathrm{CO}_{2}\right)$, methane $\left(\mathrm{CH}_{4}\right)$ and water vapor) in the atmosphere. This natural process called the greenhouse effect give rise earth to warm. The presence of redundant gases in the atmosphere causes the reflected radiation to be held at a high level, resulting increase in warming and temperatures than the normal level in the earth. The activity of the people, especially the emissions of $\mathrm{NO}_{\mathrm{x}}$ pollutants formed from the consumption of fossil fuels, cause the greenhouse effect to intensify by increasing the amount of greenhouse gases. The formation of greenhouse gases more than normal in the atmosphere, brings with it climate change and global warming.

Rain is very effective in removing $\mathrm{NO}_{2}$ gases from the atmosphere. However, the contact of $\mathrm{NO}_{2}$ gas with water produces nitrous acid $\left(\mathrm{HNO}_{2}\right)$ and nitric acid $\left(\mathrm{HNO}_{3}\right)$, which have a very corrosive effect (Figure 2). This leads to acid rain, which is harmful particularly for plants. In addition to acid rain, the combination of $\mathrm{NO}_{2}$ emissions with hydrocarbon (HC) emissions leads to the formation of photochemical smog.

Many precautions are taken by various organizations to reduce the negative effects of $\mathrm{NO}_{\mathrm{x}}$ emissions on human health and the environment, and various policies and laws are being established. In 2030, if severe climatic policies are implemented, two-thirds of the $\mathrm{NO}_{\mathrm{x}}$ emissions in 2005 will be reduced [16]. Creation of clean air zones, establishment of emissions standards by various organizations, taking necessary measures to eliminate pollutant emissions are among the policies 


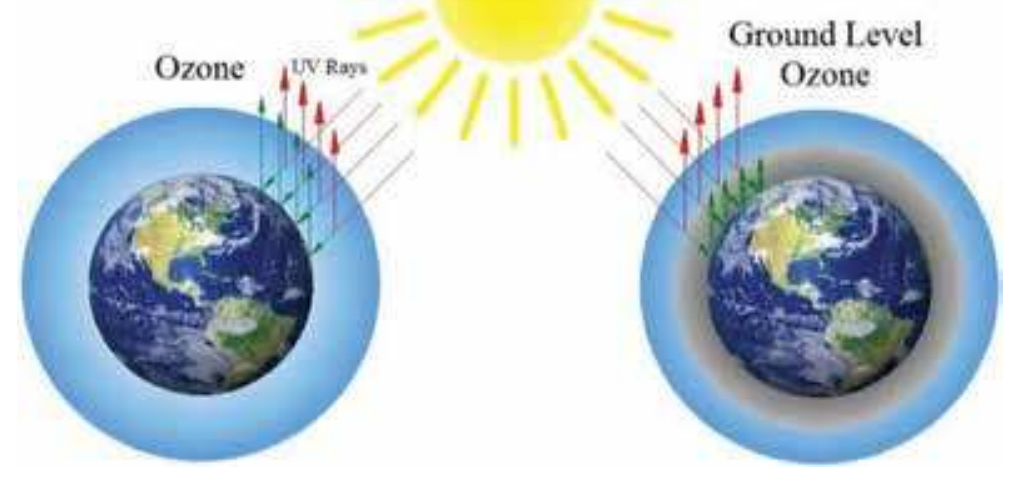

Figure 1.

Ozone \& ground level ozone and greenhouse effect.

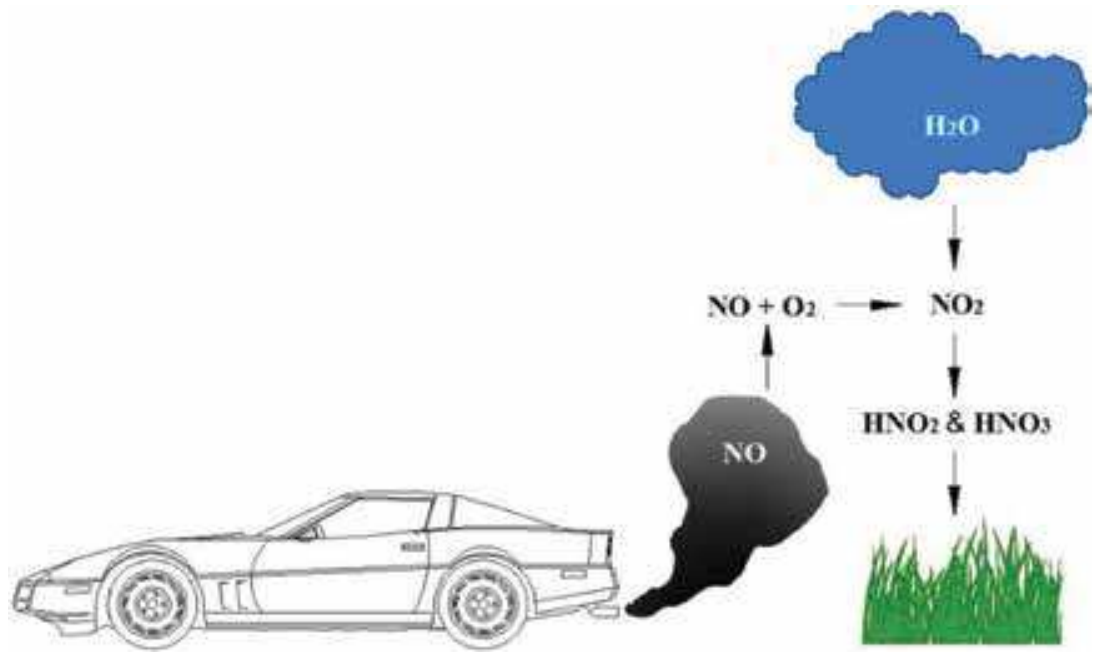

Figure 2.

The formation of acid rains.

that developed to prevent $\mathrm{NO}_{\mathrm{x}}$ emissions. Significant work is being done around the world to remove old model vehicles which are far from emissions standards, and which cause high levels of pollutant emissions and leading to serious environmental and human health problems. As a result of established policies and measures taken, in many countries, $\mathrm{NO}_{\mathrm{x}}$ emissions and other pollutant emissions have been significantly reduced compared to previous periods [7, 10, 17-19].

\section{2. $\mathrm{NO}_{\mathrm{x}}$ emissions from diesel engines}

Road transport takes place on the top among sources that bring on the formation of $\mathrm{NO}_{\mathrm{x}}$ emissions. Due to its high efficiency and low fuel consumption, diesel engines with a wide range of applications in the transportation sector lead a high rate of $\mathrm{NO}_{\mathrm{x}}$ emission. Diesel vehicles play an important role in the formation of $\mathrm{NO}_{\mathrm{x}}$ emissions causing air pollution. 
There are three different mechanisms of $\mathrm{NO}_{\mathrm{x}}$ formation in diesel engines, prompt $\mathrm{NO}_{\mathrm{x}}$, fuel $\mathrm{NO}_{\mathrm{x}}$ and thermal $\mathrm{NO}_{\mathrm{x}}$. Prompt $\mathrm{NO}_{\mathrm{x}}$ formation occurs because of rapid reactions between the nitrogen, oxygen and hydrocarbon radicals. In case of the presence of nitrogen content in the fuel, the nitrogen contained in the fuel reacts with oxygen and this mechanism defined as fuel $\mathrm{NO}_{\mathrm{x}}$. In the thermal $\mathrm{NO}_{\mathrm{x}}$ mechanism, nitrogen and oxygen react at high temperatures and cause $\mathrm{NO}_{\mathrm{x}}$ formation [20].

The thermal $\mathrm{NO}_{\mathrm{x}}$ mechanism is generally seen as the main source of $\mathrm{NO}_{\mathrm{x}}$ formation in diesel engines. The Zeldovich model given below explains this mechanism.

$$
\begin{gathered}
\mathrm{O}+\mathrm{N}_{2} \leftrightarrow \mathrm{NO}+\mathrm{N} \\
\mathrm{N}+\mathrm{O}_{2} \leftrightarrow \mathrm{NO}+\mathrm{O} \\
\mathrm{N}+\mathrm{OH} \leftrightarrow \mathrm{NO}+\mathrm{H}
\end{gathered}
$$

The NO emissions resulting from the reaction (1)-(3) can be converted to $\mathrm{NO}_{2}$ or back to NO form with the following reactions.

$$
\begin{gathered}
\mathrm{NO}+\mathrm{HO}_{2} \rightarrow \mathrm{NO}_{2}+\mathrm{OH} \\
\mathrm{NO}_{2}+\mathrm{O} \rightarrow \mathrm{NO}+\mathrm{O}_{2}
\end{gathered}
$$

Temperature and oxygen content are the two basic parameters affected the thermal $\mathrm{NO}_{\mathrm{x}}$ mechanism. Diesel engines are operated with lean mixtures that had high air excess coefficients. Thus, the combustion process involves more oxygen than necessary. On the other hand, the high compression ratios of diesel engines create high combustion end temperatures in combustion chamber. Therefore, diesel engines offer a very effective infrastructure for the formation of $\mathrm{NO}_{\mathrm{x}}$ emissions. Compression ratio and air excess coefficient values of diesel engines are considerably higher than those of gasoline engines. In this case, when compared with gasoline engines, diesel engines causes the generation of $\mathrm{NO}_{\mathrm{x}}$ emissions at much higher rates.

When cylinder temperature exceeds about $1500^{\circ} \mathrm{C}, \mathrm{N}_{2}$ gas in the air taken into the cylinder reacts with oxygen to form $\mathrm{NO}_{\mathrm{x}}$ [21]. Depending on the increase in temperature, $\mathrm{NO}_{\mathrm{x}}$ also increase. Each increase of $1 \%$ in temperature over $1700^{\circ} \mathrm{C}$ causes $20 \%$ increase in $\mathrm{NO}_{\mathrm{x}}$ [22].

Besides the combustion end temperature, thermodynamic conditions, combustion reaction, flame speed and the time that the burned gases exposed to high temperature are the main parameters affected the formation of $\mathrm{NO}_{\mathrm{x}}$ emissions. All kinds of engine specifications, which have an effect on these parameters, play an effective role in the formation of $\mathrm{NO}_{\mathrm{x}}$. Some of these specifications include compression ratio, injection system, injection timing, combustion chamber geometry, air excess coefficient, engine speed and fuel composition.

The air excess coefficient, which is the function of the amount of oxygen present in the cylinder, is obtained by dividing the actual air/fuel ratio received into the cylinder to the theoretical air/fuel ratio required to burn a unit fuel. The air excess coefficient is denoted by the symbol $\lambda$. When $\lambda$ is bigger than 1 , it means that the mixture inside the cylinder is lean and when it is smaller than 1 , it means that the mixture inside the cylinder is rich and when it is equal to 1 , it means that it is the stoichiometric ratio. When $\lambda$ is around 1.1, maximum $\mathrm{NO}_{\mathrm{x}}$ formation occurs. As the air/fuel ratio increases above 1.1 and the mixture becomes leaner, the cylinder temperature decreases and $\mathrm{NO}_{\mathrm{x}}$ emissions decrease. 


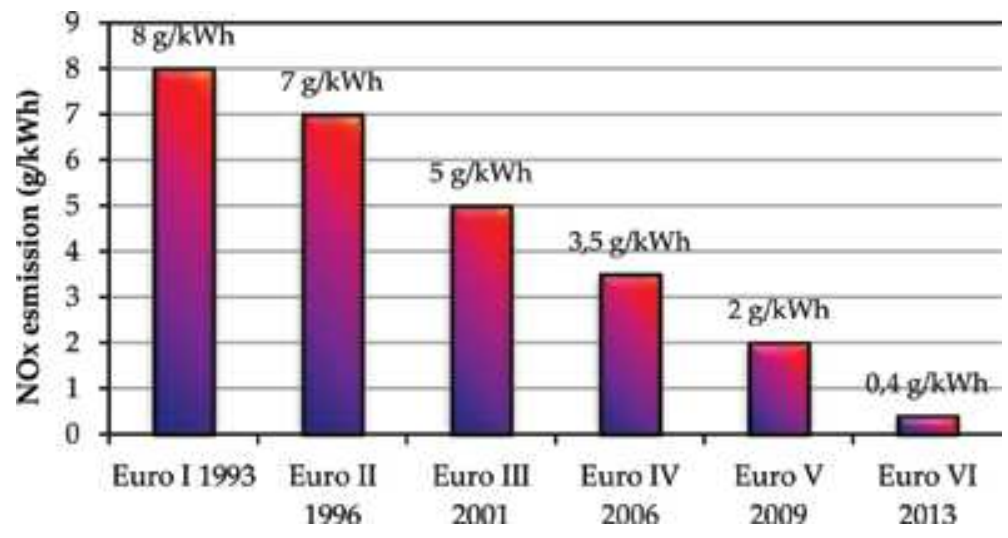

Figure 3.

Euro standards of $\mathrm{NO}_{x}$ emission for heavy-duty vehicles [24].

In diesel engines, a large majority (80-85\%) of $\mathrm{NO}_{\mathrm{x}}$ emissions formed as a result of combustion are in $\mathrm{NO}$ form. Almost all of the $\mathrm{NO}_{\mathrm{x}}$ emissions occur during 20 CAD (Crank Angle Degree) following the start of combustion [23].

The fact that diesel-powered vehicles have more widespread use due to their superiority over gasoline-powered vehicles and the ever-increasing number of diesel-powered vehicles leads to a significant increase in $\mathrm{NO}_{\mathrm{x}}$ emissions released to the environment.

Figure 3 presents the Euro Standards of $\mathrm{NO}_{\mathrm{x}}$ emission for heavy-duty vehicles. The European Union first introduced euro standards for heavy-duty vehicles in 1993 to reduce the damages of $\mathrm{NO}_{\mathrm{x}}$ emissions from diesel vehicles on human health and environment.

The amount of $\mathrm{NO}_{\mathrm{x}}$ applicable to heavy-duty vehicles under Euro VI standards, which has been in effect since 2013 , has been reduced to $0.4 \mathrm{~g} / \mathrm{kWh}$. This value is exactly $92 \%$ lower compared to the Euro III standard which was implemented in 2001. It is aimed to reduce the amount of $\mathrm{NO}_{\mathrm{x}}$ to below $0.1 \mathrm{~g} / \mathrm{kWh}$ in 2023 .

Many research and development activities are carried out scientifically or commercially to eliminate $\mathrm{NO}_{\mathrm{x}}$ emissions from diesel engines. Developed methods for reducing $\mathrm{NO}_{\mathrm{x}}$ emissions in these activities are divided into pre-treatment and aftertreatment methods. Reducing of $\mathrm{NO}_{\mathrm{x}}$ emissions before directing to the exhaust port of the engine is called pre-treatment method and reducing of $\mathrm{NO}_{\mathrm{x}}$ emissions after directing to the exhaust port of engine is called after-treatment method. Exhaust Gas Recirculation (EGR), electronically controlled fuel injection, engine modification, increasing injection timing, water spray in the combustion chamber, improvement of fuel properties, use of fuel additives, etc. are pre-treatment methods of reducing $\mathrm{NO}_{\mathrm{x}}$ emissions. Lean $\mathrm{NO}_{\mathrm{x}}$ trap (LNT) catalysts and the Selective Catalytic Reduction System are the examples of after treatment methods. This study focuses on Exhaust Gas Recirculation (EGR), Lean NOx trap (LNT) catalysts and Selective Catalytic Reduction (SCR) systems, which have been developed to prevent $\mathrm{NO}_{\mathrm{x}}$ emissions and which are widely used in diesel engines. Since they are the most effective methods for eliminating $\mathrm{NO}_{\mathrm{x}}$ emissions, these three systems are focused on. Each $\mathrm{NO}_{\mathrm{x}}$ emission control system is addressed in detail in the light of current information.

\section{Exhaust gas recirculation (EGR)}

EGR is a system developed to incorporate some of the exhaust gases in the cylinder into the combustion process with the intake air. The purpose here is to lower the 
combustion end temperature and thus the $\mathrm{NO}_{\mathrm{x}}$ emission values by deteriorating the combustion performance, because high temperature is the main influence in the formation of $\mathrm{NO}_{\mathrm{x}}$ emissions. The use of the EGR system reduces the amount of oxygen in the cylinder, and therefore resulting in a decrease in the combustion end pressure and temperature. The decrease in the amount of oxygen suppresses the formation of $\mathrm{NO}_{\mathrm{x}}$. The exhaust gas recirculated in the cylinder and containing large amounts of $\mathrm{CO}_{2}$ and $\mathrm{H}_{2} \mathrm{O}$ increases the specific heat capacity of the intake charge, and this reduces the temperature values in the compression and combustion processes [25]. Displacement of some of the oxygen content in the intake charge by the exiting exhaust gases reduces the air excess coefficient and increases the ignition delay by diluting the intake charge. This slows the mixture of oxygen with fuel and therefore the combustion rate.

The EGR system developed to reduce the combustion end temperature in the cylinder has been widely used by automobile manufacturers since the past. The circulation of the exhaust gas with the intake air can be achieved in two different ways; external and internal [26]. In the external exhaust gas recirculation, the exhaust gas taken from the exhaust manifold is sent to the intake stream through a valve and a coolant. In the internal exhaust gas recirculation, unlike the external exhaust gas recirculation, some of the combustion exhaust gas is withdrawn to the combustion chamber before exiting the exhaust valve. This is accomplished by delaying the camshaft and closing the exhaust valves a little later than normal. The late closing of the exhaust valve allows the piston to draw a portion of the exhaust gas at the outlet of the exhaust valve into the cylinder while the piston is moving downward at intake stroke. The engines, which have the internal EGR systems, are run with variable valve timing. Compared with external EGR, the internal EGR system remains weak in controlling exhaust gas into the cylinder. In addition, since no cooling operation can be performed on the recirculated exhaust gas, desired reductions in $\mathrm{NO}_{\mathrm{x}}$ emission values are not achieved. The internal EGR system is generally preferred for gasoline engines, which have lower $\mathrm{NO}_{\mathrm{x}}$ emissions compared to diesel engines. On the other hand, external EGR systems are widely used in diesel engines.

Figure 4 shows the structure of a conventional EGR system used in diesel engines. The system simply consists of valve, control unit and coolant. The EGR valve mounted on the intake manifold is controlled by the control unit. The function of the EGR valve is to control the flow of exhaust gas to intake port depending on the engine load. The amount of exhaust gas sent to the intake port may constitute a maximum of $50 \%$ of the air taken into the combustion chamber [27]. Because of the high exhaust gas content included in the combustion, the combustion performance is greatly affected; therefore the engine performance can decrease significantly. For this reason, the exhaust gas content mixed with the intake air does not exceed $20 \%$ in practice.

The cooling of the exhaust gas included in the combustion process in the EGR system allows the higher amount of exhaust gas to be included in the combustion process and at the same time the combustion chamber temperature and hence $\mathrm{NO}_{\mathrm{x}}$ emissions can be further reduced. For this reason, in the EGR systems, the exhaust gas is passed through a cooler and sent to the intake stream. Cooling is carried out using engine coolant. In an electronically controlled cooling system, the cooling process is optimized depending on different engine loads, temperatures and conditions.

In turbocharged diesel engines, the use of EGR takes place in two different ways; high pressure and low pressure. In a high-pressure EGR system, the exhaust gas is recirculated to the intake channel before the exhaust gas goes to the turbine and in the low-pressure EGR system the exhaust gas is recirculated after passing through the turbine. 


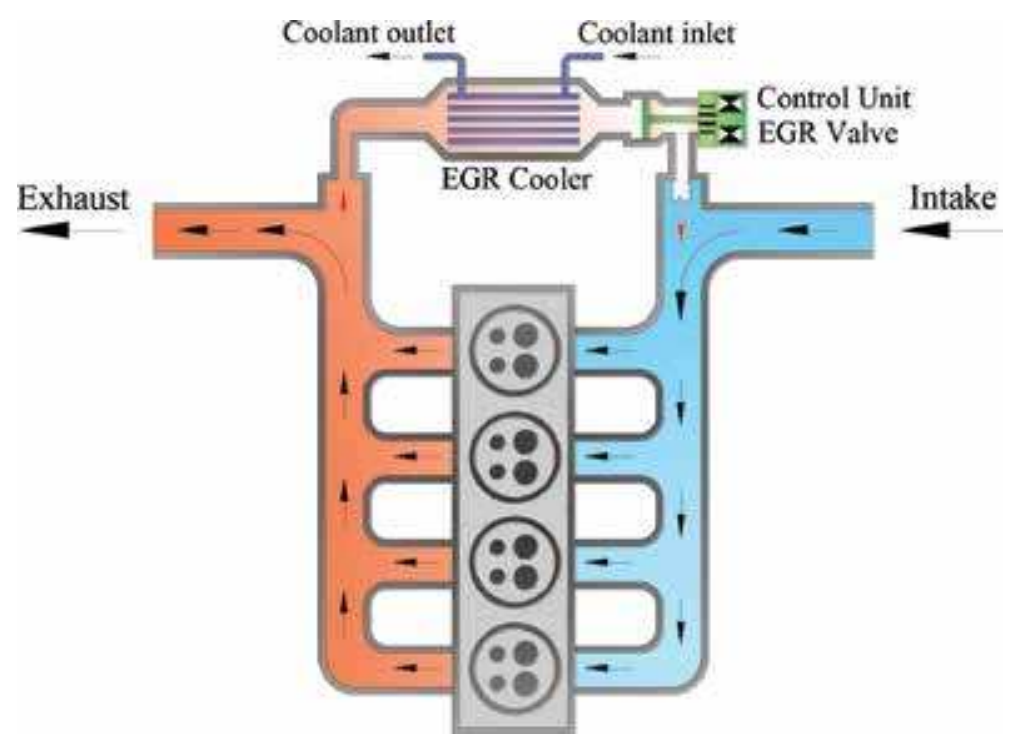

Figure 4.

Exhaust gas recirculation (EGR).

Thanks to the EGR system, the $\mathrm{NO}_{\mathrm{x}}$ emission in diesel engines can be reduced by up to $50 \%$ [26]. However, in this method, combustion is worsened, engine performance decreases, and other pollutants, especially particulate emissions (PM) slightly increases. At the same time, the EGR system leads to an increase of about $2 \%$ in fuel consumption [28]. Due to the flow of the exhaust gas, EGR system can affect the quality of lubrication oil and the engine durability negatively, and erosion on piston rings and cylinder liner can increase [29]. These disadvantages and developed aftertreatment emission control technologies have overshadowed the EGR system [30].

\section{Lean $\mathrm{NO}_{\mathrm{x}} \operatorname{trap}(\mathrm{LNT})$}

Lean $\mathrm{NO}_{\mathrm{x}}$ trap (LNT) technology, also referred to as $\mathrm{NO}_{\mathrm{x}}$ absorber catalyst (NAC), $\mathrm{NO}_{\mathrm{x}}$ storage catalyst (NSC) or $\mathrm{NO}_{\mathrm{x}}$ storage/reduction (NSR) catalyst, is a method used to convert $\mathrm{NO}_{\mathrm{x}}$ emissions at particularly low exhaust gas temperatures. At low exhaust gas temperatures, $\mathrm{NO}_{\mathrm{x}}$ emissions in the exhaust gas content are absorbed at the catalyst surface and released when the exhaust temperature reaches high values.

Coating surface in LNT catalyst consists of an oxidation catalyst, an absorbent combined with alkali metals and a reduction catalyst. In LNT catalysts, there is usually Platinum and Rhodium supported by $\mathrm{Al}_{2} \mathrm{O}_{3}$ structure with component that has a $\mathrm{NO}_{\mathrm{x}}$ storage property such as barium carbonate $\left(\mathrm{BaCO}_{3}\right)$. The reactions in the LNT catalyst occur in two different cycles; lean and rich. In the lean cycle, NO is absorbed into the storage component and converted to $\mathrm{NO}_{2}$ by being oxidizing on the catalyst surface and stored in the nitrate form on the surface. In the rich cycle, the stored $\mathrm{NO}_{\mathrm{x}}$ is released from the surface and converted to $\mathrm{N}_{2}$ on the catalyst surface via $\mathrm{CO}, \mathrm{HC}$ and $\mathrm{H}_{2}$, which are formed due to incomplete combustion. All of the reactions taking place in the LNT catalyst are given in Eqs. (6)-(11).

$$
\begin{gathered}
\mathrm{NO}+1 / 2 \mathrm{O}_{2} \rightarrow \mathrm{NO}_{2} \\
\mathrm{BaCO}_{3}+\mathrm{NO}_{2}+1 / 2 \mathrm{O}_{2} \rightarrow \mathrm{Ba}\left(\mathrm{NO}_{3}\right)_{2}+\mathrm{CO}_{2}
\end{gathered}
$$




$$
\begin{gathered}
\mathrm{Ba}\left(\mathrm{NO}_{3}\right)_{2} \rightarrow \mathrm{BaO}+2 \mathrm{NO}+1 / 2 \mathrm{O}_{2} \\
\mathrm{Ba}\left(\mathrm{NO}_{3}\right)_{2} \rightarrow \mathrm{BaO}+2 \mathrm{NO}_{2}+1 / 2 \mathrm{O}_{2} \\
\mathrm{NO}_{2}+\mathrm{CO} \rightarrow \mathrm{NO}+\mathrm{CO}_{2} \\
\mathrm{NO}+\mathrm{CO} / \mathrm{HC} \rightarrow 1 / 2 \mathrm{~N}_{2}+\mathrm{CO}_{2} / \mathrm{H}_{2} \mathrm{O}
\end{gathered}
$$

In Eq. (6), $\mathrm{NO}$ emissions at low exhaust gas temperatures are oxidized on the Platinum catalyst and converted to $\mathrm{NO}_{2}$ form. $\mathrm{NO}_{2}$ emissions are then absorbed in the Barium nitrate form, which has a storage feature of $\mathrm{NO}_{\mathrm{x}}$ emissions (Eq. (7)). When the storage capacity is full, regeneration is started by increasing the exhaust gas temperature to high levels. During the regeneration process, the stored nitrogen compounds become thermodynamically unstable and decomposed into $\mathrm{NO}$ and $\mathrm{NO}_{2}$ forms (Eqs. (8) and (9)). In the presence of $\mathrm{CO}, \mathrm{HC}$ and $\mathrm{H}_{2}$, the released $\mathrm{NO}$ and $\mathrm{NO}_{2}$ components are then reacted on catalyst to form $\mathrm{N}_{2}$.

Increasing the exhaust gas temperature for regeneration in LNT systems can be achieved by injecting extra diesel fuel or hydrogen into the cylinder. Since diesel engines have lean mixture, HC is included externally by being injected into the exhaust gas. In the LNT technology, the amount of injected fuel, injecting timing and the ability of the catalyst to store $\mathrm{NO}_{\mathrm{x}}$ are parameters that must be optimized to ensure fuel economy.

Although LNT technology is a suitable solution for $\mathrm{NO}_{\mathrm{x}}$ conversion at low exhaust gas temperatures, it has some disadvantages. LNT catalysts usually contain precious metals such as $\mathrm{Pt}$ at high level to increase the oxidation process of NO emissions and to ensure their continuity. However, this situation increases the cost. At the same time, LNT catalysts need the supply of $\mathrm{NO}_{2}$ with $\mathrm{NO}$ oxidation to provide storage. For this reason, they do not have high $\mathrm{NO}_{\mathrm{x}}$ storage efficiency at exhaust gas temperatures below $150^{\circ} \mathrm{C}$. On the other hand, Nitrates $\left(\mathrm{NO}_{3}\right)$ formed as a result of storage are highly stable and they need to be decomposed in rich operating conditions for reacting of $\mathrm{NO}_{\mathrm{x}}$ emissions with reductants such as $\mathrm{HC}, \mathrm{CO}$ and $\mathrm{H}_{2}$ on the catalyst surface to form $\mathrm{N}_{2}$. This affects the fuel economy negatively, and undesirable increases can happen in $\mathrm{CO}, \mathrm{HC}$ and PM emissions. In the LNT catalysis, $\mathrm{NO}_{\mathrm{x}}$ adsorption can be poisoned by sulfur compounds and this undesirable sulfur poisoning causes the catalyst to lose its properties. Sulfur poisoning can be removed by desulphurization at exhaust gas temperatures of $600-750^{\circ} \mathrm{C}$. This increases fuel consumption and other pollutant emissions. The use of low sulfur diesel fuel (ULSD) reduces sulfur poisoning and the frequency of desulphurization. To overcome these disadvantages of LNT catalysts, different catalyst types such as Ce, Paladium and different methods have been investigated [31].

LNT technology has a wide range commercial application worldwide. Yang et al. [30] indicated that the LNT technology was adapted to more than half a million vehicles by many manufacturers, including VW and BMW. Up to $90 \%$ conversion efficiency at the low engine loads and its combination with the SCR system has raised the use of LNT technology in market.

\section{Selective catalytic reduction of $\mathrm{NO}_{\mathrm{x}}$ emissions}

The selective catalytic reduction of $\mathrm{NO}_{\mathrm{x}}$ emissions was dates back to 1970 s but was used commercially in heavy-duty vehicles in 2005 [32, 33]. In the selective 
catalytic reduction process, $\mathrm{NO}_{\mathrm{x}}$ emissions in the exhaust gas are converted to $\mathrm{N}_{2}$ and $\mathrm{H}_{2} \mathrm{O}$ via a reducing agent. $\mathrm{NH}_{3}$-SCR and HC-SCR systems, where $\mathrm{NO}_{\mathrm{x}}$ emissions are eliminated by the use of ammonia and hydrocarbons, are the most widely used technologies.

\subsection{Selective catalytic reduction of $\mathrm{NO}_{\mathrm{x}}$ by Ammonia $\left(\mathrm{NH}_{3}-\mathrm{SCR}\right)$}

In SCR systems, ammonia $\left(\mathrm{NH}_{3}\right)$ which is generally highly efficient is used as reducer. Ammonia is obtained from aqueous urea solution called AdBlue in the market to prevent burning due to high exhaust gas temperatures. The aqueous urea solution consists of $67 \%$ purified water $\left(\mathrm{H}_{2} \mathrm{O}\right)$ and $33 \%$ urea solution $\left(\left(\mathrm{NH}_{2}\right)_{2} \mathrm{CO}\right)$. Aqueous urea solution (AdBlue) is the most commonly used reductant in SCR systems. Particularly at high exhaust gas temperatures $\left(350-450^{\circ} \mathrm{C}\right)$, $\mathrm{NO}_{\mathrm{x}}$ emissions in exhaust gas can be eliminated at high rates using AdBlue [34]. However, at low exhaust gas temperatures below $200^{\circ} \mathrm{C}$, the conversion efficiency is underperforming and ammonia accumulates on the exhaust line and the catalyst surfaces. Temperatures above $600^{\circ} \mathrm{C}$ are a major problem for the $\mathrm{NH}_{3}$-SCR system. Because high temperatures can cause the reductant to burn before reaching the catalyst, and at the same time cause catalyst deformation. The active operating range of the $\mathrm{NH}_{3}$-SCR system is between 200 and $600^{\circ} \mathrm{C}$ exhaust gas temperatures. A maximum conversion efficiency can be achieved about $350^{\circ} \mathrm{C}$ [35].

Figure 5 visually shows the reactions that occur when the aqueous urea solution is sprayed onto the exhaust gas.

In $\mathrm{NH}_{3}$-SCR system, the aqueous urea solution sprayed on the exhaust gas is first subjected to thermolysis and hydrolysis reactions under the influence of high temperature (Eqs. (12) and (13)). These reactions result in the production of two molecules of ammonia from one molecule urea.

$$
\begin{aligned}
& \left(\mathrm{NH}_{2}\right)_{2} \mathrm{CO} \rightarrow \mathrm{NH}_{3}+\mathrm{HNCO} \text { (thermolysis) } \\
& \mathrm{HNCO}+\mathrm{H}_{2} \mathrm{O} \rightarrow \mathrm{NH}_{3}+\mathrm{CO}_{2} \text { (hydrolysis) }
\end{aligned}
$$

The main reactions occurring in the system after the thermolysis and hydrolysis reactions are given in Eqs. (14)-(16).

$$
\begin{gathered}
2 \mathrm{NO}+2 \mathrm{NO}_{2}+4 \mathrm{NH}_{3} \rightarrow 4 \mathrm{~N}_{2}+6 \mathrm{H}_{2} \mathrm{O} \\
4 \mathrm{NO}+4 \mathrm{NH}_{3}+\mathrm{O}_{2} \rightarrow 4 \mathrm{~N}_{2}+6 \mathrm{H}_{2} \mathrm{O} \\
6 \mathrm{NO}_{2}+8 \mathrm{NH}_{3} \rightarrow 7 \mathrm{~N}_{2}+12 \mathrm{H}_{2} \mathrm{O}
\end{gathered}
$$

Eq. (14) provides the highest conversion efficiency in the conversion reactions taking place in the $\mathrm{NH}_{3}$-SCR system. This reaction usually takes place when a diesel oxidation catalyst (DOC) is present before the $\mathrm{NH}_{3}$-SCR system. DOC converts NO emissions to $\mathrm{NO}_{2}$ form and when the content of $\mathrm{NO}$ and $\mathrm{NO}_{2}$ in the exhaust gas get close to each other, higher efficiency is achieved in the $\mathrm{NH}_{3}-\mathrm{SCR}$ system. Therefore, $\mathrm{NH}_{3}$-SCR system usually needs DOC and they are used together in applications. Eq. (15) occurs when there isn't any DOC before the $\mathrm{NH}_{3}$-SCR system and NO emissions are included with large amount in the exhaust exit. If the DOC catalyst 


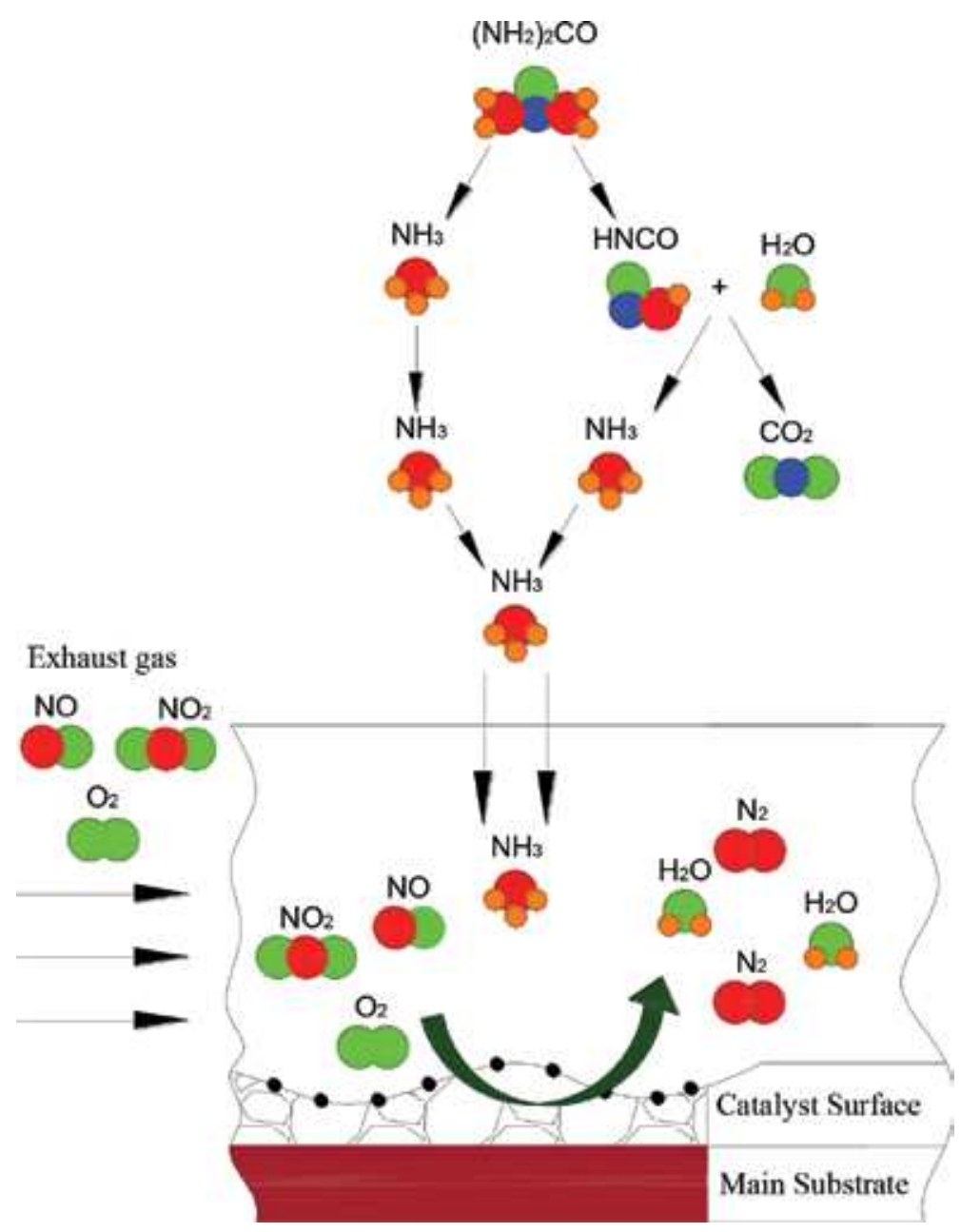

Figure 5.

$\mathrm{NO}_{x}$ conversion reactions in $\mathrm{NH}_{3}-\mathrm{SCR}$.

is larger than the necessary and consequently the vast majority of NO emissions are converted to $\mathrm{NO}_{2}$, the Eq. (16) is realized. In terms of efficiency, this equation exhibits the worst conversion performance [36].

Figure 6 presents a schematic view of a classical $\mathrm{NH}_{3}$-SCR system. In this system managed by an electronic control unit, the data from the $\mathrm{NO}_{\mathrm{x}}$ and temperature sensors is evaluated and injector sprays the reductant with an optimized rate onto the exhaust gas.

Thanks to the $\mathrm{NH}_{3}$-SCR system, diesel engines can be operated at high combustion end temperatures, thus resulting in improved engine performance and fuel consumption. With the use of the $\mathrm{NH}_{3}$-SCR system, fuel consumption can be reduced by $5 \%$ [37].

Metal oxides and zeolites are the most commonly used catalyst types in $\mathrm{NH}_{3}$ SCR systems. Metal oxide catalysts are a group of catalysts produced from metals such as vanadium and titanium $\left(\mathrm{V}_{2} \mathrm{O}_{5}-\mathrm{WO}_{3} / \mathrm{TiO}_{2}\right)$, which operate efficiently generally between 250 and $400^{\circ} \mathrm{C}$ [38]. When compared to metal oxide catalysts, zeolite catalysts are capable of operating in the high temperature range of $400-550^{\circ} \mathrm{C}$ [39]. While $\mathrm{V}_{2} \mathrm{O}_{5}-\mathrm{WO}_{3} / \mathrm{TiO}_{2}$ catalysts were preferred for commercial use of $\mathrm{NH}_{3}-\mathrm{SCR}$ in the vehicles in 2005, Fe-zeolites began to be used more widespread in the period after 2010 [40]. In addition to these catalysts, $\mathrm{Cu}-\mathrm{ZSM} 5$ and $\mathrm{Ag} / \mathrm{Al}_{2} \mathrm{O}_{3}$ catalysts 


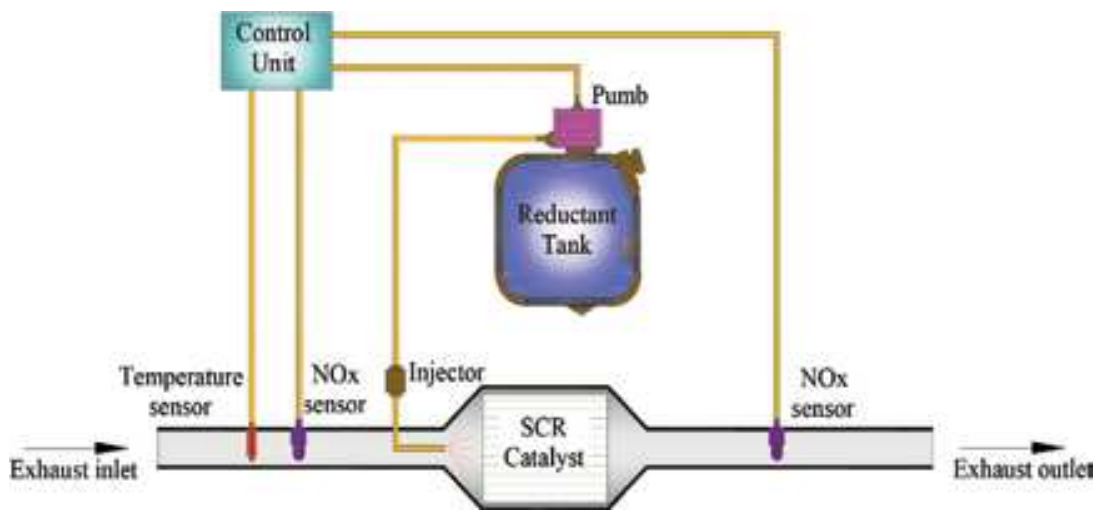

Figure 6.

$\mathrm{NH}_{3}$-SCR system.

may be preferred in applications. In particular, $\mathrm{Ag} / \mathrm{Al}_{2} \mathrm{O}_{3}$ catalysts can exhibit high performance at low exhaust temperatures.

Cost, an extra storage that it requires and the space that it takes up on the vehicle are the biggest problem in using the $\mathrm{NH}_{3}$-SCR system. However, as a result of the studies performed in the $\mathrm{NH}_{3}$-SCR system, it is achieved that a volume reduction of $60 \%$, a weight reduction of $40 \%$ and a cost reduction of $30 \%$ when compared to 2010 [41]. Low efficiency at low exhaust gas temperatures, ammonia slip, lifetime, adaptation to different operating conditions, integration with other oxidation and particulate filter systems are the negative aspects of $\mathrm{NH}_{3}$-SCR systems. In addition, the $\mathrm{NH}_{3}$-SCR system requires a pre-catalyst (DOC) because they exhibit the best performance while $\mathrm{NO} / \mathrm{NO}_{2}$ ratio is 1 .

Even if $\mathrm{NH}_{3}$-SCR system has been developed for heavy-duty vehicles in general, it is widely used in many automobiles thanks to innovations (electronic injection, etc.) in the system [42]. $\mathrm{NH}_{3}$-SCR is the most effective system to meet the $\mathrm{NO}_{\mathrm{x}}$ emission values determined by the organizations in the current situation [40]. In addition, the fuel consumption of engine improves with the use of $\mathrm{NH}_{3}-\mathrm{SCR}$ system.

\subsection{Selective catalytic reduction of $\mathrm{NO}_{\mathrm{x}}$ by hydrocarbons (HC-SCR)}

When compared to $\mathrm{NH}_{3}$-SCR, HC-SCR systems have stayed in the background due to their low efficiency, but the catalysts in which hydrocarbons are used as reductant have been developed since 1980 [33].

As an alternative to $\mathrm{NH}_{3}$ reductant in SCR systems, the use of HCs improves the performance of the SCR system at low temperature. The use of diesel fuel or unburned HCs in the exhaust stream simplifies the system and reduces the cost. In addition to diesel fuel, oxygen-containing HCs such as ethanol, methanol, and propanol are highly effective in $\mathrm{NO}_{\mathrm{x}}$ conversions [43].

The $\mathrm{NO}_{\mathrm{x}}$ conversion reactions occurred in HC-SCR systems are given below.

$$
\begin{gathered}
\mathrm{NO}+\mathrm{O}_{2} \rightarrow \mathrm{NO}_{2} \\
\mathrm{C}_{\mathrm{x}} \mathrm{H}_{\mathrm{y}} \mathrm{O}_{\mathrm{z}}+\mathrm{NO}_{2} \rightarrow \mathrm{N}_{2}+\mathrm{CO}_{2}+\mathrm{H}_{2} \mathrm{O}
\end{gathered}
$$

HC-SCR system is an up-to-date field of study, where many researches has been made on. The studies have focused especially on the development of catalysts 
for HC-SCR systems. $\mathrm{Ag} / \mathrm{Al}_{2} \mathrm{O}_{3}$ catalysts are the most preferred type of catalyst in HC-SCR systems. Besides, silver, gold, copper, platinum, rhodium, cobalt and ironbased zeolites are used as catalysts in HC-SCR systems [44].

In the $\mathrm{HC}$-SCR systems where conventional Ag-containing $\mathrm{Al}_{2} \mathrm{O}_{3}$ structures are used as catalysts, $\mathrm{NO}_{\mathrm{x}}$ conversions exceeding $80 \%$ can be achieved in the temperature range of $350-500^{\circ} \mathrm{C}$. At the same time, these structures are very resistant to the adverse effects of water and sulfur. It is even indicated that the sulfur formation on the silver catalyst enhances the conversion efficiency [45]. In Ag-containing catalysts, hydrogen accelerates the oxidation of $\mathrm{HC}$, thereby increasing $\mathrm{NO}_{\mathrm{x}}$ conversion efficiency. In addition, the use of hydrogen increases $\mathrm{NO}_{\mathrm{x}}$ conversion efficiency at low temperatures by retaining radicals in reducing $\mathrm{NO}_{\mathrm{x}}$ emissions [46].

The conversion efficiency of $\mathrm{NO}_{\mathrm{x}}$ emissions in HC-SCR systems varies depending on the $\mathrm{HC}$ and $\mathrm{NO}_{\mathrm{x}}$ ratio in the exhaust gas content. That the amount $\mathrm{HC}$ is 2-4 times higher than $\mathrm{NO}_{\mathrm{x}}$ emission can provide conversion in $\mathrm{NO}_{\mathrm{x}}$ emissions up to $80 \%$. However, in diesel engines, the exhaust gas does not contain $\mathrm{HC}$ in this amount. Therefore, the amount of HC in the exhaust gas content must be provided by enriching the mixture during combustion or spraying it directly on the exhaust gas [47]. Direct injection of HC's onto the exhaust gas can be controlled by different parameters via an injector and control unit. Increasing the amount of $\mathrm{HC}$ in the exhaust gas content by enriching the mixture in the engine is an indirect method and high $\mathrm{NO}_{\mathrm{x}}$ conversion efficiency cannot be obtained.

\section{Conclusion}

$\mathrm{NO}_{\mathrm{x}}$ emissions and the air pollution resulting from it are not the precepts of the countries. Establishing policies, making regulations, taking the necessary measures and making them sustainable for reducing pollutant emissions, especially $\mathrm{NO}_{\mathrm{x}}$ emissions in the world, will prevent air pollution and global warming and thus the world will become more liveable in terms of environment and human health.

Although diesel engines cause high level $\mathrm{NO}_{\mathrm{x}}$ emissions in the combustion stage, these harmful gases can be disposed of at very high rates by improving the emission control systems before and after the engine.

Although the EGR system which is one of the pre-engine emission control systems can provide up to $50 \% \mathrm{NO}_{\mathrm{x}}$ conversion, it is inadequate to provide the desired emission values. In the present case, the desired reductions in $\mathrm{NO}_{\mathrm{x}}$ emissions can be achieved with post-engine emission control systems.

In post-engine control systems, $\mathrm{NO}_{\mathrm{x}}$ emissions can be reduced in the desired level without any reduction in engine performance due to the catalysts used. LNT and SCR technologies are effective post-engine emission control systems used in $\mathrm{NO}_{\mathrm{x}}$ disposal.

In LNT technology, $\mathrm{NO}_{\mathrm{x}}$ emissions absorbed at low exhaust temperatures are released at high exhaust gas temperatures and reacted with $\mathrm{HC}, \mathrm{CO}$ and/ or $\mathrm{H}_{2}$ and converted to nitrogen. LNT technology can especially provide suitable solutions for light duty vehicles. However, LNT systems doesn't have high $\mathrm{NO}_{\mathrm{x}}$ storage capacity, it is highly susceptible to sulfur poisoning and it needs rich operating conditions for regeneration process. These problems restrict the efficiency of LNT system.

Thanks to SCR technology, high conversion rates can be achieved in $\mathrm{NO}_{\mathrm{x}}$ emissions. Today, the SCR system is the most efficient of the post-engine emission control systems used to reduce $\mathrm{NO}_{\mathrm{x}}$ emissions. However, even though the SCR systems perform well at temperatures above $200^{\circ} \mathrm{C}$, they do not perform well when the exhaust gas temperature is below $200^{\circ} \mathrm{C}$ during initial operation of engine. 
In SCR systems, performance at low exhaust gas temperatures can be avoided by an LNT catalyst used before the SCR system. LNT catalysts provide the conversion of $\mathrm{NO}_{\mathrm{x}}$ pollutants in SCR system by absorbing NOx emissions at low exhaust temperatures and releasing $\mathrm{NO}_{\mathrm{x}}$ emissions when the exhaust temperature reaches high levels. While the LNT catalyst has high $\mathrm{NO}_{\mathrm{x}}$ absorptive ability at low exhaust temperatures, $\mathrm{NO}_{\mathrm{x}}$ conversion performance of the SCR system is low. At high exhaust gas temperatures, while the LNT catalyst has low $\mathrm{NO}_{\mathrm{x}}$ absorptive ability, $\mathrm{NO}_{\mathrm{x}}$ conversion performance of the SCR system is high. For this reason, the two systems complement each other and $\mathrm{NO}_{\mathrm{x}}$ emissions can be controlled both at low exhaust gas temperatures and at high exhaust gas temperatures. With the combined use of SCR and LNT technologies, $\mathrm{NO}_{\mathrm{x}}$ emissions can be eliminated in all operating conditions.

In the years to come, it is inevitable that emissions standards put into effect by various organizations for diesel vehicles will be further strict in order to prevent air pollution and global warming caused by it. In this sense, researches on emission control systems will maintain their continuity for a long time. Future standard values to be determined can only be achieved with post-engine emission control systems. The use of post-engine emission control systems is essential to ensure the desired emission values.

Future studies to be performed on $\mathrm{NO}_{\mathrm{x}}$ emission control methods will focus on optimizing $\mathrm{NO}_{\mathrm{x}}$ control systems, lowering cost, creating simpler structures, increasing engine efficiency, and increasing $\mathrm{NO}_{\mathrm{x}}$ conversion efficiency at low exhaust temperatures. The findings and innovations to be achieved as a result of these studies will enable the development of more environmentally friendly diesel vehicles.

\section{Author details}

İbrahim Aslan Reşitoğlu

Department of Automotive Technology, Technical Sciences Vocational School, Mersin University, Mersin, Turkey

*Address all correspondence to: aslanresitoglu@gmail.com

IntechOpen

(C) 2018 The Author(s). Licensee IntechOpen. Distributed under the terms of the Creative Commons Attribution - NonCommercial 4.0 License (https://creativecommons.org/ licenses/by-nc/4.0/), which permits use, distribution and reproduction for non-commercial purposes, provided the original is properly cited. (cc) BY-NC 


\section{References}

[1] World Health Organization. 9 out of 10 People Worldwide Breathe Polluted Air, but More Countries Are Taking Action [Internet]. 2018. Available form: https://www.who.int/news-room/ detail/02-05-2018-9-out-of-10-peopleworldwide-breathe-polluted-air-butmore-countries-are-taking-action [Accessed: Jun 15, 2018]

[2] Deschenes O, Greenstone M, Shapiro JS. Defensive investments and the demand for air quality: Evidence from the $\mathrm{NO}_{\mathrm{x}}$ budget program and ozone reductions. NBER Working Paper No. 18267. Aug 2012. DOI: $10.3386 / 18267$

[3] Organisation for Economic Co-operation and Development. The Economic Consequences of Outdoor Air Pollution. Paris: OECD Publishing; 2016. 17 p. DOI: 10.1787/9789264257474-en

[4] Canadian Council of Ministers of the Environment. Management Plan for $\mathrm{NO}_{\mathrm{x}}$ and VOCs. Canadian: CCME Publishing; 1990. 176 p

[5] New York City Community Air Survey. New York City Trends in Air Pollution and its Health Consequences. New York: NYC Health; 2013. 15 p

[6] Department for Environment Food \& Rural Affairs. Air Pollution in the UK 2015. UK: DEFRA; 2016. 115 p

[7] Gjorgjeva S, Pietarila H. Macedonian air quality assessment report for the period 2005-2015. Skopje: Ministry of environment and physical planning and Macedonian environmental information center; 2017. 68 p

[8] European Environmental Agency. Air Quality in Europe-2017 Report. Denmark: EEA; 2017. 74 p

[9] World Health Organization. Health Risk Assessment of Air
Pollution-General Principles.

Copenhagen: WHO Regional Office for Europe; 2016

[10] Astrom S, Gustafsson T, Lindblad M, Stigson P, Kindbom K. Estimating Air Pollution Emission Abatement Potential in Sweden 2030. Sweeden: IVL Swedish Environmental Research Institute; $2013.36 \mathrm{p}$

[11] Agrawal AK, Singh SK, Sinha S, Shukla MK. Effect of EGR on the exhaust gas temperature and exhaust opacity in compression ignition engines. Sadhana. 2004;29(3):275-284. DOI: 10.1007/BF02703777

[12] Price K, Jacques J, Pauly T, Wang

L. Impact of SCR integration on $\mathrm{N}_{2} \mathrm{O}$ emissions in diesel application.

SAE International Journal of

Passenger Cars-Mechanical Systems. 2015;8(2):526-530. DOI: 10.4271/2015-01-1034

[13] Langton LL, Pinner HQ, Ho H. Lethal and Illegal: Solving London's Air Pollution Crisis. London: Institute for Public Policy Research; 2016. 51 p

[14] Mendola P, Wallace M, Hwang BS, et al. Preterm birth and air pollution: Critical windows of exposure for women with asthma. The Journal of Allergy and Clinical Immunology. 2016;138(2):432-440. DOI: 10.1016/j. jaci.2015.12.1309

[15] Vilcekova S. Advanced Air Pollution: Indoor Nitrogen Oxides. Croatia: InTech; 2011. p 31-50. DOI: $10.5772 / 16819$

[16] Collette A, Granier C, Hodneborg Q, et al. Future air quality in Europe: A multi-model assessment of projected exposure to ozone. Atmospheric Chemistry and Physics. 2012;12:10613-10630. DOI: 10.5194/ acp-12-10613-2012 
[17] Department for Environment Food \& Rural Affairs. Improving Air Quality in the UK: Tackling Nitrogen Dioxide in our Towns and Cities Draft UK Air Quality Plan for Tackling Nitrogen Dioxide. London, UK: DEFRA; 2017. $81 \mathrm{p}$

[18] Maryland Department of the Environment. Maryland: Maryland Clean Air 2017 Progress Report. 2017

[19] Gregory D, Mclaughlin O, Mullender S, Sundararajah N. New solutions to air pollution challenges in the UK. In: London Forum for Science and Policy Briefing Paper. London: Grantham Institute; 2016.6 p

[20] Guardiola C, Martin J, Pla B, Bares P. Cycle by cycle $\mathrm{NO}_{\mathrm{x}}$ model for diesel engine control. Applied Thermal Engineering. 2017;110:1011-1020. DOI: 10.1016/j.applthermaleng.2016.08.170

[21] Parash SM, Kalam MA, Masjuki HH, et al. Impacts of biodiesel combustion on $\mathrm{NO}_{\mathrm{x}}$ emissions and their reduction approaches. Renewable and Sustainable Energy Reviews. 2013;23:473-490. DOI: 10.1016/j.rser.2013.03.003

[22] Seykens X. Development and Validation of a Phenomenological Diesel Engine Combustion Model [Thesis]. Netherland: The Netherlands Eindhoven University of Technology; 2010. 220 p. DOI: 10.6100/ IR656995

[23] Lloyd's Register of Shipping. Emissions of Nitrogen Oxides from Marine Diesel Engines. 2002

[24] Delphi. Worldwide Emissions Standards-Heavy Duty and OffHighway Vehicles. Delphi; 2017

[25] Asad U, Zheng M. Exhaust gas recirculation for advanced diesel combustion cycles. Applied Energy. 2014;123:242-252. DOI: 10.1016/j. apenergy.2014.02.073

[26] Thangaraja J, Kannan C. Effect of exhaust gas recirculation on advanced diesel combustion and alternate fuels-A review. Applied Energy. 2016;180:169-184. DOI: 10.1016/j. apenergy.2016.07.096

[27] Hawley G, Brace CJ, Wallace FJ, Horrocks RW. Handbook of Air Pollution from Internal Combustion Engines: Combustion-Related Emissions in CI Engines. USA: Academic Press; 1998. 663 p. DOI: $10.1016 / B 978-0-12-$ 639855-7. X5038-8

[28] Jordal J. Reducing Air Pollution from Ships. Kopenhag: Danish Ministry of the Environment; 2012. 120 p

[29] Abd-Alla GH. Using exhaust gas recirculation in internal combustion engines: A review. Energy Conversion and Management. 2002;43:1027-1042. DOI: 10.1016/S0196-8904(01)00091-7

[30] Yang L, Franco V, Campestrini A, German J, Mock P. $\mathrm{NO}_{\mathrm{x}}$ Control Technologies for Euro 6 Diesel Passenger Cars-Market Penetration and Experimental Performance Assessment. ICCT White paper, Sep 2015

[31] Theis JR, Lambert CK. An assessment of low temperature $\mathrm{NO}_{\mathrm{x}}$ adsorbers for cold-start $\mathrm{NO}_{\mathrm{x}}$ control on diesel engines. Catalysis Today. 2015;258:367-377. DOI: 10.1016/j. cattod.2015.01.031

[32] Jung Y, Shin YJ, Pyo YD, Cho CP, Jang J, Kim G. NOx and N2O emissions over a urea-SCR system containing both $\mathrm{V}_{2} \mathrm{O}_{5}-\mathrm{WO}_{3} / \mathrm{TiO}_{2}$ and $\mathrm{Cu}$-zeolite catalysts in a diesel engine. Chemical Engineering Journal. 2017;326:853-862. DOI: 10.1016/j. cej.2017.06.020

[33] Kass MD, Thomas JF, et al. Selective Catalytıc Reduction of diesel engine NOx emissions using ethanol as a reductant. In: Proceedings of the U.S. Department of Energy 9th Diesel Engine Emissions Reduction Conference; 24-28 
August 2003; Newport. Rhode Island: IEEE; 2003. p. 1-8

[34] Liu ZG, Ottinger NA, Cremeens $\mathrm{CM}$. Vanadium and tungsten release from V-based selective catalytic reduction diesel aftertreatment. Atmospheric Environment. 2015;104:154-161. DOI: 10.1016/j. atmosenv.2014.12.063

[35] Way P, Viswanathan K, Preethi P, Gilb A, Zambon N, Blaisdell J. SCR performance optimization through advancements in aftertreatment packaging. SAE Technical Paper 200901-0633. DOI: 10.4271/2009-01-0633

[36] Resitoglu IA, Altinisik K, Keskin A. The pollutant emissions from diesel-engine vehicles and exhaust aftertreatment systems. Clean Technologies and Environmental Policy. 2015;17:15-27. DOI: 10.1007/ s10098-014-0793-9

[37] Cummins. Diesel Exhaust Fluid (DEF) Q \& A. Bulletin. USA: Delphi; 2009

[38] Gao G, Shi JW, Liu C, Gao C, Fan $\mathrm{Z}$, Niu C. $\mathrm{Mn} / \mathrm{CeO}_{2}$ catalysts for SCR of $\mathrm{NO}_{x}$ with $\mathrm{NH}_{3}$ : Comparative study on the effect of supports on lowtemperature catalytic activity. Applied Surface Science. 2017;411:338-346. DOI: 10.1016/j.apsusc.2017.03.164

[39] Baranski K, Underwood B. Mitigate Air Pollution with Catalytic Technology. USA: American Institute of Chemical Engineering; 2014. pp. 30-34

[40] Cho CP, Pyo YD, Jang JY, Kim GC, Shin $\mathrm{YJ} . \mathrm{NO}_{\mathrm{x}}$ reduction and $\mathrm{N}_{2} \mathrm{O}$ emissions in a diesel engine exhaust using Fe-zeolite and vanadium based SCR catalysts. Applied Thermal Engineering. 2017;110:18-24. DOI: 10.1016/j.applthermaleng.2016.08.118

[41] Brezny R. $\mathrm{NO}_{\mathrm{x}}$ Reduction from Heavy-Duty Engines. Motor Vehicle/
Vessel Emission Control Workshop, Hong Kong. Dec 14, 2016

[42] Marek V, Tunka L, Polcar A, Slimarik D. Reduction of $\mathrm{NO}_{\mathrm{x}}$ emission of a diesel engine with a multiple injection pump by SCR catalytic converter. Acta Universitatis Agriculturae et Silviculturae Mendelianae Brunensis. 2016;64:1205-1210. DOI: 10.11118/ actaun201664041205

[43] Björn W, Christian KCU, Ingemar $\mathrm{O}$. Transient modelling of a HC-SCR catalyst for diesel exhaust aftertreatment. Chemical Engineering Journal. 2002;92:27-39. DOI: 10.1016/ S1385-8947(02)00118-3

[44] More PM, Nguyen DL, Granger P, Dujardin C, Dongare MK, Umbarkar $\mathrm{SB}$. Activation by pretreatment of $\mathrm{Ag}-\mathrm{Au} / \mathrm{Al}_{2} \mathrm{O}_{3}$ bimetallic catalyst to improve low temperature HC-SCR of $\mathrm{NO}_{\mathrm{x}}$ for lean burn engine exhaust. Applied Catalysis B: Environmental. 2015;174-175:145-156. DOI: 10.1016/j. apcatb.2015.02.035

[45] Jagtap N, Umbarkar SB, Miquel P, Granger P, Dongare MK. Support modification to improve the Sulphur tolerance of $\mathrm{Ag} / \mathrm{Al}_{2} \mathrm{O}_{3}$ for SCR of $\mathrm{NO}_{\mathrm{x}}$ with propene under lean-burn conditions. Applied Catalysis B:

Environmental. 2009;99:416-425. DOI: 10.1016/j.apcatb.2009.04.001

[46] Gu H, Chun KM, Song S. The effects of hydrogen on the efficiency of $\mathrm{NO}_{\mathrm{x}}$ reduction via hydrocarbonselective catalytic reduction (HC-SCR) at low temperature using various reductants. International Journal of Hydrogen Energy. 2015;40:9602-9610. DOI: 10.1016/j.ijhydene.2015.05.070

[47] Piumetti M, Bensaid S, Fino D, Russo N. Catalysis in diesel engine $\mathrm{NO}_{\mathrm{x}}$ aftertreatment: A review. Catalysis, Structure \& Reactivity. 2015;1(4):155-173. DOI: 10.1080/2055074X.2015.1105615 
Identification of the Minor Chemical Elements in the Particulate Matter Exhaust Emissions From In-Use Diesel Engine Passenger Vehicles

\author{
Richard Viskup, Christoph Wolf and Werner Baumgartner
}

\begin{abstract}
In this research, we investigate the minor chemical elements contained in the particulate matter (PM) exhaust emissions, generated by in-use diesel engine passenger vehicles. For this purpose, we apply a high-resolution optical emission spectroscopy technique, for precise, spectrochemical analysis of diesel particulate matter (DPM). By means of the laser-induced breakdown spectroscopy analytical method, we analyse PM from different road diesel engine vehicles. DPM were obtained from miscellaneous in-use diesel engine passenger vehicles of diverse types and models from major brand car producers in Europe. We analysed particulate matter extracted from the exhaust manifold part, from 67 different passenger vehicles, which are used in daily life environment.
\end{abstract}

Keywords: laser-induced breakdown spectroscopy, LIBS, laser-induced plasma spectroscopy, LIPS, particulate matter, particulates, soot, carbon emissions, vehicle emissions, exhaust emissions, ultrafine particles, metallic nanoparticles, trace metals, trace elements, trace emission, air quality

\title{
1. Introduction
}

Problems with diesel engine emissions and control failures [1-3] are present in public perception around the world. To breathe clean air is very important for human health not only for lungs and cardiovascular system, but also for the brain and central nervous system $[4,5]$. Therefore, it should be amongst our highest priorities to find new techniques and technology to successfully solve the emission issues.

In this study, we applied a laser-induced breakdown spectroscopy technique [6] for qualitative spectrochemical analysis of diesel particulate matter (DPM) emitted from in-use diesel engine passenger vehicles.

We analysed particulate matter from 67 different diesel engine passenger vehicles of major EU car producers, used in daily life environment. The aim of this study is to compare particulate matter (PM) composition, mainly agglomerated minor chemical elements. Special attention is given to the analysis of different PM 
for a qualitative comparison of the Laser induced breakdown spectroscopy (LIBS) spectral signal. The presence of agglomerate chemical elements in diesel exhaust emissions is due to different processes involved within the combustion. These are mainly related to the diesel fuel, fuel additives, engine lubricants, engine performance, applied aftertreatment devices like selective catalytic reduction devices and diesel particulate filtering techniques. All these input parameters influence the final chemical composition of exhaust emissions and consequently the diesel particulate matter emitted from in-use diesel engine vehicles.

The current existing emission standards in the European Union, like European emission standards - Euro [7, 8], or in USA - Tier [9], or LEV [10], for diesel engine vehicles specify the maximum allowable emissions of hydrocarbons, carbon monoxide, nitrogen oxides, and particulate matter (PM). PM is measured as the total number of all generated particles from diesel exhaust, expelled from diesel exhaust fumes. Currently, there are no specific emission standards for additional compounds or chemical elements contained in the exhaust emissions, i.e., exhaust vapour, diesel particulate matter, particulate matter, black carbon, or in the soot, formed by the diesel or biodiesel, from internal combustion engines. The agglomerated chemical elements in diesel particulate matter additional to carbon, presents a very large fraction of the total DPM or soot emission contents. Particularly, the inhalation of metal dusts and ions has numerous negative health effects, especially upon long-term exposure. Automotive emissions are considered as the dominant source for air-borne metal pollution in urban areas. Therefore, accurate in-situ technique to assess the on-line elemental composition of particulate matter from automotive emissions would be desirable.

Generally, exhaust emissions from diesel engines can form a very complex mixture of gases, vapour, and particles consisting of countless elements and compounds. Gaseous compounds of diesel emission include carbon dioxide, oxygen, nitrogen, water vapour, carbon monoxide, nitrogen compounds, sulphur compounds, and numerous low molecular weight compounds [11]. The vapour phase contains larger molecular weight compounds, located in unburned tailpipe emissions. The diesel exhaust particles are agglomerates of many primary spherical particles that differ in size [12], composition [13], and solubility [14]. The particles in diesel exhaust emission consist of particulate matter - diesel particulate matter. This is further classified, depending on the size of particles as particulates of an aerodynamic diameter of less than $10 \mu \mathrm{m}$, fine particles of diameters below $2.5 \mu \mathrm{m}$, ultra-fine particles - below $0.1 \mu \mathrm{m}$, and nanoparticles - characterised by diameter less than $50 \mathrm{~nm}$. DPM is composed of elemental carbon in core and adsorbed compound. The elemental carbon core has a high specific surface area and serves as a nucleus for condensation of compounds with good adsorption properties mainly from the unburned or incompletely burned diesel, particles or from crankcase oil volatilised metallic nano-particles from the cylinder walls.

Amongst the early pioneers in measurement of particulate trace emissions from vehicles was the group of Schauer et al. [15] as they used a comprehensive dilution source sampler, organic chemical analysis, and X-ray fluorescence analysis for mass and chemical composition measurements of fine particles. Other groups [13, 16-18], used inductively-coupled plasma mass spectrometry ICP-MS and XRF for characterisation of metals and other particle-phase species from on-road motor vehicles. They found the following trace elements in the particles: $\mathrm{Al}, \mathrm{Ba}, \mathrm{Be}, \mathrm{Ca}$, $\mathrm{Cd}$, Co, Cr, Cu, Fe, K, Mg, Mn, Mo, Na, Ni, Pb, Pt, S, Sr, Ti, V and Zn.

Other groups [19-23], used ICP-OES to characterise the different biodiesel samples with special concern to quantify the $\mathrm{Al}, \mathrm{Ca}, \mathrm{Cu}, \mathrm{Fe}, \mathrm{K}, \mathrm{Mg}, \mathrm{Mn}, \mathrm{Na}, \mathrm{Ni}$, $\mathrm{P}, \mathrm{Sr}, \mathrm{B}$ and $\mathrm{Cl}$ content, to evaluate the fuel quality and to control the emission of pollutants to the atmosphere. In this case, the samples were prepared using a high 
pressure ashier digestion procedure for metal determination in biodiesel samples. Different groups used ICP-MS to characterise additional bound elements, like Cd, $\mathrm{As}, \mathrm{Ba}$ and $\mathrm{Ti}$ in the particulate matter collected from ultra-low sulphur diesel and biodiesel-powered engine exhaust emissions [24].

The first pioneering group investigated the metallic elements in diesel soot collected on filter by means of laser-induced breakdown spectroscopy was by Lombaert et al. [25]. They found that $\mathrm{Fe}, \mathrm{Cu}, \mathrm{Ca}, \mathrm{Zn}$ and $\mathrm{Mg}$ appear as the main metallic species deposited within diesel particles on the reference filter.

The qualitative and quantitative characterisation of major chemical elements in different types of diesel particulate matter collected from in-use diesel engine passenger vehicles, analysed by laser-induced breakdown spectroscopy have been studied by Viskup et al. [26].

The aim of this research is to investigate the minor chemical elements contained in the particulate matter exhaust emissions, generated from diesel engine passenger vehicles equipped with internal combustion engines. For this purpose, we apply high-resolution optical emission spectroscopy technique for precise spectrochemical analysis of DPM. By means of the laser-induced breakdown spectroscopy analytical method, we analyse PM from different on-road diesel engine vehicles. DPM were obtained from miscellaneous in-use diesel engine passenger vehicles of diverse types and models from major brand car producers in Europe.

\section{Methodology}

Laser-induced breakdown spectroscopy (LIBS) [27-29] is an optical measurement technique [30] for rapid qualitative [31] and sensitive quantitative [32] compositional analysis of various forms of materials like solids [33], liquids [34], gases [35], powders [36] or nanoparticles [37].

In laser-induced breakdown spectroscopy, a high-power laser radiation, with nanosecond or shorter pulse duration, is interacting with the investigating material [38]. This short light-matter interaction generates a plasma, of which the optical emission spectrum is collected by the optical spectrometer and then further processed by computer. From LIBS spectra, the elemental chemical composition of the examined sample can be obtained. The qualitative spectral information can be further calibrated, to obtain quantitative results. The LIBS technique provides very sensitive and rapid analytical measurements, without sample pre-treatment, in the range of ppm levels [39], almost instantaneously. This advantage pushes the LIBS technique forward in many new research areas and makes it also attractive for industrial applications [40].

The LIBS technique can almost instantly measure the minor compounds of DPM and provide the qualitative results about the chemical composition. The fingerprints of minor chemical elements in PM exhaust emissions are related to different processes. These are fuel oil type, fuel quality, fuel composition, fuel additives, engine lubricants, performance of combustion engine, catalytic reaction, particulate filtering technique, deterioration of engine or some parts, etc.

\section{Experimental setup}

\subsection{Experimental LIBS setup}

The experimental setup for LIBS measurement consists of high-intensity pulsed laser system, experimental chamber, collection optics and with high precision 
optical spectrometer. Laser beam is guided via optical mirrors into the focusing lens. Plasma is generated by focusing of laser radiation into the material. Schema of LIBS experimental set-up is shown in Figure 1.

For laser-induced plasma, we have used solid state Nd:YAG laser from Quantel. The laser has $8.5 \mathrm{~ns}$ pulse duration, and fundamental laser wavelength operating at $1064 \mathrm{~nm}$ in invisible infrared spectrum. For the measurements, we have used the laser energy of $300 \mathrm{~mJ}$ per single pulse. Due to the large variations of different DPM samples, we apply higher laser energy, to enhance the plasma emission and to ensure the gain in overall optical signal for all spectra lines and samples. The laser radiation has been focused with $10 \mathrm{~cm}$ focusing lens into the plane solid target surface to create plasma. Optical emission from plasma has been collected perpendicularly via optical telescope into the high resolution Echelle spectrograph model Aryelle Butterfly from LTB Berlin equipped with ICCD detector. Spectrometer consists of two separate spectrographs, one part for UV range from 190 to $440 \mathrm{~nm}$ and the second part for VIS optical spectrum in range $440-800 \mathrm{~nm}$. Spectral resolution capability is from 3 to $7 \mathrm{pm}$ for VUV part and 4-8 pm for VIS part, thus providing spectral information of a broad spectral range with high resolution and variability. The delay time $1 \mu$ s and gate width $2 \mu$ s after the trigger signal has been used. The LIBS emission has been recorded in open air atmosphere under an atmospheric pressure at room temperature.

\subsection{Particulate matter collection and sample preparation}

Sixty-seven different samples from in-use diesel engine passenger vehicles of major brand car producers in Europe have been analysed by LIBS. Vehicles selected for the DPM sample collection were from our daily life environment, as anyone is using to drive to work, etc. Generally, neither special test vehicles, nor driving test cycles or test engines were used. Diesel particulate matter was collected and extracted directly from the tail pipe at the end of the exhaust system. We analysed particulate matter (PM) extracted from the exhaust tail pipe, from 67 different passenger vehicles. Selections of the vehicles were performed randomly and no company, brand or vehicle type was given preference. The collected DPM from Diesel engine vehicles tail pipe deposits has been mechanically pressed into small pellets with $6 \mathrm{~mm}$ diameter and with a flat, disc-like shape.

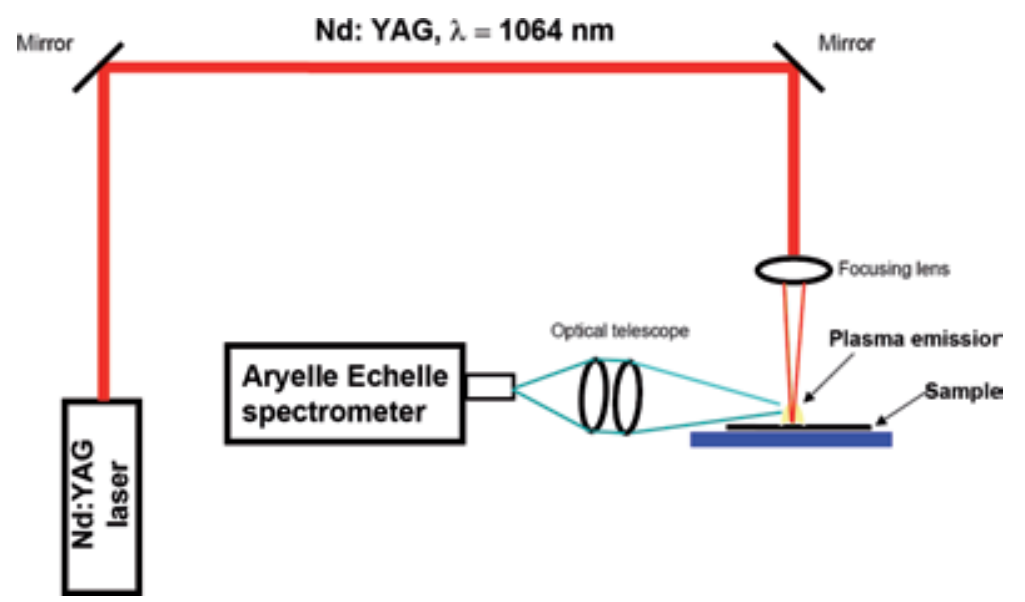

Figure 1.

Layout of LIBS experimental setup. 
We are well aware, that it is uncommon to use tail pipe deposits for exhaust particulate matter analysis. It is also worth noting, that the actual composition of this material may differ largely from the particulate matter, which leaves the exhaust system together with the gases. The reason, why we chose to use deposit material is of purely practical nature: As our main goal in this project was to establish the LIBS method for Diesel PM trace element analysis, we needed large sample volumes for many repetitive measurements and the samples needed to provide a shelf life over the entire project time frame. Therefore, this study is not meant to provide representative composition data for airborne particulate matter, but rather to present a methodological approach, that can easily be applied to airborne DPM composition analysis. However, one can still expect to find significant differences amongst individual samples, which arise from the many factors, some of which were enumerated above. Thus, this method of sample collection can be considered sufficient for the declared goal of the project.

\section{Results and discussion}

\subsection{Identification of the major elements in the DPM}

Obtained signal from laser-induced breakdown spectroscopy measurements of diesel particulate matter from three selected samples are shown in Figure 2. The strong optical emission is characterised from Carbon, Iron, Magnesium, Aluminium, Chromium, Zinc, Sodium and Calcium. These elements were previously identified in PM as major components of diesel particulate matter [26]. LIBS spectra generated from particulate matter collected from in-use diesel engine passenger vehicles exhibits characteristic spikes - optical emission lines with distinct peaks of atomic, ionic and molecular origin included in the signal.

\subsection{Identification of the minor elements in the DPM}

To identify the minor elements of DPM, the state-of-the-art laboratory laserinduced breakdown spectroscopy setup has been used to obtain high-resolution optical emission spectral images. Here, we restrict our attention to minor chemical elements, particularly to dominant spectral lines from atomic and ionic emission from: Silicon, Nickel, Titan, Potassium, Strontium and Molybdenum.

Minor elements of DPM matrices:

Silicon spectral line: atomic emission from Si I @ $288.16 \mathrm{~nm}$ is shown in

Figure 3a. In this figure, the raw spectral signal from LIBS measurements of 67 different samples of diesel particulate matter is shown. From these spectroscopical results, one can observe that the silicon signal, mainly peak shape, peak intensity and peak width at FWHM varies for each DPM sample. The strength of the LIBS signal of particular atomic or ionic line is basically proportional to the concentration of the analyte in studied sample. Therefore, for detail comparison, we numerically calculated the integral values of each signal peak to obtain qualitative information about chemical composition of diesel particulate matter. The results from these calculations are shown in Figure $3 \mathbf{b}$. Here, one can easily compare the variations of silicon signal/concentrations (a.u.) within diverse DPM matrices. However, for detail quantitative analytical characterisation of Si in DPM, the calibration of LIBS signal would be desirable. To compare, very high content of Si is in the sample \# 25, 31, 51, 55. From LIBS analytical measurements and numerical 


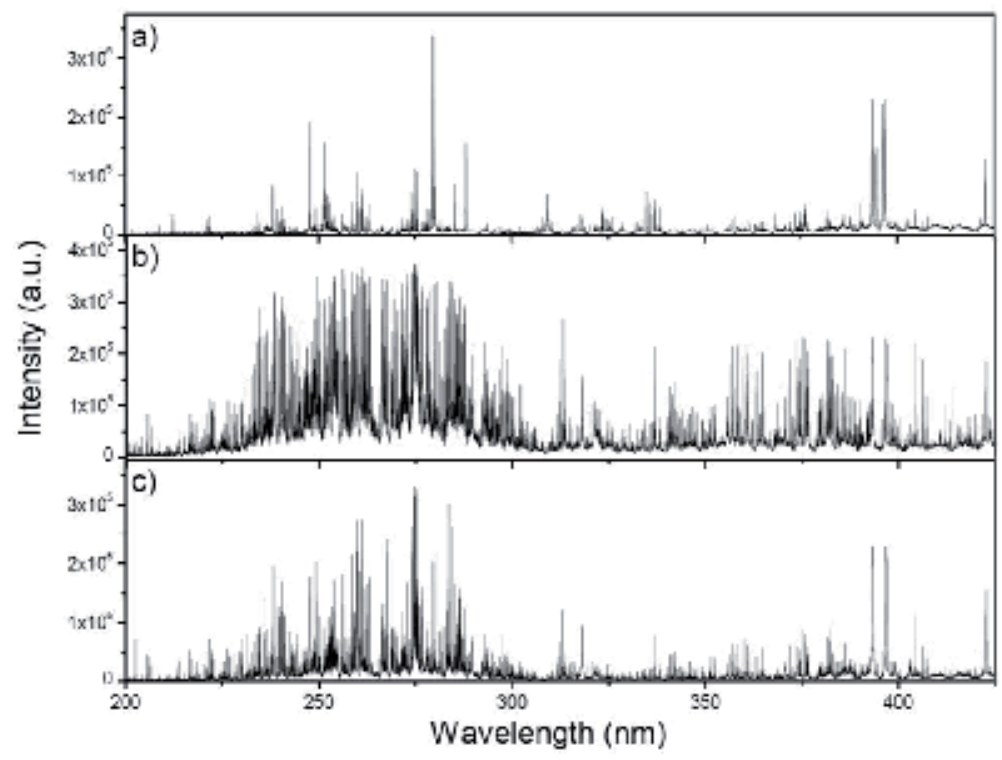

Figure 2.

Optical emission LIBS spectra from three different particulate matter matrices. High intensity spectral lines are from major chemical elements - carbon, iron, magnesium, aluminium, chromium, zinc, sodium and calcium. (a) C, Mg, Ca and $\mathrm{Al}$; (b) Fe, Cr and Ca, Mg; and (c) C, Ca, and $\mathrm{Mg}$.
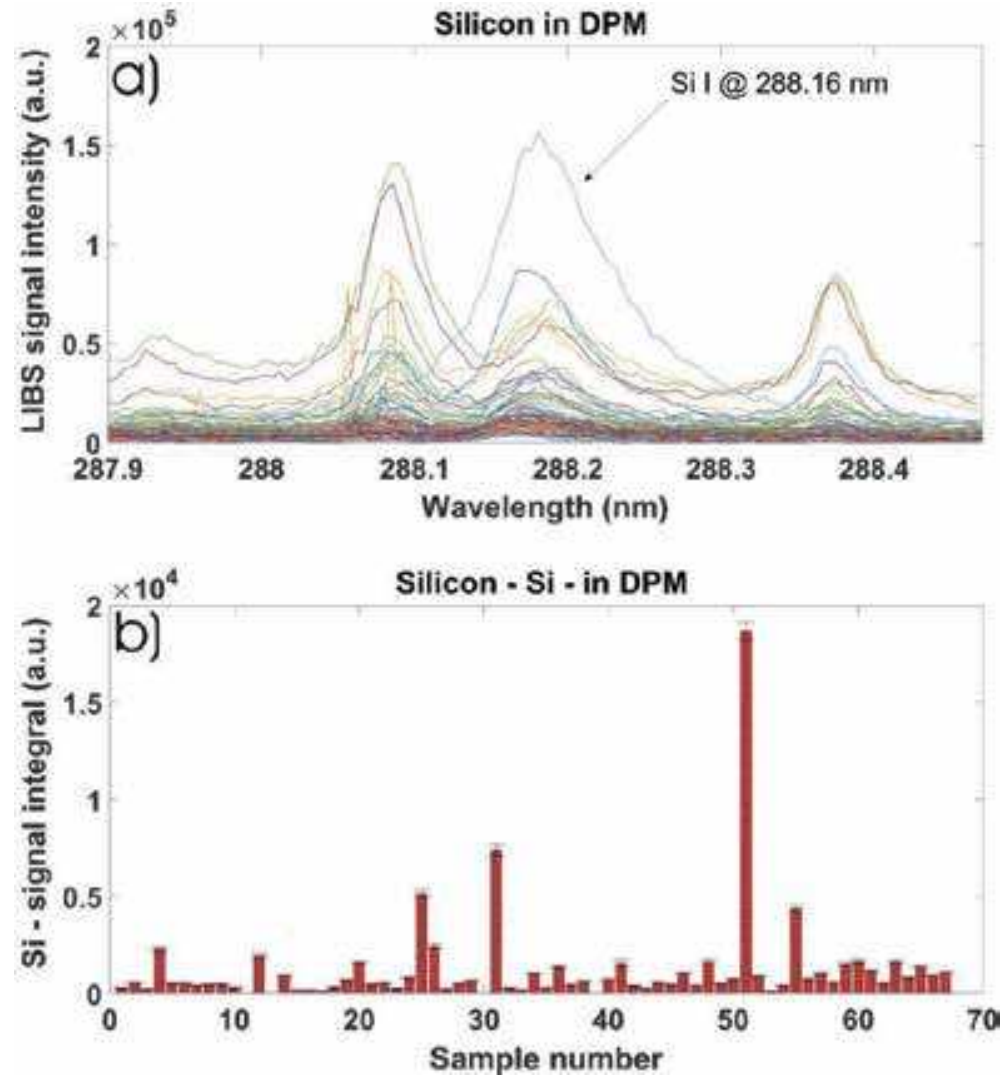

Figure 3.

(a) Optical emission spectra from silicon measured by high resolution LIBS technique from 67 different diesel particulate matter samples collected from in-use passenger diesel engine vehicles. $(b)$ Calculated integral values from Si peak optical emission spectra. 
calculations, we can conclude that silicon is minor element and it has been measured in 63 from 67 different DPM samples.

Nickel spectral line: in Figure 4a, the comparisons of ionic emission from Nickel, spectra line Ni II at $221.64 \mathrm{~nm}$ are shown. One can see that this signal response is quite strong. The results from calculation of peak signal integral values are shown in Figure 4b. Samples with high content of Nickel are \# 4, 5, 12, 20 and 34. Nickel in DPM is present as minor element in 43 samples.

Titan spectral line: is compared in Figure 5a, where the ionic spectra lines $\mathrm{Ti}$ II at $334.94 \mathrm{~nm}$ are shown. From the numerical calculation in Figure 5b, one can see that optical emission from this element is present in 32 DPM matrices. High content of Titan is present in sample \# 51, 55 and 59.

Potassium spectral line: is shown in Figure 6a, as atomic line K I at $766.48 \mathrm{~nm}$ in infrared spectral range. High content has been measured in sample \# 4, 8, 25, 26, 28 and 51. The comparison of integral spectral peak calculated values are shown in Figure 6b. Potassium is present in 50 different samples.

Strontium spectral line: the raw peak signal from 67 different DPM samples is shown in Figure 7a. The Sr ionic line Sr II at $407.77 \mathrm{~nm}$, is present in visible spectral range. From numerical calculation in Figure $\mathbf{7 b}$, the Strontium as minor element has been measured in 35 different DPM samples. Strong signal from $\mathrm{Sr}$ is in sample \# 4, 5, 41 and 51.

Molybdenum spectral line: atomic emission from Mo I @ $390.29 \mathrm{~nm}$ is shown in Figure 8a. From this figure, higher content of molybdenum is in five samples, \# 12,
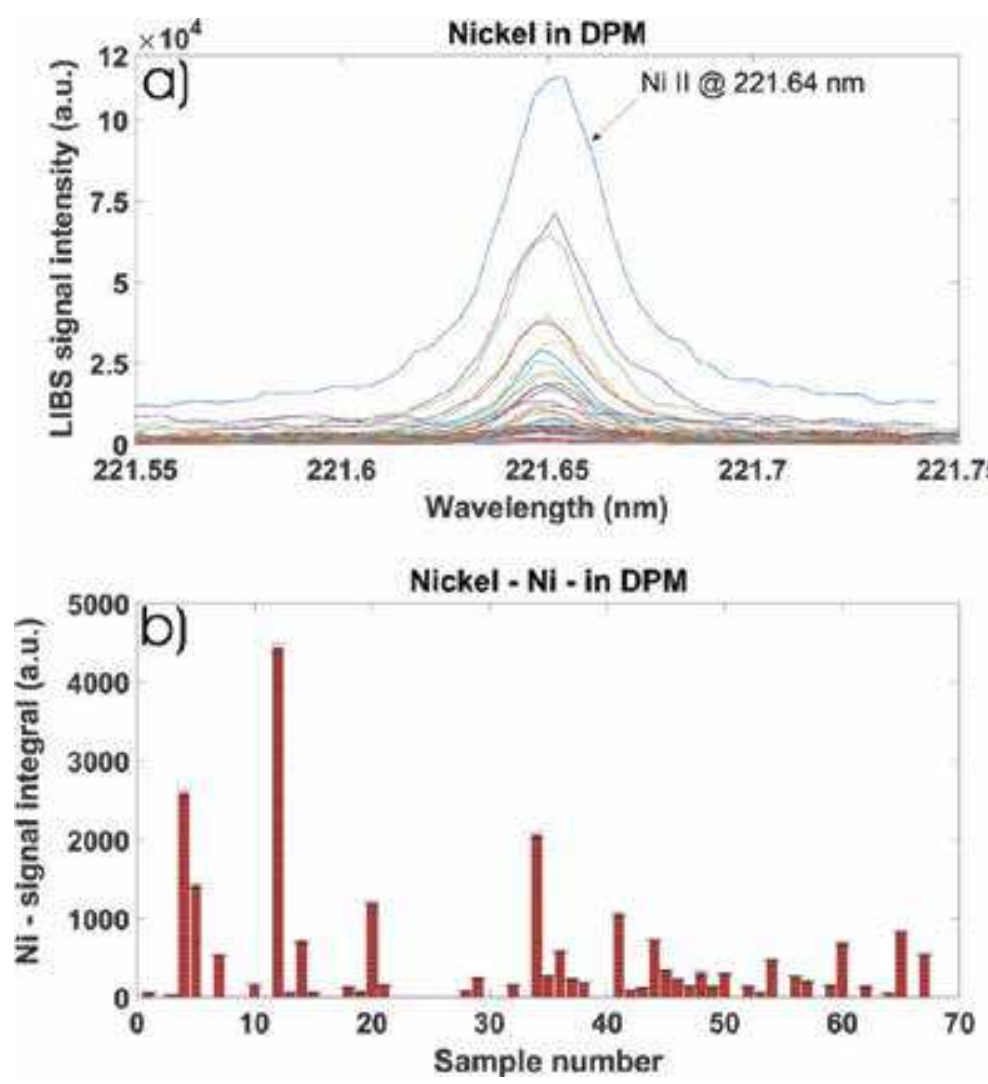

Figure 4.

(a) Optical emission spectra from Nickel measured by high resolution LIBS technique from 67 different diesel particulate matter samples collected from in-use passenger diesel engine vehicles. (b) Calculated integral values from Ni peak optical emission spectra. 

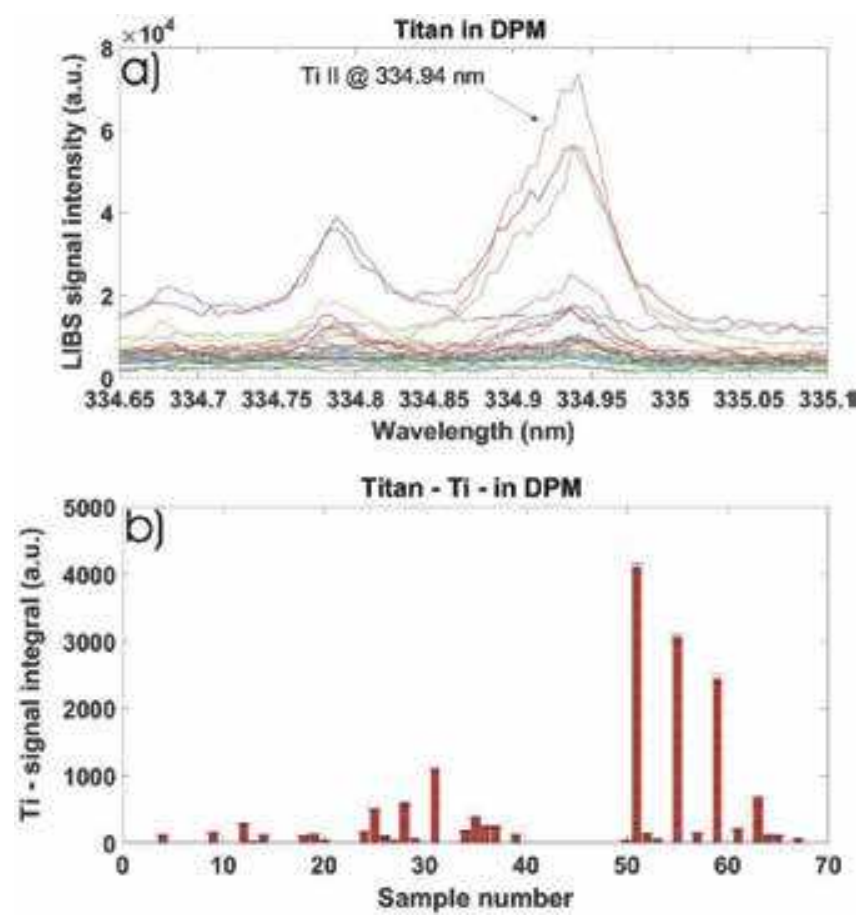

Figure 5.

(a) Optical emission spectra from Titan measured by high resolution LIBS technique from 67 different diesel particulate matter samples collected from in-use passenger diesel engine vehicles. (b) Calculated integral values from Ti peak optical emission spectra.
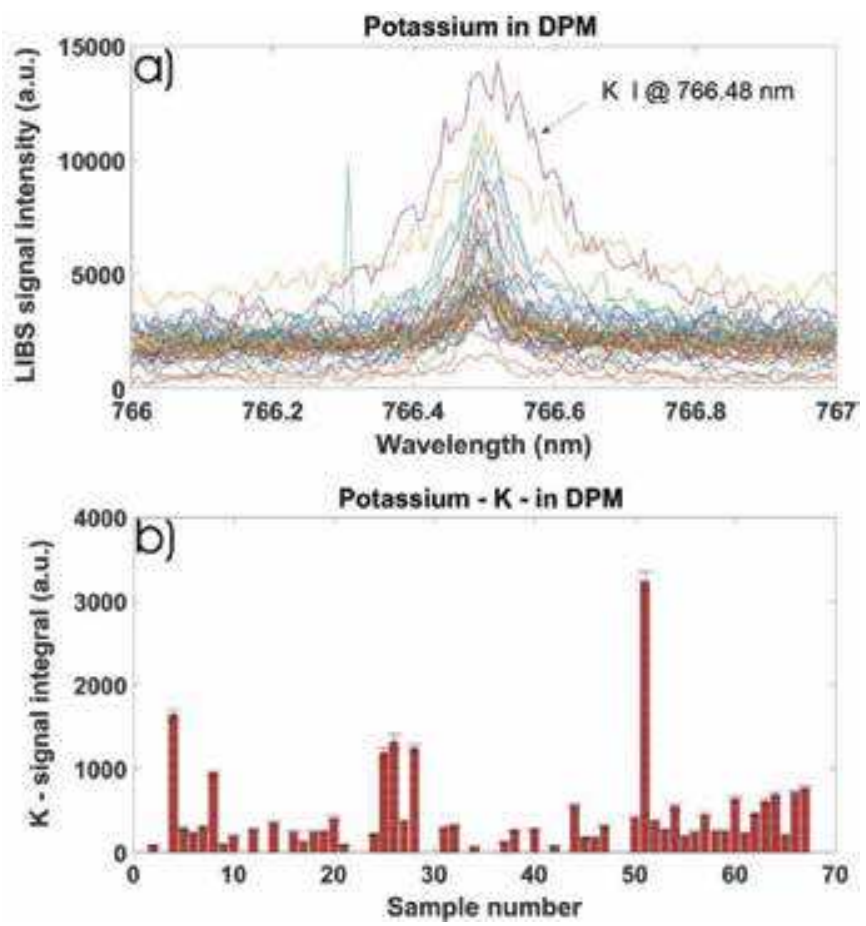

Figure 6.

(a) Optical emission spectra from potassium measured by high resolution LIBS technique from 67 different diesel particulate matter samples collected from in-use passenger diesel engine vehicles. (b) Calculated integral values from K peak optical emission spectra. 
Identification of the Minor Chemical Elements in the Particulate Matter Exhaust Emissions... DOI: $h$ ttp://dx.doi.org/10.5772/intechopen.90760
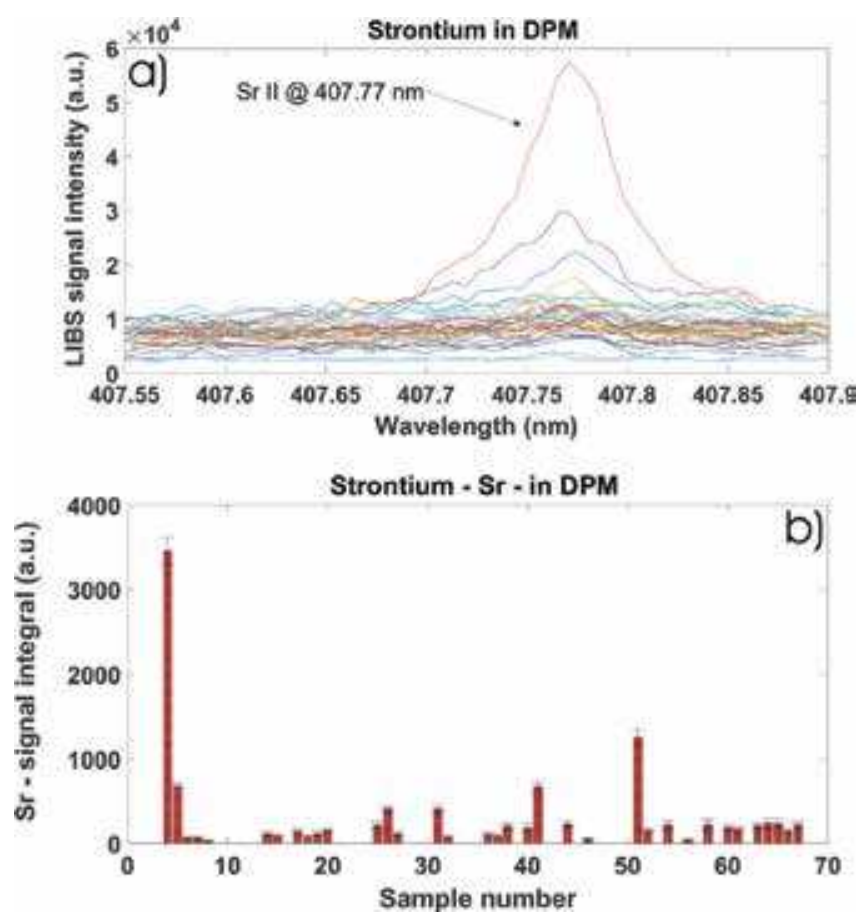

Figure 7.

(a) Optical emission spectra from Strontium measured by high resolution LIBS technique from 67 different diesel particulate matter samples collected from in-use passenger diesel engine vehicles. (b) Calculated integral values from Sr peak optical emission spectra.
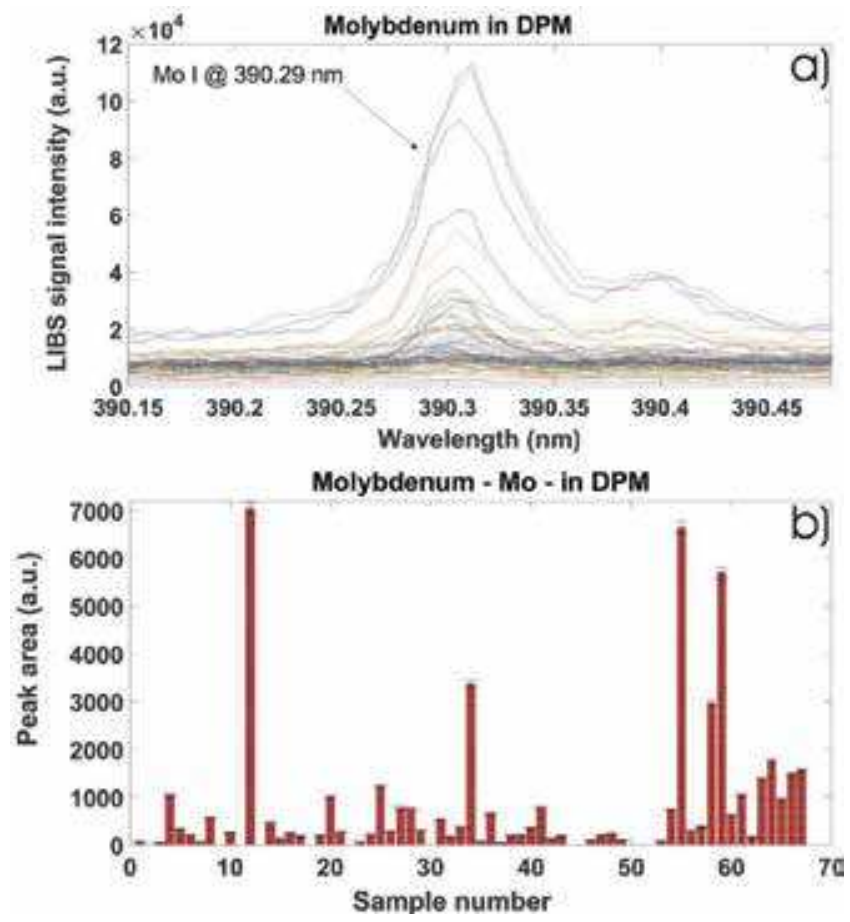

Figure 8.

(a) Optical emission spectra from Molybdenum measured by high resolution LIBS technique from 67 different diesel particulate matter samples collected from in-use passenger diesel engine vehicles. (b) Calculated integral values from Mo peak optical emission spectra. 


\begin{tabular}{lccc}
\hline Analyte & Spectral line & Wavelength $(\mathbf{n m})$ & Detected in/total number of samples \\
\hline $\mathrm{Si}$ & $\mathrm{Si} \mathrm{I}$ & 288.16 & $63 / 67$ \\
\hline $\mathrm{Ni}$ & $\mathrm{Ni} \mathrm{II}$ & 221.64 & $43 / 67$ \\
\hline $\mathrm{Ti}$ & $\mathrm{Ti} \mathrm{II}$ & 334.94 & $32 / 67$ \\
\hline $\mathrm{K}$ & $\mathrm{K} \mathrm{I}$ & 766.48 & $50 / 67$ \\
\hline $\mathrm{Sr}$ & $\mathrm{Sr} \mathrm{II}$ & 407.77 & $35 / 67$ \\
\hline $\mathrm{Mo}$ & $\mathrm{Mo} \mathrm{I}$ & 390.29 & $55 / 67$ \\
\hline
\end{tabular}

Table 1.

Spectral lines used for analytical measurements and number of samples with detected element.

34, 55, 58 and 59. Molybdenum as minor element has been measured in 55 different DPM samples. The comparison of calculated integral values from Mo peak optical emission spectra is shown in Figure $\mathbf{8 b}$.

Table 1 summarised measured analytes, the spectral atomic or ionic lines used for analytical LIBS measurements and number of samples where the minor element has been successfully detected.

\section{Conclusions}

In this chapter, we have shown an exemplary investigation of the minor chemical elements present in diesel particulate matter. The DPM have been collected from 67 different in-use diesel engine passenger vehicles. Selections of diesel passenger vehicles have been performed randomly, from daily life environment and from major brand car producers in Europe. Particulate matter samples have been analysed spectrochemicaly by means of a high-resolution laser-induced breakdown spectroscopy (LIBS) technique. The qualitative analytical results have shown the presence of minor chemical elements: Silicon, Nickel, Titan, Potassium, Strontium and Molybdenum in diesel particulate matter. These elements were measured by LIBS as strong spectral lines of atomic and ionic emissions in laser induced plasma. The spectral LIBS signal from each minor element was further numerically processed. The integral values of individual signal lines have been calculated to obtain qualitative comparison of individual minor elements in different diesel particulate matter matrices. From analytical measurements and numerical calculations, we can conclude that Silicon as minor element has been detected in 63 from 67 DPM samples. Nickel and potassium have been detected in 43 and 50 samples, respectively. Titan has been detected in 32 and Strontium has been detected in 35 samples of DPM. The element Molybdenum has been detected in 55 DPM samples from different in-use diesel engine passenger vehicles.

Measured minor elements $\mathrm{Si}, \mathrm{Ni}, \mathrm{Ti}, \mathrm{K}, \mathrm{Sr}$ and Mo together with major elements $\mathrm{C}, \mathrm{Fe}, \mathrm{Mg}, \mathrm{Al}, \mathrm{Cr}, \mathrm{Zn}, \mathrm{Na}$ and $\mathrm{Ca}$ are forming an important part of the Diesel particulate matter composition. All these elements are altogether contributing to overall exhaust emissions from diesel engine passenger vehicles.

We can conclude that the LIBS technique can almost instantly measure the major and minor compounds of DPM to provide qualitative information about the chemical composition. The presence of these chemical elements in PM exhaust emissions is related to different processes in Diesel combustion engine.

However, in the future, a detailed quantitative analytical characterisation of minor elements, together with a calibration procedure would be necessary to obtain. This would help to understand the minor element concentrations in diesel particulate matter. 
Identification of the Minor Chemical Elements in the Particulate Matter Exhaust Emissions... DOI: http://dx.doi.org/10.5772/intechopen.90760

\section{Acknowledgements}

The authors would like to thank to the Austrian Science Fund - FWF (Fonds zur Förderung der wissenschaftlichen Forschung) for providing financial support. The study was funded by the grant number: FWF - P27967. This work has been supported by the COMET-K2 Center of the Linz Center of Mechatronics (LCM), funded by the Austrian federal government and the federal state of Upper Austria Additionally, the authors would like to thank Dr. Maria Rusnak for the proofreading and for the corrections.

\section{Author details}

Richard Viskup*, Christoph Wolf and Werner Baumgartner

Institute of Biomedical Mechatronics, Johannes Kepler University Linz, Linz, Austria

*Address all correspondence to: richard.viskup@jku.at

\section{IntechOpen}

(C) 2020 The Author(s). Licensee IntechOpen. Distributed under the terms of the Creative Commons Attribution - NonCommercial 4.0 License (https://creativecommons.org/ licenses/by-nc/4.0/), which permits use, distribution and reproduction for non-commercial purposes, provided the original is properly cited. (cc) BY-NC 


\section{References}

[1] Ntziachristos L, Papadimitriou G, Ligterink N, Hausberger S. Implications of diesel emissions control failures to emission factors and road transport NOx evolution. Atmospheric

Environment. 2016;141:542-551. DOI: 10.1016/j.atmosenv.2016.07.036

[2] Zacharof N, Tietge U, Franco V, Mock P. Type approval and real-world $\mathrm{CO} 2$ and NOx emissions from EU light commercial vehicles. Energy Policy. 2016;97:540-548. DOI: 10.1016/j. enpol.2016.08.002

[3] Commission Regulation (EU) 2016/646. Commission Regulation (EU) 2016/646 of 20 April 2016 amending Regulation (EC) (No 692/2008) as regards emissions from light passenger and commercial vehicles (Euro 6) [Online]. Available from: http://eur-lex. europa.eu/eli/reg/2016/646/oj

[4] Calderón-Garcidueñas L, MoraTiscareño A, Ontiveros E, et al. Air pollution, cognitive deficits and brain abnormalities: A pilot study with children and dogs. Brain and Cognition. 2008;68:117-127. DOI: 10.1016/j. bandc.2008.04.008

[5] Block ML, Calderon-Garciduenas L. Air pollution: Mechanisms of neuroinflammation and CNS disease. Trends in Neurosciences. 2009;32(9):506-516. DOI: 10.1016/j. tins.2009.05.009

[6] Viskup R. Single and double laser pulse interaction with solid state Application to plasma spectroscopy. In: Dumitras DC, editor. Nd:YAG Laser. Croatia: InTech, Rijeka; 2012. ISBN: 978-953-51-0105-5

[7] Commission Regulation (EC) 692/2008. Commission Regulation (EC) 692/2008 of 18 July 2008 implementing and amending Regulation (EC) No 715/2007 of the European Parliament and of the Council on type-approval of motor vehicles with respect to emissions from light passenger and commercial vehicles (Euro 5 and Euro 6) and on access to vehicle repair and maintenance information [Online]. Available from: http://eur-lex.europa.eu/eli/ reg/2008/692/oj

[8] Regulation (EC) No 715/2007. Regulation (EC) No 715/2007 of the European Parliament and of the Council of 20 June 2007 on type approval of motor vehiclEs with respect to emissions from light passenger and commercial vehicles (Euro 5 and Euro 6) and on access to vehicle repair and maintenance information [Online]. Available from: http://eur-lex.europa.eu/eli/ reg/2007/715/oj

[9] United States Environmental Protection Agency, Regulations for Emissions from Vehicles and Engines, Tier 3 Motor Vehicle Emission and Fuel Standards [Online]. Available from: https://www.epa.gov

[10] California Environmental Protection Agency, Low-Emission Vehicle Program - LEV III [Online]. Available from: https://www.arb.ca.gov/

[11] Kittelson DB. Engines and nanoparticles: A review. Journal of Aerosol Science. 1998;29:575-588. DOI: 10.1016/S0021-8502(97)10037-4

[12] Takahama S, Russell LM, Shores CA, Marr LC, Zheng J, Levy M, et al. Diesel vehicle and urban burning contributions to black carbon concentrations and size distributions in Tijuana, Mexico, during the CalMex 2010 campaign. Atmospheric Environment. 2014;88:341-352. DOI: 10.1016/j.atmosenv.2013.09.057

[13] Kleeman MJ, SchauerJJ, Cass GR. Size and composition distribution of fine particulate matter emitted from motor 
vehicles. Environmental Science \& Technology. 2000;34:1132-1142. DOI: 10.1021/es981276y

[14] Burtscher H. Physical characterization of particulate emissions from diesel engines: A review. Journal of Aerosol Science. 2005;36:896-932. DOI: 10.1016/j.jaerosci.2004.12.001

[15] Schauer JJ, Kleeman MJ, Cass GR, Simoneit BRT. Measurement of emissions from air pollution sources. 2 . C-1 through C-30 organic compounds from medium duty diesel trucks. Environmental Science \& Technology. 1999;33:1578-1587. DOI: 10.1021/ es980081n

[16] Lough GC, Schauer JJ, Park JS, Shafer MM, Deminter JT, Weinstein JP. Emissions of metals associated with motor vehicle roadways. Environmental Science \& Technology. 2005;39:826-836. DOI: $10.1021 / \mathrm{es} 048715 \mathrm{f}$

[17] Cheung KL, Ntziachristos L, Tzamkiozis T, Schauer JJ, Samaras Z, Moore KF, et al. Emissions of particulate trace elements, metals and organic species from gasoline, diesel, and biodiesel passenger vehicles and their relation to oxidative potential. Aerosol Science and Technology. 2010;44:500513. DOI: $10.1080 / 02786821003758294$

[18] Ntziachristos L, Ning Z, Geller MD, Sheesley RJ, Schauer JJ, Sioutas C. Fine, ultrafine and nanoparticle trace element compositions near a major freeway with a high heavy-duty diesel fraction. Atmospheric Environment. 2007;41:5684-5696. DOI: 10.1016/j. atmosenv.2007.02.043

[19] Packer AP, Sarkis JES, Giné MF, Santos ÉJ. High pressure Asher (HPA-S) decomposition of biodiesel samples for elemental analysis by inductively coupled plasma optical emission spectrometry (ICP OES). Journal of the Brazilian Chemical Society. 2014;25:743749. DOI: $10.5935 / 0103-5053.20140028$
[20] Fontaras G, Karavalakis G, Kousoulidou M, Tzamkiozis T, Ntziachristos L, Bakeas E, et al. Effects of biodiesel on passenger car fuel consumption, regulated and nonregulated pollutant emissions over legislated and real-world driving cycles. Fuel. 2009;88:1608-1617. DOI: 10.1016/j. fuel.2009.02.011

[21] Edlund M, Visser H, Heitland P. Analysis of biodiesel by argon-oxygen mixed-gas inductively coupled plasma optical emission spectrometry. Journal of Analytical Atomic Spectrometry. 2002;7:232-235. DOI: 10.1039/b111476j

[22] Gangwar JN, Guptab T, Agarwal AK. Composition and comparative toxicity of particulate matter emitted from a diesel and biodiesel fuelled CRDI engine. Atmospheric Environment. 2012;46:472-481. DOI: 10.1016/j. atmosenv.2011.09.007

[23] Agarwal AK, Gupta T, Kothari A. Particulate emissions from biodiesel vs diesel fuelled compression ignition engine. Renewable and Sustainable Energy Reviews. 2011;15:3278-3300. DOI: 10.1016/j.rser.2011.04.002

[24] Betha R, Balasubramanian R. Emissions of particulate-bound elements from stationary diesel engine: Characterization and risk assessment. Atmospheric Environment. 2011;45:5273-5281. DOI: 10.1016/j. atmosenv.2011.06.060

[25] Lombaert K, Morel S, Le Moyne L, Adam P, de Maleissye JT, Amouroux J. Nondestructive analysis of metallic elements in diesel soot collected on filter: Benefits of laser induced breakdown spectroscopy. Plasma Chemistry and Plasma Processing. 2004;24:41-56. DOI: 10.1023/B:PCPP.00 $00004881.17458 .0 \mathrm{~d}$

[26] Viskup R, Wolf C, Baumgartner W. Qualitative and quantitative characterisation of major elements in 
particulate matter from in-use diesel engine passenger vehicles by LIBS. Energies. 2020;13:368. DOI: 10.3390/ en13020368

[27] Noll R. Laser-Induced Breakdown Spectroscopy, Fundamentals and Applications. Berlin, Germany: Springer-Verlag Berlin Heidelberg; 2012

[28] Miziolek AW, Palleschi V, Schechter I. Laser-Induced Breakdown Spectroscopy (LIBS): Fundamentals and Application. New York, USA: Cambridge University Press; 2006

[29] Cremers DA, Radziemski LJ. Handbook of Laser-Induced Breakdown Spectroscopy. New Delhi, India: John Wiley \& Sons Inc.; 2013

[30] Hahn DW, Omenetto N. Laserinduced breakdown spectroscopy (LIBS), part II: Review of instrumental and methodological approaches to material analysis and applications to different fields. Applied Spectroscopy. 2012;66:347-419. DOI: 10.1366/11-06574

[31] Noll R, Fricke-Begemann C, Brunk M, Connemann S, Meinhardt C, ScharunM,etal.Laser-inducedbreakdown spectroscopy expands into industrial applications. Spectrochimica Acta Part B: Atomic Spectroscopy. 2014;93:41-51. DOI: 10.1016/j.sab.2014.02.001

[32] Wang ZZ, Deguchi Y, Zhang ZZ, Wang Z, Zeng XY, Yan JJ. Laser-induced breakdown spectroscopy in Asia. Frontiers of Physics. 2016;11:114213. DOI: $10.1007 / \mathrm{s} 11467-016-0607-0$

[33] Viskup R, Praher B, Linsmeyer T, Scherndl H, Pedarnig JD, Heitz J. Influence of pulse-to-pulse delay for $532 \mathrm{~nm}$ double-pulse laser-induced breakdown spectroscopy of technical polymers. Spectrochimica Acta Part B: Atomic Spectroscopy. 2010;65:935. DOI: 10.1016/j.sab.2010.09.003 et al. Application of laser-induced breakdown spectroscopy to in situ analysis of liquid samples. Optical Engineering. 2000;39:2248-2262. DOI: 10.1117/1.1304855

[35] Effenberger AJ, Scott JR. Effect of atmospheric conditions on LIBS spectra. Sensors. 2010;10:4907-4925. DOI: 10.3390/s100504907

[36] Stehrer T, Praher B, Viskup R, Jasik J, Wolfmeir H, Arenholz E, et al. Laser-induced breakdown spectroscopy of iron oxide powder. Journal of Analytical Atomic Spectrometry. 2009;24:973-978. DOI: 10.1039/b817279j

[37] Viskup R, Praher B, Stehrer T, Jasik J, Wolfmeir H, Arenholz E, et al. Plasma plume photography and spectroscopy of Fe-oxide materials. Applied Surface Science. 2008;255:5215-5219. DOI: 10.1016/j. apsusc.2008.08.092

[38] Aragón C, Aguilera J. Characterization of laser induced plasmas by optical emission spectroscopy: A review of experiments and methods. Spectrochimica Acta Part B: Atomic Spectroscopy. 2008;63:893916. DOI: 10.1016/j.sab.2008.05.010

[39] Stepputat M, Noll R. On-line detection of heavy metals and brominated flame retardants in technical polymers with laser-induced breakdown spectrometry. Applied Optics. 2003;42:6210-6220. DOI: 10.1364/AO.42.006210

[40] Noll R, Sturm V, Aydin Ü, Eilers D, Gehlen C, Höhne M, et al. Laserinduced breakdown spectroscopy From research to industry, new frontiers for process control. Spectrochimica Acta Part B: Atomic Spectroscopy. 2008;63:1159-1166. DOI: 10.1016/j. sab.2008.08.011

[34] Samek O, Beddows DCS, Kaiser J, Kukhlevsky SV, Liska M, Telle HH, 



\section{Edited by Richard Viskup}

The internal combustion engine was invented around 1790 by various scientists and engineers worldwide. Since then the engines have gone through many modifications

and improvements. Today, different applications of engines form a significant technological importance in our everyday lives, leading to the evolution of our modern civilization. The invention of diesel and gasoline engines has definitely changed our

lifestyles as well as shaped our priorities. The current engines serve innumerable applications in various types of transportation, in harsh environments, in construction, in diverse industries, and also as back-up power supply systems for hospitals, security departments, and other institutions. However, heavy duty or light duty engines have certain major disadvantages, which are well known to everyone. With the increasing usage of diesel and gasoline engines, and the constantly rising number of vehicles worldwide, the main concern nowadays is engine exhaust emissions. This book looks at basic phenomena related to diesel and gasoline engines, combustion, alternative fuels, exhaust emissions, and mitigations.

\section{IntechOpen}

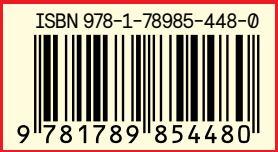

